\title{
Digitalising Tax, The Kenyan way The travels and translations of ITax in Kenya
}

Nimmo Elmi

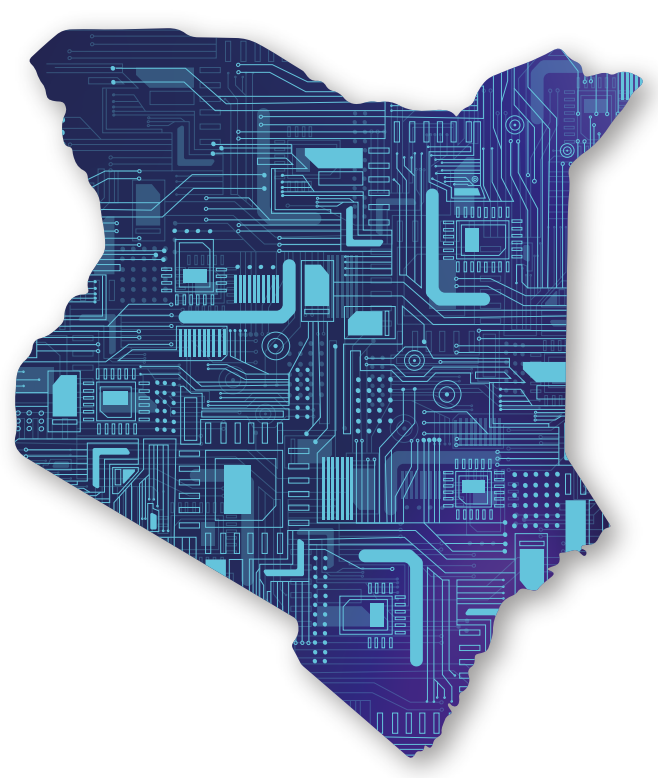





\section{Digitalising Tax, The Kenyan Way \\ The Travels and Translations of ITax in Kenya}

Nimmo Osman Elmi

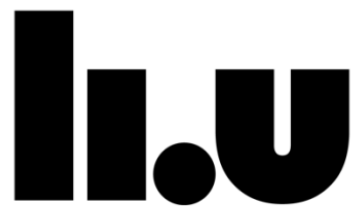

LINKÖPING UNIVERSITY

Department of Thematic Studies, Institute of Technology and Social Change Linköping University, Sweden

Linköping 2021 
Linköping Studies in Arts and Sciences No. 813

At the faculty of Arts and Sciences at Link ping University, research and doctoral studies are carried out within broad problem areas. Research is organised in interdisciplinary research environments and doctoral studies mainly in graduate schools. Jointly, they publish the series Link ping Studies in Arts and Sciences. This thesis comes from the Department of Thematic Studies - Technology and Social Change.

Distributed by:

Department of Thematic Studies - Technology and Social Change

Linköping University

58183 Linköping

Nimmo Osman Elmi

Digitalising Taxation, The Kenyan Way.

The Travels and Translations of ITax in Kenya.

Edition 1:0

ISBN: 978-91-7929-025-2

ISSN: 0282-9800

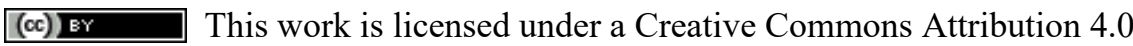
International License.

https://creativecommons.org/licenses/by/4.0/

(C) Nimmo Osman Elmi, 2021

Department of Thematic Studies - Technology and Social Change 2020

Cover design by Jama M Jama

Printed by: LiU-Tryck, Linköping 2021

Defence date: 2021-09-24

Institution: Tema Technology and Social Change

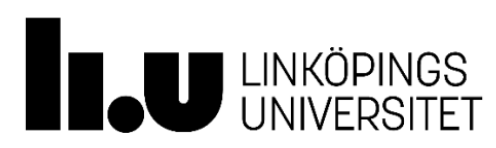


Dedicated to all the amazing women in my life,

Sisters can be seen as people who are both ourselves and very much not ourselves - a special kind of double.

Toni Morrison 


\section{ABSTRACT}

Kenya, as with other developing countries, has joined the global bandwagon of using digital technologies to increase domestic revenues. Within the new strategies, lie great potential in achieving sustainable development, however, the shift is happening quite rapidly and has been made mandatory within a short period of time. The implications of this shift have prompted this research to analyse how it has shaped tax practices in Kenya. This study addresses the implementation strategies of an e-filings system, ITax in Kenya that was piloted, adopted and made mandatory in a short period of time. ITax as demonstrated in this dissertation, has led to complexities including shifting tax expertise from tax consultants to information and communication technology (ICT) experts. I analyse what is at stake for all actors involved from those who commission its use to the taxpayers. I also analyse whether Kenya was prepared economically or infrastructurally for this shift. The outset for this dissertation is models like ITax interface with the different interests of social/institutional worlds as it travels and get translated generating complex and unintended effects. This study therefore combines postcolonial and technoscientific approaches in order to understand how the current implementation of ITax is connected to colonial development and fiscal rationale. Methodologically, this dissertation contributes to the socio-cultural perspectives to studying tax.

Keywords: Digitalisation, Taxation, Kenya, Technology, Sustainable Development, Anthropology 


\section{ABSTRAKT}

Kenya har som så många andra utvecklingsländer, följt trenden att digitalisera beskattningen för att öka skatteintäkterna. De nya digitala strategierna har stor potential att medverka till hållbar utveckling, men då förändringen sker mycket snabbt är en viktig fråga hur digital beskattning påverkar människorna, samhället och den allmänna viljan att betala skatt. Denna studie analyserar implementeringsstrategiernalTax, Kenyas digitala beskattningssystem, som testades, antogs och gjordes obligatoriskt på kort tid. Avhandlingen visar att ITax tvärtom avsikten av förenklad beskattning har lett till ökad komplexitet för skattebetalarna, att beskattning i allt större omfattning handlar om tillgång till digitala teknologi och att nya aktörer kommit in på skattearenan. Skattekompetens har flyttat från skattekonsulter till IT-experter. Avhandlingen baseras på etnografiskt fältarbete i Kenya och beskriver vad som står på spel för alla inblandade aktörer: från beställarna och administratörerna på Kenyanska skattemyndigheten, för skattekonsulter och leverantörer av IT-tjänster till skattebetalarna i Kenyas olika samhällssegment. Den teoretiska utgångspunkten för min analys är postkoloniala teknik och vetenskapsstudier. ITax kan ses som ett exempel på en västlig beskattningsmodell som när den implementeras förändras givet de tekniska förutsättningarna, existerande samhällsekonomi samt de sociala och kulturella värdena i Kenya. När modellen "reser" och "översätts" för att anpassas till nya genererar det komplexa och oavsiktliga effekter. Denna studie kombinerar därför postkoloniala tillvägagångssätt med teknikvetenskapliga för att förstå hur den nuvarande implementeringen av ITax är kopplad till kolonial utveckling och finanspolitiska principer. Metodiskt bidrar denna avhandling till de sociokulturella perspektiven för att studera skatt. 


\section{ACKNOWLEDGEMENTS}

This has been a long journey that has engulfed my whole life the past five years. I want to start by thanking God for facilitating this incredible opportunity to achieve my PhD. My journey to this $\mathrm{PhD}$ started at the University of Oslo where I as a bachelor student would walk around the offices on the $6^{\text {th }}$ floor at the Social Sciences Faculty building and imagine that I would one day soon occupy such an incredible space. LiU welcomed me and I have been able to grow and flourish like the artistic expressions of birds we have in our fika room at Tema T. Thanks to everyone at Tema T. Thank you to Carin and Eva for all your support during these difficult times. Your promptness made my life so much easier. Thank you to Jelmer as the then head of department in making my life easier as well.

I would also like to thank $60 \%$ opponent and fellow Fair Tax member Karen Boll. Our discussions on that day as well as before and after that have been great and you have been supportive. My reading committee as well Anette Wickström and Lisa Guntram thank you both for your guidance and support. For my $90 \%$ seminar, I would like to thank my opponent Marc Berenson as well as the reading committee Gabriella Körling, Johanna Sefyrin and Dick Magnusson. The comments and directives given at this stage were crucial and helpful to the development of this thesis. Thank you to my defence main opponent Richard Rottenberg, and the reading committee Paula Uimonen, Emer Mulligan, Oliver Owen.

This work would not be possible without the Horizon 20/20 Fair Tax Project Funding thank you for the generous funding that allowed this work to flourish. I would also like to thank all the working package team members it was a great honour working with you and sharing ideas big and small while I situated my work within the contemporary issues of Tax.

Lotta Bjorklund Larsen, my main supervisor and friend, you have been amazing throughout this journey, and I will be lost without getting your emails and WhatsApp calls when I had several panic attacks. You always had great ways to get me to focus and see my work as being amazing. Our memories will remain with me forever. You turned me into a tax nerd and now we are bound together in world of anthropology of tax. Tusen Hjertelig Takk!!!

My co-supervisors C.F Helgesson and Corinna Kruse, thank you for the valuable friendship and supervision. You are both too cool for the STS and Forensic world! I really learnt a lot from you too and have great memories of being supervised from my hotel in Stockholm. You both were so flexible and great at giving feedback. C.F you loved to use technology to get your points across and Corinna your love for metaphors is incredible. Corinna, thank you for stepping in and making yourself at home in my work.

To my D15 Crew Amelia, Fredrik, Jeffery, and Daniel thank you for making the experiences memorable. Amelia you were the best office mate! Thanks for the great discussions and support. Fredrik, my Swedish teacher, thank you for the great laughs and advice on taking life easy. Jeff as always, we had great discussing and laughs especially when we were at Values and Daniel it was always a pleasure having philosophical discussions about the environment.

I would like to thank two of my seminar Groups ValueS and P6. ValueS you challenged my STS identity until I am now confident in identifying myself as an STSer. Thank you to C.F, Steve, Dave, Else, Ivanche, Fredy, Francesco ,Teun, Camillo and Jeffery for the amazing seminars, lunches, and dinners. I would especially like to thank Johan Nilsson for becoming such a good friend and support through my journey from when you first showed me around LiU during my interview to hanging out in Stockholm. I am grateful for your friendship.

My p6 family, I thank you for accommodating me and my disorganized self in the beginning. My research topic was so new to everyone (except Lotta), but everyone embraced it and even looked forward to learning new things about taxation in Kenya. This was humbling and a huge milestone in my life. I would like to thank Kristin, Ericka, Lisa, Lotta, Jelmer, Hannah, Corinna, 
Alex, Jenny, Alma and Kristina for graciously reading my work and giving great feedback. To my Antroforum group our meetings were always great!

Dee! thank you so much for being my African sister at LiU. We have now become fully fledge sisters and I am glad you spoke to me to when we met on the bus. Your support while I was based in Nairobi was appreciated. Thanks to Vero for being such a good colleague and friend we shall continue exploring the developmental world together.

Special thanks to Pacific Africa Group especially Wambui. You were an integral part of this journey as you not only provided me with an office and unlimited coffee but moral support that gave me such an amazing space to work. I treasure all of you from the cleaners to the chef and to all other support staff. I do not take this for granted and pray that you will be rewarded greatly for this. Thank you as well to your family for extending that service to me as well.

My podcast group members although we stopped making podcasts, we still know that we are destined to share our amazing talents with the world. This journey is ours and the success is ours too. You are all amazing and I don't take your love, prayers, and support for granted. I love you all. Sofia and Maureen thank you for your diligent work editing and proofreading my work. To WT and KB thank you for all your support during this time I appreciate you too.

To my siblings, your encouragement, support, babysitting services, prayers are not being taken for granted. This PhD was for all of you. I love and cherish you all and pray that you too can achieve your dreams! To all my nieces and nephews, I am truly blessed to be your aunt.

To my amazing mom, Amina. This journey started because you dared to dream about having an education for yourself was lucky enough to take this to the next level and show that dreams can come true. You are the best mom ever and I do not take your support, love and prayers for granted. I pray that you live longer to keep on witnessing more success. Abo, you passed when I was doing my masters and I wish you had been alive to see this unfold. You live within me, and I am constantly reminded of your love of scholarship and how you believed in its power to change live. Allahakunaharisto Abo

To my main partners in Crime! my lovely children, Yasmin and Dahir! Yasmin, this is it I promise. I broke the promise to you that I would not take on new projects after my masters, this is it (I think). I promise that my life will not be as hectic as it has been. I want you to always now that you can pursue your dreams no matter what. Nothing can stop you. I love you my darling for always bearing with your crazy mom while still being my biggest supporter. I do not deserve you! I treasure and love you and dedicate this to you and your brother, Dahir. Dahir you are too young to know what is going on, but you were my PhD miracle. You decided to show up 3 months early so that I could stop stressing and come back stronger and more focused. You were such a great surprise and gift. The laughter and joy you brought into our lives made the journey bearable.

Finally, Hussein. Our journey started as PhD candidates one more seasoned than the other and it ended up with us sharing a life. I did not believe that one can have it all, but it seems that if you can truly dream big enough you can. I love and cherish you for all your support for asking me to be selfish and making sure that all my needs and those of the children are met. I am glad that we are in this journey of life together my darling.

Linköping September 2021

Nimmo O. Elmi 
Acronyms

$\begin{array}{ll}\text { AAAA } & \text { Addis-Ababa Action Agenda } \\ \text { AFDB } & \text { African Development Bank } \\ \text { ASAL } & \text { Arid and Semi-Arid Lands } \\ \text { ATI } & \text { Addis Tax Initiative } \\ \text { ANT } & \text { Actor-network theory } \\ \text { AU } & \text { African Union } \\ \text { CG } & \text { Commissioner General } \\ \text { CRA } & \text { Commission of Revenue Allocation } \\ \text { DRM } & \text { Domestic Revenue Mobilisation } \\ \text { ECOSOC } & \text { United Nations Economic and Social Council } \\ \text { ETR } & \text { Electronic Tax Receipt } \\ \text { EU } & \text { European Union } \\ \text { FCDC } & \text { Frontier Counties Development Counties } \\ \text { FFD } & \text { Financing for Development } \\ \text { GDP } & \text { Gross Domestic Product } \\ \text { GoK } & \text { Government of Kenya } \\ \text { GPO } & \text { General Post Office } \\ \text { ICT } & \text { Information Communication Technology } \\ \text { ICPAK } & \text { Institute of Certified Public Accountant of Kenya } \\ \text { IFMIS } & \text { Information Finance Management } \\ \text { IMF } & \text { International Monetary Fund } \\ \text { IT } & \text { Information Technology } \\ \text { ITax } & \text { Integrated Tax System } \\ \text { ITMS } & \text { Integrated Tax Management System } \\ \text { KCB } & \text { Kenya Commercial Bank } \\ \text { KNBS } & \text { Kenya National Bureau of Statistics } \\ \text { KOT } & \text { Kenyans on Twitter } \\ \text { KRA } & \text { Kenya revenue authority } \\ \text { MDGs } & \text { Millennium Development Goals } \\ \text { MNEs } & \text { Multinational Enterprises } \\ \text { MRI } & \text { Magnetic Resonance Imaging } \\ \text { NARC } & \text { National Rainbow Coalition } \\ \text { NOFBI } & \text { National optic fiber backbone } \\ \text { NPM } & \text { New public management } \\ \text { OECD } & \text { Organization of Economic Cooperation and Development Adjustment Programmes } \\ \text { OSR } & \text { Own source revenue } \\ \text { PAYE } & \text { Pay as You Earn } \\ \text { PCT } & \text { Platform for the Collaboration of Tax } \\ \text { PIN } & \text { Personal identification number } \\ \text { RARMP } & \text { Revenue administration reform and } \\ \text { SAPs } & \text { modernization } \\ & \end{array}$


SDGs

SIDA

STA

STS

SMES

UN

UNDP

USSD

VAT

WB

WEF

WESP
Sustainable development goals

Swedish international development cooperation agency

Swedish tax agency

Science and Technology Studies

Small medium enterprise

United Nations

United nations Development Programme

Unstructured Supplementary Service Data

Value added tax

World Bank

World Economic Forum

World Economic Situation and Prospects 
Table of Figures

Figure 1:Taxpayers standing in Line at times towers KRA ................................... 1

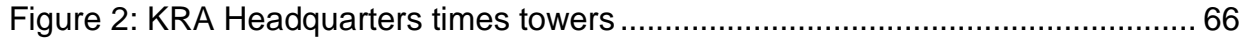

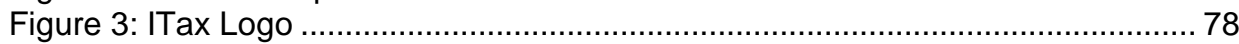

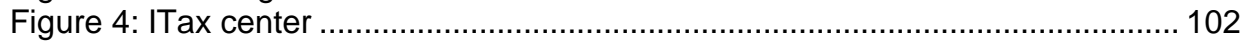

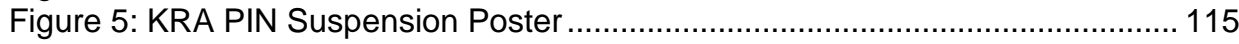

Figure 6: Taxpayers standing in Line at ITax support center................................. 117

Figure 7: Example of KRA Tax Compliance Certificate ......................................... 126

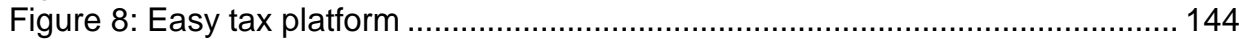

Figure 9: Maps showing the transformation of towns along the railway line. .......... 154

Figure 10 Kenya's National Fiber optic Map in 2014 ............................................. 155

Tables

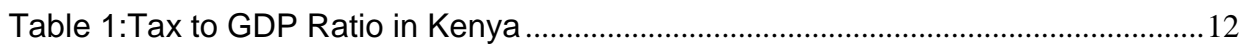

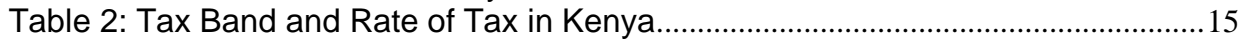

Table 3: Total Gross Domestic Product in Kenyan Counties:....................................... 160 


\section{TABLE OF CONTENTS}

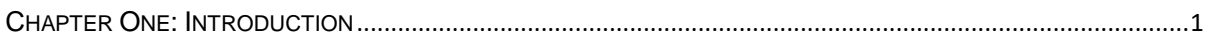

1.1 Introduction: Go Online and File your taxes! ........................................................................ 1

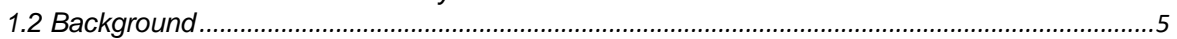

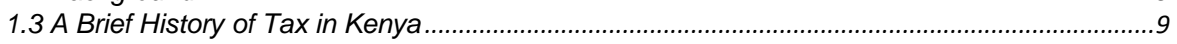

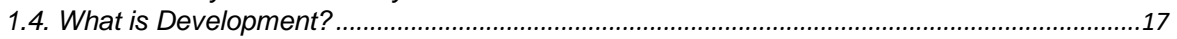

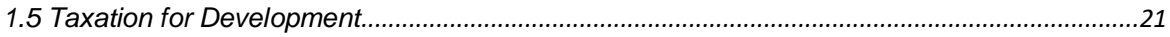

1.6 Digitalising Tax, Digitalising Development?...........................................................................24

1.7 Approaches used to study Taxation, Development and Digitalisation .....................................27

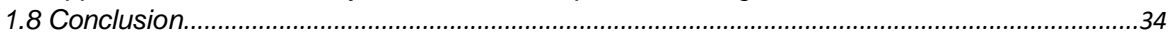

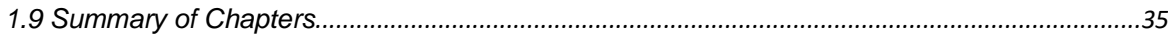

ChaPter TWO: ANALYTICAL FRAMEWORK: POStCOLONIAL TECHNOSCIENCE ........................................39

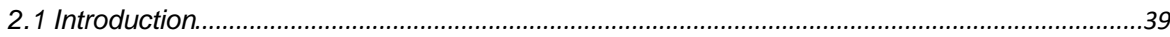

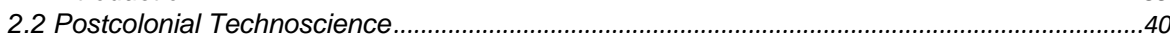

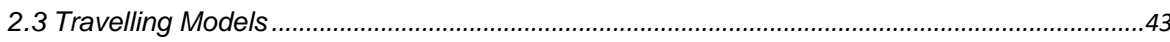

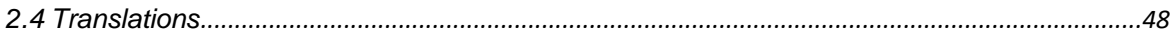

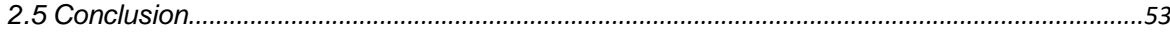

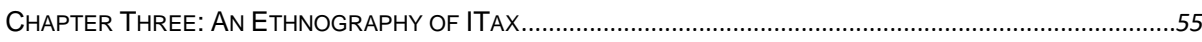

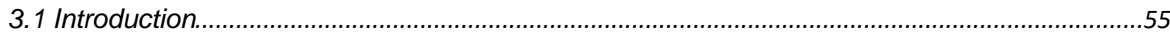

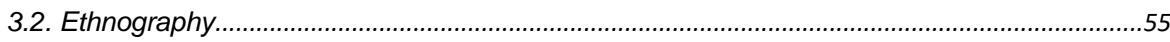

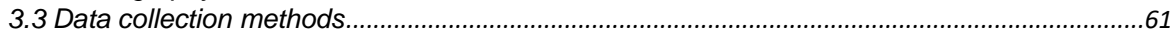

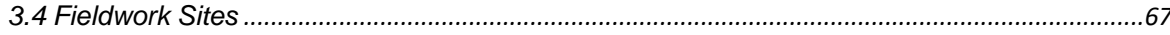

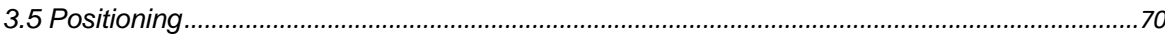

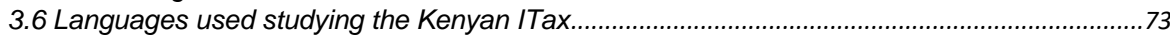

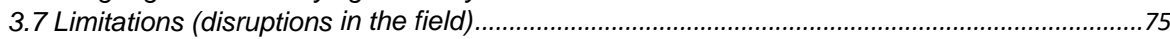

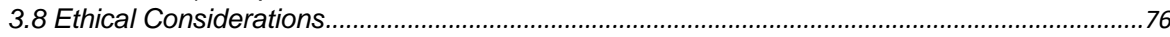

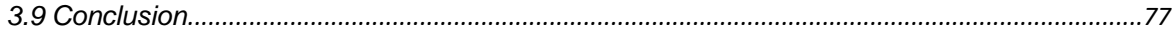

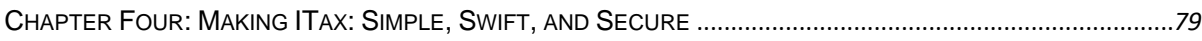

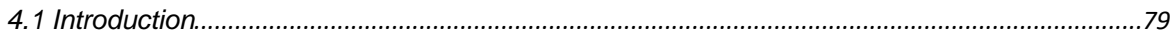

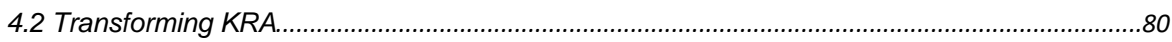

4.3 The Senior ITax Managers: Enhancing Customer Experience .............................................83

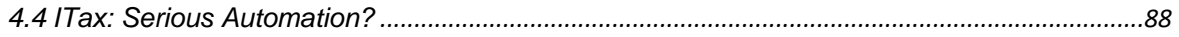

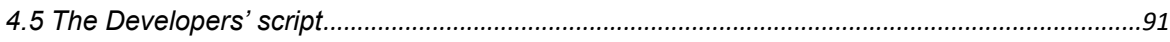

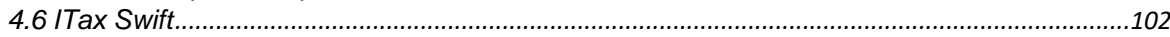

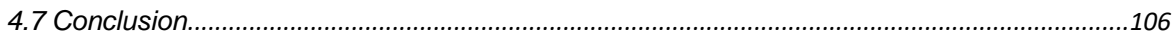

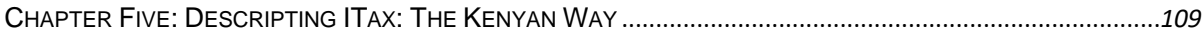

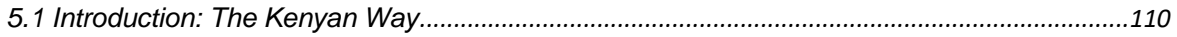

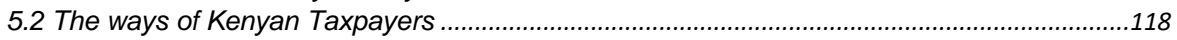

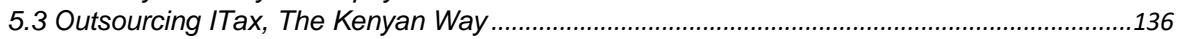

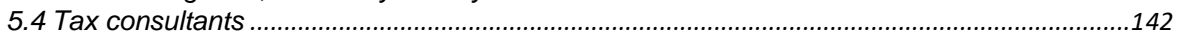

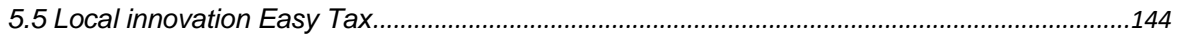

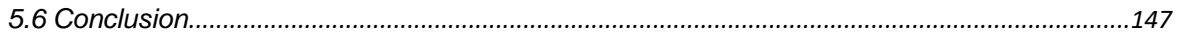

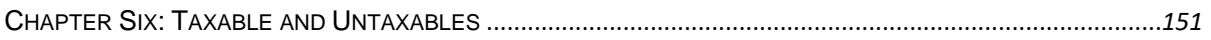

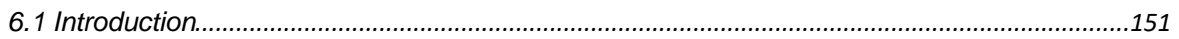

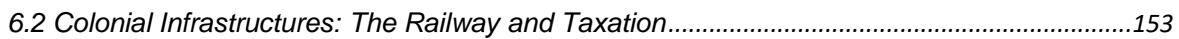

6.3 Historical Economic Policies ................................................................................................157

6.4 'Hapa tunadigitika!' (We are digitalising here! my translation from Kiswahili)........................162

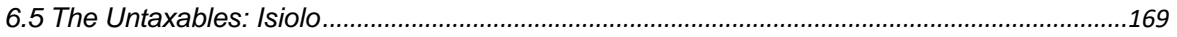

6.6 Huduma Centre Isiolo...........................................................................................................178

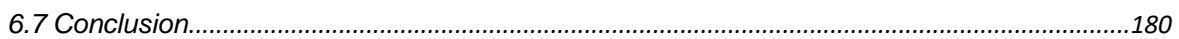

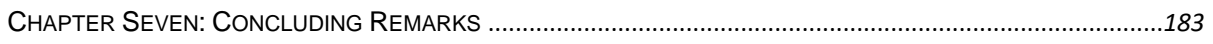

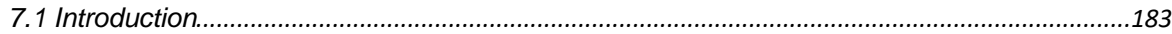

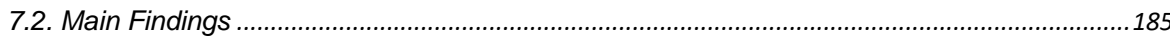

7.3 The Implications of Travelling Models of Development .......................................................194 
7.4 Conclusion.

Bibliography. 


\section{Chapter One: Introduction}

\subsection{Introduction: Go Online and File your taxes!}

Figure 1:Taxpayers standing in Line at times towers KRA

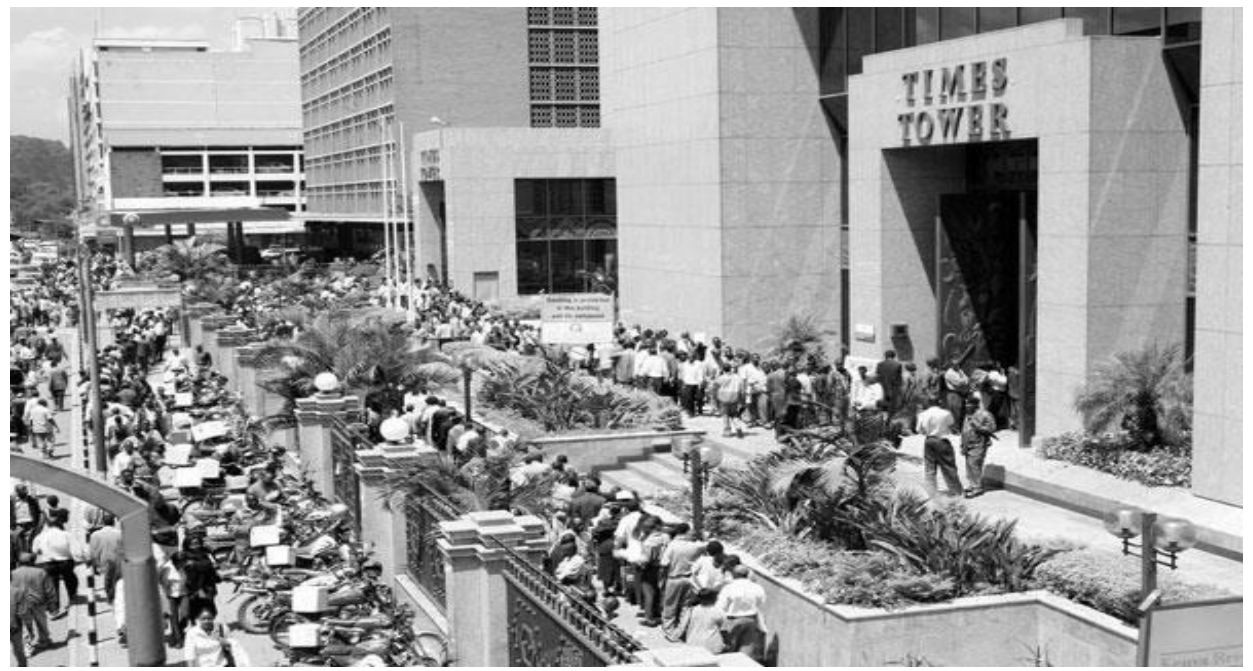

SOURCE:HTTPS://WWW.NATION.CO.KE/NEWS/4-8M-KENYANS-RISK-LOSING-KRA-PINS/1056-40439869W5GE8Z/INDEX.HTML

On May $27^{\text {th }}, 2015$, the Kenyan revenue authority, the KRA, informed the Kenyan public through one of its most popular newspapers, "The Daily Nation", that it had found a solution to the problem taxpayers had been facing during filing seasons. Taxpayers get reminded of the 'the horrendous' lines they are subjected to as seen in the picture above. The solution, according to the article, was the KRA's latest e-filing system, ITax. Taxpayers are urged to 'Go online and file their tax returns' in order to avoid lines as shown in the picture. In what seemed like a Public Relations strategy for the KRA, the article informed taxpayers that they could use ITax from the comfort of their homes, any day, at any time. The use of ITax was on a voluntary basis and the instructions seemed straightforward. "You will be able to log on to ITax, 24/7 from the comfort of your home" explains that article. "Lines will be a thing of the past" it affirms. 
Barely a year after its introduction, the KRA announced that ITax had now become mandatory. Taxpayers were urged to sign up to ITax or face the consequences of being categorized as non-compliant. ITax was first introduced in 2014 , then completely implemented in 2015, and finally declared compulsory in 2016. The rapid adoption, the implementation and usage of ITax have complicated tax filing processes for both the taxpayers and the tax authority. The instructions given by the article fashioned an expectation of what ITax could deliver. Filing tax returns on ITax was seen by KRA as stated in their mantra as being "simple, swift and secure". Yet, the process of "going online" was not as simple. Taxpayers featured in this study were unable to use ITax prompting them to seek help with mediators of all kinds based on their economic status ITax's implementation and adoption was shaped by local, global, colonial, and economic factors. Factors such as technical flaws, rushed implementation, inadequate infrastructure, and lack of taxpayer foresight in the design of ITax, shaped how the new system was received and utilised by the local taxpayers and the KRA. Due to the complexities inherent with its use, new means of complying with the tax requirements emerged that were neither traditional nor mainstream. This is referred to as the Kenyan way, in which taxpayers cooperate out of fear of the repercussions of failing to do so, while others have no choice but to comply because they are obligated to do so by law to print the compliance certificates ${ }^{1}$ to get work or government contracts. In Kenya and across the globe, ITax is seen as a tool for increasing domestic revenues that would thereby lead to sustainable development (UN,2015; KRA,2014). This research takes a closer look at this concept and demonstrates that it was not as simple as policymakers had hoped.

We may appreciate the intricacy by looking at how ITax ideas and adoption evolved as they moved from the global to the local arena. In Kenya, ITax is also publicly

\footnotetext{
${ }^{1}$ (https://www.kra.go.ke/en/individual/filing-paying/types-of-taxes/tax-compliance) A tax compliance, otherwise known as a Tax Clearance Certificate is an official document issued by KRA, as proof of having filed and paid all your taxes. KRA issues the following Tax Compliance Certificates upon application:1. Tax Compliance Certificates for Taxpayers seeking tenders with Government Ministries and Institutions.2. Tax Compliance Certificates to employees leaving service nor seeking new job opportunities.3.Tax Compliance Certificates for taxpayers seeking liquor Licenses.4. Tax Compliance Certificates to Clearing and Forwarding Agents.
} 
discussed as a tool for making tax administration easier for the KRA. ITax's success, however, was limited to those who were e-literate, could afford to pay for mediators, and had access to the internet and computers, as we will see. The adoption of ITax was seen to be much faster in the local counties which were seen to be economically stronger. On the flip side, however, it further marginalised communities who had historically been seen as uncooperative with the colonial administration. Since colonial times, these communities lacked access to infrastructures such as roads, the railway, water, and even electricity. ITax has also changed tax structures in Kenya by introducing new identities, with information and communication technology (ICT) technicians taking on the role of tax specialists as their knowledge is deemed to be more valuable (see chapter four and five).

The purpose of this thesis is to investigate how ITax has influenced tax practices in Kenya. The specific objectives are to look at how local, global, and historical structures influence and are influenced by ITax implementation from policymakers through KRA to taxpayers. To accomplish this, the study analyses the features of fundamental activities and techniques utilised to promote ITax implementation both within and beyond Nairobi, the Capital city. Following this introduction of the research questions and aims, the study connects the implementation of ITax to the overall debates of digitalisation, development, and taxation. The goal is to show how the recent shift to digitalisation is linked to colonial development concepts that historically saw technology as a key tool for modernisation (Gardner,2013). This chapter also includes a review of the literature on the approaches utilised to address the case study in this thesis. The final section of this chapter summarizes all the chapters in this thesis.

The questions posed in this study are as follows:

1. How has ITax's rapid implementation shaped tax practices in Kenya?

2. How is the implementation of ITax connected and influenced by local, global, and historical aims?

3. What can we learn from a postcolonial approach within technoscience to understand the digitalisation of taxation?

The primary goal of this study is to acquire insight into two things: first, Kenya's rapid shift toward digitalisation of e-filing systems, and second, its limitations. The scope of this research is informed by approaches within postcolonial technoscience (Anderson 
2002; McNeil 2005) and anthropology of tax (Björklund Larsen,2017; Boll,2011). Applying theories from postcolonial technoscience the study explores the relationship between the colonial state and technologies. The anthropological perspective is used to understand how culture and ethnography can be used to attain a socio-cultural understanding of the implications of ITax. The study uses ethnography as the main mode of inquiry using methods such as participant observation as well as fieldwork at the various sites dealing with ITax to understand the implementation and its limitations.

This study attends to the mandatory shift towards digitalising e-filings in Kenya by analysing the strategies employed to fulfil the objectives as decided by the policymakers, donors and by the KRA. By situating ITax in this discussion, the study ties the global discussion on tax policy development in Africa to local practices in Kenya, emphasizing the need of comparing global and local practices. The usage of the terms 'local' and 'global' in this study is intended as an analytical construct to show discourses travel across different scales. They are used in this study as inspired by Sara de Wit in her ethnography of travelling discourses on climate change where she stated that 'the terms global and local are used as analytical constructs rather than merely as geographical denominators, or empirical realities' (De Wit,2011:27). Departing from this, ITax can thus be seen as a model of analytical representations of aspects of reality created as a protocol for intervention (c.f, Behrends et al.,2014). Moreover, digitalisation can be described as the spread and use of digital technologies to collect, store, analyse, and exchange information digitally (IMF,2020).

This dissertation thus makes several contributions. Firstly, the study connects the overall debate of tax policy development in Africa to local practices in Kenya thereby highlighting the importance of scaling the analysis between the global and the local. Following that, it adds to tax research through contributing to socio-cultural approaches to tax research. Existing research on tax tends to focus on either the law or economic models to explain the tax models. However, this research focuses holistically on the actors involved in developing and using ITax. Within technology studies, this study contributes to a better understanding of how digital technology travels to nations like Kenya and how it interacts with local and historical realities to shape the outcomes of the objectives. Within postcolonial studies, this study contributes to an understanding of how technology has been used historically and is still being used to propagate notions of modernity and development. The study claims 
that the global digital models are still based on colonial logic, with nations considered to be developed and modern being entrusted with helping countries like Kenya become developed by using their countries as templates.

The next section, provides a background of the research aims and questions.

\subsection{Background}

During the African tax research conference (ATRN) in 2016, the method by which tax models travel globally became very evident to me as a researcher. Many African speakers presented at the conference and reacted positively to my presentation- PhD thesis on ITax. The presenters shared local experiences on taxes. Uganda for example, has also digitalised its tax system also referred to as ITax and is executed by TATA, the same IT consulting firm that is implementing the system in Kenya. $A$ variety of perspectives and experiences with TATA were given by the different speakers. They noted that TATA was able to establish a tax e-filling system that is being used across many African states. From all the shared experiences shared at the conference, the most intriguing point to note is that the continent's adoption of electronic filing systems was nearly as swift as Kenya's. While I did not pursue this comparatively, it was interesting to observe how the findings presented resonated with many conference attendees.

Over the last several years, various foreign policymakers, such as the International Monetary Fund (IMF), World Bank, and Organisation for Economic Cooperation and Development (OECD)have been pressing African countries to digitalize their tax systems. Support for tax administrations has been a part of foreign technical aid for public sector reforms in developing countries over the past two decades (Fjelstad 2014). The technical assistance includes reforms of tax legislation as well as simplification of tax structures and abolishment and introduction of some taxes. The overarching objective has however been to raise revenues. In Kenya, the tax reforms were historically part of the larger Structural Adjustment Programmes (SAP). The structural adjustment programs (SAPs) were loans provided by the IMF and the World Bank to nations with economic challenges. The SAPs, according to the international financial bodies, were aimed at restoring the country's economic structure. These programs were included in the national economic restructuring agreement between Kenya's government and the IFl's (Fjelstad and Rakner,2003, Moyi and Ronge, 2006). 
Kenya adopted the recommended tax reforms in order to continue receiving international grants and loans (Moyi and Ronge,2006). The recommended improvements frequently changed as the donor countries' economic paradigms evolved.

Digital taxation was founded on economic theories that viewed technology as having the ability to make systems more efficient, hence raising domestic revenues and attaining sustainable development. Earlier tax reforms were based on the experiences of developed economies (Kaldor,1963). Tax revisions in the past were based on developed economies (Kaldor,1963). They developed tax model templates for developing countries, which have been endorsed and are still being suggested to developing countries as a condition of help (C.f Nederveen Pieterse 2010, 21, 23). The underpinning assumption is that expert knowledge and innovations are expected to trickle down to the less wealthy nations and reform them. The premise that development and modernity are linear fuels these assumptions and recommendations. The models, on the other hand, are created worldwide and then translated locally.

Lledó and Poplawski-Ribeiro (2013) contend that African countries tend to adopt global tax policies that lead them to develop overambitious fiscal policies, targets, weak budgeting procedures and the political pressure to overspend or overtax. That Kenya being a country with relatively weak technological infrastructures implements an e-filing platform expected to improve tax compliance leading to increased revenues was based on assumptions regarding Kenya's e-readiness as well e-literacy(c.f Daniels,2013).E-readiness purport to show how ready the countries are to exploit the potential of new information and communication technologies while e-literacy is an individual's level of expertise and competence in the use of information technology.

Digital innovations in Kenyan are based on successes from mobile banking platform brought about by Mpesa(Daniels,2013). However, countries in the so-called Western Hemisphere or industrialized nations have yet to reap the benefits of mobile banking (Mpesa), which has been around in Kenya and East Africa for over 20 years. Nonetheless, strategists endorse digitalisation based on Mpesa's success without a real understanding of the factors that propelled its success. Mpesa's success is due to the fact that it works on both basic and advanced platforms, making it accessible to 
all citizens. Citizens do not require a laptop or a smartphone to access Mpesa services because they can use the USSD application. Currently, this is not the case with ITax. Although an individual can use a KRA application on Mpesa to pay for their tax arrears, the application is not interactive, and taxpayers are not able to use it to declare their tax filings, for example. It is therefore imperative to analyse the travels of such ideas as they are not informed by local realities. On the global arena Kenya is seen as an innovative and technologically advanced country. As will be shown in the empirical chapters this does not apply to every part of the country.

The digitization of taxation is seen as a stimulus for raising domestic revenues, leading to economic growth. Governments are introducing innovations in their organizational structures, procedures, and competencies to achieve this transition by using information and communication technology (ICT) to efficiently deliver services to their citizens (Ferro et al.,2009).Yet, what is often forgotten in these innovation attempts is the historical context. Schumpeter (as quoted in Musgrave,1992) contends that a country's fiscal structure and history have a significant impact on how it evolves (Musgrave, 1992: 90). Understanding the historical characteristics of colonial fiscal systems in Africa is crucial for understanding how colonial tax policies develop and change the modern state and institutions (Gardner,2012). This is because taxation was one of the most contentious issue that shaped the expansion of the colonies as well as the public policies at all levels in the colonies (Gardner,2012). Gardner also claims that a significant amount of resources and manpower were devoted to tax collection, which influenced the nature of the relationship between tax collectors and taxpayers. To comprehend the need to enhance domestic revenues in nations like Kenya, one must consider historical debates where countries developing countries were viewed as economically trailing. This was then attributed to their inadequate revenue creation, forcing concerned development economists to urge governments to "learn how to tax."

Nicholas Kaldor (1963) famous call to teach developing countries "how to tax" were based on his assumptions on the "developed" economies. He claimed that underdeveloped countries already had the ability to tax; all they needed was instruction on how to do so. As a result, tax models were developed that considered personal income tax as the best tax for developing countries because it targeted individuals rather than big groups of people. It was assumed that the large population 
comprised of a huge tax potential as the population was able to support this model. Despite its historical ties to colonial policies, the concept of "learning to tax" or "taxing more" has become a prominent feature of current digitalisation reforms, with technology seen as critical in assisting taxpayers in filing their taxes and assisting revenue administrations in taxing more efficiently. This is the subject of the next section where the study describes how Kenya's governance system works as well as how the counties are devolved along ethnic lines.

\subsubsection{Background of Kenya}

As of 2019, Kenya's population was 52.2 million people. Nairobi is the country's capital and largest metropolis. Mombasa, a coastal town, is the next largest city, followed by Kisumu. Kenya's new constitution was approved in 2010, decentralizing the country's governing system to 47 counties overseen by elected governors. The country was previously divided into eight provinces. This was regarded as being unrepresentative of the country's 52 tribes. The tribes have their own language and way of life connected to their main economic activity like pastoralism or agriculture. The major goal of decentralizing government was to devolve power, resources, and representation to all levels of government across the country (Ngigi and Busolo,2019). Devolution was considered as critical to realizing Kenya's economic potential through distributing responsibilities. The decentralized government is designed to help counties identify problems, develop policies, plan and collect money, implement budgets, accounting, auditing, and monitoring and evaluation, as well as enabling citizens to participate in decision-making (SID, 2011). Devolution is defined in Article 174 of the Constitution as providing people self-governance powers and enhancing their involvement in the exercise of power, as well as managing their own affairs and furthering their development.

The new constitution signified a complete break from the country's previous form of national governance, which had been in place since independence (Ngigi and Busolo,2019). The previous mode of governance was characterized by challenges that included marginalization, inequalities, and exclusion of many communities from the decisions processes (Ngigi and Busolo,2019,210). To address this, the new constitution permitted the formation of the Commission on Revenue Allocation (CRA), which is responsible for ensuring an equitable distribution of national funds between 
the national and county governments. However, this was not as successful as expected, as the economies of two counties represented in chapter six of this thesis, Kiambu and Isiolo, are still shaped by colonial fiscal policies, which benefited Kiambu economically while Isiolo remained economically marginalized.

In most counties, there is a dominant tribe, which adds a tribal element to devolution. Kiambu, for example, is dominated by the Kikuyu tribe, one of Kenya's major tribes. The Kikuyu have historically linked themselves with the colonial administration, and as a result, were empowered and favoured by the policies such as settlement along Kenya's fertile districts near the railway line. To cement the divide, President Jomo Kenyatta, who was chosen to succeed the colonial authority after independence, was from the Kikuyu tribe. On the other hand, Isiolo and most of Kenya's marginalized areas are inhabited by the Cushitic group of people, who historically occupied the grazing areas of the east African portions of Africa. They come from the Borana, Somali and Turkana tribes. Historically, these tribes were hostile to the colonial administration. In return, they were reprimanded with harsh colonial economic policies that are still in effect to date.

Kenyan culture has also been shaped by the country's colonial history. Kenyan culture presents itself in a variety of ways depending on the situation. Stereotypes and accepted behaviour from citizens and the state make up the culture. Based on the Kenyan culture, citizens tend to respond to the ever-changing government policies with a variety of coping techniques that are considered both inventive and disconnected. On the other hand, the Kenyan government's policy-making culture is based on assumptions about citizens' reactions and non-consultative policymaking. This has shaped the relationship between citizens and the state and especially when it comes to taxation.

\subsection{A Brief History of Tax in Kenya}

The earliest forms of taxation recorded in the African history goes back to as early as the eighth century. It is described to have taken place in the gold trading industry in what is modern-day Ghana (Gardner,2012). This was not described as taxation as the notion of the state was non-existent. However pre-colonial tribes and nations in Africa traded with each other and they paid tributes or tithes to their chiefs as payment for the protection they enjoyed by being part of the tribe (Gardner,2012). These payments 
symbolized a reciprocal relationship where the chief or king would provide protection and food in times of famine to his people. The tributes were key in creating and sustaining social relationships (Gardner,2012; Brautigam et al.,1998). It is believed that the informal social contract in Africa that exists till today is derived from this prehistoric relationship (Gardner,2012).

Taxation in Kenya, as we know it today, was introduced by the British colonial administration (Gardner,2012). In 1895, the British Empire established the East Africa Protectorate. In 1920, however, it was renamed the Kenya Colony. In 1901, the Hut Tax Regulation was enacted, imposing a one-rupee tax on every native hut in British East Africa, payable in kind or through labour (Waris,2008). The natives found ingenious ways to avoid the hut tax by living together under one roof and being taxed as a single entity. This was quickly identified, and the Poll or Head tax was adjusted. The new tax was imposed on every liable person regardless of their income or assets (Gardner,2012; Brautigam et al.,1998).

The main objective of the introduction of taxation in the colonies was to finance the administration of the British East African empire (Gardner,2012). The British colonial authority discovered that running its colonial administration was very expensive thereby considered taxation as its solution (Gardner,2012;2013). Ideally, taxation should be utilised to fund public goods and services while also assisting residents in achieving economic stability, equal income distribution, and social welfare (OECD, 2014). However, the system introduced in the colonies did not represent the tenets that were supposed to support the growth of fair and equitable tax systems. In the colonies, taxation was imposed on individuals in a coercive and oppressive manner. It was largely imposed on taxpayers with little or no benefits in exchange, generating a shaky relationship between the state and its citizens to this day (Moore et al. 2018). Developed nations are seen as having transformed tax policies and systems from coercive to contractual tax systems, allowing them to flourish democratically while also being held accountable for fair revenue collection and redistribution (Moore et al.2018). This has allowed them to flourish democratically while also being held accountable for their revenue collection and redistribution.

Coercive tax systems refer to the enforcement activities and penalties posed during tax collection (Fjelstad,2001). Coercive tax schemes are shown to raise taxes while 
lowering reciprocity and the state-citizen contractual relationship. Odd Helge Fjelstad (2001) claims that coercive tax regimes raise taxes per capita, but that this is due to a higher level of distrust in the collection mechanism (Fjelstad,2001,293). Countries like Kenya categorized as low-income nations tend to use coercive measures to collect tax as there exist little trust between the revenue authority and the taxpayers (c.f Fjelstad,2001). The revenue authority uses coercive means to get taxpayers to comply as they are not trusted to comply on their own. For taxation to develop a social contract between citizens and their state, tax collection strategies cannot be coercive; instead, we should ask ourselves "should tax collection be connected to redistribution?".

In 1986, the Kenyan government adopted the Tax Modernisation Programme (Gichuki,2015). This was part of Kenya's economic growth policy outlined in the Sessional Paper No. 1 of 1986 (Ouma,2019). The modernisation initiative attempted to increase the government's revenue base by enforcing rigorous fiscal limits on spending. By raising tax compliance and collection, enhancing institutional capacity, and establishing adequate database management systems, the reforms planned to increase tax revenues from 22\% in 1986 to $24 \%$ by the mid-1990s (Gichuki,2015,12). The current reforms, as well as the second ICT Strategy 2014-2018, laid out a roadmap for greater investment, increased revenue, and service delivery through automation programs (KRA,2014). This Strategy established a framework for utilizing and leveraging existing and emerging technology, as well as the adoption of best practices, in order to transform business processes and achieve full electronic customer service (KRA,2014). The vision was 'To Achieve Fully Integrated Electronic Customer Service'. The KRA said it would 'proactively leverage on innovative technologies to enable and support business through the provision of quality ICT services and solutions' (KRA,2014, XI).

As a means of boosting revenues, Kenya has previously focused on bridging the "taxation gap" and growing the tax base. The focus of tax reforms since 1993 has centred on trade liberalisation and the adoption of a system of value added tax (VAT). The Kenya Revenue Authority (KRA) was established as a result of this expansion of the tax administration's capability and efficiency. Even though many of the proposed economic reforms have been successful, the Kenyan government is no longer able to rely on tax revenue as it did ten years ago. This is demonstrated by the fact that, while tax revenues have increased over the current reform processes, the revenues have 
decreased in relation to the GDP, while the share of government revenue derived from tax revenues has remained the same.

To date taxation remains the largest source of government revenue in Kenya (ICPAK,2012). Tax revenues constitute over $65 \%$ of total government finances (KNBS,2014). Based on numerous recommendations from global policymakers like the IMF, World Bank and the UN, Kenya has been reforming its tax policy since its independence in 1963 (Moyi,2003). According to the Institute of Certified Public Accountants of Kenya (ICPAK), Kenya was among Africa's top 10 economies in 2014 (ICPAK,2014). Prior to 1995, Kenya's tax system faced several major challenges like high tax evasion; low tax revenues and complex structures that made it difficult to administer taxation in Kenya (Moyi and Ronge 2006).

In the past, tax reforms increased taxation in Kenya making it the largest source of government revenue in Kenya placing Kenya among the top ten economies in Africa. (Kerandi 2015), (World Bank 2014), (Tyce 2020) However, as shown by the graph below, the tax to GDP ratio in Kenya has been declining since 2014(Tyce 2020).

Table 1:Tax to GDP Ratio in Kenya

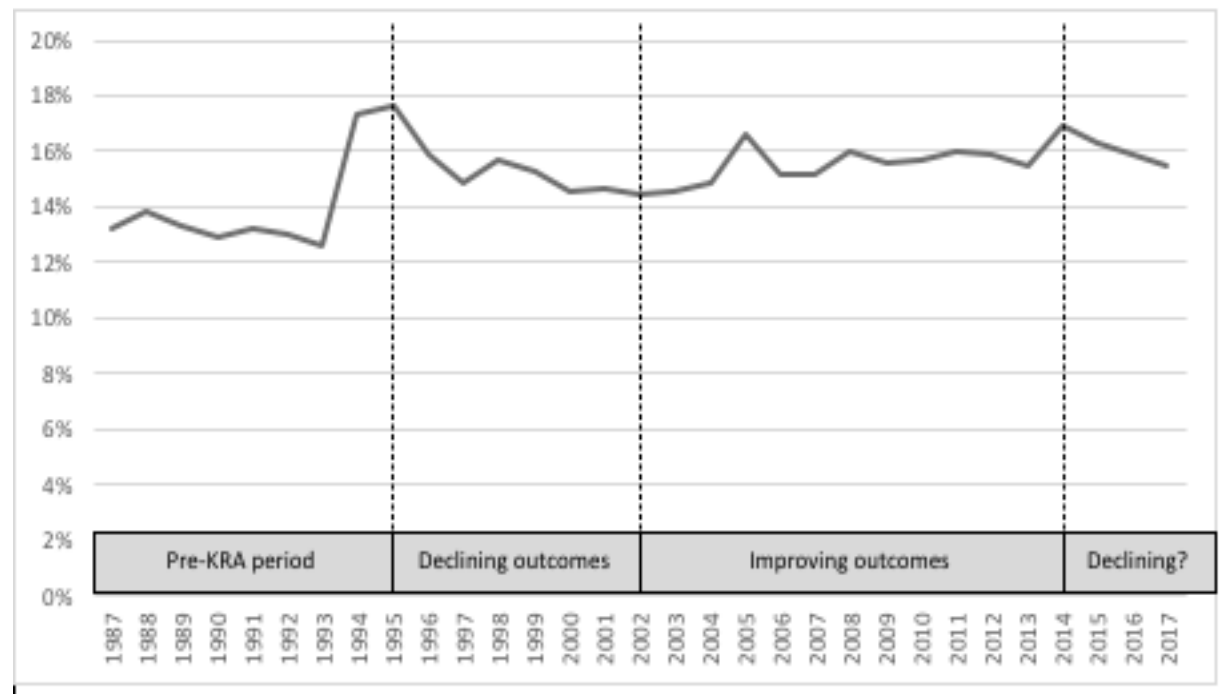

Source: Tyce 2020 
The Kenyan economy has a large untapped tax potential in the informal sector. Kenya's economy, like that of any other developing country, is dominated by the informal sector. The informal sector consists of small-scale traders generally operating at subsistence levels with few employees (World Bank,2006). They engage in smallscale manufacturing, production, building, or offer repair services. Given the vast number of unregistered taxpayers and unreported activities and revenues associated with these activities, their informality remains a hurdle to domestic resource mobilisation in Kenya. In 1993, the Kenya National Bureau of Statistics projected that 910,000 small and medium firms (SMEs) were operating in the country, employing up to 2 million people. By 2015, the informal economy had grown considerably, employing an estimated 12.5 million people, or $82.8 \%$ of the workforce, according to the Economic Survey 2016 (KNBS,2016a).

Responding to the stated challenges, the government established the KRA in 1995 as a semi-autonomous organization. The main purpose of its establishment was to enhance the mobilisation of revenue, improve tax administration and sustainability of tax. Another factor that prompted the formation of the KRA was a global surge of greater public-sector reforms based on new public management ideas (Fjelstad and Rakner,2003), (Moyi and Ronge, 2006). KRA outlines its core functions are being the following ${ }^{2}$ :

- To assess, collect and account for all revenues in accordance with the written laws and the specified provisions of the written laws.

- To advise on matters relating to the administration of, and collection of revenue under the written laws or the specified provisions of the written laws.

- To perform such other functions in relation to revenue as directed by Treasury. With the goal of transforming the KRA into a contemporary, fully integrated, and clientfocused institution through the adoption of technology, in 2004 the Revenue Administration Reforms and Modernisation Program (RARMP) was established (the KRA 2010). The KRA incorporated the use of ICT into its strategic plan 2004/05 highlighting the growing faith of governments institutions globally in technology as a driver of progress and social change (KRA,2004). RARMP revered information and

\footnotetext{
${ }^{2}$ https://www.kra.go.ke/en/about-kra
} 
communication technology (ICT) as critical to the modernisation of the tax system. Technology was seen as an important driver of transformation especially with public administration.

While the KRA was leveraging on technology for increasing effective administration, The Kenyan government adopted the vision 2030 strategy, a national blueprint strategy that would guide national development. ICT was regarded in the strategy as key tool for achieving the national development goals (Poggiali 2016,2017). The Kenyan government made ICT a central component and even described itself as a 'digital government' with the current president and vice president being referred as the "digital duo" (Poggiali, 2016, 2017).

In the recent years revenue mobilisation has been a central policy in Kenya as the new constitution adopted in 2010 , increased the expenditure putting pressure on the KRA and the treasury to increase revenues at all costs (Gichuki,2015). Through its revenue authority, the KRA, that was established by the Kenya Revenue Authority Act Cap 469 of $1995 .^{3}$ Kenya has undertaken a lot of reforms to help address the issues relating to revenue mobilisation. KRAs latest reforms, as highlighted in their sixth corporate plan, establishes its vision as: 'To facilitate Kenya's transformation through Innovative, Professional and Customer-Focused Tax Administration' (KRA,2014). KRA second ICT Strategy 2014/15-2017/18, laid out a roadmap for ICT investment and service delivery focusing on utilizing and leveraging existing and upcoming technology, as well as the adoption of best practices, towards achieving full electronic customer service (KRA,2014). The vision was 'To Achieve Fully Integrated Electronic Customer Service', while the mission was 'To proactively leverage on innovative technologies to enable and support business through the provision of quality ICT services and solutions (KRA,2014).

With its vison and mission at hand, the KRA forged ahead and embarked on this digitalisation journey with the main aim of transforming the administration by leveraging on technology to achieve its goals. Like many other African Tax administrations, the ambitious agenda for reforming taxation has always been

\footnotetext{
${ }^{3}$ The Public Finance Management Act, 2012, Laws of Kenya
} 
connected to ideas of innovation based on recommendations from global policymakers (Moore, Pritchard and Fjelstad 2018). This research reveals that this foundation is still quite relevant within the existing tax policy in Kenya whereby policymakers and donors' have taken up the responsibility of teaching developing nations like Kenya "how to tax" by endorsing the use of technology in tax. The government uses the generated revenue to provide public goods and services and to assist citizens in achieving economic stability, equitable income distribution, efficient resource allocation, and social welfare.

Taxation is a legal requirement in modern-day Kenya, as stated in Article 209 of the Kenyan Constitution of 2010. The article outlines how both the national government and county governments can impose taxes or raise revenue. Income taxes, valueadded taxes, customs fees, and excise taxes are all imposed primarily by the national government. Article 209 gives the county government the authority to levy property taxes, entertainment taxes, and any other tax approved by a law passed by the Act of Parliament (Laws of Kenya 2020). It's worth noting that Kenya's tax system is strongly skewed toward income taxes and Value Added Taxes (VAT) as the two main sources of the overall tax revenue. For example, income tax collection amounted to $36.3 \%$ of total government revenue from 2005/06 to 2011/12 (total taxes plus appropriation-inaid). On December 24, 2020, the income tax was amended. The KRA informed the public about adjustments to tax rates enacted by the Tax Laws (Amendment) No. 2 Act of 2020. These additional changes were meant to aid Kenya's recovery from Covid 19. The rates were advertised as follows:

Individual Income Tax Bands and applicable rates ${ }^{4}$

Table 2: Tax Band and Rate of Tax in Kenya

Tax Band

Rate of Tax

On the First KSh 24,000 per month or KSh 288,000 per annum

$10 \%$ 
On all income amounts in excess of KSh 32,333 per month or KSh 388,000 per annum

Source: KRA 2021 (accessed www.KRA.gov.ke on 29.01.2021

In Kenya, The Commission of Revenue Allocation (CRA) is tasked with revenue allocation and redistribution. Revenue distribution is determined by a formula based on the amount collected at the county level. The KRA allocates greater funds to the counties that gather the highest revenue. Yet, as will be shown in chapter six, this among other historical policies has led to economic marginalization in certain counties. These counties were not seen as having tax potential. Kenya's revenue reallocation formula is based on the county's own revenue generation. Counties like Isiolo and Kiambu, for example, are incomparable due to the disparate abilities to collect revenues based on their economic and social status. While Kiambu is located near the capital and experiences relatively good weather, contributing to its economic advantage, Isiolo on the other hand is semi-arid and has far less revenue generating activities. Under the current reallocation system, Isiolo county will remain underfunded which impacts negatively on its development. While Kiambu can afford to build state of the art hospitals, Isiolo still struggles to offer basic health care to its citizens.

Despite the numerous tax reforms undertaken by the Kenyan government since 2003, Kenya still faces challenges, typical in most developing countries that includes among other factors, slow economic growth, corruption, and poor governance. From the tax modernisation program in 1986 and the subsequent ones in 2004 and 2014, KRA has been on the path of achieving modernisation using different strategies. As will be demonstrated in this thesis these ideas remain the same despite the changes in strategies such as the introduction of technologies. The next section of the research connects the ideas of adopting ICT to develop Kenya through taxation with development theories. Development policies are rooted in this belief that economic growth and 'modernisation' can be accelerated through transferring ideas and technologies. 


\subsection{What is Development?}

Richard Rottenburg (2009) argues that investigating the transitions between representations and practices in terms of how they are institutionalized and deinstitutionalized is critical to understanding the phenomena of development (Rottenburg, 2009; pg. 31). As in 'representative architecture,' representation refers to visualizing, depicting, acting as a proxy, bringing to mind, and providing an example of something (Rottenburg,2009;32). According to Rottenburg (2009), the development agenda follows two scripts: one is the transmission of technical knowledge, capital, and technology, which the implementor views as neutral and "teachable," and the other is the expectation that the knowledge will transform social order (Rottenburg,2009).

The idea that technology can transform the economy is being marketed like in the case of ITax as shown in this research. Due to its relationship with the technologies and habits formed by them, technology has long been considered as a driver of modernity and development (Von Schnitzler,2016). Sarah Harding (2011) argues that western nations believed that traditional societies had to do away with their religious beliefs, myths and superstitions in order to achieve social progress and scientific rationale. This rationale is quite relevant as countries like Kenya with low gross domestic product $(G D P)^{5}$ are seen to be economically underdeveloped. Policymakers therefore task themselves to develop and share models that aim to help these countries 'leapfrog' to the" global" standards of economic development (Acemoglu et al.,2001; Mosse,2004). This standard is often modelled after western countries as it is assumed that they have already "progressed" (Harding,2011).

Development theorists view the world as being divided into developed and developing. Countries that are seen to be lagging economically are seen as "developing" while those that are seen as having achieved economic growth and stability are seen as "developed". The idea as revealed in its semantics is used to refer to what needed to be achieved and by whom. Those seen as developing should ideally aim to become developed. The economic models used in developing contexts are often modelled

\footnotetext{
${ }^{5}$ Gross domestic product (GDP) is the total monetary or market value of all the finished goods and services produced within a country's borders in a specific time period. As a broad measure of overall domestic production, it functions as a comprehensive scorecard of a given country's economic health
} 
after the developed countries. ${ }^{6}$ In this dissertation, the terms 'developing' and 'developed' are used in the public policy to make visible how development policy is formulated and integrated into ITax by KRA and by policymakers who endorse the use of technology for development.

The idea of development is a process that is seen as achievable through interventions (Heyneman,1980). Countries are categorized into these two categories based on their economic position, such as average per capita income, national wealth (Gross Domestic Product/GDP), literacy rates, birth rates, industrialization, and reliance on foreign trade $(\mathrm{UN}, 2014){ }^{7}$ There have been various debates about the negative connotations of the terms, however, this research found it necessary to illustrate the imbalance in the continual need to "develop" developing countries.

\subsubsection{Development Reinvented?}

"We must embark on a bold new program for making the benefits of our scientific advances and industrial progress available for the improvement and growth of underdeveloped areas. More than half the people of the world are living in conditions approaching misery.... For the first time in history, humanity possesses the knowledge and skill to relieve the suffering of these people... The United States is pre-eminent among nations in the development of industrial and scientific techniques.... our imponderable resources in technical knowledge are constantly growing and are inexhaustible" (President Truman cited in Porter 1995).

The ideas of development have in over the last fifty years been spread globally with the aim of bringing economic prosperity to countries. In his legendary inaugural statement on January 20, 1949, US President Harry S. Truman announced that the

\footnotetext{
${ }^{6}$ There are broadly two economic worlds that cut across the globe, the Western countries, and the Developing countries. The Western countries represent the economically developed societies of Europe, North America, Australia, Israel, whilst the Developing countries represents the economically backward countries of Africa, India, China, Brazil, Mexico amongst others. While Western countries are wealthy, technologically advanced, politically stable and aging as their societies tend towards zero population growth. Developing countries are agrarian based, dependent economically and politically on the Western countries, the Western countries has continued to dominate and direct the developing countries in international trade and politics.

${ }^{7}$ https://www.un.org/en/development/desa/policy/wesp/wesp_current/2014wesp_country_classification .pdf.
} 
fourth goal of his foreign policy was to assist in the spread of global industrial and scientific growth. This statement is seen as having laid the foundation for the idea that 'development' could be modelled for what was now considered developing countries. Economic growth is viewed as a process that may be cultivated by providing the right and timely inputs (Abuiyada,2018). President Truman contended that the nations that were pre-eminent in the development of science and technology like the USA would need to take it upon themselves to spread this knowledge. Western scientific rationality and expertise therefore was understood as the solution to the slow or stunted economic growth in poor societies (Harding 2011,19). Even today, reforms that are endorsed at the global level are expected to address the same issues across several countries and achieve similar results.

After the second World War, the 'development' agenda began with science and societal progress based on modernisation theory and belief in the 'beneficial capabilities of scientific rationality (Harding,2001; Rist, 2014). As a result, Western modern science and technology were seen as the crown jewels of modernity (Harding, $2011,48)$. The idea of development thereby contains constant re-enactment of the differences that exist as well as mechanisms to help rectify them. Development was supposed to be an imitative process in which less developed countries gradually adopted the characteristics of developed countries by growing gross savings and investments until the economy reached a position of self-sustainability (Burkey,1993). Contrary to these expectations, critics argue that what was happening in most lowincome nations instead was increased poverty, negative growth, and the debt crisis (Burkey,1993).

This way of thinking is grounded in modernisation theory. In the 1950s and 1960s, modernisation theory became popular as a way of comprehending economic and social development challenges and developing strategies to aid poorer nations' economic and social transitions (Gwynne,2009). At the time- during the scientific revolution- the theories of modernisation were tied to science and technology based on advancements in Europe (Prasad,2008). The challenge was that the plan of achieving modernity and development changed so rapidly that making the idea of modernity seemed non-existing. Modernisation theory became prominent in the $1950 \mathrm{~s}$ and 1960s used to understand how economic and social development would assist economic and social transitions in poorer countries (Gywnne,2012). 
Modernisation theorists like W. W. Rostow (1960) claimed that poor countries could only grow by adopting Western-style developmental policies, processes, and strategies. The underlying logic is that all nations must be brought to a level of economic equality (Walter Waitman Rostow 1960).As stated by Rostow (1960,6): "The pre-conditions of take-off [for transformation from a traditional to a modern society] were initially developed in Western Europe in the late seventeenth and early eighteenth centuries as the insights of modern science began to be translated into new production functions..." (Rostow 1960: 6). According to Moses Onyango (2010) "the postcolonial perspective of modernisation approach had two distinct engines: the first was when colonial states were required to modernize the 'primitive,' and the second was the belief that 'developed' countries must provide foreign aid to foster development in 'underdeveloped' countries. (Development became organized around initiating economic and social development to post-colonial states.

\subsubsection{Developing Africa}

African countries have been urged to broaden and deepen their tax and revenue collection bases and leverage digital technologies to boost collection and compliance. This is viewed as crucial to ensuring long-term development (UNECA,2019). The continent's weak revenue-to-gross domestic profit (GDP) ratio stood at 21.4 per cent in 2018, was in need for reform as adequate finances were key to achieving the continents development goals known as Agenda 2030 and Agenda 2063. The continent was seen as being able to solve this crisis by aligning fiscal policy with the business cycle (UNECA,2019). Reforming tax administration systems using digitization among other propositions were given as recommendations for expanding resources needed to finance development in Africa (ATI,2015). Kenya for example is categorized as developing country and has been a recipient of development aid since the 1980s. The projects referred to as development projects are aimed at accelerating the economic growth in the recipient countries (Mwega,2009).

There have been several attempts to accelerate economic growth in countries like Kenya that are deemed to have weak economies. In terms of revenue mobilisation, these assertions linking taxation to development frequently link these universal claims to scientific progress (Oppenheimer,2011). Fairclough (2003) argues that the representation of the global as an entity that is free from human authority seeks 
universal status that can be used to spread certain visions. Interests, identities, representations come under certain conditions to be claimed as universal (Fairclough,2003). These representations, according to Fairclough, rest between assumptions and assertions. However, as has been the case since World War II, development is still absorbed into the greater development agenda for economic development (Stewart,2003). This has led to the rise in the financing for development movement.

The various initiatives have put great focus on the need to increase domestic resources and develop alternatives to finance development in developing nations like Kenya. In this section, the researcher connected post second world war developmental theories to the current digitalisation wave arguing digitalisation is grounded in modernisation and developmental theories where countries that are seen as "developed" come up with solutions on how these "underdeveloped" countries can catch up economically. The development solutions as discussed are endorsed in countries seen as having stronger economies and implemented in those like Kenya seen to be lagging economically. These ideas are now rooted within taxation. The next subsection, connects the notions of financing for development to taxation to show how taxation has been made a central strategy by policymakers geared towards achieving economic growth.

\subsection{Taxation for Development}

Taxation is an important element in financing national development and the pressure to collect more revenues is brought by the growth of the government's role. In developing countries, the pressure to collect more taxes is even more urgent as they are historically unable to finance their own development without foreign aid and grants. This has always led to several tax reforms being endorsed by policymakers and donors in order to help developing countries like Kenya 'leapfrog' to the global standards of economic development (c.f, Acemoglu et al.,2001; Mosse, 2004). In March 2002, in Monterrey, Mexico, the financing for development agenda was launched. The Monterrey Consensus was adopted as a result of the meeting, which "resolved to address the challenges of financing for development" and "to eradicate poverty, achieve sustained economic growth, and promote sustainable development" (UN,2003,5). 
The second conference for financing for development was held in Qatar in 2008. The meeting led to the adoption of the Doha Declaration that also alluded to similar goals, culminating in the financing for development ( $F f D$ agenda). The third financing for development conference in Addis Ababa in 2015, was a follow up to the two conferences whereby Addis Ababa Action Agenda (AAAA) was formulated. The AAAA outlined how the international community will fund the world's new sustainable development agenda $(\mathrm{UNDP}, 2015)^{8}$. After the Addis conference in 2015, the governments of Germany, the Netherlands, the United Kingdom, and the United States of America initiated the Addis Tax Initiative (ATI) ${ }^{9}$. The main goals of ATI were to raise much more funds for capacity building in the field of domestic revenue mobilisation, as well as a commitment to the creation of transparent, fair, and efficient tax systems. Expansion of technical assistance for financial market growth and enhancing statistical data dissemination through knowledge sharing were two of the activities agreed upon (ECOSOC,2011).

In 2015, the United Nationals Economic and Social Forum (ECOSOC) held a conference initiating the financing for development agenda. ${ }^{10}$ Their main argument was based on the idea that developing countries could use foreign aid to plan for their domestic revenue mobilizing initiatives that mostly included strengthening tax systems. Subsequently, the UN adopted the Sustainable Development Goals (SDGs) through a resolution 70/111 in September 2015 (UN,2015). Goal 9 of the sustainable goals calls for 'building resilient infrastructure, promote inclusive and sustainable industrialization and foster innovation'. Under this goal, the resolutions are aimed at facilitating sustainable and resilient infrastructure development in developing countries through technological and technical support (UN 2015, 20-35). What was made quite central after the adoption of this resolution was that developing countries would need

\footnotetext{
${ }^{8} \mathrm{https} / /$ www.africa.undp.org/content/rba/en/home/ourperspective/ourperspectivearticles/2015/07/29/t he-addis-ababa-action-agenda-a-step-forward-on-financing-for-development.

${ }^{9}$ www.addistaxinitiative.net.

${ }^{10}$ In March 2002, the United Nations held the first International Conference on Financing for Development in Monterrey, Mexico to consider new approaches to financing more equitable global development. The resulting Monterrey Consensus "resolved to address the challenges of financing for development" and "to eradicate poverty, achieve sustained economic growth and promote sustainable development."

11 Transforming our world: 2030 Agenda for Sustainable development.
} 
to be assisted with increasing domestic revenues in order to finance their own development. Domestic revenue mobilisation (DRM) was then brought to international attention when donors stated that financial aid was reduced drastically due to the to the financial crisis of 2007-2008 (OECD, 2016; ATAF, 2016).

This put great focus on the need to increase domestic resources as well as find independent ways to finance development in developing nations like Kenya. Domestic revenue generation (DRM) then became the central driver of sustainable economic growth (UN,2015). Increasing investments, taxation and technology are seen to be the main drivers of generating more revenues. To achieve this, donors and international organizations are urging tax reforms, the most recent being the digitalisation of taxation. (OECD,2016; ATAF,2016).

This led to the first ever global conference on tax for development being held at the United Nations (UN,2018) in February 2018, where international economic partners (OECD, IMF, World Bank and UN) created a platform for collaboration of tax (PCT). The conference's goal was to learn how to mobilize domestic resources for development, including adopting tax policies to support long-term economic growth, enhance investment and trade, and consider the social aspects of taxation (income and gender disparity, human development) (PCT Report,2018). This propelled the idea of taxation as the main vehicle for achieving development. Thereby, technologies or ICT is fronted as the silver bullet to the tax problems facings developing countries.

Tracing the production of financing for developing knowledge and expertise is key as this justifies the adoption of reforms such as ITax. The initiative pushes for the urgency of increasing domestic revenues and has recruited more than 60 developing countries. All member countries are expected to finance their own development goals by increase the domestic revenues as they are only able to generate approximately $15 \%$ of their domestic revenues. This would mean that the implementation of the development goals would vary based on the available resource. These new strategies were being endorsed quite rapidly in order to collect more revenue for the development agenda. In the case of ITax, this digitalisation effort was seen as being a quick fix to the low tax compliance that was being experienced in the country.

Misinformed tax policies are often used to respond to the underperformance experienced in African countries (Owen,2018). According to Oliver Owen (2018), the 
continent's average tax-to-GDP ratio is $19.1 \%$, compared to $34.3 \%$ for the OECD. This figure is even considerably biased upwards by the diversified middle-income economies of Morocco, Tunisia, and South Africa (Owen, 2018,2). This leads to misinformed policies for example when underdevelopment in low-income countries is seen to be brought about by untaxed sectors or the use of inefficient strategies. This is most probably the case in Kenya.

This section, looks at how the financing ideas for development initiatives, which first began in Mexico in 2002, were now introduced to developing countries at large with an understanding that they all faced similar challenges with regards to financing for development. These led to development of misinformed tax policies that neither represent the developed or the developing countries. The next section describes how the new financing for development movement uses digitalisation as its vehicle to achieve sustainable development.

\subsection{Digitalising Tax, Digitalising Development?}

ICT was the key political bargaining chip during the last two elections in 2013 and in 2017.To add to this, Kenya is benchmarked globally as being leading innovative country that successfully leverages on technology. This illustrates Manuel Castells (1998) argument that 'the critical factor in generating and accessing wealth, power, and knowledge in our time' is based on the ability to access, utilise, and adapt information and communication technology (Castells,1998, p. 92). Terms such as 'digital transformation', 'digital disruption' and 'digital inclusion' are an indication of how our lives are being shaped by digital technologies. Technology is often portrayed as 'equalising', 'value free' and 'universal' (Fisher,2010). This discussion is centred on how technology is viewed as having the capacity to revolutionize society and solve problems, such as low tax compliance and revenue in this case study (Turner,2006), (Mosco,2004). This is reflected globally in the current fourth industrial revolution whereby digitalisation is seen as its main catalyst (WEF,2016). The fourth industrial revolution is characterised by technological advances matching with those of the first, second and third industrial revolutions. Digitalisation is thought to be a good approach to cut costs, improve services, save time, and increase effectiveness and efficiency in government (Alshehri and Drew 2010). Digitalisation is defined as the use of information and communication technology (ICT) and other web-based 
telecommunication technologies to improve and enhance the efficiency and effectiveness of public service delivery ${ }^{12}$

Revenue authorities, donors as well as policymakers regard digitalisation as being key in achieving sustainable development. It is even endorsed by the United Nations as a crucial component of achieving the Sustainable Development Goals (SDG) ${ }^{13}$ (UN 2015). As quoted by the EU ambassador Stevens in 2018: "We are aware of the fact that digitalisation can be a strong driver of sustainable development and inclusive growth" (EC,2018). The EU Ambassador Stevens quoted above in his opening remarks at an international conference, went on to cement EU's commitment to supporting the technology for development reforms globally. The ambassador's remarks were important in this debate as the EU is the largest donor of development aid in the world, and its development policy is becoming increasingly digital, reflecting its commitment to achieving the 2030 UN Sustainable Development Goals. According to the EU development policy, 'digital technologies and services are to be considered as a tool to achieve the objectives within the focal areas and cross-cutting themes of the EU development policy' (EC,2018). The ideas within this development policy endorse the use of technology in achieving development. Other International organizations such as the United Nations (UN) and the Organization for Economic Cooperation and Development (OECD) agree that digitalisation is 'fundamental to reform, modernisation and improvement of government' (OECD 2005; p.97).

The UN estimates developing economies like Kenya will need to grow by at least 11 per cent annually through 2030, to achieve the Sustainable Development Goals (SDGs). Given the global financial system and present economic environment, the United Nations' World Economic Situation and Prospects (WESP) 2017 focuses on the challenges of getting sufficient money for the SDGs. Developing countries are expected to require up to US\$2.5 trillion per year through 2030 to meet their SDGs. Global organisations such as the World Bank, the OECD, and the World Economic Forum (WEF), have backed the financing shortages. This has put domestic revenue

\footnotetext{
12 Gartner. (n.d.). Retrieved from Digitalization: http://www.gartner.com/it-glossary/digitalization
} 
mobilisation (DRM) in a challenging position with developing countries being urged to take radical measures like digitalizing to increase revenues.

What this translates to in practice is that countries like Kenya are witnessing rapid adoption of technological platforms like ITax which in turn leads to destabilizing and potentially disempowering consequences. Kenya is not unique as the digitalisation wave has been felt in several developing countries however Kenya is viewed as an epicentre for technological development by most international organizations (Poggiale,2017), perhaps due to the success of Mpesa. The country also has great access to international funds for development in a way making it a testing ground for initiatives that can be replicated in other countries. The time frame, however, of the adoption of digitalisation is quite short not allowing the citizens to become familiar with the technologies (Loos, Haddon, and Meijer, 2008). According to Loos et al. (2008), it is the social dynamics at work between potential users and those in their social settings that contribute to the construction of an "ideal" society, not the platforms. The rationale for deploying digital tax technologies such as ITax not only travelled but also came with significant resources for developing countries. Already in the 1990s, supra international institutions such as the World Bank, for example, spent nearly $\$ 14$ billion on tax reform in 67 countries and a good portion of this investment went into technology-driven reforms aimed at improving efficiency and effectiveness in taxation (Barbone et. al, 1999).

Successful digitalisation projects are however heavily reliant on a country's ICT ereadiness. The ability to use ICT to build one's economy and foster one's riches is characterized as e-readiness, which is a measurement of the government's implementation process. E-readiness is analysed by its preparedness through analysing its ICT infrastructure, local expertise, electricity, networks, computer hardware and software as well as political will. ICT has been promoted since the mid1990s by major international development agencies, including the World Bank (World Bank, 1999), the United Nations Development Program (United Nations Development Program,2001), and the World Economic Forum as a model for economic development (Dutta and Mia, 200914). These agencies argue that the use of

\footnotetext{
${ }^{14}$ http://www3.weforum.org/docs/WEF_GITR_Report_2010.pdf
} 
technology in tax administrations helps provide better services to taxpayers and lower their operational costs (OECD, 2016, s. 16). This rationale implies that ideas or technologies can move across the globe, enlightening people's lives (World Bank, 2008).

The main challenge with this shift is the fact that some parts of the world are still in the second or third stage of industrial revolution and lack access to basic infrastructures like electricity, water and the internet (UN,2017). Despite this, such regions that are 'lagging behind' are being encouraged to digitalise with little or weak infrastructures available to support this shift. Daniels (2017) argues that Africa's mobile penetration success like in the case of the mobile banking platform, Mpesa, in Kenya is seen to be the blueprint for ICT development in Africa. However, what is left out in ICT policy development is that the infrastructures that are needed to support this shift. Within taxation, technology is assumed to have the capacity to influence taxpayer's behaviour thus increasing their compliance and revenues. While this is evident in countries with strong tax frameworks, emerging countries face hurdles, particularly in terms of implementation. While this has been evident in countries with strong tax structures, developing states are experiencing challenges especially with the implementations. To understand the transformation of ICT in government, one must understand the stages of e-government development.

\subsection{Approaches used to study Taxation, Development and Digitalisation}

This sections briefly discusses the main approaches used to study ITax. The usage of the approaches will be further discussed in chapter 2 where theoretical framework of this research will be introduced. The methodological approaches will also be described.

\subsubsection{Postcolonial Technoscience (STS)}

In this study, postcolonial approaches are used to attend to the travels of technoscience to postcolonial countries like Kenya. Mainstream technoscience studies focused seldom on postcolonial contexts as if the travels of science and technology would remain the same as its point of origin with little focus on how science and technology historically and to date has travelled along historical, cultural, economic, and political paths. In this research, the concept of travel and translation will be employed within postcolonial technoscience to analyse how ITax has altered 
and transformed tax processes in Kenya. As it is considered as an abstraction of the social environment that is carried from one culture to the next, the concept of travelling models is utilised as a theoretical guide (Rottenburg,2009; Behrends et al.,2014; Weisser et al.,2014). Tax models have been used historically as explained in this chapter to help developing countries like Kenya accelerate their economic growth. This study affirms that these models meet existing understandings of the world changing their practices from their intended objectives (Behrends et al. 2014). The models are subjected to translations by the actors who bargain and put them into use by their interpretations and uses. These approaches within postcolonial technoscience allow this study to attend to how models travel in postcolonial environments such as Kenya. According to Warwick Anderson (2017), STS approaches to postcolonial contexts should analyse phenomena based on the model being examined as well as the historical implications that are visible or invisible. This would therefore help reveal how technology was utilised as a tool for oppressing as well as rewarding the colonies based on their allegiance. In Kenya for example, colonial tax administration developed tax policies that were coercive. These tax policies are still at play in the current tax reforms. STS's engagement with postcolonial theories has however leaned mostly towards using Euro-American analytical terms (Law and Lin,2017). Many researchers have warned against essentializing spatial and cultural difference and stressed the importance of contingency in revealing what Warwick Anderson (2009a) described as "the heterogeneous, haunted, uneven terrain of contemporary power relations, according to Lin and Law (2017) in "Where is East Asia in STS" (Lin and Law,2017). In response to this critique, postcolonial techno scientists see the need to problematize "northern science studies" and the power dynamics within technoscience in order to comprehend the intertwining of science, technology, and society (Harding,2008; Prasad, 2008, Anderson 2002,2009, Seth,2009, Harding,2011).

Bruno Latour (1987) coined the term "technoscience" to argue that rather than "black boxing" science's technical components, we should look for its social impact Latour, 1987). According to Latour (1987), scientists use rhetoric, laboratories, and scientific "black boxes" to persuade audiences that their theory is superior to others' $(1987,2$ 3). Within science studies, the notion of the "Blackbox" has been defined as "a technical artifact" that is frequently employed for a specific scientific function without regard for the artifact's social workings. This research employs Latour's concept of 
technoscience to demonstrate the impact of colonial systems on technological advancements, such as the digitization of taxes. Although digitalisation is seen as the solution to underdevelopment, it navigates through several 'black boxes' that when opened reveal the historical and cultural structures that challenge or influences its outcomes. This research combines this concept with postcolonial theories to see how technoscience in this case study is loaded with colonial rationale for developing the "natives". Latour's concept of technoscience is crucial for comprehending the link between science and technology in the current digital development agenda.

Sandra Harding (1994) proposed that scientific studies programs originating in Western countries be re-located on a more realistic historical map generated by new postcolonial studies (Harding,1994, 327). This is due to the fact that postcolonial scholars have been doing so for a long time, but their work was completely unknown in European and North American science circles (Anderson,2002,645). STS has in the last 30 years, contributed to making the interconnectedness between science, technology and society visible (Latour and Woolgar [1979] 1986; Haraway,1991 and Prasad,2008). This research contributes to this conversation within postcolonial STS because the study is carried out in Kenya and takes into consideration current and historical understanding of technoscience as understood by the locals. As proposed by Harding it is important to analyse projects of science from their premises in order to understand holistically what influences its practice.

Another important contribution to postcolonial STS is Helen Verran's work (Verran,2001). Helen studied the interaction of local knowledge practices: one 'traditional', the other 'scientific' among the Yolngu people of Arnhem Land. Her goal was to gain epistemic clarity through cross-cultural study of knowledge traditions, rather than just exploiting the contradictions of Western rationality. In her findings, one of the most influential analysis of the mobility of technoscience within STS was actor network theory. Her work contributed to an understanding of how digital technologies perform in postcolonial environments. Verran argues that the concepts of digitization must be addressed by researching procedures that can alter the meanings of the desired goals. The historical relationship between the tax man and the taxpayer still influences how fiscal policies like digitalising tax is implemented. It is therefore key to take such matters into consideration when studying the travels of such ideas into postcolonial environments like Kenya. It is also critical that the research is focused in 
order to understand how ideas generated by society's interactions with digital technologies are replicated in multiple locations at the same time.

Marianne de Laet and Anne-Marie Mol (2000) study show how the design of a Zimbabwean bush pump changed as it migrated from village to village while still staying a Zimbabwean bush pump. De Laet and Mol (2000) argue that bush pump was unlike other water pump models that were almost always succeeded by newer models that entered the market. It was fluid and able to retain most of its original features making it quite recognizable as the old model (Mol and De Laet,2000). The bush pump was popular because of its adaptability and functionality, as well as how it could be reinvented by other users. The pump's use was also fluid since it played a vital ceremonial purpose both locally and nationally in addition to providing water to the community. The bush pump could be re-developed at all local levels while still retaining its initial purpose as a bush pump. I connect this to ITax's fluidity in its aims that were both local and international. It also has different meanings for different actors. Locally it was seen as being able to help KRA increase revenues while globally it was seen as a vehicle for achieving economic development.

Amit Prasad's (2008) work, which examines Magnetic Resonance Imaging (MRI) research and development in the United States, India, and the United Kingdom to highlight how colonialism continues to inform techno-scientific research, is another source of inspiration for the technique employed in this study. Amit claims that STS must change its approaches when analysing the movement of science and technology to trans-national or global arenas. In what he describes as "science in motion" he supports the importance of shifting the focus from the impact of colonialism alone to analysing "science in motion" across nations and societies. According to Prasad (2008), "Science in Motion" can reveal inequalities within networks and flows of knowledge, objects, and people. Inspired by Prasad's perspective, this study views the endorsement of digital technology for development as an extension of the colonial rationale for developing nations seen as being economically weak. I use this argument as well to show that infrastructures are still shaped by colonial structures as shown in chapter six where the two counties are shaped differently by the colonial policies. 


\subsubsection{Digitalisation}

Lisa Poggiali (2017) investigated ethnographically how digital technologies have become idioms through which Kenyans discuss national politics when it comes to digitalisation in Kenya. She introduces the term "digital citizenship" to demonstrate how digital technologies in Kenya have become a forum for asking concerns about citizenship. Her research is key in understanding how hybrid identities are created through digitalisation. In Kenya, Lisa Poggiali (2017) investigated the discursive development of 'ICT' environment (Poggiali,2017,254). The current government according to Poggiali, hinged on making Kenya an African High-Tech capital in their campaign even promising laptops to all school-going children once they were elected. Poggiali goes on to say that Kenya's elite technology sector, as well as the Kenyan government, deployed a techno-utopian discourse that portrayed the government as technical rather than ethical or political. Nairobi's burgeoning technology sector further positioned digital technology as a key project of pan-ethnic nationalism, tying Kenya's economic success to prescribed ways of belonging to the state (Poggiali 2017; 255). Using Poggiali's work, I contextualize the current digitization wave in Kenya. While she was focusing on how the Kenyan government was using technology in politics so that the country was a digital giant, I can find common grounds where this rationale is being used in taxation.

With her case study of pay meters, Antina Von Schnitzler $(2015,2016)$ demonstrated that apartheid techno politics in South Africa was manifested in infrastructure and procedures, as opposed to the west, where the notion of modernity was related to modern citizenship regimes. She focuses on the "travels" of a modest technical device to investigate the politics of infrastructure in South Africa. She claims that the rise of 'modernity' is frequently linked to the centrality of technology and the resulting habits, thoughts, and sociality (Schnitzler,2013). This then, according to Schnitzler, linked modernity in the colonies to processes of extraction and biopolitics that were bound by the project of domination. Schnitzler (2013) argues that the residents in South Africa bypassed pay meters enabling the illicit use of electricity and water forcing its inventor to constantly reconfigure the technology (Schnitzler,2013). She traces the meter's history from Victorian Britain, where it was designed for the working-class "moral improvement", to late-apartheid South Africa, where it was reassembled as a counterinsurgency instrument against the anti-apartheid "rent boycotts" 
(Schnitzler,2013). According to Schnitzler, the meter was distinct to many ethical regimes and political projects. ITax's ideas and models travel along colonial historical structures, shaping the consequences when implemented locally and nationally in Kenya, much as apartheid techno politics.

\subsubsection{Anthropology of Tax Approaches}

Tax research is typically not studied from social-cultural perspectives. This research engages with socio-cultural approaches within tax to understand how ITax is implemented and its implications. Most tax research focuses mainly on either tax law, economics or accounting perspectives (Björklund Larsen,2018). However, sociocultural approaches to understanding how tax reforms such as digitalizing tax filings affect taxation in people's daily lives are frequently overlooked. My approach holistically analyses the travels of a tax model from the different actors and sites involved in its reality allowing for an understanding of how ideas change as well as determine whether such technology achieve their set objectives.

Anthropologists' engagement with tax has led to three approaches (Makovicky and Smith 2020). First, it is based on actions and discourses in which the ideal taxpayer is envisioned through practice. Second, it considers taxation as a social field with competing actors, logics, and action plans (Gracia and Oats,2012). Finally, the concept of assemblage is used to demonstrate compliance as "the result of a heterogeneous assembly of actors and behaviours," which includes "auditors and taxpayers, as well as the knowledge, technology, rules, and regulations that offer active enforcement to these varied people" (Makovichy and Smith,2020). Karen Boll work $(2012,2014)$ views tax as assemblages interconnected with various ideas, actors, sites and goals (Boll 2012: 225; see also Boll 2014a, 2014b). I find this quite close to my own research where ITax is a result of many assemblages that includes various actors, sites and ideas. With increase of digitalisation of tax all over the world my approach contributes to an anthropological understanding of the digitalisation of tax in Kenya.

The few existing anthropological studies of tax compliance and the willingness of taxpayers to comply with the tax rules, often privilege practice over tracing the policies and their origins, which is essential in understanding the interface with the local context. Björklund et al.2018 for example, analysed how tax policy was implemented 
in European countries. By applying an 'ethnographic gaze' they could reveal different ways in which the policy steers tax compliance. They were looking at how one policy from the OECD, 'corporate compliance' was being implemented in their respective countries. They revealed that despite having similar tax policies, the policy outcomes were very divergent in practice.

In Sweden, Björklund Larsen deemed the policy a 'failure' because the legal barriers and lack of proper implementation created an impediment for the success of the program (Björklund Larsen,2017). While Karen Boll (2017) work on the other hand found that the Danish policy was successful due to the fact that there was openness in the tax governance structures leading to innovative ways of getting corporations to comply. These two examples show that ethnography is an important method of inquiry into understanding the travels of tax policies in different contexts. Secondly, their work demonstrates that local structures play an important role in how policies implemented successfully. My study, like theirs, employ ethnography to track the development rationale behind ITax. Using multi-sited ethnography, my research compares ITax's desired goal to its implementation.

Janet Roitman's work is particularly important to this research because she investigated the concept of "economic citizenship" by looking at practices in Chad's cross-border territories, Basin (Roitman,2005). She demonstrates how the coexistence of regulated and unlicensed economic activities leads to 'fiscal disobedience' among taxpayers, arguing that the refusing to pay tax is more often a tool of political contestation in which notions of citizenship influence the economic relationship of taxation. As found by Roitman (2005) found that the relations of exchange are essential for the formation and maintenance of social relations of obligations and reciprocity. The concept of "economic citizenship" has inspired this research to explain how different counties in Kenya operate differently as a result of the categorization of economically viable and non-viable areas. Although this study does not use the term economic citizenship, it employs the thinking behind the terms "taxable and untaxable" as used in chapter six. Taxation was used historically during colonial times to categorise natives who would be empowered by paying taxes or those who would be marginalised because of not being seen as being loyal to the administration. Chapter six connects how similar colonial policies have led to "taxable" and "untaxable" Kenyan citizens. 
As a result, my work contributes to the anthropology of tax agenda, which has been underrepresented in the larger field of tax research. Using anthropological/ethnographic methods, such as participant observation, enables my work to delve deep and get first-hand experiences to record challenges taxpayers face while trying to comply with ITax. These methodological approaches allow me to demonstrate how the digitalisation of tax has not only created hybrid identities where the new tax experts are ICT technicians but also how the re-defined the new relationships between the KRA and the taxpayers were made. This research aims to understand why digital technologies in development projects are aimed towards offering socio-economic solutions that are not always representative of the local realities. There are few anthropological ways to examining tax policy in postcolonial countries, especially when it comes to comprehending the tax agenda in postcolonial environments. It does, however, allow for a socio-cultural analysis of ITax deployment and its consequences for the many groups of people who interact with it. As a result, I make a case for the necessity of tax anthropology.

\subsection{Conclusion}

Countries like Kenya are adopting digital tax technologies rapidly. The implications of this are unknown prompting this research, to show how the swift introduction of mandatory digital tax reporting shapes tax practices in Kenya. ITax, as presented in this chapter paused some challenges when it was made mandatory. The country was not ready for the shift; neither infrastructurally, politically nor economically. The tax reform did not include thoughts about the use of technology in taxation. Through the background information on how the shift to digitalisation is tied to development and taxation discourses, the current study connects the ideas inside the use of technology in taxes to numerous global models that are templated from countries with strong economic structures.

The tax for development agenda advocates for tax policy improvements that are unrelated to Kenya's tax cultures. When models such as digitalizing tax filings are adapted for different interests of social/institutional worlds and local politics it may generate complex and unintended effects (c.f, Mosse,2005). This study is concerned with these consequences and its implantation on tax practices in Kenya. This chapter connects historical concepts of development to the current digitalisation practices. It 
shows that the theoretic of development is an ongoing one that finds new ways of manifesting itself.

To this end, my research focuses on three different theoretical disciplines. Postcolonial technoscience, digitalisation and anthropology of taxation. My work lies in the nexus of various fields, particularly in the case of ITax, with the endorsement of science and technology for development. ITax is viewed as transformative tool by KRA capable of helping achieve sustainable development.

The next section gives a summary of the chapters in this study.

\subsection{Summary of Chapters}

This dissertation is structured as follows:

Chapter two outlines the theoretical approaches as well as the concepts that employed in this thesis. In this chapter, I introduce postcolonial technoscience and discuss the insights that such a viewpoint might provide. Additionally, the chapter introduces the concepts of travelling and translation and their relevance in tracing models such as ITax.

I also go over my understanding and application of in scripting and descripting as tools for understanding how ideas are embedded in technology and then transformed into practice. This study tracks the journeys of ideas and technologies that materialize in practices like tax digitalisation by integrating technoscience with postcolonial analysis. I also discuss my understanding and usage of in-scripting and descripting as ways to understand how ideas are embedded into technology and subsequently how they are translated in practice. By combining technoscience with postcolonial analysis, this study can trace the travels of ideas and technologies that manifest to practices such as the digitalisation of tax.

Chapter three introduces the methodological framework, ethnography. Here the chapter describes how ethnography can contribute to a holistic understanding of issues such as the rapid digitalisation of tax in Kenya. Here, the data collection methods are discussed outlining the opportunities and challenges of using ethnography a means of studying the implementation, usage and understanding of ITax. Ethical considerations and the limitations of the research are discussed in this chapter as well. 
Chapter four is the first empirical chapter. The chapter examines the travel of the tax model that later become ITax among those actors that work with it. Further, the shows how the ideas of using ITax changes from the top leadership at KRA to the developers of ITax as well as the lower-level tax officers. This is done by observing the actors involved in propagating and implementing ITax at the tax authority comprehend and contribute to ITax's inscriptions.

In what is referred to as the "Kenyan approach," Chapter 5 describes how ITax has been translated into practical use by mediators and taxpayers. Using Michael Herzfeld (2004) cultural intimacy concept, I present how terms like the "Kenyan way" represents both positive and negative aspects of the Kenyan culture with regards to implementing ITax. It is used as both a coping mechanism as well KRA's way of blaming taxpayers for any technical mishaps. In this chapter, we look at how some taxpayers come up with novel ways to comply, as well as how others carve themselves niches as intermediaries.

Chapter six shifts the focus away from individual actors' work, ITax usage, and comprehension to explain how ITax usage is shaped by and shapes existing economic systems. History is a determining factor of how ITax travels and transforms locally. To strengthen this argument, I compare two very different counties in Kenya, Kiambu, and Isiolo to show how ITax travels according to political priorities? This was seen have been shaped by historical economic policies. Kiambu County refers to itself as digicounty and adopts the use of the technology not only to make tax administration effective but on its overall performance as a county government. Isiolo on the other is described in local discourses as the "not yet Kenyan" county. This chapter demonstrates how counties have their own "Kenyan way "of using digital policies especially with regards to taxation.

Chapter seven is the conclusion. It gives a summary of the chapters capturing the main arguments. The chapter concludes by discussing recommendations to researchers as well as policymakers. Based on the limitations presented in chapter one, recommendations for further studies will be offered. This chapter is not only a conclusion rather an opening to a larger inquiry into the changing modes of governance through taxation in developing countries. I introduce in this chapter some 
strands of research that came up during my research that I could be interested in pursuing in the future. 


\section{Chapter Two: Analytical Framework: Postcolonial Technoscience}

\subsection{Introduction}

The study's fundamental framing, postcolonial technoscience, allows us to interact with the relationship between colonial science and technology and modern tax procedures in Kenya, such as the digitalisation of e-filing systems. I view postcolonial technoscience as defined by Warwick Anderson (2002) as new configurations of technoscience as well as the critical modes of analysis that identify them(Anderson,2002). This approach allows my study to address how the dichotomies created under the colonial era influence scientific practices like digitalizing taxes in Kenya. The prefix 'post' distinguishes a time after colonialization however it is very difficult to therefore conclude who and what should be included or excluded in the discourse (Harding,2011). I view the postcolonial as including the continuous engagements with colonial ideas and structures.

The "postcolonial" is evidently present in my research not only because Kenya is a post-colony, but also because of the legacy left within the cultural, economic, and political structures. The relationship between the state and the citizens in Kenya and even how institutions function is greatly influenced by colonial legacy. Technoscience studies have been criticised for not engaging enough with postcolonial contexts (Anderson,2002), (Harding,2011). In this study, a postcolonial technoscientific approach reveals how ITax travels, is applied, and translated in Kenya's postcolonial setting. Within this framework of rapid adoption of digitalised governance platforms such as ITax, it is paramount to analyse how these ideas are connected to colonial rationale that sees technology as the vehicle of change. I use the term 'postcolonial' not as signal to an end in colonial influence and power, but rather signalling the effects of colonialism that are constantly being reinvented in practice (c.f, Anderson,2002).This perspective allows for a more in-depth examination of the colonial power structures that shape current social hierarchies, discursive spaces, psychological relationships, cultural assets, political and economic interactions, and historical developments (Ha, 2015, p. 177). 
This chapter introduces postcolonial technoscience as well as the main framing of this study (c. f, Rottenburg,2009; Behrends et al., 2014; Weisser et al., 2014). The study uses the concept of travelling and tech. These approaches are complimented by script analysis inspired by Madeline Akrich's work which involved photo lightning kits in some West African countries. Script analysis allows a critical analysis into how the ideas get into artefacts. Michael Herzfeld's concept of cultural intimacy is utilised in Chapter 5 to illustrate how cultural stereotypes are used to explain how citizens adapt policies that are foreign to their surroundings in a way that accepts or conforms to some norms while rejecting others.

In this dissertation, I examine ITax's travel within Kenya, as models or ideas no longer require foreign mediators to travel; instead, ITax follows manifestations, carriers and translators of ideas (Bierschenk et al., 2002). ITax is a model and technology that is transferred from one cultural setting to another, sometimes through a political process (Schnegg and Linke, 2016). The current study is concerned with why and how ITax travels and get translated in relation to this postcolonial regime and political projects (c.f Von Schnitzler 2013,2016). By tracing iTax to the postcolonial manifestation of development, the research unpacks the ideas embedded within ITax rather the motivations behind ITax's formulation and travels.

To begin, I examine postcolonial technoscience as the study's fundamental framing, claiming that it enables it to address the colonial legacy of technology in development. Thereafter, I delve into the concepts of travelling and how it plays an important role in understanding how models such as ITax that conceptualised in the global arena make their way to the local tax practices in countries as in the case in Kenya. To understand how the models are then put to use, I offer the concept of translation suggesting that models are frequently modified when they travel. Their original objective may be forgotten, or adaptations may be required, leaving them subject to interpretation based on interactions with local, historical, and economic variables. The translations guide the script analysis section which will review the study's investigation into how models travel and get translated.

\subsection{Postcolonial Technoscience}

As shown in the main aims of this study, Kenya's ITax has travelled alongside political, economic and historically constructed paths (c.f, Peck and Theodore, 2010). This is 
because ITax promises social change and transformation as stated in its mantra; simple, secure, and swift. Taxation in Kenya was developed and structured during colonial times. As a result, discussing the adoption and implementation of new tax models without taking into account the postcolonial tax mechanisms at play is challenging.

The Eurocentric rise of science was boosted by George Bassalla's concept, which projected that if modern science was transferred to non-European nations, it would gradually form its own scientific organization, producing what was dubbed "colonial science," (Basalla,1967,617). Basalla's model was seen as prescribing the straight path towards scientific development in non-European contexts. The colonial science was seen as eventually maturing into the "science" found in European contexts. Postcolonial technoscience is the term used to explain the interaction between science and technology in a colonial context (Anderson,2002).

The study of how scientific and technological activities become zones for "fabricating, linking, contesting, and disrupting local and global identities" is aided by postcolonial technoscience (Anderson, 2002; 644). Motivated by Warwick Anderson (2002, 2009); Suman Seth (2009) and Maureen Mc Neil (2005), this study sees the recent shift to technology for development as a continuation of the colonial scientific logic, which saw technologies as "gifts" to "natives" to assist them catch up to the colonizer's development ideologies (Seth, 2009). Furthermore, a postcolonial technoscience approach is well adapted to research "changing political economics of capitalism and science, mutual reorganization of the global and local, and expanding transnational traffic of people, practices, and technology" (Anderson, 2002;644).

Colonial tax structures were used to extract revenues and resources for running the colonial administration. These groups were viewed as those that were unable to follow the rules that had been established for them. Pastoralist societies, for example, were unable to settle down as they wandered around with their flocks in search of pastures. This was seen as unfavourable as the colonial administration wished to impose taxes on them. This led to the development of closed-door policies in 1920 that are still in effect in Kenya (see chapter six). The closed-door policies were introduced to ensure that the population that were seen as not cooperating with the colonial administrative 
policies would be economically and physically barred from interacting with other groups in a way excluding them from any benefits that would $g$

The independent Kenya as a postcolonial state adopted a rigid approach to tax administration maintaining the rift between themselves and taxpayers. This already built upon the weak relationship between the colonial administration and the taxpayers. This shaped both the historical and the current relationship between the taxpayers and the administration. ITax is a tax reform aimed at ensuring long-term growth, based on the same logic that was used during colonial rule, with former colonial administrations creating policies that dictated economic development models. Tax models developed in countries with strong economies were expected to perform with similar outcomes in developing economies. In the case of ITax, the rapid digitalisation was seen as a vehicle for increasing revenues thereby spiralling development. However, this rapid shift raises concerns addressed in this thesis, whereby it is seen that the adoptions might follow the same trajectory of historical and economic inequalities. This idea was translated differently as models travels without the intended objectives.

While I do not disregard the efficiency of the postcolonial analysis without the technoscientific approach, I combine the two approaches to allow my lens to be focused to the role science and technological advancements is taking in the current development discourse in countries such as Kenya. Postcolonial technoscience scholars have concluded that science studies and postcolonial studies have remained remarkably separate (Anderson,2009), (Harding,2008), and (Seth,2009). This technology assists my research in connecting digital technology as a new instrument for raising revenues, as endorsed by policymakers such as the OECD, IMF, World Bank, and the UN. As a result, it's critical to engage them in "constructive" dialogue (Anderson 2009,644).

This section illustrates the importance of analysing the case study within the postcolonial technoscientific framework. As a result, it will allow this study to examine how Kenya as a postcolonial country continued to have an imbalanced relationship with technologies that are intended to develop them as shown by the case study. This has always been the case since the colonial period, and it is still the case in the current funding for development movement. Within this technoscientific framework, I use the concepts of travelling and translation in order to trace and track the movement of 
models such as ITax in Kenya. This is because the models are no longer seen as being transferred as was the case within previous policy studies. The term "traveling" was coined to describe how models are negotiated and implemented around the world, particularly in postcolonial settings. In the following section, I introduce the traveling notion in postcolonial technoscience, which enables the rationale to be traced inside ITax.

\subsection{Travelling Models}

The notion of travelling models became evident for me when attending the African tax research conference (ATRN) introduced in chapter one. I presented my case study on ITax in Kenya based on desk review findings as my fieldwork had not yet begun. When I presented my paper in front of an audience that was comprised of both tax practitioners and researchers, I got reactions that similar platforms to ITax were being implemented in several African economies. In Uganda it was referred by the same name, 'ITax' and executed by the same consultants who had implemented the system in Kenya. The question that arose from this was why there was such a sudden shift towards digitalizing tax administration. Further investigation revealed that the same developers who created ITax had built nearly identical sites in Uganda and Zambia. Moreover, they had also been contracted to implement ITax in other African countries. Several African countries appeared to have received digitalisation recommendations and financial backing from international politicians in 2016.

The concept of 'travelling' was first proposed by Edward W. Said's (1983). Said is mostly known for his work on the notion of Orientalism (1978), which was a critique of what he called the western world's perspective of the Orient. Said is known for his work on the concept of Orientalism (1978), a critique of the cultural representations of the orient what he described as the western world perception. Said's theories transformed the academic discourse of researchers in literary theory, literary criticism, and Middle Eastern studies on how academics examine, describe, and define the cultures being studied. With regards to concept of travelling, Edward Said (1983) inquired about how theories move from one place to another and how they get changed as they move. He is especially concerned with the different circumstances that they get caught up and how they are used for something else (Said,1983). In my case study, the idea of digitalisation was caught in between several cultural, historical 
and economic factors changed the intended objectives to outcomes that were not intended like the empowerment of mediators and the increased gap between taxpayers and the KRA. Said (1983) used the metaphor of voyages, he argues that theories get shaped, reshaped by local productions, receptions, transmissions, and resistance (Said,1983).

Said also suggests that the understanding of a cultural event or phenomenon is filtered through a theoretical formulation, which derives its strength directly from concrete, historical context. He proposes four basic stages of tracking travelling theories. Initially, a hypothesis circulates within the scientific and intellectual communities. Second, it becomes a work-in-progress that is put to the test. Third, the theory is tested against local knowledge and altered accordingly. Finally, the theory takes on a new identity as an instrument for analysing local social reality; it gains new applications as well as a new ethos (Said,1983). Using Said's four steps as a guide, I've discovered that my research intersects the historical, political, and economic settings of colonial practices.

Travelling models' thinking in recent years is developed mainly by Barbara Czarniawska (1996) in organizational studies and later introduced to STS and Anthropology by Richard Rottenburg (2009, orig. 2002;2005). According to Czarniawska (2002) and Sevón (2005) models do not travel by themselves; they must be transported and translated by commodities or people, or, as they put it, 'ideas must materialize, at least in someone's head; and symbols must be inscribed' (Czarniawska and Sévon,2005, 9). The expressions "traveling ideas," "traveling paradigms," "traveling blueprints," and "traveling mobile policies" have all been used in conjunction with the term "traveling" (Von Schnitzler,2016, Rottenberg,2009, Czarniawska and Sévon,2005).

Another approach that is interesting is when travelling models are often transferred from one cultural context to another and are continuously co-produced and reshaped by varying actors in its journey to the 'local' level (Schnegg and Linke, 2017). They are rooted on a global story that international experts seize upon to spread it beyond its original context (Sardan et al.,2017). The success of digitalisation of tax administrations in countries with strong economies are seen as replicable in other contexts they are uninformed of the structures that are needed to support or will create barriers for the successful implementations. According to Sardan et al. (2017), a 
traveling model goes through three phases that are largely overlapping: they include narrative creation (a founding success story), shaping (the construction of a mechanism and its devices), and networking (global dissemination) (Sardan et al.,2017). The narrative creating in this case is that digitalized tax systems increase revenues. The shaping is done by connecting digitalisation to development rhetoric. And lastly the networking is done almost simultaneously as witnessed at the conference I attended. These processes are important in understanding how such models are negotiated and applied and the implications when they meet existing understandings of the world. This process involves a myriad of players debating the usefulness and accuracy of the models' assumptions, its interpretations, and applications (Behrends et al.,2014).

In this dissertation, I mainly use the 'travelling model' as used by Richard Rottenburg in his book Far-Fetched Facts (2002; translated and revised 2009a) for the analysis of the proliferations of development models in my study. Models, according to Rottenburg (2009), are analytical representations of reality produced as an apparatus or protocol for interventions. This helps me understand how dominant development models were created in countries considered to be "developed," and how scientific knowledge was applied. Global governments and revenue agencies see technology as a vehicle to drive development. As a result, the concepts are accepted and implemented in countries through foreign grants or loans, as demonstrated during the conference.

Rottenburg states that:

While analysing the problem, Western society and its organizational forms are transformed into traveling models that provide the basis for identifying problems in developing countries. Over time, what had initially been merely a figure of thought becomes an objectivist assumption. In the discourse of development cooperation, idealized models from Europe and the United States - for example, civil society, the market, and rational bureaucracies - are ultimately regarded as tangible realities (Rottenburg 2009a: 64).

Traveling models are thought to have their origins in a founding experience (a success story) someplace in the world, which worldwide experts grasp on in order to spread them beyond their initial environment (Rottenburg,2002). Rottenburg asks "If models 
are inscripted with rationale, can they travel and remain the same?" (Rottenburg, 2009). He argues that "the practice of development is primarily a matter of selecting one of the existing globally circulating and highly esteemed models for development and adapting it to a local context' (Rottenburg 2009: xxvi-xxvii). When development models travel, they are mimicked and re-territorialized in new contexts, decoupling them from the political and economic logics that guided their original creation (Behrends et.al,2014). There have been numerous methods for development in the past (see chapter one), but the most recent one, based on technology, is considered as having multiple aims.

The digitalisation of e-filing systems considered by KRA and policymakers as a tool achieving modern revenue authorities that digitalized as well as increase domestic revenues leading to sustainable development (KRA,2014). In this dissertation I view them as analytical representation of the realities inscripted into them (Rottenburg,2002). They become models due to the knowledge that is ascribed to them before, during and after their travels. The digitalized systems such as ITax, a model developed by international policymakers then disseminated to developing countries almost simultaneously is aimed at producing economic development. The issues raised in this study are whether the interventions remain the same when they travel.

ICT as a model for economic development has been promoted since the mid-1990s by major international development agencies, including the World Bank (World Bank, 1999), the United Nations Development Programme (United Nations Development Programme, 2001), and the World Economic Forum (Dutta and Mia 2009). It was introduced in an almost identical template across numerous countries in Africa. Its rationale was based on prescriptive economic models that believed that tax revenues could be maximised through the adoption of effective systems. These interventions as shown in this thesis are confronted with pragmatic implementation contexts that are always varied and specific, and which lead to unintended consequences. ITax was confronted with complexities as well as lack of the necessary infrastructures to support this mandatory shift. ITax was made to seem organic by the KRA.

In political sciences, travelling models are referred to as the 'transfer' of a public policy (Dolowitz and Marsh (2000). Mukand and Rodrik (2005) assert, 'difference in policy outcome can arise from differences in institutional settings-historical trajectories, 
geography, political economy, or other initial conditions'- even if countries adopt similar policies. The policy transfer framework does not have the explanatory power to fully account for such institutional settings. I propose in this study to use travelling models instead to account for the issues raised by Mukand and Rodrik (2005). In my case as ITax was deemed as travelling model as it was implemented in many countries as the same time in an attempt to increase sustainable development was not something that was initiated by the Kenyan government as a policy rather it was adopted a model for increasing domestic revenues

In the case of economic policy, Callon and Muniesa (2005) contend that models are produced inside the experimental setting, being shaped and deformed to order some particular economic traits(Callon and Muniesa,2005)Thus when policy models aim to establish and validate a set of clear rules, processes, and behaviours, they are constantly disrupted by the messy realities of policymaking at the 'ground' level (Rottenburg, 2009).

In this case study, I view models as implemented due to the needs of the revenue authority needs. It is therefore important in this study to view ITax as a revenue administration model as shown in chapter four where the developers of ITax were working with a script developed by the KRA for making tax administration easier for them. The lack of taxpayer's perspectives in the design of ITax made the platform work for the KRA while complicating matters for taxpayers. ITax was assigned many goals by KRA and worldwide policymakers, with one goal being to change taxpayers' views toward taxes in order to increase revenues and willingness to pay tax, and another goal being to achieve sustainable development.

The development of models or technologies can thus be said to involve several translation processes. Firstly, the model travels as an idea. Secondly, it interacts with the structures and ideas on the ground. Thirdly, users of this model make it work for them by utilizing their own networks and understandings of the concept. In the following section, I examine the concept of translation and how it relates to ITax implementation. In the next section, I analyse the concept of translation and how it is important in attending to ITax's implementation. 


\subsection{Translations}

Traveling models must be conveyed and translated by things or people, as Czarniawska and Sévon phrased it: "ideas must materialize, at least in somebody's head; symbols must be inscribed" (Czarniawska and Sévon, 2005, 9). Translation is therefore key in tracing the travels of models. The act of transferring, interpreting, and recounting models from one place to another is referred to as translation. 'Translate' is a verb that suggests change and equivalence, or the idea that one object can stand in for another. (Law,1992, 5-6). Every version of each actor's interest translates the interests of the others, resulting in a 'sort of hegemony' (Latour 1987, 121). The translations in my case study show how taxpayers react to the ITax's implementation. They find diverse ways to understand ITax and appropriate it for their own use. They translate the aims into practical solutions like using mediators and finding innovative ways to comply that translated differently to the mainstream tax compliance theories. As will be highlighted in the empirical chapters' taxpayers did not comply voluntarily as had been hoped by the policymakers and KRA rather they complied out of fear of the repercussion that they would be subjected to.

Michel Serres provided a loan of translation in the social sciences (Serres,1982), (Czarniawska and Sevón,2005). Serres considers translation to be a broad operation that is not restricted to linguistics and can take many other forms. These may entail the displacement of something or a substitute act, but they always involve transformation. Translation theories or perspectives are widely used by scholars in various fields. These theories include institutional theory (Czarniawska and Sevòn, 2005b) and the actor-network theory (Latour,1986; Callon,1986) as well as postcolonial studies (Anderson, 2002).

Models do not travel with their original ideas and rationale; the users must find innovative ways to first understand the rules which in this case was mainly technical and thereafter find ways in which the model can help them achieve their goals. In this context, it is being tax compliant. Furthermore, the methods by which these translations take place are dependent on previous translations and must be inscribed into intermediaries. As a result, according to Callon (1990), it is necessary to describe the medium or material into which a translation is inscribed. The basic operation of translation, whatever form it takes, is always triangular: there is a translator, something to be translated, and a medium on which it is inscribed (Callon 1990, 143). As will be 
demonstrated in this research, one must follow the different vehicles and brokers involved in the translation process.

Taxpayers are affected by ITax's implementation as well as the global, historical, and cultural factors at the ground level. As will be shown in chapter four and five, ITax was not designed with the Kenyan taxpayer in mind. Additionally, it had technical flaws that led to resistance and formulation of a cultural way of dealing with the complexities described as the "Kenyan way" of complying. This did not necessarily reflect what KRA had envisioned for ITax. The idea of analysing the end user makes visible who the intended user of the technology is, shows the environment of the end-user as well their ability to access technology. Moreover, there would be more acceptance and uptake of the platforms if the intended user was included in the design of such technologies.

I find translation an important approach that can help not only unpack the barriers but follow how ideas travel. The act of transferring, interpreting, and recounting models from one place to another is referred to as translation. In his 1921 essay 'The Task of the Translator', Water Benjamin argues that translation is an art form whose appreciation does not rest on interpreting its content to derive a moral or lesson from it (Benjamin 1921, 253). Translations may entail the act of displacing or substituting something, but they always involve alteration. As a result, whatever is involved in translation, whether it be knowledge, people, or objects, has an ambiguous identity. As a result, each act alters the translator and what is translated (Czarniawska and Sevón, 2005).

The initial objective of the global digitalisation efforts was to increase economic development. Technology is viewed as being transformative and effective for both the administration and the taxpayer. The intention was that the taxpayers would adapt to ITax, ultimately changing their attitudes thereby increasing revenues. Studying the translation of such models as the ITax is key as it enables the comparison of the intended objective of the model to the actual practice. A closer look into translations also requires an analysis of how ideas get into practice through what is described by Madeline Akrich (1992) as script analysis. The ideas are developed with certain actors and functions in mind, however, as we will see in this dissertation they do not remain when they travel and are implemented. The next section introduces script analysis as an important concept in understanding the translations of ITax. 


\subsubsection{Script Analysis}

Script analysis enables this study to compare the rationale by the designers to the actual practice. The rationale within models or technological artefacts contains a 'message' from the designer or producer describing the products' intended use and meaning (Akrich,1992). When actors within a particular network accept and delegate tasks to each other, they act within a script or a scenario. Understanding how developers and users negotiate and establish a domain of action and meaning is crucial. Successful scripts help translate the actions of actors involved, because their scripts invite certain actions and discourages others (Latour,1992). Using metaphors from theatre and the film industry, Akrich (1992) contends that "like a film script, technical objects define a framework of action together with the space in which they are supposed to act" (Akrich, 1992, s. 208). The designers' job is to inscribe their vision of the world into new objects or ideas. When users develop new ways of using technology, they are also hired as designers, as will be demonstrated in Chapter 5 . Kenyans found creative ways to get around the complexities of ITax. This will also be demonstrated in Chapter 5. They changed the intended script of ITax because ITax's original script did not travel as it was, instead, it was translated as will be shown in chapter five and six.

Moving between the social and the technical aspect of the script demonstrates how the technical objects confine the users' interactions with the items and with one another (Akrich 1992, 206). In technological items, the designer's point of view is rather limited, forcing us to alternate between "the designer and the user, the designer's projected user and the real user, as well as the world inscribed in the object and the world characterized by its displacement" (Akrich,1992.208-209). This is because technical objects contribute to the creation of heterogeneous networks that connect the many actors. Script analysis can also examine the extent to which the actors within the heterogeneous networks can reshape the objects and the various ways they can be used (Akrich, 1992, s. 206).

In this case study, I examine the relationship between users and the platform in order to comprehend the restrictions and repercussions imposed by ITax's quick and required adoption. I pay attention to how ITax's script changes as it travels from one actor to another, from one context to another, from one geographical location to another. ITax ideas are objectified and coupled with material technologies in order to 
put them into practice and transmit them as blueprints to new sites. (C. f, Akrich 1999, Behrends et al.2014b:2). ITax's script is developed to serve local and international goals.

Across the world, the script is developed by global policymakers with the idea of developing economies through the financing for development movement. Locally, it is regarded by the senior officials as a tool that will transform KRA. Yet, individuals and collective actors take various scripts of the models turning it into something different imagined by KRA and the policymakers. Some taxpayers in the study viewed ITax as being complex, relating it to KRA's tax enforcement tactics. It was imagined that taxpayers would embrace ITax, but this was not the case. Taxpayers found innovative ways of understanding ITax's script and translated it in their own understandings (see chapter five).

Scripts can aid in analysing the roles that players play when interacting with digital technologies. This is accomplished by comparing the anticipated goals of digital technologies to actual practices and outcomes. In order to do so, I employ a feminist sociologists' terms 'implicated actors and end-users' (Casper and Clarke,1998). End users are defined as persons and groups affected downstream by technological innovation products, whereas implicated actors are those who are silent or not present but are influenced by the action" (Casper and Clarke,1998: 267). In this study, taxpayers are described as the end users of ITax as they are not involved in policy design and development. However, they are recruited once platforms such as ITax are in place. This is because, despite being the model's key stakeholders, they have little or no say in tax policy design, as this thesis will illustrate.

In the next section, I will analyse the process of making a script analysis which is the inscription and description. These terms are used in this dissertation to study ITax's rationale as well as the translations by taxpayers.

\subsubsection{Inscription and Description}

Innovators spend a lot of time 'inscribing' a vision of (or prediction about) the world in the technological substance of new objects. Models' ideas are objectified and merged with material technology in order to put them into practice, and then moved as 
blueprints to new locations (Akrich,1999, Behrends et al.2014b:2). An inscription is the product of a person's interest being translated into material form (Callon 1991, 143). There are four essential features of inscriptions: the material being inscribed, the person who inscribes them, how they are inscribed, and the efforts employed to oppose an inscription (Monteiro and Hanseth 1996, 330). The last part of this is what is described as descriptions or translations. Inscriptions as used in this dissertation refer to ideas that are embedded into ITax and the effects it has in how the system functions. This will be further discussed in chapter four where I analyse the KRAs vision and mission for ITax and trace ITax's functionality. The ideas shared by the top leadership as well as the developers understand ITax to be a tool for administering taxes. This optimises the KRAs functions while proving problematic as shown in chapter five for the taxpayers.

Descripting refers to the process in which translations are made by the user based on their needs for the technology (Akrich, 1992). This is due to the fact that models are frequently converted into objects and transmitted to locations other than those from which they originated, even resulting in the creation of new things (Czarniawska and Sévon, 2005). They are actively received as they move through various contexts, where they are modified, interpreted, and reshaped in both discourse and practice (Draude,2018). Focusing on the spaces where translation proves to be tough and problematic is an important means of obtaining insight into the translation practices that allow ideas to spread. It's crucial to pay attention to the manner in which specific claims to scientific knowledge come to attain remarkable political salience.

These concepts are crucial in this study in order to understand how the original script which is based on making ITax easier for taxpayers is contradicted by the later scripts that arise from the processes of design and redesign. In chapter five, taxpayers and mediators 'descript' ITax the 'Kenyan way' to comply with ITax. What I mean by this is, Kenyans translate ITax in their own social and cultural ways as a way of dealing with the complexities brought by using the new technology. I view descripting the "Kenyan way" as a form of cultural intimacy. According to Michael Herzfeld, Cultural Intimacy is the acknowledgement of features of cultural identity that are perceived as a cause of external discomfort but that still supply insiders with their assurance of common sociality (Herzfeld,2004,3). He refers to it as "creative dissent," and it can be used to understand how citizens in modern nation-states navigate their social identities 
and their day to day lives while being fiercely patriotic and equally rebellious (Herzfeld,2004,91). In this study, the concept is used to explore how the 'Kenyan way' is translated in a variety of ways by KRA and taxpayers in order to help people cope with new government policies or make excuses when the platform fails (see chapter five).

\subsection{Conclusion}

In this chapter, I analysed the case study within the context of postcolonial technoscience as it's critical for understanding the impact of colonial historical, cultural, political, and economic frameworks in my research. Postcolonial approaches are combined with technoscientific perspectives in this study to trace the travels and translations of platforms like ITax in developing countries such as Kenya. I gave a background of how STS interacted with postcolonial theories in the past and how such an approach helps address the gaps that exist within postcolonial technoscience studies in STS.

I combine two concepts, travelling and translations within postcolonial technoscience to attend to the movement of how global ideas are implemented locally. These concepts allow my study to trace the rationale within models comparing the intended objectives to the actual practices. It has also allowed my study to attend to how ITax was translated locally. Travelling models are blueprints for global ideas with a purpose of achieving similar results in different contexts. They travel on ideologically created paths however they interface with the local realities creating varied outcomes. Translation involves various processes. In my study I combine the ideas of translation with the processes involved in creating objectivity within ITax. Inspired by Madeline Akrich (1992) I use the terms inscriptions, descriptions, and scripts to unpack the ideas within ITax models before and after they travel to see how these concepts will help my work follow how ideas travel. The concepts of Akrich will be utilised to trace how models are objectified and combined with material technologies to put them into practice and transmit them as blueprints to new sites (Akrich,1999, Behrends et al.2014, b:2); when they travel. 
The next chapter introduces ethnography, the study's methodological approach. I connect the issues mentioned in the first chapter and suggest that adopting anthropological methodologies to tackle this case study is critical. 


\section{Chapter Three: An Ethnography of ITax}

\subsection{Introduction}

Tax research is dominated by legal, economic, and accounting perspectives. While this may serve the purpose each of the disciplines aim to fulfil, I find the existing research within tax studies lacking socio-cultural perspectives (c.f, Björklund Larsen,2018). To address this, I use ethnographic methods in this study to understand the rationale behind the rapid implementation of ITax. Before embarking on my fieldwork, I found that the data on Kenya's ITax was limited. It was only available as government reports and online media articles. This study aimed to understand the implications of the rapid implementation of ITax. Such reports could not explain why ITax was rapidly implemented as well as made mandatory within a short period. Moreover, the reporting on its impact was not done. Ethnography served as the solution to this as it allowed my work to be placed in the middle of the discourse following the sites and actors involved in either designing, implementing, and even using ITax I conducted multi-sited ethnography to make a compelling argument about the implications of travelling models in shaping tax practices in Kenya.

In this chapter, I will first present ethnography as the main method of inquiry into understanding the implications of ITax's rapid implementation in Kenya. Secondly, I delve into multi-sited ethnography and the relevance of being open and flexible to what might happen in the field as this study moves between physical and online sites and even between actors. Thirdly, I present the data collection methods I used in this study, the sites I visited and make some reflections on which type of data they provided. This is followed by the issue of positioning in ethnography. I reflect on how my role and biases can influence the type of data I collect. Lastly, I discuss the ethical considerations dealing with people while studying ITax

\subsection{Ethnography}

The study of social interaction and culture among societies, groups, organizations, or teams is known as ethnography (Reeves et al.,2013). Its fundamental goal is to provide deep, comprehensive insights into people's worldviews and actions, as well as the nature of the environment they live in (Hughes,1992). As Hammersley (1985) stated, "ethnographers' task is to document the culture, the perspectives and practices 
of the people to 'get inside' the way each group of people sees the world" (p152). Ethnographers are encouraged to spend at least a year in the field, to learn the language, and to live as one of the populations which they study. I however did not require this much time as I had other aims for my research. Due to the ongoing elections in Kenya, I was unable to complete the first round of fieldwork for six months and returned to complete the second round in two months.

Ethnographers adopt a "reflexive" role involving observing, reflecting, and testing. Due to the element of subjectivity in a research method, the process is critical; the researcher is the instrument. The process is essential, because of the element of subjectivity in a research method the researcher is the instrument. An example from my fieldnotes highlights how reflexivity can help achieve an understanding of how things are in practice and not in policy. Experiencing standing in lines and even going with taxpayers to their tax consultants allows the study to achieve an emic understanding of the research problem. Like in the example given below, KRA had been on a transformational journey yet my experiences standing in lines reveal other aspects of the taxpayer's journey. I understood from the picture used in the introduction that KRA had been using the queues at the KRA's head office to motivate taxpayers to adopt ITax. I wanted to understand why the queues had become famous in motivating taxpayers to use ITax. The following excerpt from my fieldnotes shows how I was able to understand the queues at KRA from my participant observations.

I had grown curious about these infamous lines and at the beginning of my fieldwork at the KRA not only when I saw them in the newspaper article but also as described to me by numerous interlocutors. On a Tuesday morning, I had several meetings at the KRA's headquarters, Times Towers. I had clearly not anticipated the time it would take me to 'check in'. As I stood outside by the security checks, I became overwhelmed and confused by the building. Nothing could prepare me for the magnanimity of the building. Despite having seen this building several times from a distance getting closer, I felt intimidated. Finally, I locate the right entrance, as this thirty two-story building has several entrances, yet there are no queues! I get curious about the lack of the horrendous lines that the tax administration had become famous for.

Getting into the building felt like being in an airport. You stand in line, take off your jacket (depending on the weather) and go through a metal detector. Your 
laptop goes through an $\mathrm{x}$-ray machine. Once you're done, you have to register all your electronics at a different counter. You get a coupon with the number of your computer and this must be handed back before exiting to collect your gadgets. Once this is done, you head off to a security team (a male and female) who frisk you with their mobile metal detectors that will reveal what the other checks might have missed. The security check however seems so routinised like in many places in the country, so I had become used to this. I however read the body language of those in front of me (taxpayers) who complied with the check in order to get the assistance they needed. They all look almost robotic as though this was something normal for them. Being an African, however having lived in the west, my body is not used to this type of control- Go here! Move there! Yet, because I look like a local person, I got treated the same way. On the other hand, I had observed several researchers who appeared different getting preferential treatment. I got into the main building through gigantic doors. It felt as complex as the way my interlocutor described taxes in Kenya. It is almost like the architects have designed it to reflect the complexities related to it.

Ethnography relies on detailed observation of social activities and interactions, such as the line-ups at the Times Towers. It entails the understanding of the social world's meanings, metaphors, and symbols (Asher and Miller 2011, p. 2). While standing in line at the times towers, I observed that contrary to the ongoing transformation project, taxpayers were still being subjected to lines and even being turned away. A simple observation like this helps this study interpret taxpayers' experiences into meaningful understandings of processes and practices. As Clifford Geertz eloquently put it, "anthropology is not an experimental science in quest of law, but an interpretive science in search of meaning." $(1973,5)$. It turned out that queuing to get access to various sites gave important insights to studying ITax.

Ethnographic tools and strategies have evolved throughout time to allow ethnographers to "be present" for the mundane, exceptional, and extraordinary events in people's lives (Blomberg,2002). Using emic perspectives, ethnographers aim to describe and explain the culture. This means that the views and language of members of a particular community are used to study and explain their culture. By analysing the 
taxpayer experiences, this study was able to understand the challenges they go through in using ITax. The study not only took their word for it, but also observed them while using ITax as well as waiting in queues and engaging tax consultants and brokers to ensure they comply with the required procedures.

In anthropological studies of taxation, ethnography has been used to highlight how tax authorities in nations like Sweden and Denmark establish legitimacy and confidence by relying on fairness and reciprocity values (Boll and Brehm,2018; Bjorklund Larsen, 2017, 2018. Oliver Owen's (2018) ethnographic work in Benue State, Nigeria, brings out moments of transformations, as the rural public reorients itself towards new state government revenue policies. The reforms expose how local communities think about the legitimacy and utility of taxation in this agrarian region as shown through historical experiences. These experiences are marred on the one hand with violence and coercion, and on the other embed notions of morality, status, citizenship, and legitimacy (Owen 2018, III). Tax reforms in Kenya, for example, are carried out with a strict adherence to the country's historical tax legacy, which continues to affect the interaction between the taxpayer and the authority, as well as the state and the citizens.

Anthropologists have historically often implemented projects aimed at understanding and translating cultures to assist colonial governments in governing their colonies (Asad,1973). Knowledge that was often produced was used to determine strategies on how the "natives" should be governed. In this study, the strategies employed by the colonial administration from the knowledge produced are still being used to date in countries like Kenya. We therefore must be aware of how we conduct ethnography and the type of knowledge we produce. Kathleen Gough (1968a, 1968b) took a strong stand against anthropology's complicity in colonialism and its failure to adequately characterize colonialism's effects on the people anthropologists examined. She suggested that anthropologists track the impacts of colonialism to current day events. Talal Asad (1973) and Diane Lewis (1973) seminal texts and essays on anthropology and colonialism encourage anthropologists to take a closer look at the colonial roots, since this will allow them to better understand how they continue to shape communities. This study therefore analyses underlying factors such as the colonial legacy within ITax's implementation and how this shapes e-filings tax practices in Kenya. Historically, the colonial legacy shaped the relationship between the revenue 
authority and the taxpayers. This relationship is still significant in how ITax was implemented and how KRA interacts with taxpayers, demonstrating that tax policy implementation should consider historical and local realities.

Ethnography allows my study to gain a close understanding of the problem's taxpayers are facing, contrary to just taking other people's word for it. Many other disciplines studying tax are not concerned with taxpayers' experiences as they focus on either the legal, political and economic perspectives to tax. Taxpayers' experiences are not generally regarded as relevant sources of data. Ethnography takes this seriously allowing their experiences to guide the research. My experiences standing in the queue and even getting worried that I too would be turned away made me understand more about the unbalanced relationship that existed between KRA and the taxpayers. ITax was meant to close the gap between the taxpayers and KRA; however, from the experience it seemed that it had become even bigger. This study sought to determine how ITax had influenced tax practices in Kenya. For this reason, it was necessary to look into the 'the native's point of view'. The 'natives' are everyone who engaged with ITax from the initial stages of development to the application of ITax. This includes the Kenya Revenue Authority (KRA), taxpayers, tax consultants, tax brokers, the ICT officers and experts working on ITax, as well as all the interlockers. I visited several places in Kenya to understand how ITax compared to other counties.

In this study, the ethnography is based on six months of fieldwork and two months of follow-up during my $\mathrm{PhD}$ studies after the first fieldwork, to address difficulties that arose throughout the analysis. Ethnography allows for the return to the field as it is understood that the initial data collected acts like metadata whereby it leads to insights and questions that often require a return to the field. In my case, Isiolo was a site that was important, however during my fieldwork I had to conduct interviews as travelling there was not safe due to the elections taking place in Kenya at that time. Returning to the field months later allowed a closer understanding of how the region was being excluded from national development through infrastructure and lack of internet connectivity. One such action was standing in line with all other taxpayers once more, which helped me realize and understand the issues that taxpayers had been experiencing as a result of the shift to digitalisation. While it was visible from outside 
KRA that the lines had disappeared, inside the lines existed however they were quickly dismantled, as taxpayers were sent to other places.

\subsubsection{Multi-sited Ethnography}

My ethnographic fieldwork aimed to understand how cultural, economic, global, and colonial factors influence the adoption and use of ITax in Kenya. This interconnectedness is seen to be the cause of a host of 'anthropological problems' in what is described as 'global assemblages', in Ong and Collier's words (2005). This study used multi-sited ethnography, as outlined by George E Marcus, to investigate global assemblages such as the funding for development movement (see chapter one), which supports the use of technology in taxation (1995). According to George $E$ Marcus (2005), ethnography is used to investigate social problems that cannot be explained by focusing on a single location. Previously, the 'world system' was viewed as a framework within which the locals might be contextualized or compared; currently, it is understood as inherent to and incorporated in multi-sited objects of study. Multisited ethnography enables for involvement with ostensibly large-scale entities while maintaining a close portrayal of people's lives.

The term "site" in the context of multi-sited is broadened to include those who completely engaged with the study object, rather than just a geographical location. It is seen as an extension of ethnography from its single site location to multiple sites of observations and participation (Marcus, 1995). The site was understood important to understandings particular set of social relations and practices. The site also allowed for the comparison of other practices in other places. The contents could be generalised to some extent into local, regional, or, most optimistically, worldwide knowledge (Falzon,2009). The term "multi-sited ethnography" claims to defy this convention. The goal of a multi-sited research is to track people, links, and associations to see how ideas, technologies, and even cultures affect people outside of their own borders (Falzon,2009).

According to George Marcus (1995), "multi-sited ethnography" leaves behind the restricted field-site in favour of following people, their stories, metaphors, or things as they move from one place to another and between different media. According to Marcus (1995), multi-sited ethnography should identify 'systemic' realities in 'local' locales, examining the world system directly on the ground. The basis of a "multi-sited 
ethnography" (Marcus,1995) is because it focuses on a group of localities where behaviours and interactions are inextricably linked. The researcher starts with one entity - a person or a 'thing' - and follows it from context to context, charting 'the social life of things' (Appadurai 1986). This method enables researchers to track and 'translate' details that might otherwise be obscure.

How could I then approach the issue of studying the impact of technology on tax compliance in Kenya? To grasp the historical impact of ITax's implementation as well as the actors and sites involved, I conducted multi-sited fieldwork in Kenya. My study involved attending international and regional meetings, tax conferences, standing in line at tax services centres, following taxpayers around and lastly travelling to different counties to compare how ITax was being used in these places. This allowed me to understand the current tax practices from the viewpoints of various stakeholders including the taxpayers, the KRA staff and tax consultants. I participated in international conferences where one of the presenters was the commissioner general of the KRA. His speech at this venue was important in understanding KRA's vision and mission for ITax.

My field shifted not only physical spaces but also digital ones. Researching the impact of technology involves mobility. In my case it was not just the field that was multi-sited, I also had multiple roles to play. I participated in various forums as a researcher, observed different practices at the KRA as an observer but also performed roles like helping administrative work like printing and reading research papers that some of the employees wanted to publish. I stood in long queues with taxpayers as well as accompanied them to meetings with their tax consultants. This was important in my study as society is increasingly becoming characterized by connections, mobility, and communication (Urry,2000).

\subsection{Data collection methods}

According to Clifford Geertz (1973), ethnography is about 'establishing rapport, identifying informants, transcribing texts, taking genealogies, mapping fields, keeping a journal, and so on' (1973,6). Gilbert Ryle's concept of "thick description," claims that "to come to the point of thick description is to arrive at a discourse of and about humans" (Hoey and Fricke,2007: 5). Ethnography through its methods of participant 
observation and interviews as well as immersing myself in the Kenyan tax culture allows this study to arrive at findings that were only available to those who took what the taxpayers or KRA did and said seriously. For example, "the Kenyan way" of taxation discussed in chapter five came about after numerous conversations with Kenyans describing how they cope with the innovations. This statement that was taken for granted by many locals including myself initially, turned out to be important in understanding how Kenyans find innovative ways to cope with the ever-shifting governance issues.

Researchers are at liberty to choose what to include and exclude in the field setting, both by defining the study object and context, and by defining the field setting's boundaries. The interactional patterns that the researchers can discern are influenced by these limits as well. With this background, I also define my research field and its boundaries. Communication, socialization, and interpersonal processes are not obvious in my research.

I kept several fieldworks diaries, and this was an ongoing activity both on site and in the evenings after fieldwork. This allowed me to analyse the data as it was being generated thereby allowing me to continuously work on my design. Ethnographic research includes participant observation, carrying out in-depth unstructured and structured interviews, submitting some questionnaires, getting information from focus groups, mapping, photography, and video documentation. The data collection methods were derived from participant observation, interviews, and public documents both in the form of reports and online resources. I discuss my data collection methods below and reflect on some insights that they provided.

\subsubsection{Participant Observation}

Participant observation entails following the subject or object of your study and participating in their activities (Malinowski in Fangen,2005). ITax was my object of study. I therefore participated as an observer in arenas where ITax was being developed (KRA), maintained (IT engineers) and used (taxpayers, consultant, and brokers). Choosing to conduct participant observation at sites like KRA was intimidating as they were not used to having researchers attending their meetings or just showing up almost every day to carry out the study through interviews or observations. In the beginning, my interlocutors found my frequent presence a little 
strange, however after a while I was no longer conspicuous. Although with time, they accepted my presence some still felt strange as they were used to researchers conducting interviews and not participant observations.

Ethnographic research has evolved over the years with researchers spending years learning the culture and language of the "native". For me to be able to observe participants at KRA, I was assigned tasks such as reloading the printers with the required papers. These tasks gave my work legitimacy and allowed me to analyse the role of KRA in developing platforms like ITax. The insights I gained could not be achieved by mere interviews. When I was standing at the service centres with the taxpayers, I was making my observations based on what the taxpayers were going through to comply with ITax. This method allowed my insights to be directly influenced by my own experience. However ethnographic research requires reflectivity. I was aware that my data would not be as representative as I was only engaged in the field for six months and I was not a Kenyan taxpayer.

\subsubsection{Interviews}

Before going for my fieldwork, I had planned to go to different sites to collect different types of data. The sites I wished to include in my study initially were in Nairobi and its outskirts. As the preparations came to an end, I realised that the study would have to include more sites both physical and digital to understand the implication of ITax's implementation. I wanted to ensure that all the actors that were relevant in my research could have a voice making the research more representative. The actors I interviewed were selected either before fieldwork based on where they worked or through a snowball method based on recommendations during fieldwork. I managed to meet with most of the people on my list however due to the elections that were ongoing in the country some of the areas that I had planned to visit were deemed too dangerous as there had been political tensions between the opposition and the authority. I had plans of gathering some data from those who were excluded in my study due to the importance of showing as many sides as possible of the research. I had to be flexible and visit Isiolo, one of the important sites in this study after my fieldwork.

I conducted interviews and observed participants. I conducted 18 interviews where ten were recorded while eight were handwritten. The recorded interviews were mostly at the revenue authority and the tax consultants. They were more comfortable being 
recorded, however some taxpayers felt that the information was too sensitive and preferred not to be recorded. From this data collection process, I was able to analyse those taxpayers were wary of being recorded not only because they were doing anything wrong but also because they did not trust anyone engaged in taxation matters, even researchers. The data from taxpayers were written down and after the meetings I would take an hour or two to work on the notes. The recorded and handwritten interviews were transcribed and saved on my hard drive.

As part of the investigation, I interviewed actors operating within the tax environment in Kenya, KRA officials, taxpayers, ICT officers within and outside KRA, Tax consultants, cybercafe attendants, and county officials from the two counties (Kiambu and Isiolo) (See appendix 1). This holistic approach allowed my study to follow ITax among all relevant actors and sites. If I wanted to know why and how ITax was implemented, I needed to speak not only to the source, but also down the line, the end users. This was tasking as it involved understanding the dynamics at play and being level- headed not to get caught up with what each side was alleging. I quickly realised when working with governance issues such as tax filing, there is a lot of mutual blame on both sides- the government and the citizens. It was therefore imperative to choose relevant interlocutors who had experiences using ITax. This was because some of them were not taxpayers but wanted to provide information on ITax. This would have no bearing on the data's veracity because it was intended to be indicative of their experiences.

When it comes to my interlocutors, I recruited them in various ways. Some were accidental like the man I met on the plane (described on p. 69). Others were introduced through snowballing. My interlocutors referred me to other people within their networks who they felt could add on to my research. Thereafter, I followed other leads that were offered within popular media like social media or by acquaintances. The taxpayers in my study ranged from high-level business owners to Uber drivers who had found themselves in a scenario where they were paying both local and foreign taxes. It was not difficult to recruit my interlocuters as my fieldwork preceded the tax filing season and many were going through the process of trying to comply with the "new" system. I stood in line at the service centres and observed how taxpayers struggle to use ITax by either going to a cybercafé or through their tax consultants, who I interviewed as well. 
I had planned to interview mostly the leaders of units, especially within the revenue authority. What I would find out through recommendations by the heads of the unit was that those who really knew the relevant information were the junior staff, meaning those who worked closely with the implementation of the KRA's policies. An interview with the knowledge department confirmed this as well. The experience that the junior staff had acquired, described by my informant as their 'tacit' knowledge here, was something that would be impossible to transfer to other entities as it was based on experience. This was a lesson that I would take with me to my other fields as well.

\subsubsection{Public Documents}

Another important source of data was all public documents concerning ITax, reported in both printed and social media platforms. The media in Kenya plays a crucial role in informing the public. The government would use the media to make important announcements because despite having websites, most Kenyans had no access to it. Print media remained the important source of information sharing in the country. The media created a niche for itself facilitating interactions between the state and the citizen. One specific issue that highlighted the role of the media as a spokesperson for public institutions was the hacking incident where ITax was hacked in 2017. The KRA shared no information on this issue. Nearly everyone locally and internationally relied on the media to understand what had happened. I visited the headquarters the day after it had been announced in the media. I wanted to understand how this impacted the authority internally and I could not get any official statements. I relied on my interlocutor to tell me what was happening. My main informant, Charles, told me that this was an 'inside job' as it involved some KRA employees, however it seems that it was something done at a very high level. He said that everyone was weary because the information about the investigations was not being shared. Charles explained that this might be a public scandal however there are worse things that happen that will take over in the media.

\subsubsection{Digital Sites}

My data was also collected from online newspapers as shown in chapter one as well as sites where bloggers such as Nyambura (see chapter five) write about their 
experiences with ITax. I ran into Nyambura's blog while researching online while other bloggers and articles were recommended to me by some of my interlocutors. KRA had specifically used social media and websites as their popular mode of communication with taxpayers. This mode of data collection enabled me to not only study human interactions but include the relevance of digital sites as suggested by Marcus (1995). Researchers are recommended to therefore shift their focus from the mainstream media to new places of interactions. My take on this is that if I'm looking at a digital platform like ITax, I need to match my analysis to the websites and online interactions that are talking about ITax.

My multi-sited fieldwork involving mediators such as bloggers had become relevant in helping taxpayers use ITax. These bloggers had used digital spaces to help taxpayers with tutorials on how to use ITax and give their personal details so that taxpayers could contact them in case they needed further help. These digital sites were included in this thesis as important in creating spaces where mediators can help with ITax. I analyse whether they ease or make e-filing complicated for taxpayers. 


\subsection{Fieldwork Sites}

Figure 2: KRA Headquarters times towers

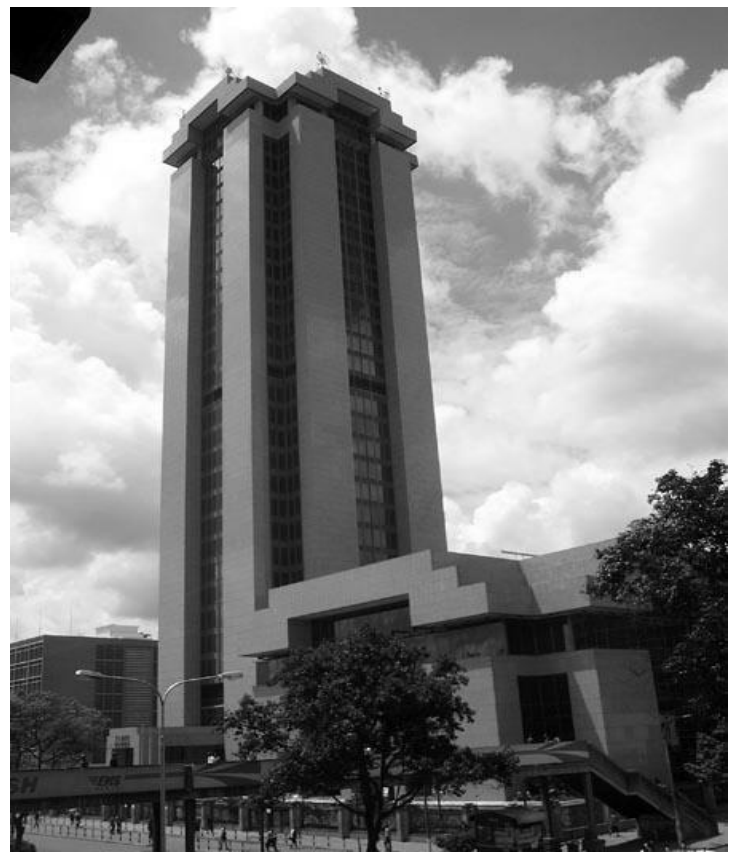

Source: www.dailynation.co.ke

The KRA's headquarters was one of my sites during my fieldwork. I was interested in achieving a holistic perspective in my case study on ITax. Inspired by Latour's (1986) view of translations remaining similar at the origins, I wanted to understand the KRA visions for ITax. The revenue authority is housed in a building known as Times Tower. At the time of its construction, it was the tallest building in east and central Africa covering 60,000 square meters. I felt like the building was a metaphor for surveillance as it was big, and it housed the "taxman". The building was magnanimous and as one went closer it was intimidating and created a sense of being watched. The revenue authority was the big brother who had a view of everyone's activity. The building in my view represented the relationship between the administration and the citizen. It was complex and evoked feelings of fear and being overpowered. Being in the central business district it would make sense that the site of the building would not only serve 
as a reminder to passers-by of their obligation but also serve as a reminder that they were following your every move.

My fieldwork had started on the plane ride from Sweden. Sitting next to my daughter and I, was a Kenyan engineer living in South Africa on his way to Nairobi. I was reading a book that I had taken with me on the field about African democracy and the gentleman seemed interested. We started talking and I was surprised at the enthusiasm I received about my research questions on ITax. I was unprepared for this interview as I started writing at the back of my boarding card. The engineers remarks and views were interesting and justifying the need to conduct ethnographic fieldwork following ITax. The experience he shared about his mother not being able to use iTax because she had to go through a slew of mediators, mirrored experiences from other taxpayers and shaped this study's design and findings.

Initially, my field site was to be in Nairobi and its outskirts. Yet, the field as we know, could be on an airplane, at a conference, any part of the world. It is truly multi-sited. As researchers are following their objects they should also move within the sites. My study for example led me to counties outside of Nairobi as I was made aware of the dynamic that was going on there leading to the analysis in chapter six. I was interested in how ITax as a travelling model was being used within Nairobi and its outskirts as well as by different actors. By following ITax's use in different places and actors, I, as suggested by Igor Kopytoff (1986) aimed to make salient what might otherwise remain obscure. I conducted fieldwork at the headquarters of the revenue authority where I interviewed and conducted participant observation in its various departments. I visited the national services centres set up by the government to provide e-services known as Huduma centres.

In my research, the Huduma Centre piqued my interest because it provides a one-stop shop for all governance-related issues. The current government has invested billions of Kenya shillings in these centres and their aim for the "Huduma" centres was to transform public service delivery in Kenya. The services they provide include applying for a passport, national ID and even tax services. These service centres exist in various areas in Nairobi and in some 32 out of 47 counties in Kenya. I visited some of the large ones in Nairobi as well as the main one in Kiambu County. I stood in line with taxpayers on one occasion accompanying a friend. These first-hand experiences enabled me to understand how the service centres work and gauge through 
observation how much time and effort the taxpayers used to comply with the set guidelines. The distribution of Huduma centres as shown in chapter six was not uniform, empowering and marginalising the citizens that either have or do not have access respectfully.

My fieldwork was in different places around Nairobi and in other counties in Kenya. I was mainly in the capital city, Nairobi, with some travels to Kiambu county located an hour from Nairobi, and Isiolo located $4 \mathrm{hrs}$ from Nairobi. It was multi-sited, and the study took eight-months to carry out. I employed participant observation and conducted interviews. I was based at the University of Nairobi's law department while conducting fieldwork. It was difficult getting access to the revenue authority however the law department at the local university had a memorandum of understanding (MOU) which enabled me to gain access to the KRA. At the university of Nairobi, the team working on tax, and I set up monthly tax talks aimed at creating spaces where tax professionals, researchers, taxpayers, civil society, and students could engage and learn about different topics related to tax. This was a source of networking for me where I got a chance to not only present my research interests but also build contacts that proved important for my fieldwork. There was a local tax technology platform developed by a local university. I conducted fieldwork at their offices, ILab. I went there on several occasions to really understand their role in developing technologies for the counties.

It was therefore important to be flexible over actors and sites that come up during the fieldwork. This study was only available to me after I followed leads, I had received during fieldwork. I compared the two counties in Kenya that have progressed differently economically. I had initially planned to go to Kiambu, however comparing it to Isiolo became more important as recommended by my informants and after a closer scrutiny over the data that was available. I also visited cybercafés (internet cafes) as a majority of Kenyans were forced to utilise internet cafes since they were inexpensive, and the attendants were familiar with the KRA system. They are small Internet shops where you can use Internet services for very low prices. The cyber cafes are usually small scale, equipped with 5 to 10 desktop computers offering services such as printing, scanning services. Some even offer photography services normally needed when applying for visas or passports. The internet cafes have grown into significant 
sites, where attendants have even developed the expertise to provide citizen eservices such as filing tax forms on ITax. I conducted participant observation as well as interviews at several cybercafés while attempting to understand how the shift to ITax had impacted their work as it was clear that they became important brokers assisting taxpayers to file their returns. In addition, I attended two conferences, one on data for development and the other organised by SAP, a tech-company aiming to attract county governments to contract them for the delivery of e-services. In this meeting, I met my main informant in Kiambu, an information and technology officer working with Kiambu County.

\subsection{Positioning}

I had to take on different roles especially with regards to my identity. Having multiple identities, African and European I did not consider my study as a study of the 'other' as was the case with the early anthropological studies during the colonial period. Rather, I felt that I was conducting fieldwork among my own people, however highly aware of my own position as a researcher. The Kenyan taxpayers were citizens and looked like me however my positioning as a researcher had to be constantly recalibrated so that I could be unbiased in my data collection. As an anthropologist, you are an instrument of knowing (Ortner,2006). In an important way, you are your method. I used my experience as a Kenyan Norwegian, employed at a Swedish university to follow ITax in my country of origin. Phrases like 'the Kenyan way' were not new to me however as something that I too had taken for granted. The phrase became prominent in my study because I was unpacking culturally specific terms that I normally take for granted while conducting research among our own people.

As much as it is a bodily process in space and time, ethnographic sensibility is an embodied one with a lot of intellectual positionality (Ortner, 2006: 42) (McGranahan 2015:24). By standing in line with taxpayers, I was attempting to construct an understanding of what taxpayers go through in their quest of complying. I entered the field with a certain understanding. Because I had lived overseas for many years, I still felt like an outsider, even though I felt like one of the locals. This was both an advantage and a disadvantage. The advantage was the fact that I know the local languages which allowed my study to navigate between the different languages used in the field. For example, when I was Isiolo, I spoke to the residents in their local 
language, Somali, and I was able to understand when others spoke in Swahili, the national language, as well. This space is where a lot of the insights are derived. The disadvantage to being local is that a lot of the times I was not given the same privilege as other researchers from abroad got. I felt that they were more open to foreign researchers who looked different from them but once they got to spend a lot more time with me, I was able to gain their confidence.

My observations would happen while standing in line waiting to enter the KRA or while sitting in the waiting room before an interview. In some sites it was helpful for me to identify as Kenyan especially when it was with actors who were outside the revenue authority. At the revenue authority, my main informant referred me to at first as Ms PhD. The fact that I was viewed as a female PhD student intrigued some of my interlocutors. KRA staff were not used to researchers being around their offices. They have a research department, which deals mostly with their research needs. Some researchers had different approaches like the PhD student from Canada who had gained access to the KRA through the law school as well.

The Canadian student was mainly interested in accessing documents and did not interact much with the staff. Being viewed as an anomaly in that sense enabled me to gain access to the field. I had to switch between several identities: Norwegian citizen, Swedish PhD student, and Kenyan by birth. In one instance an informant was quite uncomfortable with me when I was inquiring about the projects at the KRA. On realizing this, Charles, my informant, went on to speak to me in Kiswahili making it seem like I was one of the locals.

Another issue was the knowledge of the field that I as a researcher had. I considered myself someone who through her roots and ethnicity understood the local culture and context; indeed, I was a post-colonial subject myself. This meant that my insights into the field were shaped by my identity as well as my understanding of the local history. Initially, I was unaware of how this was influencing the data that I was collecting. It was important to discuss this data with my supervisors and colleagues to understand where I was being influenced by this past.

While we know that fieldwork is multi-sited, I approach the issues around my multiple identities at play here. I found myself navigating in spaces where I outwardly look like an African. However, having lived in Europe for most of my life, I was unable to really 
connect with some of their social codes. I would get information like "you know how it is" when sometimes I was oblivious to what they meant. I was expected to know the social codes as well as the technical language. After one of the tax talks, I had a chat with a gentleman who worked as a tax consultant about my research. I wanted to understand whether his clients had issues with ITax as my interlocutors had informed me. He remarks "you know how the KRA operates? Here I was left to wonder? Did he imply that the KRA was corrupt? I couldn't ask that directly because I was not sure what he meant, and I did not want to jeopardize my chances of conducting fieldwork there as he could be connected to tax agents as many consultants were.

I have to be continuously aware of my own biases about the case study. After working with and researching on development aid programs and their impact in poor nations, I realized that I needed to constantly check and balance my viewpoint in order to gain a fair understanding of the topic. For example, when a young lady working with a Swedish transformation project known as the change project ${ }^{15}$ was describing the project to me, I had to clear my thoughts so that I could focus on her central arguments. While many researchers face this often, I would often refer to the development project as naïve and uninformed. Here, I was reluctant to describe my informant as uninformed because she really looked like she believed in what she was describing to me. The problem wasn't that the project was reluctant to take off; it was that, given my background in the industry, I was almost instinctively discarding it as a failure. I had to constantly remind myself to take off my 'glasses' that shaped how I made assumptions about these projects. My normative stance here becomes being open to what is happening in the field. If I was not careful, my analytical position would just be as the technologies I'm studying create norms of how things should be (referring to ideas about what is happening in the West) vs. how things work in Kenya.

Research questions in qualitative research should generally be flexible. I had developed a fieldwork plan with all the places, people, and questions that I would engage with while I was on the field. This changed because the more I got to understand ITax the more my plans changed. I went from following the actors to following the thing (Marcus, 1995). Fieldwork therefore enabled me to be reflective

${ }^{15}$ https://publikationer.sida.se/contetassets/c1cabe27d46c4383a4dfe11c5b45d621/de2019 $26 \quad 62256$ en.pdf(Accessed 21. May 2021) 
over my position. I had been making big claims and creating the very universals that I was claiming to study. Studying ITax ethnographically therefore allowed for such reflectivity as it required me to be aware of my own prejudices and positioning to allow me to understand the case studies holistically. Language became an important aspect of my fieldwork. However new insights and modes of language became even more important. The next section delves into the various technical and spoken languages I engaged in this study and their relevance to understanding implementation of ITax.

\subsection{Languages used studying the Kenyan ITax}

Anthropologists use fieldwork methodologies that prioritise meanings and frameworks outside the discipline, generated not solely by scholars, but also by the community where the ethnographer is conducting research (Mills and Ratcliffe, 2012). ${ }^{16}$ I was aware of this during my fieldwork. I did not take my interlocutors' phrases for granted whether they sounded ridiculous or not. The phrase, "Kenyan way" for example, was something I heard several times used in different contexts. Corinna Kruse (Kruse, 2016) an anthropologist studying forensic science in Sweden was faced as well with the languages during her fieldwork. She argues that she had to pay attention to the languages that her interlocutors made in their everyday language (Kruse,2016). Kruse (2016) had to learn about the differences for example between murder and manslaughter and between theft and unlawful in order to gain an emic understanding of the cultural norms at her field of forensic research. Failure to attend to the languages or sayings that arise from the field could bar the researcher from collecting that data that is representative of the field.

Having been born and lived in Kenya, I speak Kiswahili and English, the two national languages fluently. English is often used as the main language in public and private spaces. While Kiswahili is spoken more unofficially. However, one can choose to speak both languages however English is made to seem like the language of modernity prompting those who wish to be seen as progressive to communicate in the language. All Kenyan government's digital platforms are in English. There is a broad 
assumption made by policymakers in Kenya regarding English literacy. Yet, statistics show that a large majority in Kenya who live in rural areas do not speak or understand English. That English is the digital language, therefore marginalises the majority Kiswahili speaking population. It was therefore critical to pay attention to concerns such as how language is utilised in digital platforms and the type of "othering" that results while doing fieldwork. In chapter four I gave an example of an older lady who needed to register for her KRA personal identification number (PIN). She was not eliterate, nor did she speak English. The staff at the ITax center had to assist her with getting the documents, all the while, she understood very little of the process.

I also had to learn the ICT technical terms as well as the language of taxation. The first time I engaged with the ITax lingua was in an interview with my informant Charles addressing the history of ITax. I had done my background research on ITax but what he was describing seemed like one of the 'thick descriptions' of ITax. Charles went on to use very complex language which was very difficult for me to ask follow-up questions. For example, he spoke about 'the consultants from India having the source code of ITax'. For example, did his references to "the source code" sound as something very important despite my ignorance on what it was and why he felt it was important that the authority had rights to it. ${ }^{17}$

Tax terminologies was yet another "language", not just the tax law itself but how professionals talked about "tax". At the KRA, tax terminologies were being served to me as though I was a tax expert. Tax treaties, tax exemptions and VAT were among the buzzwords and fuzzwords of my fieldwork (c.f Cornwall, 2007). I was therefore required to understand what the various taxes were as well as the issues relating to them. Having engaged with tax terms previously in courses at my university, it was interesting to learn about the uniqueness of each country's tax system and how they chose to categorise the different taxes. To stay on top of the terms being introduced, I engaged with tax lawyers, consultants as well as other tax experts based at the University of Nairobi, Law School where I was a visiting researcher during my fieldwork. Participating in their seminars helped to understand taxation from various perspectives. In the next section, I discuss the limitations of conducting multi-sited

\footnotetext{
${ }^{17}$ The source code as will be discussed in chapter four is the code in which ITax programming is located. This code is important in ITax's core functioning.
} 
ethnography specifically how I approached the field with regards to the changing nature of the field.

\subsection{Limitations (disruptions in the field)}

My fieldwork, like most, was faced with some disruptions that required quick change of plans. Kenya had gone through disputed elections that had now led the Supreme Court to nullify the election results. The country was ordered to organize a re-election within 60 days. This distracted most of my interlocutors working with the government and even at KRA as they were too political positions. KRA officials were elected by the sitting government. My interlocutors at KRA were also preoccupied with the elections. I realized that some positions at the revenue authority of the KRA were political, meaning they were dependent on the outcome to keep their jobs despite the KRA being a semi-autonomous public organization. Both the ruling party and the opposition had numerous campaign rallies, some getting out of hand. When this happened, the public would avoid certain areas. I found a way around this, however, by arranging my meetings in some areas outside the central business district which was the epicentre of the campaigns. This meant that on the days those rallies were held, I would not go to KRA as it is located at the heart of the business district. This restricted my fieldwork especially with my plans to travel upcountry to Isiolo county. The county is described as marginalized not only because of its geographical location in the northeast of the country, but also because it is considered lagging behind economically. There were reports of these areas being caught up in the political unease and I was then advised to restrict my fieldwork to Nairobi and Kiambu counties initially, and later travel to Isiolo once the country had settled down from the elections.

Another limitation I had was the limited number of interlocutors allocated to me at the KRA. I had aimed for a representation of the entire organization, yet as mentioned earlier, researchers were often distrusted and even seen as spies or journalists. The KRA allocated the people I was to interview, and I had to work with this arrangement despite some not even working with ITax or even with taxpayers. The ICT consultants were unwilling to meet and get interviewed as they were afraid of being misquoted or misunderstood. I relied on the local ICT technicians who worked closely with them to understand ITax from a designer's perspective. It would have been very intriguing to see how the consultants view iTax as an organisation amongst other views. This 
therefore meant that my data was influenced to a certain degree by access to interlocutors as well as political situations in the country. IT became clear that flexibly as well as snowballing would become relevant in my fieldwork. Fieldwork as I understood from this exercise could be done in phases where the researcher could return to follow up on things that were not completed in their earlier phases.

\subsection{Ethical Considerations}

The data I collected came from different sources; from regular conversations either at coffee houses or at the university where we had a small group working on tax issues. I was forthcoming about my role as a researcher especially within the revenue authority. One of the reasons why it was difficult to gain access to the authority was because journalists have posed as researchers before compromising confidentiality. I have anonymized all my interlocutors. This is especially important for those who were with me at the KRA as I did not want any of them to have any problems at work as I had been told would be the case as the topic was considered sensitive. This was the only way they would agree to participate in the study. I also wanted to maintain a good relationship with them for future research and references. Charles, my main informant at the revenue authority informed me that there had been several incidents where researchers had been granted access. This however led to sensitive information being leaked to the public. It was therefore very important for the authority to conduct background checks as well as verify information before allowing anyone access. I therefore got consent before any interview and even asked if the interviewer would want to proofread my transcriptions of the interview. Most did not seem interested in that because they knew they would be anonymous. The few that had accepted the offer in the beginning of the interview relaxed knowing they were in control over the information that I was gathering from them.

While conducting fieldwork at a service centre, I had to be careful on how I managed the knowledge I received from there. I was sent there by the KRA, and they knew whom I would be talking to specifically. I had to frame some of my questions in a way that they would not feel like I was sent to spy on them because I realised that the service centres were managed by the KRA. The taxpayers are also anonymised as they feared that KRA might go after them based on the information they gave. It would be unlikely but the fear they had of KRA would not allow them to participate in the 
study if they were not anonymous. It was a fair compromise as I was not willing to collect data that would cause problems for my interlocutors.

\subsection{Conclusion}

To sum up, my fieldwork involved visiting different places and observing their practices in relation to ITax. Ethnography allows the unpacking of problems such as the impact ITax has had on taxation practices in Kenya. To follow how ITax was implemented in Kenya, as the main aim of this study, I used multi-sited ethnographic fieldwork. This enabled me to holistically follow ITax through the different sites and meet actors who engage with it. This increased my understanding of their tax practices to understand what worked or did not work for them. I thus visit tax centres and national egovernment service centres as they all offer similar services with regards to taxes. I was interested in how the service providers and the taxpayers interacted in the process of accessing tax services; in this case ITax. I observe as well as participate by standing in line with other taxpayers at the various centres. As an ethnographer, it is relevant to not only talk to taxpayers about their experiences with different tax policies but also to observe and participate in their daily routines especially during the filing of tax returns period which the country is currently going through.

I use ethnography to show how taxpayers for example react to ITax. From the man on the plane to the CG, it was important to understand how different actors view ITax and how they are either empowered or marginalised by it. The man on the plane was so opinionated about ITax really justifying my fieldwork just as I was embarking on it. The CG's understanding of ITax as a transformative tool gave insights of how KRA views ITax and how this knowledge is inscripted into ITax. By following notions that are used in the empirical chapters such as "ITax makes me feel stupid", I demonstrate ethnography's strength when we take such mundane issues like feeling "stupid" and connect them to larger societal problems where taxpayers experiences are not taken into consideration.

I discussed the limitations of the fieldwork in my study which included the national elections. It did not significantly impact my work however future researchers could consider how national politics influence data collection. I highlighted the importance of positioning oneself in the field using experiences as a strength in data collection. I 
discuss my positioning and the importance of reflexivity in our positions as researchers. I had to reflect over my normative stance to analyse my new case study in its own context. Researchers are not as neutral as we might think because our privileges and prejudices influence the data we collect and the analysis we make thereafter. Within postcolonial technoscience, it is also helpful for anthropologists to be aware of the origins of anthropology from when anthropologists worked closely with the colonial administration to use the knowledge produced to govern the colonies. As much as the discipline has evolved, we must be aware of our history and how inquiries into the colonial legacy can help mitigate that. 


\section{Chapter Four: Making ITax: Simple, Swift, and Secure}

\subsection{Introduction}

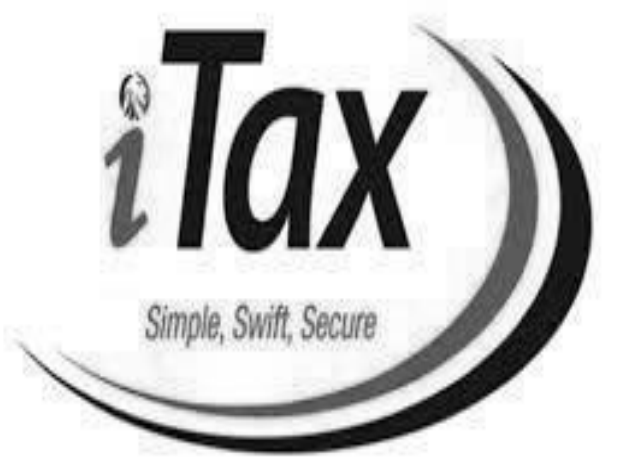

Figure 3: ITax $\log 0^{18}$

"Kenya Revenue Authority (the KRA) is acknowledged as a tax authority that has progressed to a customer centric institution. This has ensured that we remain at the forefront in exploiting technology to provide enhanced services to citizens and businesses, to deploy improved compliance programs and maximize revenue collection, and to drive organizational culture change' (John Njiraini, Commissioner General, Strategic report 2014-2019).

This statement in the KRA's strategic planning report of 2014-2019 indicated a turning point in the organisations' transformational journey. As also indicated in ITax's mantra in the picture above, ITax was going to make e-filings, simple, swift and secure. Njiraini stated that KRA had been "exploiting" technology to enhance services to citizens

\footnotetext{
${ }^{18}$ ( Source :www.kra.go.ke)
} 
(taxpayers) as well as maximize revenue collection. This idea was however not new as indicated in the introductory chapter; it was part of the global financing for development movement that aimed to leverage technology for increasing revenues thereby leading to global development. The ideas of digitising tax administration as a way of increasing revenues are left open to interpretation at the local level as will be shown in this chapter as it interfaces with the local, historical, and economic factors.

In this chapter, I analyse how the ideas developed within the global financing for development (FfD) agenda travel and get inscribed into ITax by the KRA. The idea that technology will increase domestic revenues leading to sustainable development gets embedded into KRA transformational objectives. Analysing the inscriptions at KRA will make visible how ideas are transferred to new sites (Behrends et al.2014b:2). As suggested by Monteiro and Hanseth (1996,330), I will look at "what is inscribed, who inscribes them and how are they inscribed".

I begin by looking at the Commissioners General's perspective of ITax as a transformative tool in the KRA. Then I look at how well the ITax management team agrees with the CG's viewpoints. Here, I analyse how the ideas within digitalising tax filings travel as they are envisioned globally or do; they change several times as they change sites and actors. Thereafter, we look at the technical development of ITax through the ICT team at KRA to compare their understanding of ITax's vision and mission to those outlined by the KRA staff. Lastly, I investigate how these ideas translate to practice at the different KRA ITax centres specifically designed to help ease taxpayers into using ITax. The chapter travels as with the case of ITax from when the ideas were initialised by the CG to different management levels at KRA to ITax designers and finally when it is implemented at ITax service centres and Tax clinics.

\subsection{Transforming KRA}

In 2016, at a conference in Vienna, Austria, months after ITax had been made mandatory, The KRA Commissioner General (CG) John Njiraini presented the 'positive' changes that were happening at the KRA. Sitting in the audience, I listened to how the CG talked about the authority's move towards becoming customer centric focusing on their new policies which shifted their modus operandi from enforcement to service delivery. He explained that the past relationship between the KRA and taxpayers was one that was based on coercive means of compliance. What he meant 
by this was they had previously used enforcement measures to make the taxpayer comply. However, the KRA had been transforming towards service delivery turning the taxpayer into a customer. The citizen had now become an important stakeholder and partner. It is believed that citizen centric approaches within e-governance would deliver some stated objectives of increasingly better services to citizens as well as enhance the democratic dialogue between citizens and their government (Sigwejo and Panter 2016).

The CGs statements were in line with the financing for development movement rationale of how digitalisation could help transform tax practices and make tax services easier for taxpayers. Digital technologies have had an impact on the primary sectors of finance and development outlined in the funding for development agenda, also known as the Addis Ababa Action Agenda (see chapter one), since 2015, according to the UN's 2020 report on financing for sustainable development. According to the research, technological advancements have enormous prospects for developing a more sustainable financial system that helps to accomplish the Sustainable Development Goals (SDGs). At the Vienna conference, Njiraini presented a muchneeded solution to the problems that had been previously faced by KRA and the taxpayers. The problems stated included tax evasion as well as low compliance. This was stated to be the cause of the low generation of domestic revenues in Kenya.

The CG described that within the transformed KRA, taxpayers were regarded as customers. Borrowing ideas within new public management policy (NPM), KRA was using private management models making KRA seem more business-like ${ }^{19}$. Njiriani discussed this at the conference and stated this in the organisation's report. Their transformation journey was based on "enhancing customer satisfaction. ${ }^{20}$ (Kenya Revenue Authority, 2015a, p.13f.)

The picture painted by the commissioner general at this conference was that the KRA had in practice used technology to make tax practices easier for the taxpayers. It was

\footnotetext{
${ }^{19}$ New Public Management (NPM) is an approach used to run public institutions and agencies, at both sub-national and national levels. NPM was developed during the 1980 s as part of an effort to improve public sector's efficiency by using private sector management models.

${ }^{20}$ the KRA ICT Strategy 2014-2018
} 
believed that it would change KRA employees' attitudes towards delivering services to the taxpayers and externally enhance customer experience thereby changing the taxpayer's negative perception towards KRA. The theory of change was that digitalisation would ultimately lead to high tax compliance and increase domestic revenues. ${ }^{21}$ It however seemed that the KRA had embarked on a journey motivated by the incoming Kenyan government in 2013.The newly elected government embraced e-governance as a central governance strategy (c. f, Poggiali,2016). The government was determined to get all its institutions to be digitised and within a short period of time there were numerous e-governance services led by the government as well as the establishment of tax centres aimed at helping citizens access the services. This idea that technology would deliver all stated objectives became internalised within the KRA's vision and mission for ITax.

The KRA had already embarked on the Revenue Administration Reform and Modernisation Programme (RARMP), which was inaugurated in FY2004/05 by the new KRA top management that had been appointed by the Kenyan government in 2003-2007 (AFDB,2010). The goal was to turn "KRA into a modern, fully integrated and client focused organization" (AFDB, 2010). This transformation journey resulted in, among other things, the adoption of e-filing systems. However, KRA has also been forced to navigate an even more difficult and unpredictable tax policy environment during this transformational period (Tyce,2020). During the first few months of his first term in 2013, President Kenyatta passed a new VAT Act that he had helped to formulate as the former finance minister(Tyce,2020).This spiked Kenya's tax-to-GDP ratio in 2014 as KRA tapped new revenue streams while using technology to make tax collections more efficiency(Tyce,2020). However, since then, various provisions within the Act have been reversed, weakened or stalled(Tyce,2020). The ruling party, Jubilee made heavy use of tax exemptions both as an investment tool and for political purposes (Wawire,2020). This has deprived KRA of new revenue sources, forcing it to keep on overburdening those already complying (Tyce,2020). There have been numerous reforms however many were politically motivated both as a bargaining chip during elections as well as a way of finding new sources of revenues to finance government spending.

\footnotetext{
${ }^{21}$ the KRA ICT Strategy 2014-2018
} 
ITax's script as described by the CG as a tool for improving compliance, maximizing revenues, and even leading to organisational change. This was also highlighted with numerous posters plastered all over the place describing the "new and improved KRA". The CG described ITax as a successful platform that had been recognized for its contributions to achieving a well-functioning tax system leading to customer satisfaction. Certain circumstances however could influence how inscriptions in technologies are performed (Akrich,1992). The ideas within ITax would most likely change as they moved within KRA thereby influencing its implementation. What was however left out here was as suggested by Tyce (2020). The jubilee government put pressure on KRA to increase revenues in order to fund rising government spending, particularly when the new constitution was introduced in 2010 (Tyce,2020).

ITax was now tasked by the CG to transform KRA through making it more customer centric, moving away from the enforcement strategies that were used previously. The idea that these would motivate taxpayers to be more tax compliant. Those working within the ITax department are tasked with making ITax's script and ensuring that the transformational ideas by the CG are encompassed within ITax. CGs inscriptions, however, remain as ideas that are transferred to his colleagues for execution. The next section examines the process of creating ITax's script and if the ideas remain consistent with the CG's as they pass through KRA's senior leadership. In the next section, we'll look at how two senior managers, Allan and Anna, see ITax's function at KRA and how they interpret, or rather, convert, the CG's vision and goal for ITax into a customer-centric tool that will assist Kenya achieve sustainable development.

\subsection{The Senior ITax Managers: Enhancing Customer Experience}

The journey to meeting senior management was tasking. The headquarters of the KRA, Times Tower is located in central Nairobi. At the time of its construction, in 1997, it was the tallest building in east and central Africa covering 60,000 square meters. Having gone into this building several times I am always amazed at how big it is. As explained in chapter three, getting into the Times Towers is tedious; almost like taking a flight. While trying to make it for my meeting at the headquarters, I did not account for the time it takes to get into the building. I am already fifteen minutes late and send messages apologizing for my late 'check in'. Finally, I get in and I am relieved as I proceed to take the lift to the fifteenth floor. 
Suddenly, another three lines appear leading up to the huge doors. I was in disbelief having stood in the queue getting into the building. Taxpayers around me looked confused. Some on their smartphones maybe calling their contacts to apologize for being late, others were worried that they might not get admitted into the building frantically clutching onto their documents chanting something that seemed like a rehearsal for the man, wearing an employee badge who was going around asking everyone the reason for their visit. "This is not a service center. He repeats rather loudly and rudely" As he turns away, many others join the line-up almost synchronized. Slowly the lines got shorter as many of them were sent to the service centres. I wondered why they had not been sent away at the first point of entry. It felt frustrating to have waited so long and gone through the 'security check' only to be turned down before 'boarding'. Some taxpayers who may or may not know where they were going seemed obliged to follow his orders. Others insisted on going through as they explained using their passports(papers) that their matters could only be resolved at the headquarters. He gets to me, and I show him an email confirming my meeting at the KRA as well as the notification that my research at the authority was approved.

Like the taxpayers, I felt nervous that I might be turned away. If the KRA had become customer centric, why were the taxpayers being treated in this manner? The taxpayers in-line looked dismayed. Some even tried to call their contacts at the KRA. Some were rescued while many had to go elsewhere. All this, and I still had not gotten to the counter. Ironically, at the entrance where we were standing, a poster with 'enhancing customer satisfaction' was on display. The taxpayers who were turned away did not look satisfied. After I declared my intention to the immigration officer(receptionist), I got a card that could be used to access only the floor where my interview would be taking place. KRA's vision of transforming into a customer centric institution was not translating into practice. The taxpayers might have had issues that could have been solved at the headquarters. The senior officer engaging in admitting or dismissing taxpayers was however concerned with getting rid of the queues.

\subsubsection{Allan: Senior Manager ITax}

I went on to meet with Allan, a senior ITax manager at his office cordoned off from the rest of the team on the floor. He was tasked with overseeing ITax operations at the headquarters. Charles had reminded me several times that he was an important man 
and not to ask irrelevant questions. Allan is, however, warm and starts by giving me a background of KRA transformational journey. Like the CG, Allan described the past as being bad for taxpayers and KRA and they were currently enforcing measures to make taxpayers comply. He claimed that KRA was now a transformed organisation. He informed me that in the past, KRA's coercive nature of administering taxes made them an unpopular organisation that did not even help increase revenues. Allan added, in line with the CGs statement, that the previous systems were not as modern as ITax causing hindrance to tax compliance as both taxpayers and the KRA found it to be complex.

Digitalisation had now, according to Allan, assisted KRA get to the next level where they could provide better services to the taxpayers. It allowed them to be fairer as they were now able to analyse the difficulties taxpayers face when filing their taxes. This was because it became imperative for the KRA to develop a customer friendly system that would enhance tax compliance as well make administrating tax easier for KRA as well. Allan explained that the simpler the process, the more effective and efficient tax filings would be for the taxpayers and KRA. This, according to him, would happen ideally as the KRA goes paperless. Paperless, he explained, is the automation of tax systems. The KRA has invested in solutions like ITax to make tax administration easier as well as becoming a modern institution that is digital. He affirmed: "The more digital we are, the more services we can offer the taxpayers." According to him, the digitalisation of tax filings would enhance compliance as they would be able to serve more taxpayers(customers) when they previously had to hire many staff to deal with taxpayers. ${ }^{22}$ The taxpayers who were trying to get into Times Towers could have been facing difficulties navigating the online platform as witnessed by some taxpayers (which will be discussed in chapter five). With the variety of government and ITax centres opened to the public to help with digital services it is not difficult to see how it can become confusing as to where they can go to seek help.

I raised the issues of the "check-in" and how intimidated and frustrated myself and other taxpayers felt while trying to get into the building. He was quite puzzled when he found out about the queues. He claimed to be unaware that taxpayers were being

\footnotetext{
${ }^{22}$ Notes from interview held on the 12.04.2017
} 
turned away however he described this as teething problems. He described Kenyan taxpayers as being stubborn and creatures of habit. Citizens have always been set up to come to Times Tower, which explains the long queues during filing season. His solution to this was that they had no business at the KRA headquarters, rather they should go online or get help at the service centres. Allan stated that they did not communicate this to the taxpayers and would be working on a media strategy. Yet not much seemed to happen. During my fieldwork at the KRA over a period of six months I was constantly faced by the same long check-in procedures.

Another reason for implementing ITax according to Allan was to reduce corruption. The KRA, according to him, was historically one of the most corrupt organisations in Kenya. With the implementation of ITax, this changed, as it has disallowed tax agents who received bribes to alter the system to help taxpayers evade or avoid taxes. The transformation of KRA including the implementation of ITax had now turned the corrupt practices around, reducing almost all manual or analogue interactions. The taxpayers who were able to pay off tax agents in the past denied the KRA the right taxes. Allan assured me as if almost trying to convince me that this had now changed with ITax. Everything could be tracked digitally making it impossible to crack the system. When I conducted this interview, the 4 billion USD hacking of ITax that made international headlines had not yet happened (see page 116). The manager was however adamant that ITax was secure as it disallowed altering taxpayer information and their tax liabilities by corrupt tax agents. Digitalisation was seen as being important in curbing corruption not only at KRA but across other government agencies. This was however difficult to achieve as 200 KRA employees were charged in 2020 over alleged corrupt dealings including altering citizen information on ITax. ${ }^{23}$ Despite their understanding of ITax as being a solution to corruption, the taxmen who were arrested found a way around the system thereby compromising it. Charles stated that KRA employees were receiving minimal wages that made them susceptible to corruption as they are surrounded with opportunity to steal. He mentioned that "you can always tempt a hungry man". The changes would need to start internally. According to Charles, tax agents would need to be fairly reimbursed in order to fulfil their duties effectively.

\footnotetext{
${ }^{23}$ https://www.pd.co.ke/news/kra-staff-charged-with-corruption-granted-sh200000-bail-59167/
} 
Allan understood the implementation of ITax as a straightforward process that has allowed taxpayers to file more effectively and efficiently. He seemed disconnected to the realities around its complexities as I would find out later that the feedback loops at KRA were not as strong as intended. What this meant was that lower-level employees like those at the entrance of KRA would not regularly share feedback about customer experiences with senior managers like Allan as they felt that their views would not be taken seriously as explained by Charles. Another issue is that the feedback culture flowed in one direction from the top to the middle and this was the most common way of communication. This therefore led to senior managers like Allan to make claims that make it seem that ITax was an ideal platform that was working well for taxpayers which this study has shown is not the case.

\subsubsection{Anna, Senior Manager Transformational Office.}

Another senior manager I interviewed was Anna during one of my field visits at the KRA. Anna, a senior manager at the transformation office, was working closely with the Swedish tax agency (STA) to implement what she described as the change management program. This program was meant to help KRA transform into a tax administration that was respected and customer friendly as this was believed to be key in increasing revenues. Anna stated that the idea of automating e-filing started during the RARMP. They were now faced with converting ITax's business use, as it was established during the enforcement era but applied during the transformative era defined by the CG. The transformation office was not only ensuring that ITax was customer centric but also transforming KRA into a customer friendly organisation. The shift has however not been without challenges as it proved difficult to change a system once it has been designed as an enforcement tool.

Anna explained that when ITax was developed, KRA was more concerned with increasing revenues by enforcing tax compliance. This included enforcing penalties that would sometimes be seen as being unfair or popular among the taxpayers. Some of the penalties were imposed for failure to register on ITax or for not filing nil for those who were in the category of non-taxable activities. There was little room for adjustment according to Anna. The deactivation of the tax personal identity numbers (PIN) as described in chapter five is another example of how the ITax had been made powerful by the Kenyan government linking many important government services to the tax PIN. 
At the time of this research, KRA had deactivated taxpayers' PIN affecting business activities and impacting over 4.8 million Kenyans (See chapter five). ${ }^{24}$ Transforming KRA into a customer centric tax administration would entail that it delivers on what it promises the customer (taxpayer) which in this case is "simple, swift and secure" efilings.

The innovator's beliefs about the relationship between objects and their users are used to predict the users' needs and reactions to the object (Akrich,1992). This is often done in isolation, with little consideration for the users' perspectives, but instead focusing on what the innovators assume to be their needs (Akrich,1992). For both Allan and Anna, it seemed like their inscription of ITax was based on creating a perception of change rather than implementing specific changes at the KRA. It would seem that convincing taxpayers of the changes that had been implemented by printing posters and media campaigns were enough rather than implementing the changes. Taxpayers being turned away from the Times Towers could be seen as an indication of this as they are unable to get their needs met. Allan, like the CG stated that ITax was created to transform KRA into a customer centric institution. However, the practices like turning taxpayers away from queues at Times Tower was different from their vision. Anna's portrayal of ITax as an enforcement instrument, as well as the example of an unlucky PIN deactivation, show that, despite the modifications proposed by the CG, changing KRA's attitude toward ITax, taxpayers and taxation in Kenya will take time. In the following section, I examine how junior officers, such as my informant Charles, are more aware about ITax as they often interact with taxpayers and have a better understanding of how ITax is changing tax procedures.

\subsection{ITax: Serious Automation?}

Charles, my main interlocutor at KRA was a junior ITax officer and he worked on several aspects relating to ITax including customer outreach. He was also a selfdeclared ITax expert. During one of our many interviews, Charles started to explain what ITax was and how it worked.

\footnotetext{
${ }^{24}$ In May,2021 KRA issued a notice of PIN deactivation for tax evaders arguing that they would be barred from accessing important government services including pensions and health.
} 
"ITax started with Tera Term. ${ }^{25}$ Tera Term was used to capture the details, do the assessment for you, bring us your income details, we asses you, we ask you to pay then we came to what they call 'legacy', it is just a colloquial name, we send you the forms you fill them, you send back and then we capture the details but whatever is captured is not available for you unless you come and ask for it. This request is the compliance certificate. So, after that we at the KRA went a level higher with what the Chileans had developed, ITMS, that is Integrated Tax Management System. ITMS brought the ability of the taxpayers to do the return and send back to us digitally however the data was captured slowly so we started to appoint people to capture it. Because this was not as successful as planned, we went to the third level, what I call 'serious automation' which is ITax".

Charles stated that ITax was a 'serious automation'. He argues that both the first attempt described as Tera Term and then ITMS were unsuccessful leading to the third successful attempt to e-filing system which is ITax. Serious automation refers to the ability of ITax to deliver on the tax administrative needs of ITax and make tax filings easier for taxpayers. Charles viewed ITax as successful and had compared it to the earlier, unsuccessful, digitized tax filings attempts. ITax's development was a collaborative effort between the KRA and the developers TATA Group. KRA had worked closely with the developers to ensure that their needs were well represented in the system, mostly learning from the mistakes they had learnt from their previous systems. These inscriptions by KRA define their "specific tastes, competences, motives, aspirations, and political prejudices" (Akrich,1992,208). The KRA, according to Charles, was getting it right as ITax was delivering on the KRA's latest vision and strategy that involved increasing domestic revenues. The expectations of ITax at KRA were quite high as it was seen as the solution to all the problems that KRA had been facing which included low tax morale among taxpayers as well as the low tax revenue generation.

\footnotetext{
${ }^{25}$ Tera Term is an open-source, free, software implemented communications program. It emulates different types of computer terminals. It also has a built-in macro scripting language.
} 
As it stands, Charles made it seem that ITMS was ITax. ITax, according to him, was made to seem new, however it had a lot of the older features from the older ITMS system. Charlies stated that there were many stakeholders (internally) and donors (externally) who wanted to see a new system like ITax in place as they believed this would help increase domestic revenues and reduce reliance on foreign aid. The "wakubwa" (Kiswahili translating to the "important guys"), according to Charles, financed the redevelopment of ITax putting pressure on the developers and the KRA to make it seem new. When new development projects are done at the KRA, donors often need the ideas not to seem redundant to get approved by their home offices. As much as KRA had partly financed the transition to ITax, they still worked closely with several donors to finance the shift.

ITax was however not fully developed as this was going to be an ongoing process according to Charles, He argues "You see God created the earth in six days so ITax had also to be rolled out in a similar manner of creation: beginning with taxpayer's registration, then payments, then compliance then audits - such things". ITax was thus constantly being developed and upgraded and this affected its rules and how taxpayers were supposed to relate to it. A lot of the times the new changes were announced on the media platforms, however it isn't always that taxpayers were aware of the changes. The incidents like the PIN deactivation in chapter five are attributed to the changing nature of laws and requirements by KRA that are not informed by law. The ambiguity of tax rules, as well as changes in them, have an impact on how taxpayers perceive ITax. As Charles stated, "Taxation is a procedure of the law thereby if the law changes everything has to change - even ITax'. ITax's ability to be changed allowed KRA to customize it based on its needs. Charles described ITax as an agency centric tool for increasing revenues and reducing tax evasion.

Ideas however do not travel as seamlessly as imagined within organisations (Rottenburg 2009, Behrends et al,2014). Charles' understanding of ITax was based on the information received from his superiors. The translations of ITax's aims from the CG to Charles could be explained by the hierarchy. Most information was disseminated to senior staff in seminars where new policies at KRA, changes in objectives, visions, and mission are discussed. The senior staff then convey the message back to lower-level employees, according to Charles. However, he claims that the messages occasionally got lost in translation. The lower-level staff like himself 
understand KRA vision and mission based on what their superiors inform them. They translated it according to their interpretation of the mission and vision, but much of it was lost in translation. Charles says that at the lower levels, they deal with a lot of technical concerns as well as customer relations, therefore their work is more about descripting iTax to help taxpayers rather than inscripting it as their superiors do. Tax agents like Charles as described by Akrich (1992), translate the scripts based on examining the users and on relying on their own experience and expertise (Akrich, 1992, p. 276). The inscriptions in this case only work downwards.

Here we see ITax as translated by Charles and his fellow colleagues to offer support to taxpayers. ITax's script is travelling and getting translated within KRA. This creates varied understanding of ITax's role in one way as viewed by the CG as a transformative tool with futuristic goals of achieving increased revenues and sustainable development on the other hand. Charles views it as an e-filing tool that is helping taxpayers file their taxes. In the next section, we analyse how ICT developers of ITax understand ITax's script as they work closely with senior management to include these ideas in design.

\subsection{The Developers' script}

I include the developer's script because they worked closely with KRA to develop a platform that is supposed to be representative of taxpayer's needs. Developers' behaviours are described by Akrich (1992) in connection to how they envision their technology being utilised as well as actual user activities. Developers, she claims, characterize actors by their preferences, skills, motivations, aspirations, and political preconceptions (p.208). They also create user representations by consulting with potential users, researching existing technologies, and drawing on their own knowledge and experience (Akrich,1992, p. 276).

ITax had been hacked to the tune of 44 million Kenyan shillings before I met with the KRA ICT team working on ITax for an interview (roughly 4.4 million US dollars). This created a lot of confusion at KRA as the entire organisation was under a lot of scrutiny within and outside of it. My first visit to the ICT department was to meet Rachel, a local ICT officer working for KRA. When I got there, it seemed as if they were frantically trying to resolve the hacking incident. Nothing was confirmed; however, the 
atmosphere was tense. The consultants from the Indian ICT company, TATA group declined to grant me an interview, however they did propose talking to the local technicians. Rachel had refused to meet up elsewhere; probably as explained to me by Charles that due to the hacking incident as well as other incidents that involved KRA agents, staff were often weary with researchers as well as journalists as they were seen as spies.

There seemed to exist a hierarchy between the local and international consultants at the ICT department. As I approached Rachel, I could see her looking nervously back and forth at the consultants sitting not too far from her. I asked her in Kiswahili. First, knowing that the consultants from India would not understand what I was saying, if she wanted to meet in another place as I felt that she might be more comfortable being away from the hierarchical atmosphere at the department. Second, I wanted to break ice before the interview because Rachel seemed uncomfortable discussing ITax. She however declined the suggestion of going elsewhere arguing that she was very busy. We started the interview by discussing ITax and its predecessor ITMS. Rachel stated that ITMS had failed to deliver on the KRA's needs. According to her, "ITMS.... was seen to be problematic by both taxpayers and the KRA". Rachel gave a different understanding of ITax from Charles. Charles was under the impression that ITax was another version of ITMS made to look "new". However, Rachel's arguments were in line with the ICT expert interviewed later in this chapter. She clarified that ITMS was the older system that was developed by Chilean developers, whereas ITax was developed by the TATA group from India. There seemed to be uncertainty with regards to expertise on ITax as Rachel stated that she worked on tasks delegated by KRA. Rachel reiterated Charles' statements that ITMS was neither popular among taxpayers nor the KRA.

The challenges were many: administrative, financial, and technical. Administratively, the challenges included inadequate expertise on the local tax structures by the implementing team. KRA employees also rejected ITMS for several reasons (Ndombi, 2012). The employees were used to the old ways of doing things. Furthermore, there was a lack of commitment from management, which resulted in a longer implementation period. Lack of alignment of the KRA function-based structure to an integrated process structure suitable for the implementation of the ITMS also paused as a challenge. Due to the lack of proper procedures for giving and receiving 
(Ndombi,2012) feedback to both management and stakeholders, feedback was not shared meaning some challenges were not addressed because there was a lack of proper communication channels.

ITMS system was also not well adapted to the Kenyan tax structures, and it was difficult to make the system reflect the changes that were culturally appropriate. The culturally appropriate changes included using both national languages (Kiswahili and English) in ITax as well as not making it mandatory as the technical infrastructures are unable to fully support the shift. Technically, taxpayers found the platform to be complex because despite automation, taxpayers were still required to hand in the returns in person, thus the infamous long line at the revenue authority as described at the introduction in chapter one.

Financially, the team at the KRA which had been working with ITMS did not necessarily have the required ICT skills to develop an e-filing platform prompting them to outsource its maintenance which was not only costly but also time consuming. The challenge here was "acquiring the software, which was varied and expensive. Moreover, the cost of hiring scarce system designers was costly as they charged exorbitant fees. Training of the implementers and training of all the users and undertaking the tedious and procurement processes was also expensive" (Ndombi,2012,18-19).

Rachel also stated that ITMS limited the digital interactions between the taxpayers and the tax administration as it was not an interactive system. However, while this might have been the promise of ITax, the lines at the service centres and the use of mediators with ITax's use indicate that ITax was as well limited as most taxpayers had to find mediators to intervene on their behalf. For example, I followed Nancy, my interlocutor, as she tried to comply with penalties that she received as the owner of a business company. She had consulted a tax consultant who made mistakes while filing her returns. While trying to rectify this, she had to go to the headquarters physically as she was informed that the system could not report the problem they had been facing digitally. What this meant was that they had to go to the KRA service center in person and get assistance. Another example was experienced by an ICT researcher who even had a laptop in her bag as she stood in line at a service center (see chapter 5). She was unable to get her filings done and had to resort to standing in the same lines 
that Kenyans had been promised would be a thing of the past when ITax was introduced.

According to Rachel, KRA had learnt its lessons from ITMS on what type of system they would need thereby creating a "modern and interactive system that would simplify tax filing". This was because the Chilean developers left with ITMS and their experiences. She explained that KRA had to develop a new platform, however there were some modules from ITMS that were left behind that included taxpayer's information. This is because the models as adopted and proposed by Behrends et al (2014), do not travel on their own, rather they travel as blueprints. The blueprints are however too general and require to be made to fit the local realities. As shown in this dissertation, failure to do so creates unintended consequences see (chapter five and six). E-filing models rely on their technical developers like TATA to modify and adjust the system to suit the Kenyan tax realities. When such agencies leave however, they leave with their systems like in the case of ITMS.

Rachel helped TATA troubleshoot and maintain ITax and was confident that the local ICT team would be able to take over maintaining ITax when TATA leaves. She is part of the KRA ICT team that has been working closely with the TATA group consultants. She mentioned that TATA were still in charge of ITax front and back office however they worked with them to either troubleshoot or even adjust the system. With regards to the local ICT technicians taking over the maintenance of ITax, TATA was under contract to upgrade and maintain ITax. The knowledge of how ITax was limited to the international consultants making them critical in its development and maintenance. According to Daniels (2017) information is a vital component of the innovation process and is essential to its circulation and utilization. Understanding how technology works is critical for innovators since it determines whether their ideas will succeed.

The lack of awareness on ITax's program codes and technical information on how it works among local ICT officers like Rachel may limit their ability to maintain it once TATA's contract expires. As restated by Philip, an ICT expert, ITax would probably get replaced with another system. Rachels stated that the ability to maintain ITax after TATA could be determined by her roles at the KRA ICT department during my fieldwork. As mentioned, she was tasked in troubleshooting and helping TATA fulfil their tasks. She has not been involved in designing or creating upgrades of ITax. How then would she take over from TATA if she was not doing so during this research? 
Rachels understanding of ITax's inscriptions was that it was developed to help KRA fulfil its mandate. ITax was developed based on KRA input and recommendations. Rachel also mentioned that ITax required technical skills to access however they had created training programs that would allow taxpayers to get these skills. This became clear in this study when ICT experts became the new tax experts due to the ability to use ITax (See chapter five). In the next subsection, we analyse the end user of ITax to understand who it was designed for.

\subsubsection{ITax for Who?}

The ability to include all key stakeholders in the creation, design, and implementation of technological innovations is typically a determining factor in their success. To highlight the diversity of users and the power relations between users and other actors in technological development, feminist sociologists have differentiated between "end users" and "implicated actors (Casper and Clarke,1998). To differentiate between users enables the study to understand technological functionality and whether it can achieve its objectives. End users are often those who are affected by products of technological innovation (Casper and Clarke,1998) while implicated actors are those who are excluded yet affected by the innovations (Oudshoorn and Pinch,2003,6). End users are seen as those who are included in the overall development of the technology. The implicated actors are often not included in any decision making as those who develop and design the technology represent their needs based on their own understandings.

In this case study, I view KRA as being the end user of ITax and taxpayers as implicated actors. Taxpayers according to the CG were supposed to be the end user but through the design and development process, taxpayers were excluded thus becoming implicated actors. KRA on the other hand had inscribed their vision and mission into ITax through their designers ultimately developing a system that works for them thereby becoming the end users of ITax (c. f, Casper and Clarke,1998: 267). Taxpayers and the revenue authority have historically had a power relation with the "taxman" being feared by the taxpayers. Tax policies were seen as oppressive while taxpayers seen as being untrustworthy. Their current relationship is based on these historical structures were coercive and lacked trust. KRA development and adoption 
of ITax was not inclusive of taxpayer's views leading to an e-filing platform that represents KRA needs rather than all the stakeholders.

An understanding of how taxpayers as "implicated actors" may also highlight the importance of inclusive design in technological innovation. As shown in chapter five, taxpayers struggled with using ITax because they felt that it was complex and not attuned to their needs as taxpayers. Who was then the intended user of ITax? Determining the user of ITax allows for an analysis of who ITax was intended for. As explained by Rachel, ITax was developed and designed for the KRA. KRA worked closely with the TATA group on the ITax's design and output. The inscriptions within ITax were developed by KRA with the intention of maximizing revenues. The taxpayers had little input into ITax functionality. As mentioned by Charles, "we can't always trust taxpayers to comply, the ITax makes them comply" and by Rachel, "taxpayers are involved during training". Their attitudes lean more towards the coercive nature of tax administration. Within this system, the revenue authority has little faith in taxpayers' compliance with their procedures, making it difficult to enforce compliance. In the case of ITax, KRA used ITax to digitally enforce compliance at the very early stages of implementation as shown with the example in chapter five of the PIN deactivation.

Taxpayers have been offered ITax training physically at KRA headquarters and according to Rachel, involving taxpayers through training is more beneficial. Taxpayers could register for free for courses given by the ICT department on how to use ITax. Having attended two of those training sessions, I was unable to grasp much as they were a little technical for me. The taxpayers would require having technical skills to understand what was being taught. The trainers were asked several questions and sometimes they would try to see if the taxpayers would give them personal information to determine whether they were compliant or not. The relationship between the KRA and taxpayers would now be defined by the networks created as well as the intermediaries connecting them which in this case would be the tax centres as well as the tax consultants, cybercafé attendants among others (c. f, Callon,1991: 134).

While paying taxes is considered taxpayers responsibility in countries with low service delivery like in Kenya measures like inclusivity in design can help increase compliance. As will be highlighted in chapter five, digitalising tax filings made it cumbersome, time consuming and in some cases costly for taxpayers making them go out of their way to comply going as far as seeking help from mediators. Taxpayers are enrolled into using 
the system that has already been rolled out giving them little or almost no agency to influence how ITax would work (c.f, Callon,1991).

Tax administrations do not necessarily need to include taxpayers in policy making. However, with regards to the use of tax e-platforms, it is key as it will increase compliance if taxpayers are able to understand the process as well as consider it fair (c. f, Kirchler et al.,2006). As a result, taxation is critical in any effort to build nations, particularly in developing and transitional countries (McKercher and Evans, 2009). It also denotes the official method by which a government obtains the resources required to finance effective governance.

Tax compliance is therefore key in increasing revenues despite some arguments that do not call for the inclusion of taxpayers in tax policy design and implementation. For the taxpayer to comply with the law when it comes to digitalisation, there is a need for reciprocal interactions between taxpayer and tax agency. Additionally, the taxpayer must trust in the tax law and fairness of the tax system. Inclusivity will therefore determine the success of a platform like ITax as it will allow taxpayers to have ownership over the process and the product (c.f, Kirchler et al., 2006).

\subsubsection{ITax: Simple?}

Rachel stated that ITax had now become simpler for taxpayers. They were able to use ITax using the following simple steps. She explains:

"You first start by visiting the KRA ITax portal. You then either log on to ITax with your PIN and password or start the process by registering for a PIN. You then click on 'e-Returns' or select 'Returns' from the navigation menu and click on 'File Returns'. When asked to select the type, you enter your taxpayer's PIN and select the Tax obligation applicable to you and click 'Next'. Based on the tax obligation you have selected; it opens the relevant tax form. For example, if you have selected 'VAT' as your tax obligation, it will open the VAT return form. This page will take you through the filling process and will have detailed instructions to file tax returns. The instruction will also have links to download the tax returns form in Excel or ODS format. You will then have to click the relevant link to download the template and save it in your computer. You then 
proceed to fill all applicable areas in the downloaded tax returns form and save your document in your computer. Make sure you enable macros to be able to 'Validate' and Zip your File. Go to the iTax tax return filing page and select the period for which you are filing the returns. Upload the zip file and agree to the terms and conditions by ticking the checkbox. Finally, click 'Submit' button to upload the returns and click 'OK' for the pop-up message 'Do you want to upload the form"' It is not so complicated, she adds,

The process of filing as described by Rachel seemed very far away from the ITax mantra of "simple, swift and secure". The instructions were complicated even for someone not trying to log on to a computer. The instructions were simple if one was e-literate and had the ability to use and access hardware such as a printer, a scanner, and a computer or smartphone. These are however not common features in an average Kenyan home with most of them having to seek assistance to comply. What had however been communicated in the press and in instructions was that Kenyan taxpayers would be able to use this system from the comfort of their own homes. I was left wondering how many people in Kenya had printers, scanners, and computers at home. The issue was not only relevant in Kenya but also in developed countries where all this hardware is not a usual feature in most homes.

The complexity of the process of filing taxes with ITax is highlighted by both software and hardware needed to comply. Therefore, many taxpayers chose to use mediators for filing their taxes (see chapter five). Rachel was under the impression that ITax worked well for taxpayers as the numbers of those registering on ITax had gone up. In 2017, It was estimated that 7.2 million Kenyans had signed on to ITax out of a population of approximately 48.5million Kenyans. Rachel did not know how many Kenyans used it to file their taxes. Forbes (2018) estimated that since ITax was launched, more than 3 million citizens filed their 2017 income tax returns by the June 30,2018 , deadline, up $26 \%$ from the previous year ${ }^{26}$. That 3 million represents $16 \%$ of the total estimated working adult population, up from the $11 \%$ who filed in 2017 . While

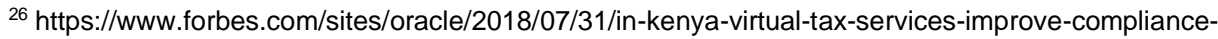
boost-revenue/?sh=5ff82c204b31
} 
3 million filed, 10 million were registered on the platform however not as having taxable financial transactions in that year.

Another issue that causes complexity is the use of English as the digital language in Kenya. The ITax platform among other government e-platforms was only offered in English. This is despite a large majority of Kenyans only speaking Kiswahili, Kenya's other official and national language. Rachel affirmed that the system was developed in English because English was one of the national languages in Kenya as well as the official language of the Kenyan government. The digital language of Kenya was English. The Kiswahili speaker becomes an implicated actor as assumptions are made by KRA of their language capabilities despite research informing that a large majority of Kenyans do not speak English. Many informal workers as well as small scale businessmen speak Kiswahili. They are required to submit tax filings, however in a language they do not speak. Thus, they are forced to do so through mediators. What is even more interesting is that ITax was complex even for the English speakers engaged in my study. It would surely make tax filings even harder for the non-English speakers as in the example given by Brian at the VIP ITax center ${ }^{27}$.

Brian, whom we will also meet in section 4.6, stated that there is an assumption in Nairobi whereby government entities assume that most Kenyans speak English. However, he recalls an incident where an elderly lady needed to register for ITax. They had to help her because she only spoke Kiswahili. This then took a long time because they even helped the taxpayer open an email account, which is a requirement for registering for the tax filing. Translating the technical terms in Kiswahili was difficult and he was sure that the taxpayer did not understand what they had done on the system as they were illiterate. This is yet another illustration of a power relationship between one; citizens and the KRA and on the other hand the illiterate and/or Swahili speaking taxpayers. There were taxpayers who were unable to understand how ITax works or their tax liability; they had to trust KRA at service centres or mediators which

\footnotetext{
27 The World Factbook (2013) states that 26 countries in sub-Saharan Africa use English either as an official language exclusively (like Nigeria and Ghana) or as an official language alongside another African language (like in Kenya or South Africa) (Negash, 2011; World Factbook, 2013). However, English is used for communicative purposes in some 53 out of the 57 countries in Africa. English is therefore considered important in the continent with government as well as innovations in science and technology primarily focusing on English as it makes the transfer of policy as well as models easier.
} 
as shown in the next chapter could cost the taxpayer dearly if they make mistakes. It is important to underline that the taxpayer is still liable for any mistakes made as the taxpayer is responsible for filings their own tax returns.

I had not interviewed non-English speakers but the ITax centres as well as cybercafé mentioned that they had Kiswahili speaking clients who were unable to use the system due to the language barrier. ITax was developed in English creating a barrier between citizens and the state as the services are limited to only those who can speak the language or maybe those who can afford to use an intermediary. What became evident with Rachels explanations was that KRA was relying on its own experiences and expertise to inform ITax's design. It was evident that KRA imagined the user as English speaking and tech savvy.

\subsubsection{Legacy Technology}

A leading Kenyan ICT 'expert', Philip described ITax ICT problems as being several. Firstly, he described it as a legacy technology. In information technology terminology, legacy technology is usually an outdated technology used by businesses (Stevenson and Helmond 2020). According to Stevenson et al. 2020, the issue with legacy systems is that they are difficult or impossible to replace with current technology due to the cost or difficulty of updating. Secondly, there was a fear of change as suggested by Rachel, the ICT officer at KRA. KRA employees resisted ITax as they were accustomed to using its predecessor, ITMS. Philip claimed that it was just a matter of time before ITax would be replaced by yet another platform. The outsourcing of technological advances to international companies has led to numerous discussions regarding innovation and technology transfer.

Developing countries, according to Philip, were normally not seen as generators of new technologies rather those who are receiving legacy technology. Thirdly, according to Philip, ITax had made the corruption easier to track as the systems are digitalised. However, he argues that some of the KRA employees' access ITax with other employees' IDs or with fake profiles making it impossible to track the transactions back to the rogue employees. This meant that the KRA would still be losing revenue through the very channel implemented to increase revenues. Lastly, another important scenario described by Philip was that ITax might have to be replaced with another platform that might or might not incorporate all the information that it now has or lacks. 
According to Philip, 'the Chileans had their own source code; ${ }^{28}$ The Indians have their own. If the Indians leave, they leave with ITax'. The source code is the most important aspect in technology. Ownership of the source code is what matters most according to Philip. TATA, according to him and even Charles, could leave the hardware behind if they left however because they owned the source code to the program ${ }^{29}$ it would make the system worthless. There were many instances where ITax crashed, and it took a long time to get it fixed. Philip explained that this was because the Kenyan ICT counterparts can troubleshoot and respond to some of the issues like taxpayer registration however they are unable to make programming modifications as access to the source code was necessary to make the enhancements. What this meant was that the system belonged to TATA and the revenue authority had to make their modifications through them.

What I found surprising was that there was no discussion about the local technicians taking over the management of the systems. What this meant in practice was that it made the process of enhancement or updating the system tasking. Rachel stated that they were able to troubleshoot and respond to some of the issues however they were unable to make modifications because access to the codes that were necessary to make the enhancements belonged to the developers. The KRA would have to continue using the developers from India to maintain ITax. Charles mentioned that engaging the consultant's costs the KRA millions of shillings yearly in what he felt the Kenyan counterparts could do. Charles stated that involving third parties takes a lot of time which results in lengthy processes when systems have broken down or even when taxpayers need assistance.

\footnotetext{
${ }^{28}$ In computing, source codes any collection of computer instructions, possibly with comments, written using a human-readable programming language, usually as plain text.

${ }^{29}$ ITax would be worthless because source code is the key feature of the technology. The source code is the key component of a computer program. The source code is created by the programmer and can be read and easily understood by a human being. The source code is therefore critical to a system functionality. Without the source code, explains the expert, ITax, would cease to exist. The source code belonged to the developers, the TATA, which meant that the revenue authority would forever rely on the developers for its maintenance.
} 


\subsubsection{ITax: Secure? The hacking incident}

ITax proved not to be secure as promised in its mantra. In 2017, hackers managed to get into the ITax system and transfer funds to their untraceable bank accounts'. KRA lost approximately 40 million dollars (4 billion $\mathrm{KSH}$ ). The incident received global attention with even a colleague in Sweden sending emails while I was on fieldwork alerting me about the incident. This created a lot of interest especially when it became known that it was an international hacking syndicate that had collaborated with some of the KRA ICT officers. The main suspect, a 28-year-old ICT expert who collaborated with KRA employees had been arrested, became very popular on social media with some taxpayers referring to the hacking incident as the taxpayer collecting tax returns. Ken, a taxpayer on twitter wrote: "the KRA never gives any cash tax return refunds. The man just paid himself what was owed to him". This is because ITax scripts were being changed. Scripts are altered and recreated for their specific circumstances after they are produced (Akrich and Latour, 1992).

Taxpayers on social media and through interviews were not shocked at the hacking incident as they believed that ICT experts in the country were able to hack the government system. In a way any system that was seen as foreign would raise interest among local innovators thereby creating a huge hacking potential. ITax as a legacy technology is seen as being outdated making it prone to attacks. Data privacy and safe systems would be the country's most pressing concerns with the technological platforms they choose to employ. Hackers, he argues, can penetrate systems that have older codes or even codes that are replicated in several countries. He recommends developing software that can only be used within the country.

\subsection{ITax Swift}

The last part of this chapter deals with different service centres established by KRA to serve taxpayers to deliver their promise as being swift with tax filings. My research, on the other hand, was able to determine the objectives for different types of taxpayers. ITax promise making tax filing swift was observed in this study as being conditional. Different centres by KRA offered different services to taxpayers based on their socioeconomic status. What this meant is that the issues of "customer centric" were reserved to those as seen as contributing more taxes than the other groups. The centres observed were situated in business centres, however, catering to those who 
were more formal. On the other hand, those who were seen as informal taxpayers were offered services through what was described as "tax clinics". As suggested by its names they are temporary centres that are often unmanned prompting the taxpayers in those areas to seek assistance with mediators based on what they can afford. I describe two service centres that were established by the KRA to support taxpayers navigate ITax and how this led to the creation of differential treatment based on assumptions of taxpayer's contributions.

\subsubsection{VIP tax filing: ITax Service centres}

The KRA set up iTax Support Centres in major cities in Kenya to help taxpayers apply for taxpayer personal identity number, file tax returns and make enquiries. The centres were rolled out shortly after ITax had been introduced as an incentive for making filings easier and more convenient for taxpayers. I visited different ITax service centres as I was told they catered to different clientele.

Figure 4: ITax center

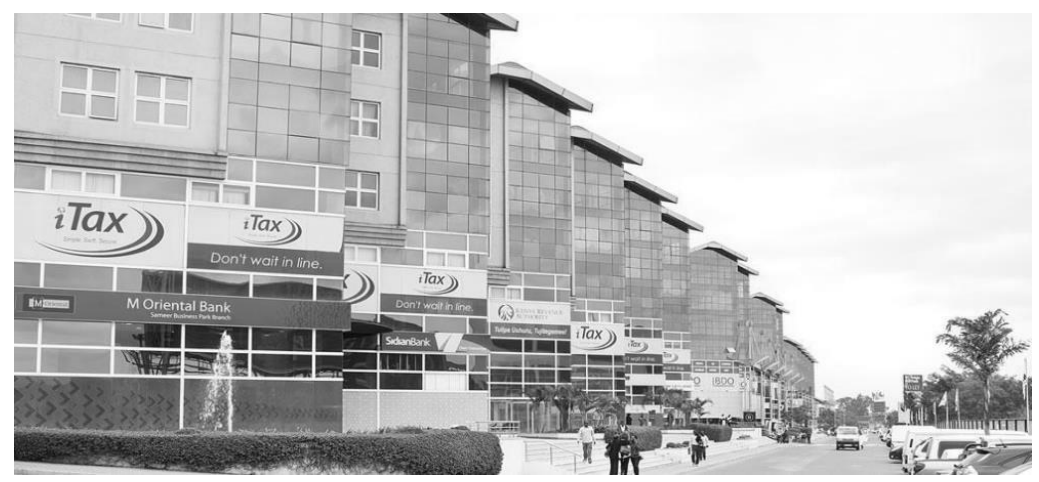

SOURCE: HTTP://SAMEER-GROUP.COM/

This ITax centre was strategically located in an affluent business center. The KRA was targeting clients and their employees who worked in this large business park. Their presence here was meant to ease tax administration for the taxpayer. It catered mainly to corporate and multinational businesses. The Business Park, known as Sameer Park, is known as a strategic location for businesses. I got there early in the morning as I wanted to see whether the famous queues during filing season had been 
eliminated from the city centre to centres outside the city. There was no line-up as indicated by the picture above. The taxpayer is advised "Don't wait in line". This ITax center was almost empty with maybe three of four taxpayers waiting to be served. The taxpayers were sitting on comfortable chairs waiting for their turn. This ITax centre seemed much friendlier and cosier than the other ITax centres I had visited. There was no barrier between the taxpayer and the tax agent. ${ }^{30}$

Brian, the manager of the center informs me something that I had not heard while conducting my fieldwork at the KRA. He says: 'Our promise is to make tax compliance a delightful experience'. He went on to explain that their motto, "building trust through facilitation" would only be achievable if taxpayers had great experiences. The only queues they experienced were during tax filings season in June. Kenyans, he explained, love to wait until the last day to make their returns and they overwhelm us' he continues 'encourage them to use the ITax however not everyone has access to a computer and the platform when accessed through a smartphone has proven to be problematic'.

I observed how fast they were serving the taxpayers however it was clear that the taxpayers were somewhat IT conversant. This taxpayer's experience was rather different from what I had experienced at Times Towers, the KRA headquarters. One taxpayer I talked to mentioned that previously he had had quite a harsh experience with the KRA employees at their headquarters. He then chose to come here as it was more friendly and professional. He pointed out that this was not the case in the government Huduma centres, nor in other ITax service centres. He owned several businesses making him the ideal client for this ITax as a member of the upper-class group. He also mentioned that most businessmen and women did not want to really struggle with lines and rude KRA employees.

Charles described these centres as offering "VIP" tax filing. Thus did KRA employees have to be more polite and not waste the client's time as these taxpayers were deemed as being very important persons. Brian states that ITax centres are still viewed as an extension of the KRA and only those like the large business who feel like this is well suited for them to see the benefits in utilising the services. Inscriptions allow for

\footnotetext{
${ }^{30}$ There is a law in Kenya that bans taking photographs at public offices. Therefore, a description of the place will have to suffice in this case.
} 
comparison, and for normalized judgments to be made, such as this one by KRA. KRA intervenes on the behalf of interests allowing the system and service to be tailored to support better management." (Chua,1995, 6). Yet what we see here is the stratification of taxpayers based on their contributions. To decentralise ITax services tax centres and tax clinics were established by the KRA. Brian observed that the main goal of decentralization was to support government services to be available to the citizens in their local municipalities. In the next subsection, I describe how the tax clinics differ from the ITax centres.

\subsubsection{Tax Clinics}

Tax clinics were very small, often mobile offices with maybe one or two KRA staff members located in selected areas within the country with an aim of offering tax services. This one that I chose to visit was a unique one. Despite having such high economic activities, it was based in a marginalised and run-down area in the east of Nairobi, Eastleigh. Eastleigh, named during colonial times after a city in England, was inhabited mostly by refugees and small-medium business owners and is a marginalised area. IT is an area that has been neglected by the government with very little government services provided. I went to the clinic on three occasions and twice it was closed and the third time they were experiencing technical issues as their mobile internet device was not working. This meant that they could not offer much help to the taxpayer as the assistance involved logging into the ITax system. The head of the business development in Eastleigh Ahmed, explained why the tax clinics were not working too well. $80 \%$ of the traders in this part of the business centre are registered taxpayers with $30 \%$ of Nairobi's revenues attributed to the business community in this area. The Somali and other related tribes from Kenya's northern region ${ }^{31}$ dominate the business centre. Ahmed said that the business community here did not have a good relationship with the authority because there were claims of extortion.

Ahmed argues that KRA agents try to get businessmen to pay bribes even when they are complying. A language barrier also exists because most of the business owners only speak Somali. Moreover, due to historical injustices done to certain communities

\footnotetext{
${ }^{31}$ Kenya got an influx of Somali refugees during the civil war in Somalia. While many went abroad as refugees some stayed on acquired Kenyan citizenship and created successful business transforming an area that was considered a ghetto to an area that is now considered a business district.
} 
as well as the fact that some residents have refugee status in the country from the neighbouring Somali, creates fear and distrust of authority, including KRA, among the locals. So, the business community came together and asked for support and got the clinic. Although I visited several times, I did not see many businessmen going there for assistance. According to Ahmed, businessmen in this area had started hiring tax consultants preferably from their own tribe mostly Somalis as they dominated this area, because they feel like they would not extort them as much ${ }^{32}$. Although they are economically successful, they feel disconnected to the state making them vulnerable to state authorities. They also paid taxes due to the fear of repercussions by the KRA. The clinic as the name suggests aims to help them overcome this fear, I was however unable to observe anyone coming for actual help. It seems like an empty space that creates a perception of caring.

\subsection{Conclusion}

ITax's mantra is 'simple, swift and secure'. While this might seem mundane and unproblematic, the promises and imaginations it produces makes ITax seem stable. However, unpacking how the ideas within ITax and usage changed as it moved from one actor to the other, it seemed that its implementation did not reflect the mantra as claimed. We have seen that despite certain inscriptions adopted as organisational strategy its interpretation may be problematic, thereby undermining the utility of the strategy. This chapter examined how ITax's inscriptions changed as it moved from one actor to the other within KRA. These findings highlighted the necessity of understanding how ideas are generated and shared inside organizations like the KRA that are transforming and increasing income through new processes. Their visions get embedded into the technology however, this vision gets altered as it moves within different levels of KRA as well as the different centres aimed at helping taxpayers use ITax. It also gets altered by technology and issues of ownership as explained by Philip and Charles.

The representational power of an inscription is related to the amount of information it may carry as well as the level of its objectivity. Scrutinising the inscriptions at the

\footnotetext{
32 There are 42 main tribes in Kenya speaking their own native language in addition to Kiswahili and English. The tribes are from the different groups that are found in other African countries as well.
} 
different levels at KRA helps reveal how organisational visions and missions are embedded within artefacts such as ITax. As explained by Akrich (1992), for inscriptions to be successful, the users need to develop a kind of literacy that is related to the intended use of the technology. The inscription must be aligned to the imagined user. Despite its many claims of "enhancing" customer service, ITax was produced to mainly serve the administration's needs whereby it was envisioned as being a tool for increasing domestic taxes. However, as seen by taxpayers being turned away at Times Towers and systems designed without user viewpoints in their design, the shift is taking place in policy rather than practice.

The idea of transforming KRA into a customer centric organisation did not get embedded in ITax. As shown in this chapter, there exists a gap between the 'inscription' and the 'inscribed models' due to varied understandings of the objectives by those involved in ITax designing and development. The examples given in this chapter showed that most of the transformational projects were able to create a perception of change rather than doing so. Like the posters that had "enhancing customer satisfaction" stamped on them as taxpayers were being away from the queues by a KRA agent. The ideas also change as they travel from the top leadership to people like Charles whose job is to support in implementing ITax.

This chapter revealed how the ideas inscribed within ITax changed as they travelled from one actor to another regardless of whether they were from the same organization or not. ITax's translations by the KRA and TATA as well as the ITax service center officers differed shows how transferring global ideas into local practices is sometimes problematic due to what is 'lost in translation'. This was exemplified by the treatment of the taxpayers at the Times Tower where they were subjected to lines as well as being turned away from being assisted at the headquarters as well as other issues like the use of English as the main language of instruction among other challenges.

The examples also show how KRA centric ITax is. How then would ITax be expected to work well for taxpayers when the ideas within its use were meant to make tax administration matters easier for KRA? The objective shared by the senior management as well as with Charlies changed when it travelled to the developers. The developers were working off a script designed by the KRA where they understood the main objective of ITax as being a platform for making tax filing processes easier 
for taxpayers. This was key in unpacking as it will reveal what ITax's intended user is, the KRA.

To understand how technical objects get translated, we must analyse the between the actual and intended users. To understand the 'world inscribed in the item and the world described' by its displacement, we must constantly move between developers and users (Akrich 1992,209). The imagined users by KRA in this case the taxpayers were unable to use ITax as prescribed by KRA. This is because the system was developed to suit the needs of KRA and not the taxpayers. Taxpayers had to 'descript' ITax based on their own interpretations changing the intended outcomes. According to their translations, they either conform to its script or extract themselves out of it. Using feminist sociological understanding of users, we were able to understand that taxpayers were implicated actors as they were not included in the design of the technology (Casper and Clarke,1998). While it might not be common to involve taxpayers in tax policy design, we have shown in this chapter that with technology it is important to involve the intended user as they might accept or reject the technology if it is not considered suitable (c.f, Casper and Clarke, 1998). The next chapter engages with the taxpayers and their mediators to understand how they descript (translate) ITax based on their needs as well as cultural understandings referred to as the "Kenyan way". 


\section{Chapter Five: Descripting ITax: The Kenyan Way}

"So, they thought they could implement a software that was smarter than Kenyans? Just because Indians designed ITax does not mean that we cannot hack the system. It's the Kenyan way. ${ }^{33}$

The above quoted statement was made on twitter by a group famously known as Kenyans on twitter (KOT). KOT had been reacting to the hacking incident that had made international headlines ${ }^{34}$. The tweet was made by a man who worked in the ICT industry in what seemed like 'bragging'. The hacking incident was seen by KOT as a protest to the outsourcing of ITax development to TATA. KOT was protesting on twitter on the use of foreign consultants by KRA arguing that Kenyan innovators hardly get the opportunity to develop platforms like ITax. The hacking incident was discussed as something that was 'Kenyan' as they viewed themselves as technologically savvy. Another tweet suggested that it would be very 'unkenyan' to be hacked

The use of the "Kenyan way" in this chapter indicates the local and cultural ways of dealing with the complexities arising from ITax implementation and usage. This is because anticipated actors might react differently from what the developers prescribe to them (Fallan, 2008; Akrich, 1992); what Akrich refers to as description. This chapter analysed how various actors in this study descript ITax using expressions such as the 'Kenyan way' as a way of coping with complexities brought about with its rapid implementations and mandatory use of ITax. I connect this idea to cultural intimacy as formulated by Michael Herzfeld (2004). Cultural intimacy as introduced by Herzfeld are those cultural traits that are specific to a certain culture. The rationale inscripted by the policymakers as shown in chapter four interfaces with the local realities including cultural ways of translating ITax. This chapter argues how expressions like the "Kenyan way" allow actors to find innovative ways of coping with changing issues relating to governance. This chapter is presented in the following ways:

Firstly, I introduce a theoretical framework that will help us understand the concept of the Kenyan way. I encountered this saying in many different contexts. It was used

\footnotetext{
33 (My translation)

34 The hacking incident made it to international headlines with leading news channels like Al-Jazeera, CNN and BBC reporting on it - even Swedish headlines (Ericka?).
} 
several times by my interlocutors, by the media, and by the KRA when they made excuses for technical problems with ITax. Thereafter I analyse how KRA used the "Kenyan way" to get taxpayers to comply with ITax in a way creating discord between the international standards that they had signed up for and domestic practices. Secondly, I investigate how taxpayers conform and respond to ITax while making excuses of why they comply in the way that they do. Lastly, I analyse the mediator's way of crafting a space for themselves in this new normal who now must shift towards attaining technical skills to compete for relevance. To illustrate my argument, I present cases from four taxpayers. I will introduce Mary, Nancy, Ayesha and Nyambura. The first three taxpayers were recruited through contacts while on my fieldwork. Nyambura is a blogger whose work I came across during my fieldwork. Their work was insightful in understanding taxpayers' engagements with ITax. I engage as well with tax consultants, cybercafé attendants as well as bloggers to see how ITax has reshaped tax expertise in Kenya.

Mary was an early career professional who had tried using ITax. She however did not feel like she had the right skills to comply. ITax, according to her, was complex, thereby outsourcing her tax filings to her local cybercafe attendant. The next example proved Mary's example was different from Nyambura's experience as she (Nyambura)had the technical skills as well as a laptop. She should have, as the mantra stated, been able to use the platform as promised. She ended up in line at KRA for seven hours showing the system was still complex for her as well. The last example, Nancy, shows how ITax is built upon the existing relationships where she fears using ITax in case she made a mistake. Despite being fined by the KRA because of her tax consultants' mistake, she would rather take another chance with another consultant than going to the KRA for support.

\subsection{Introduction: The Kenyan Way}

The 'Kenyan way' in this dissertation and chapter, is used to understand how Kenyan citizens(taxpayers) are actively involved in creating, adopting, and translating ITax to their needs. The statement of the "Kenyan way" was quite common during my fieldwork. Kenyan taxpayers use this notion to cope with the complexities that are coming their way. According to Herzfeld (2004) 'cultural intimacy' is "the recognition of those aspects of a cultural identity that are considered a source of external 
embarrassment but that nevertheless provide insiders with their assurance of common sociality..." (3). By using the term "creative dissent" he strives to understand how people "can negotiate the terrain of social identity and daily life in the...modern nationstate, and how they can be fiercely patriotic and just as fiercely rebellious at the same time" (91). This usually arises from discrepancies and contradictions between the states intended policies to how people practice it.

In other words, cultural intimacy explains the mutual reproduction of many levels of identity. Using this concept as a departure point, this chapter develops a framework for understanding how the national identity of "being Kenyan" is used ambiguously to cope with the new digital tax practices in Kenya. In some cases, it is seen as a sense of pride, at other times as a source of embarrassment. In the cases described in this chapter it is mostly used as a coping mechanism to situations that are seen as being hopeless like when taxpayers are unfairly fined for filing their taxes wrongly. I thus argue that the 'Kenyan way' can be understood as a form of cultural intimacy and thus will make us understand the implications of implementing ITax.

I first came across this phrase during my fieldwork. At the end of public seminar hosted by the local university regarding taxation and tax fairness in Kenya, an independent tax consultant walked up to me and said "why should the authority care about the impact of their policies on taxpayers...It's the Kenyan way to enforce such policies and not care for the consequences' he affirmed. While I did not pursue his comment right then, he led me to think about how this notion had become a way of dealing with complexities especially within regards to the relationship between the citizen and the state. As argued in chapter four, the consequences of not involving taxpayers into the design of ITax as well as taking their realities into consideration could be considered part of the local culture. I realised that this notion had become an accepted discourse by citizens and in this case, taxpayers to cope with the complexities that were arising from using ITax.

For example, ITax had been having technical issues leading to speculations among taxpayers as to why this was happening. The media reporting on behalf of the KRA blamed the technical issues on the taxpayers. The Star newspaper, quoting an interview with a KRA agent, blamed the taxpayers for filing the 'Kenyan way' arguing 
that, 'Too many people were logged on at the same time. ${ }^{35}$ The argument was that the system was unable to have many taxpayers logged on simultaneously. They urged taxpayers to stop filing at the last minute which was now known as a typical "Kenyan way" of filing. Within the new tax architecture, interactions were now limited to the digital platform making it difficult for both the taxpayer and the authority to rationalise the breakdown of the only digital infrastructure that is expected to facilitate tax services for them. Making excuses for technological challenges revealed a lot about the local culture of taxation (c.f, Mumford, 2002).

The taxpayers in this chapter found "Kenyan ways" to comply with ITax. They used it to show the weird way of doing things which in some ways is viewed as positive and in others as negative and mostly as a coping mechanism. With regards to ITax, it was used to make excuses for the innovative ways taxpayers complied with tax rules either through using a cybercafe or a mediator. Akrich (1992) describes the process of description as one involving translations by the end user based on their needs. KRA, as argued in Chapter four, regarded the "imagined" end-user of ITax as being an English tech-savvy taxpayer based on how ITax was developed and implemented. This was however not representative of the realities on the ground especially with regards to internet connectivity. The Kenya national bureau of statistics (KNBS) estimates that 6.3 per cent of the population are reported to have engaged in internet activities with Nairobi having the highest proportion of internet users at $25.9 \%$ (KNBS,2011). Another survey by the Pew institute in 2018 showed that internet penetration in Kenya is at $38 \%$ (PEW 2018). ${ }^{36}$ In this regard, it shows that the complexities inscripted within its use creates an impediment to the taxpayers who are not IT savvy. This would then translate to taxpayers having to find mediators to comply. While this might seem unproblematic, the lack of proper training in the affordable choices like the cybercafé creates bigger problems than is understood by the taxpayer when they sought for their assistance. The complexity caused by ITax increased the role of mediators even going further to replacing mainstream taxation experts.

\footnotetext{
${ }^{35}$ www.the-star.co.ke/news/2018/06/29/in-usual-last-minute-rush-kenyans-ask-for-more-time-tofile_c1779821 https://techweez.com/2017/08/01/KRA-ITax-pin-profiles-deadline/

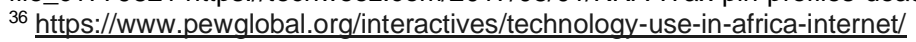


In the next section, I present how the KRA used what was described as the "Kenyan way" of digital enforcement by deactivating taxpayers' personal numbers (PIN). The deactivation was not representative of ITax initial stated aims in its mission and vision. As shown earlier, the objective as described by the CG and the senior managers was that ITax would be user centric and enhance customer experience.

\subsection{The PIN Deactivation Saga}

The KRA cancelled tax personal identifying numbers (PIN) ${ }^{37}$ less than a year after ITax became mandatory. The PIN is a unique number that is used to identify individuals while interacting with the Kenya Revenue Authority among other government agencies, and service providers. The PIN is not however the main identification number used by Kenyan citizens. Each citizen is required by law to attain the taxpayer PIN once they are 18 years old. KRA announced in the national newspapers that taxpayers who were registered on ITax but had not used the system to file their taxes would have their tax identification numbers deactivated. When this happened on the $31^{\text {st }}$ of August 2017, taxpayers found themselves unable to access tax services as well as other government services connected to the tax PIN.

The deactivation shaped tax practices in Kenya as taxpayers were able to see how powerful the KRA was. Data from the KRA had shown that many taxpayers had not migrated to the new ITax platform. Only 5.8 million of the 10.6 million registered taxpayers had signed up for the online ITax platform. Furthermore, many of those who had registered their tax accounts remained dormant. ${ }^{38}$ There were no exact figures of those who had their PINS deactivated but various media reports stated that it had affected approximately 4.8million Kenyans. Kenyan taxpayers were cut off from conducting important transactions that required proof of active registration as a taxpayer after PINs were deregistered. This included registration of land titles, approval of development plans, registration, transfer and licensing of motor vehicles, and registration of business names and companies. Some taxpayers were unable to open bank accounts.

\footnotetext{
${ }^{37}$ https:/KRA.go.ke/en/business/companies-partnerships/companies-partnerships-pintaxes/companies-partnerships-pin-registration

${ }^{38}$ https://www.mwakilishi.com/article/business-news/2017-09-07/-de-activates-thousands-of-noncompliant-pin-numbers
} 
Lawyers and experts in areas of tax opposed the deactivation noting that every taxpayer has a right to the tax PIN and cannot be taken away by anyone without following due process. In the same newspaper article, Nairobi Lawyer, Nashon Aluoka stated that: "the KRA does not issue PINs to citizens as a favour but as provided for in law, in the same way the Department of Registration of Persons issues Identity Cards or Passports". Aluoka wrote that the taxpayer PIN was a key instrument needed to transact life businesses and comply with obligations as Kenyans. He stated that the PIN could only be taken away through the law or a court order. The KRA thus bypassed the law to get taxpayers to deactivate their PINs. The KRA was seen as taking the law into their hands, and this was seen as being very "Kenyan" by my interlocutors. This was the norm as many government institutions in Kenya acted with impulse without following the law. This incident however sparked a lot of controversy regarding privacy as well as the extreme nature of digital enforcement that was ongoing.

Despite the KRA issuing notices on national newspapers and on social media, many taxpayers had felt as though they were caught unaware. Many of whom I interviewed assumed that they were already registered on ITax as it was made to seem quite similar with ITMS. They thought that ITMS had just had a name change. Very little they claimed was done to educate them of the shift to a new system. The KRA shifted the blame to the taxpayers arguing that everyone was liable for digitally registering themselves on ITax. According to Michael Herzfeld (2004) the "national traits' ' or what is known as stereotypes illustrated by sayings like the "stiff upper lip" of the British, allows us to understand how cultural traits have serious effects on our understanding of nationalism and the state of the nation. Blaming taxpayers for technical glitches is used by KRA to stereotype the Kenyan taxpayers as doing things at the last minute, resonating to a widely circulated stereotype on the "African time" where Africans were seen to arrive late and do things late. The KRA had implemented ITax at a time when there was no ICT bill or law to protect citizens rights. Some taxpayers took it further and sued the KRA for the losses they incurred during the deactivation. ${ }^{39}$

\footnotetext{
${ }^{39}$ There was no ICT bill during my fieldwork however it was adopted last year
} 
Two things stood out in this case; Firstly, there were many taxpayers still registered on the older system ITMS ${ }^{40}$ This is because KRA was still using the older database of registered taxpayers. Many Taxpayers interviewed in this study as well as on social media stated that they were unaware that they were not registered on ITax as they assumed that KRA would automatically shift their taxpayer information to the new system. Most of the taxpayers interviewed claimed that they assumed that the system was for the new taxpayers. They assumed that ITMS was an older version of ITax. KRA however stated that they expected taxpayers to register on ITax however the information was unclear. Secondly, the KRA had assumed that all those who had not migrated were non-compliant. Gauging from the media- both print and digital- many were caught unaware. The KRA came under a lot of pressure from the public, and they decided to help solve the crisis. Using the picture below, the KRA responded to the taxpayers' queries concerning the deactivation of their PIN numbers. They wondered why the authority failed to give information beforehand. They described the deactivation as a suspension. 


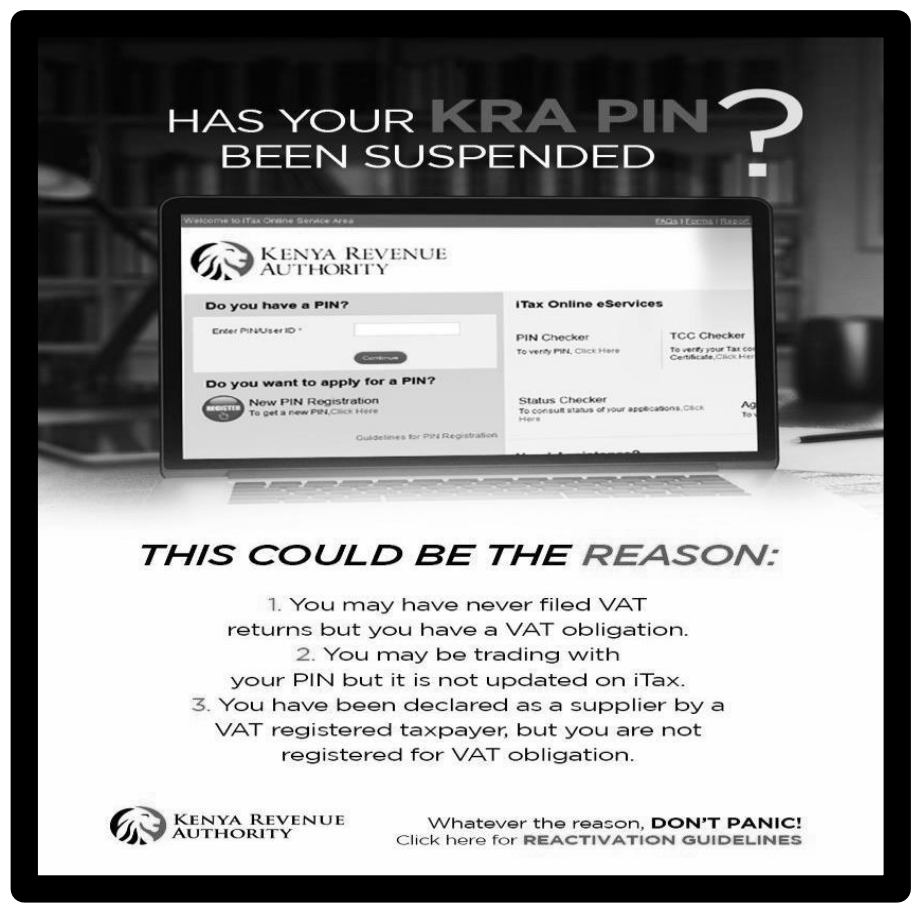

Source: Picture used on KRA social media platforms on Facebook and Twitter

KRA was seen as being "Kenyan" in the deactivation with many of my interlocutors like Nancy describing it as being 'very Kenyan' to use such measures to get citizens to comply. The Kenyan government, according to her, had been using such tactics throughout history in order to get citizens to adapt to their new policies. What was however at stake here was that it affected both taxpayers who had complied and those who had not, and this affected their attitudes towards KRA and ITax. Taxpayers interviewed for this study as well as those reacting to the KRA online campaigns stated that compliance could have been encouraged by civic education, internet literacy as well as setting up free hotspot areas as some felt that they were unable to access the necessary software and hardware needed to comply. Others also felt that The KRA in a way punished them for not adapting to ITax and its rules as rapidly as the implementation had happened. They felt like they were trying to "catch "up to the KRA ever changing policies. 
Charles had advised his 'bosses' at KRA not to implement the deactivation as viewed it as digital enforcement. They had been getting calls from worried taxpayers who claimed that they had done nothing wrong. The incident was spun by the KRA as a 'nudge' to encourage compliance (Thalar and Sunstein,2009). Nudging in tax compliance is aimed at increasing tax compliance because of their assumed effectiveness in raising tax revenue. Nudges are increasingly being embraced by policy makers, including tax policy makers, as they can be used to promote both economic and non-economic goals (Sunstein, 2014:1). The nudging in this case had an opposite effect as it was seen by not only my interlocutors but taxpayers on social media as well as being quite coercive, forceful, and lacking trust in taxpayers to do the right thing. This digital enforcement led to SME businesses to report financial losses while their PIN was deactivated, and they were followingly categorised as noncompliant. ${ }^{41}$ It would seem that the KRA's digitalisation journey that was meant to simplify tax compliance for taxpayers was using historical enforcement strategies.

The insecure relationship between the state and its citizens was shown by the deletion of pin numbers. The deactivation of the pin-numbers revealed the insecure relationship between the government and its citizens. This is another aspect of a "Kenyan way" This is symptomatic of the historical relationship between the taxman and the taxpayer in Kenya. Historically, the colonial tax administration would use extreme measures to get taxpayers to comply (Gardner,2012). People would move to the bushes to avoid the hut or head polls that were enforced. Lack to adhere to the law led to confinement. This was inherited by the "taxman" and is still shaping the relationship between themselves and taxpayers. The confusion was brought about by the shift to ITax. There were many grey zones with regards to ITax's registration and why the taxpayers were not actively using it. Some had only registered to get access to other government services as most youth in Kenya are unemployed as they as studying or unemployed, yet they have a PIN. KRA's cultural way of getting taxpayers to comply was seen as unnecessary and oppressive by taxpayers in this study and on online platforms. In the

\footnotetext{
${ }^{41}$ https://citizentv.co.ke/business/KRAthe KRAKRA-to-deactivate-pins-not-itax-system-to-boostcompliance-171949/
} 
next part we analyse how, taxpayers were grappling with several issues with regards to ITax the PIN deactivation included.

\subsection{The ways of Kenyan Taxpayers}

Figure 6: Taxpayers standing in Line at ITax support center

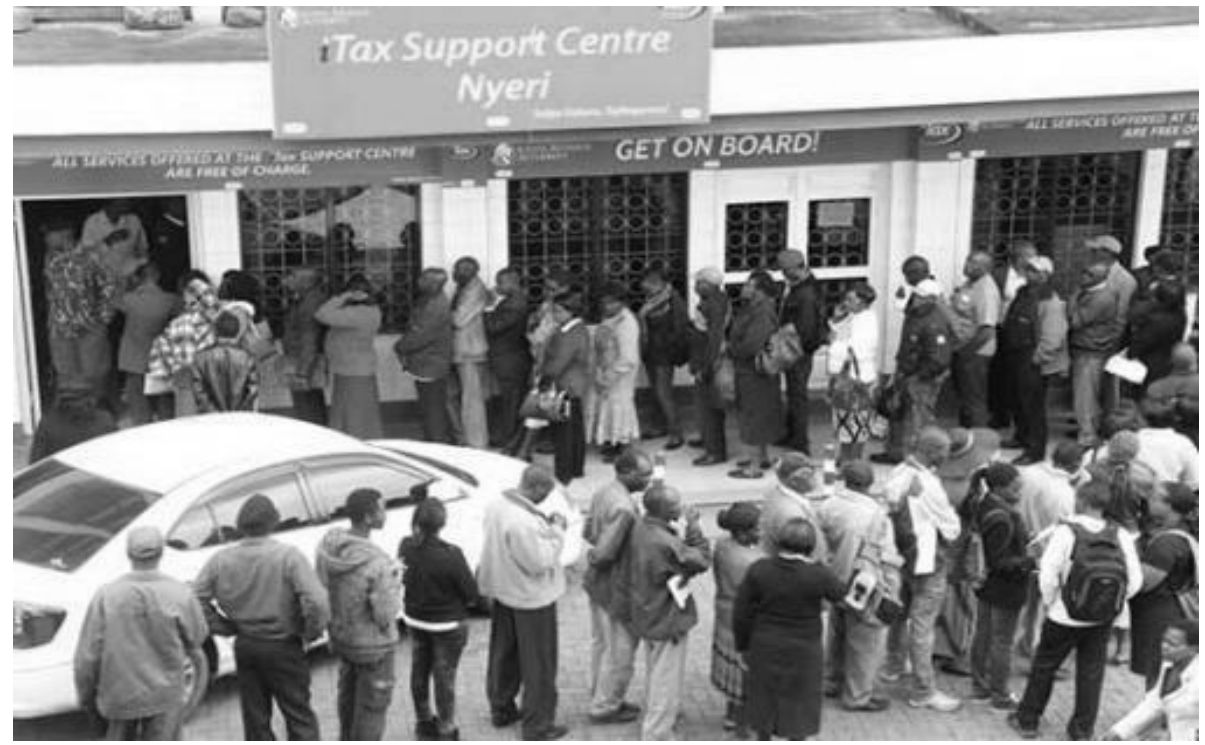

Source: www.dailynation.co.ke $\mathrm{4}^{42}$

The Kenyan newspaper, the Daily Nation, reported that new tax centres have been established in Kenya. Kenyans in Nyeri, a small town approximately $200 \mathrm{~km}$ from Nairobi, waited in line for hours hoping to make the tax returns deadline. Using the picture above of people standing in line, something that was promised would be a thing of the past, they encourage taxpayers to take advantage of the tax support centres. It seems the lines had now reappeared in the small towns. Once such queues are removed from major towns they seem not to exist, but the newspaper article shows that the queues have now become decentralized and delocalized. The newspaper goes on to explain that ITax had malfunctioned leaving Kenyans unable to file their returns on time. A KRA employee interviewed by the newspaper blamed the

\footnotetext{
42 https://www.kenyans.co.ke/news/49902-guide-filing-kra-tax-returns-itax-2020
} 
malfunction on taxpayers' last-minute filings. The technology was made to seem as flawless by shifting blame to the taxpayer. He said that it was the Kenyan way of doing things that jammed the system.

Charles' description of the manual tax process indicated that it was linear, but also cumbersome, and tedious. He claimed that it was such a tasking process which ITax had now solved. He said: "A Nil file [manually] should be a fast process. But it takes about two hours in total because of the security checks at Times Towers. A full return would take an hour to get records from the taxpayer system and if filed on the last day, it would be more than 6 hours of lining up outside Times Tower. Then wait for approximately three months for the return to be captured in the system. With ITax, however, it means no visit to the KRA office is necessary, and a shorter time to file. For example, a NIL ${ }^{43}$ filing would take a minute and can be done on the phone. Returns are also received immediately, and one can view and amend almost promptly".

His understanding of ITax imagined a user who was tech savvy. As much as I had sometimes agreed with some of his statements, his views of how ITax has simplified tax practices were mainly based on his own experiences since he was an expert when it came to tech and knew ITax from the inside out. There was absolutely no one who I met who was able to file any returns in a minute. While Charles might have just been discussing the point figuratively it was precisely this view about ITax's simplicity that made it very difficult for taxpayers to comply. The developers of ITax had in the initial phases promised to create an ITax web application (APP). However, during my fieldwork, I was informed that it was not in their plans. ${ }^{44}$ Implementation had also become costlier than anticipated, changing their original vision for ITax. Taxpayers were still encouraged by the KRA to use their phones when using ITax. In practice this would only work if you owned a smart phone which was reiterated by Charles as he tries to show me how 'simple' and 'swift' ITax really is by taking out his iPhone and logging on to www.itax.kra.co.ke. According to this demonstration, the imagined Kenyan taxpayer was tech-savvy and owned a smartphone or computer. The assumptions made here were based on the Kenyan taxpayer either residing in the

\footnotetext{
43 This is a filing that is done when the taxpayer has nothing to declare.

44 This statement was made by an ICT officer at the KRA
} 
capital city Nairobi or other urban cities. However as will be shown in this chapter techsavvy taxpayers residing in Nairobi were unable to use ITax as well. The culture here is therefore developing policies and interventions based on a very small population with the hope that the citizens will eventually conform to it or use mediators as is the case with ITax. When asked about mediators, Charles did not see anything wrong with that, arguing that it was very "Kenyan" to use "middleman when trying to deal with any government institution. In the next section, I introduce Mary, a taxpayer who felt like ITax made her feel incompetent as the new skills required were according to her too complex.

\subsubsection{Mary: "Digital on the Outside, Manual on the Inside!"}

“ITax makes me feel Stupid!" exclaimed Mary. Charles and I met Mary while having lunch at a popular local restaurant near Times Tower. Mary, who knew Charles, made the remarks when she realized I was researching ITax. Of all the comments I had heard about ITax, this was probably the one that perplexed me the most. How could ITax make her feel stupid, I thought? Was she perhaps suggesting that ITax has made her feel incompetent or disempowered? Mary goes on to explain that ITax seems "digital on the outside, manual on the inside " she argued adding that the old was made to look new. According to her, she tried using ITax and she just concluded that ITax was not developed for her despite her having some technical/digital skills. She commented that she was able to use computers however ITax required more skills than she had. She was not willing to learn ITax because she felt that it was time consuming." Why should I waste my time when I can get a friend or my cyber "guy" to help me? She wondered.

Mary's understanding of ITax was based on her own experiences as she had tried to use ITax and failed. An important aspect of descripting technology is users' reactions to the new platforms like ITax. Mary's example shows that her understanding and perceptions of ITax has influenced her self-efficacy crucial for the translation of ITax for her e-filing purposes. Self-efficacy according to Bandura and Wood (1989) is "beliefs in one's capabilities to mobilize the motivation, cognitive resources and courses of action needed to meet situational demands" (Bandura and Wood 1989, p. 506). Lack of self-efficacy like Mary's case as well as her experiences with the corrupt tax agents influenced her perceptions and willingness to use ITax contrary to what the platform had promised to deliver to taxpayers. Evoking of anxious or emotional 
reactions regarding an ICT platform results in lower intention of using any given system (Compeau and Higgins, 1995).

Akrich argues that the users' reactions become the main factor in shaping the use of the technology. According to Akrich (1992), the process of inscription is "an attempt to predetermine the settings that users are asked to imagine for a particular piece of technology and the prescriptions that accompany it"(Akrich,1992: 208). Mary compared using ITax as climbing a mountain without the proper equipment "you start out willing to do the task however you fail as eventually the system is built for those who have the right equipment". A certain level of expertise is needed in-order to use the ITax system. During my fieldwork at the KRA, I partook in ITax training given by ICT officers. They were too advanced for me included despite being fairly tech-savvy. Mary was aware of the training; she was still adamant in seeking any help offered by the KRA. She felt that it was quite tasking and asked, "Is there anyone who wants to go and stand in line at the KRA when I have options of using the cyber "guy"?

Many taxpayers like Mary opt to get a mediator involved because they had been doing this in the past with the ITMS and doing it now because ITax was not as digital and as straightforward as they were made to believe by KRA. How could ITax achieve its target objective of increasing revenues and achieving sustainable development when taxpayers like Mary feel resentment towards the system? Mary complied with ITax as several government services were connected to the PIN. Her work also required her to have a compliance certificate. However, she says that her compliance is the bare minimum. "Her cyber guy" knows how to go around the system to allow you to get your PIN activated. There existed a culture where the cyber attendant understood that most taxpayers are unable to pay what is required of them. They therefore find a way to go around the system and help taxpayers comply. I was also made aware that some of the cyber cafes had connections to KRA who helped them go around the system. Mary was asked to pay a minimal fee and file nil returns. The nil filings were normally filed by those who did not have any financial transactions either during that month or the year. Mary justified not filing the right taxes by arguing that she paid for her own health insurance among other services that the government does not offer.

Taking Mary's insights would be therefore key in understanding why ITax had not managed to increase compliance when the KRA deactivated tax pin-numbers. Mary 
had negative perceptions of the KRA, among other things based on several public scandals involving corruption and the famous hacking incident. She was unwilling therefore to pay the taxes that were owed as she felt that this money would be misappropriated. She also felt that she was unable to understand the use of the system as required making her rely on her "cyber-guy". In most urban neighbourhoods in Kenya, cybercafés have since the arrival of the internet in Kenya, played an important role offering computer related services especially with regards to internet surfing and printing as these were considered very costly initially. Despite some Kenyans getting access to the internet at work and even at their homes when the internet became more affordable, the relevance of cybercafe remained as it served a large majority of those who were unable to afford access. This became even more evident with the recent shift to digitalisation. Cybercafes have become a cornerstone with citizens looking to them for expertise as well as convenience with complying with rules especially within taxation. The cybercafe attendant usually lives in the neighbour and is well known around the neighbourhood. the KRA officials recognised this offering them training on ITax.

Many like Mary show a lot of trust on "their cyber guy" even sharing their passwords to their e-government accounts with them. The e-government account known as ecitizen had many platforms on it like to apply for a birth certificate, drivers' licence, even the Tax PIN. Mary goes on to explain why she felt that the system made her stupid: "Applying for the PIN is not a difficult task, when you are done with this, the lengthy process awaits you! Download this, print this, upload this? How can I do this at home?" Whenever she explained the process, she looked at me and asked whether I had attempted to use ITax. Mary wondered why I was surprised that ITax was complicated $^{45}$. It seemed that the idea of ITax being complicated should be almost common sense to me according to Mary like many Kenyans have accepted it as such. They had even turned to mediators as a solution as this was seen as a "Kenyan thing"

\footnotetext{
45 I informed her that I did not have to file it myself as I am not a Kenyan citizen, nor did I work in the country.
} 
to do. ${ }^{46}$ Here, reaching out to KRA and giving feedback was not seen as being fruitful as most of my interlocutors were not convinced that it would help the situation.

During a recent visit to the KRA, I shared Mary's experience with some of the KRA employees to understand what the KRA was doing about the complexity that had not only come up from Mary's story but also from many other interlocutors I had spoken to. The KRA officers remarked: "there are very few people here (pointing at the ceiling of the KRA) including the developers of the system who actually know how to use ITax". Charles who was witness to this conversation did not dispute nor add to anything that was said. In a way he neither agreed, nor denied allegations made. Was ITax also too complex for the KRA employees, perhaps underscoring that it was a model that was externally developed and supported?

Akrich (1992) states that "scripts" define a framework of action together with the actors and the space in which they are supposed to act" (Akrich,1992: 208). My informant's remarks show that ITax's complexity was caused not only by lack of taxpayer's ability to descript ITax but a problem with inscripting ITax as neither the KRA nor TATA designers included the taxpayers in their development and designing of the ITax (see chapter four). This would have helped mitigate the complexities that arose as in Mary's case. Akrich (1992) stated that reject the script when they feel like they do not understand its use. Technological artefacts like ITax can consequently create new "geographies of responsibilities", where competencies or actions are distributed according to the script inscribed in the technology (Akrich,1992: 207-208). What Mary experienced is that the system seemed digital however analogue in the way it functioned. Her experience was that it was not digital when she logged on to ITax it used components like the Microsoft excel functions as had been done previously within the manual way of filing. The Kenyan way of filing in this case is to create a perception of digitalised tax filing while features from the older systems of filing taxes. In the next section, I introduce a tech-savvy taxpayer, Dr Nyambura. She, unlike Mary, is technologically capable of using ITax, giving us another insight. She blogs on e- 
governance in Kenya. I analyse whether having technical understanding of ITax enables taxpayers like Dr. Nyambura to use ITax as promised by KRA.

\subsubsection{The Tech-Savvy Taxpayers}

As imagined by KRA Kenyan taxpayers are Tech savvy. The example below shows Nyambura, a Kenyan researcher on e-governance who tried using ITax. Despite considering herself a tech savvy taxpayer her experience with the system was challenging. Nyambura's blog caught my eye when researching my fieldwork. She wrote a blog based on her experience from standing in line at the KRA service center for hours which resulted in a blog post titled 'the 7-hour itch, diary of a Kenyan citizen'. Nyambura describes herself in the blog as being an IT savvy scholar. However, despite this and even having a laptop in her bag, which the KRA had promised she would be able to use, she had to stand in line for seven hours. It was not like within 'minutes' as promised by the KRA in the newspaper article cited in chapter one. She ended up giving as she explains below.

She argues:

'Several times in several days and from several locations within Nairobi, I tried to log on to the ITax platform in vain. Each time I tried, my screen would scream,' The site cannot open! ...Finally, I gave up and admitted defeat. I, an IT savvy scholar, am going to ask a nice steward to help me fill in my tax returns in a Huduma Centre ${ }^{47}$ Next Thursday morning I walk into a Huduma centre. There is a very long security check and a female security guard check into my handbag; she smiles when she sees my safely hidden laptop. Is she laughing at me, wondering why I can't simply use it and be one less from the queue? I am given a ticket with the number 250.At 1800hrs, seven hours later; I leave the counter and head towards the door, a lot on my mind. What day this was! What kind of service is this? What was that Ksh100? What is this deficit 48 Ironically, her research focuses on how platforms like ITax work. Nyambura's blog was part of a research series known as "Making All Voices Count". She was investigating

\footnotetext{
${ }^{47}$ state-run centers offering support with Kenya's new e-governance services.

${ }^{48}$ https://www.makingallvoicescount.org/blog/the-7-hour-itch-diary-of-a-kenyan-ecitizen/
} 
whether Kenya's new e-government platforms had enhanced citizen involvement with the government. Her example as well as Mary's show that the transition from manual to automatic was not as simple and swift as described in the KRA public discourse for ITax. Nyambura's experiences were not only academic but personal as she was trying to use ITax to file her taxes. What she experienced then shows how ITax is complicated even for technological savvy taxpayers. Most of the user manuals are displayed on YouTube, implying that their 'projected' user is a tech savvy person. However, it did not matter in this case as Nyambura considered herself a tech-savvy taxpayer. Nyambura concludes: 'I can't simply use it, I was given a ticket, I gave up, and I left the counter'. Nyambura, like Mary, is frustrated with the ITax system.

During my fieldwork there had been several comments about giving up on ITax and seeking help. Many taxpayers felt that the system was not really helping them, and neither were the service centres that were supposed to make ITax simpler, swifter and more secure. The process became complex for taxpayers who now must go through an assemblage of brokers like the cyber cafés and the tax consultants to comply. The research series concluded that the transitioning to digital government must be more inclusive in its design as citizens regardless of their technical abilities are unable to independently access the platform as in Nyambura's case.

The irony in Nyambura's case is that she had a laptop in her bag that she could not use despite the promises made by KRA. Unlike Mary, Nyambura braved the lines to get help only to give up seven hours later. These insights allow us to understand the imagined ITax user as illustrated in chapter four even if tech-savvy, English speakers are unable to use it. ITax was developed as an agency centric tool working well for KRA and not taxpayers regardless of their technical abilities. ITax was developed by ICT officers and its compliance would need a higher level of technical ability, preferably a taxpayer who has a background in ICT.

Designers anticipate the interests, expertise, and behaviour of their imagined users during the design phase, according to Akrich and Latour (1992). These representations are materialized in the technology's design, which includes the scripts or scenarios that shape its application. Nyambura's case highlights the knowledge needed to descript ITax into practical usage. According to Philip in Chapter four, the new tax expertise is now among IT technicians as the systems were developed by 
them and it makes them an important part of this new tax architecture. When taxpayers like Nyambura are unable to use ITax they turn to tax mediators who are mostly within the ICT sector. In the next section, I introduce Nancy, a taxpayer that turns to mediators as she is unable to use ITax.

\subsubsection{Nancy, The entrepreneur}

Another businesswoman, Nancy, is also quite tech-savvy, she owns a successful business selling clothes and shoes in Nairobi. Nancy had been using a tax consultant as many small medium enterprises (SME) prefer to. She had been filing her taxes ever since ITMS, the earlier version of ITax through her tax consultant. Nancy's choice of using tax consultants was because of advice she had received advice from friends with bad experiences while trying to engage with KRA directly. She had personally run into problems when her consultant filed her taxes wrongly. Not having the tax knowledge to understand how the taxes were filed as she had received a certificate of compliance. The certificate did not outline the process of filing; it only acknowledged that she had complied. The picture below was used to give taxpayers an example of how the tax compliance certificate is supposed to look like. 
Figure 7: Example of KRA Tax Compliance Certificate

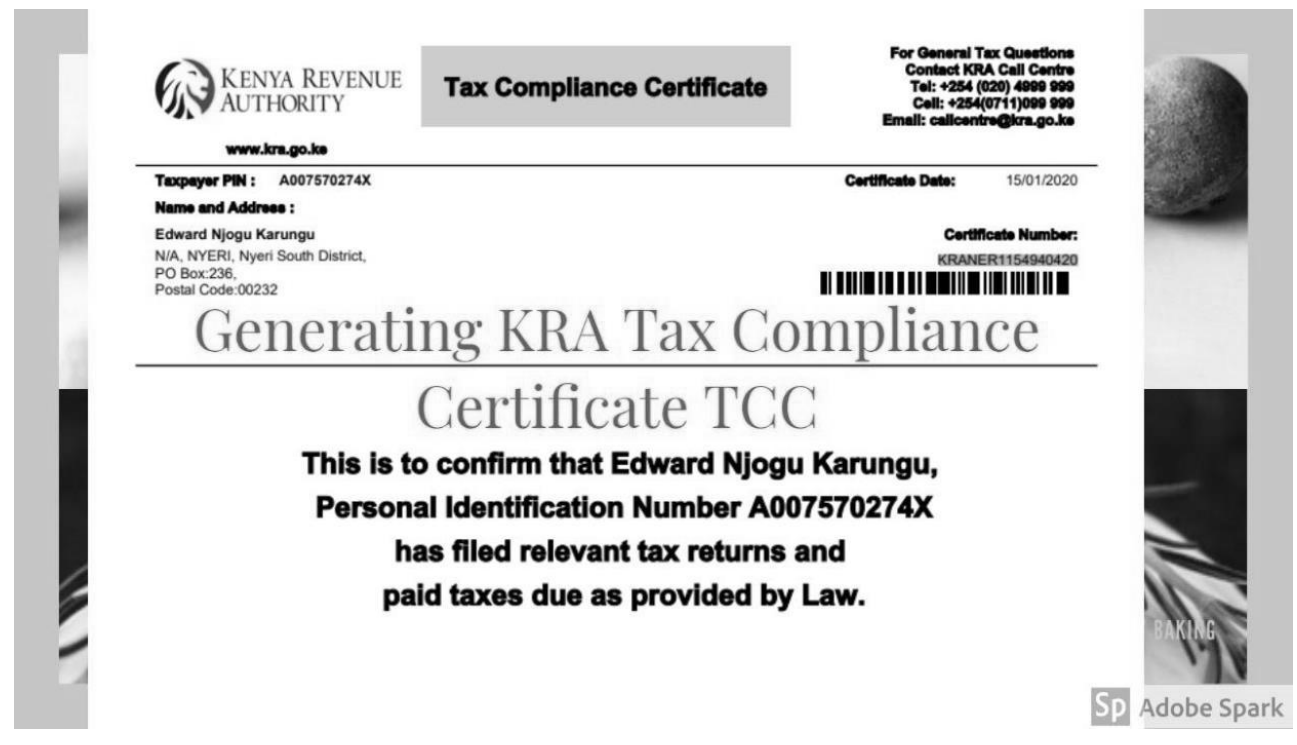

\section{SOURCE: WWW.KRA.CO.KE}

As shown above the information given to taxpayers by their tax consultants do not include any processes of how their taxes were filed. The taxpayers like Nancy trust their tax consultants to ensure that they are complaint however they are unable to understand the technical aspects of it. Like Nancy, taxpayers are interested in the certificate above as this allows them to access government services as well as others like opening a bank account. Her tax consultant had registered her businesses on a wrong tax bracket on intended for large businesses. She was then fined as she had not paid the right amount of Value Added Tax (VAT) as her registration showed that she owned a large corporation and not an SME as was the case.

Nancy, looking rather upset when we discussed it, remembers that it cost her a lot of money to get the mistake rectified. She not only paid the fine, but she had to bribe some officials as they had demanded to make the case go away or become even bigger. When asked if she had tried to rectify the wrong registration on ITax she became amused at the question. She argues that ITax is not as simple and straightforward as many are made to believe". There are certain things you can do on ITax, but most tax issues, especially wrong registrations like in her case, must be dealt with by KRA directly", she adds. 
This was different from what KRA officials had told me in the previous chapter. Not only was ITax according to them customer centric but they claimed that it would serve all filing purposes reducing interactions between the taxpayers and KRA. ITax was supposed to also reduce corruption as well as increase efficiency Nancy had however been trying for over two years trying to rectify the mistake as well as pay hefty fees and bribes to rectify the mistake. She had been fined a sum of $250,000 \mathrm{KSH}(25000$ SEK). She realised that despite using mediators, taxpayers were still at the mercy of KRA and mediators. Complying with the tax practices in Kenya were not according to Nancy based on the law rather on luck. Nancy believed that KRA failed her miserably and penalised for issues that she had been trying to resolve. She was willing to comply voluntarily however KRA did not trust that her consultant made a mistake. She was held liable for her online activities. This drastically reduced her ideas of taxation and states that she complies only to get the certificate as her work dictates it. The tax consultants offering ITax services had not really understood how to use ITax as the rules were new. This led to mistakes like in Nancy's case however not recognised by KRA.

Nancy continued to engage tax consultants instead of seeking help at the KRA as she preferred to deal with them. She did not wish to reinvent the "Kenyan" way of filing taxes that now involved using mediators. Using mediators, according to her, had become a crucial part of filing taxes in Kenya as many did not wish to make any mistakes using the system. Taxpayers also did not wish to directly deal with KRA if they could get a mediator based on what they could afford. "Many of the people who are courageous enough to tackle the KRA first-hand", she argues, "almost always regret why they were so brave ${ }^{49 "}$

Taxpayers believed that visiting the KRA, officers would try to make you pay an extra fine or a bribe as this was the culture in Kenya. Nancy believed "you go to the KRA with one problem, you leave with several". Michael Herzfeld (2004) stated that there are some stereotypes within and outside the nation state that are accepted as the culture like bribing to get government services. Not only is believed to be the norm it is upheld by those unwilling to either stand in line or go through the right channels to get help. The understanding of KRA as a corrupt institution is accepted by taxpayers

\footnotetext{
${ }^{49}$ (My notes).
} 
and KRA as well. Allan in chapter four discussed how they were moving away from this identity but he acknowledged it was not as easy to change culture. Based on Nancy's experiences as well as others in this study, the perception of KRA as being corrupt and not willing to help taxpayers with the complexities that arise from ITax has prompted taxpayers to seek help with mediators.

Taxpayers like Nancy would rather risk getting their taxes filed incorrectly than going to KRA for help. Despite her being wronged by her tax consultant she still did not see the value in suing him as she did not believe in the justice system in Kenya. She tells me to look around and realise that this is Kenya. Most tax consultants according to her, getting out of legal issues easily costing the victim a lot of time and money. Taxpayers like Nancy may play the roles that have been originally intended for them as envisaged by the designers of the ITax however they may resist the intended use - a process called 'de-scription'(Akrich 1992).

Nancy's rejection of the ITax's script was the cultural way of doing things, she explains. Nancy states that she complies at minimum cost and uses the money saved to take care of herself. Compliance here is not as imagined as KRA and paying the minimal required taxes in this case could reduce the actual amount of money required to comply. I inquired where this would put her into trouble with KRA and she stated that she only declared economic activities that involved receipts and were traceable to her. Other transactions that happened in cash or Mpesa would not be declared. She estimated that she only complied with $30 \%$ of what she was required to pay. This was not strange however she argued as this was the way citizens especially entrepreneurs dealt with the issues thrown at them by KRA. This way of complying as understood by taxpayers like Nancy become ingrained in the national identity as the Kenyan taxpaying culture especially among entrepreneurs. This understanding was also expressed when several friends or acquaintances discussed issues relating to institutions like KRA and reached a consensus on their treatment. They share ideas on how to cope with such issues and in the case of Nancy her peers in the business community shared ideas and contacts that could help deal with KRA.

Nancy was determined to stay out of KRAs radar, choosing to pay a tax consultant to help comply. She however mentions that the biggest task her tax consultant has is to find innovative ways for her to avoid paying the 'right' amount of tax. The right amount 
is not what is legally required of her rather the amount that would get her compliance at a minimum like Mary. The best consultants can manipulate the system because most of the time they have someone on the inside who can digitally change your efilings making it 'fairer' for the taxpayer. Nancy felt that business owners were being overcharged which made it fair for them to try and avoid taxes. Taxation according to her was unique as taxpayers received minimal services for the taxes they pay. She agrees to allow me to follow her journey as she tries to rectify the mistake made by her tax consultant.

Nancy hired a female tax consultant explaining to me that female tax consultants are a good fit because they sympathise with women and their plight. She felt that most of the taxpayers who struggle with ITax are women arguing "we women need to stick together". Lydia, her new consultant was a middle-income consultant based on the location of her office. I learnt that tax consultants as with every business operated within their own market. I had been to very high end and low end (cyber cafes) consultants as they had services based on the client's portfolio and budget. Nancy explains that a visit with Lydia is like a visit to her therapist as she takes away all the anxiety caused by ITax. She knew that she was in trouble, but her calmness was attributed to Lydia's assurances.

Nancy had three large files with her all with receipts she was clutching on to in case one of them would magically help her case. Nancy was so busy with the discussions that she forgets to introduce me or explain who I was, and the consultant, maybe used to friends accompanying the clients, did not seem bothered. "Have you been audited the last two years", she asked Nancy? "I see a compliance document, yet I don't see an audit report. Either these guys filed your returns, or they bribed someone". Nancy looks horrified. "Will this have an implication on my case" she asks? The tax consultant asks for her tax pin number and logs on her computer on ITax webpage.

After about 10 minutes of trying to log on, Lydia informs Mary that there isn't much they can do online for correcting the previous errors online. ITax did not allow for correcting such mistakes, she explains. They would have to go to the KRA service centre, pay the arrears and then correct the issue internally. Lydia had contacts at the KRA that could make sure this problem went away. Nancy is then given a list of documents she would need to provide to make the problem go away which included going back to the tax advisors who had gotten them into the mess. Nancy stated that 
she was unable to log on and correct the issue herself as suggested by KRA. Both she and Lydia agreed that correcting any mistakes on ITax was not an option as this was controlled by KRA.

With regards to the PIN deactivation, Nancy's account had been deactivated and both she and her consultant were unable to find out from the system. Calling KRA, according to her, seemed hopeless as many taxpayers were trying to do the same. Nancy stated that "the zebra cannot change its stripes". KRA transforming was still using the historical enforcement tactics. KRA, according to her, were concerned with creating a perception of change which made her disinterested in seeking their help.

Nancy's understanding and experiences of ITax where it was not a system that was fair to her and her situation. She therefore did not wish to engage with either KRA or ITax directly opting to use consultants despite being a tax consultant filing her taxes wrongly causing her to be penalised by KRA. Nancy compliance like Mary's is not voluntary rather driven by other services that are connected to the compliance certificate. Other interlocutors in this study agreed that their motivation was based on fear and not willingness as the services connected to the tax PIN would not be available to them if they were deemed non-compliant on ITax.

Taxpayers like Nancy have bought into the narrative that KRA cannot be trusted. This is based on her experience but what she also describes as the tax culture in Kenya. Taxpayers rely on various actors to get assistance with their tax matters and would rather pay more money as in the case of Nancy than go to KRA for support. KRA developed ITax as a way of making tax filing easy, however, as demonstrated, it became even more costly and complicated. This had drastically reduced compliance as in Nancy's case whereby KRA is seen as non-approachable. The cultural understanding of Nancy and others like her is that KRA is an institution that should be feared due to using coercive measures to get tax compliance. This hinders a healthy relationship between the taxpayers and tax authority whereby a healthy tax culture can be cultivated.

According to Herzfeld (2004), citizens contribute to a country's efficient functioning despite activities that appear to be in direct opposition to one another. Taxpayers like Nancy complied with ITax however their reasons were not as imagined by KRA and international tax policymakers. Taxpayers like Nancy did not comply due to their 
willingness rather because they felt that they had no choice. These inclinations, argues Herzfeld, are important in defining qualities of the national state (2004). In Kenya, citizens find their own ways of complying based on their experiences described by Herzfeld as "social experience" (Hertzfeld,2004).

\subsubsection{Taxpayers at Huduma Service Centres}

The Huduma centres are a negotiation point between the central government and the county government. Huduma means 'service' in Kiswahili, one of Kenya's official languages. Kenya devolved its governance in 2010 giving counties much more autonomy than they had before. The main objective of Huduma centres is to transform public service delivery in Kenya. Such services include passport application, national ID registration and replacement as well as tax services. Taxpayers have options of whether to get tax services at the KRA service centres run and managed by the KRA or at Huduma centre which is the official government e-service center.

The first Huduma centre was opened in November 2013. It is located at a historical post office building called GPO (general post office) constructed in 1907 by the colonial British government. The centre is strategically located in the middle of the city centre next to the largest government office for immigration and citizenship services. It was apparently set up near other governmental offices to ease the public congestion especially during tax return periods. I accompanied my friend Ayesha to this Huduma centre. She was going to apply for a tax compliance certificate requested by her new employer. The certificate is issued by KRA when taxpayers are seen as having complied with their requirements ${ }^{50}$.

Ayesha had warned me that we needed to go early to avoid the long lines. We made it by 8 a.m. and the service centre was not overcrowded yet. We entered and a security guard asked us what service we required. He issued us with an electronic token and showed us where we could sit. It literally took 5 minutes and my friend had finished her errands. The staff from the revenue authority were very friendly and helpful; an experience that shocked my friend. She looked at me and said in Kiswahili: "dunia inaisha", "the world is truly ending". A saying often used in Kenya in situations when

\footnotetext{
50 The certificate is normally required by banks, government institutions and even employers in order as a requirement of government policy to ensure that those who are liable
} 
the unexpected happens. Ayesha argued that this had not been the case before. Historically, the relationship between the citizen and the state in Kenya had been one of an oppressive nature especially with regards to accessing government services (c.f, Mkandawire, 2010)

Once she got her certificate processed, they told her that she would have to log on to her account and print it elsewhere. She hoped that they would print the certificate for her, but they explained that they did not have the resources to do so. She was puzzled as she expected that ITax would make the process easier. She started comparing the process with what she had done previously. "Previously, all one had to do", she explains, "was present all the documents to the counter.... Now there are many actors and sites that are involved". So, although her errand initially started at the Huduma center was handled very quickly, it became complicated as we had to go to several places to get the certificate printed. She was also told that there were some documents that she would need to bring back to the counter once she had printed them. Now one had to not only stand in line and present documents to a counter, but one had to also print and then come back and stand again in line to provide the documents to yet another counter.

As we leave the Huduma centre, the security guard points us to one cybercafé, conveniently located near the Huduma centre to print the certificate. Looking for convenience, Ayesha does not question this recommendation. We head there and enter, yet there we find a line of people waiting to print. The lines had devolved to the cybercafes. I eavesdrop on a conversation and understand that they were sent here to print by the guard at the Huduma centre. With so many cyber cafes in the area one must wonder why this one is recommended. The Kenyan way, which did not surprise me, was that the guard had obvious connections to the cybercafé and would get a small token for his recommendations. This is mostly because of the low wages' security guards earn working in public administration. They then use such moments to make tips just like in the service industry. The taxpayers would fill in their documents electronically then, they have to print them and take them back to the counter.

Ayesha had not previously discussed the process she had gone through before coming to the service center. She had first gone to the cybercafé to get an email account that was required for registration. Ayesha described herself as a tech savvy 
individual however she did not want to use her regular email on her laptop as she did not trust the KRA with her personal details. She mentioned that she normally used cyber cafes to make her returns and everything e-governance because she did not want them hacking her personal data. I was quite surprised at this suspicion seeing that she was entrusting the cybercafé attendant with all her personal information. She believed he was harmless. Many taxpayers during my fieldwork, like my friend, were constantly inquiring why the government needed all their information. All in all, she says that it took her a month before she had managed to submit the documents needed to attain a PIN. Ayesha states that she complies with ITax and KRA regulations as she had no choice as her work demanded that she has a tax compliance certificate. She states: "anything to do with taxes is cumbersome. You do not comply unless you have to".

I start talking in Kiswahili with the young man who serves her at the Cybercafe, and I inquire whether he received training for the e-services he is offering his clients. He tells us he did not require training as he had a background in information technology: "all you need now to make your tax returns is a computer and Internet, everything else and everyone else is irrelevant". The cybercafé attendant seized the opportunity created by the tax administration to create a flourishing business for himself. The taxpayer looked calmer than those I had seen standing in line at the KRA or even at the Huduma center. Here they looked confident as customers the cybercafé had to fulfil their needs. Ayesha pays 100 shillings (approximately a dollar) and gets her tax compliance certificate in numerous copies in case she wants to use them in the future. The cybercafe had helped Ayesha with another document that she needed to get from the KRA. That meant that she did not need to go back again and stand in line. It's now almost 11 a.m. and half the morning is gone, but she tells me that this is the shortest period she has ever used while engaging with the revenue authority.

The process of e-filings seems to involve numerous stops and mediators. Before as explained by my informant one only dealt with the KRA. Now there were several people involved making the taxpayers data vulnerable as well as cumbersome and costly. The cyber cafes are even known to sell information to big data companies with some of my interlocutors telling me that they make a lot of money from this. I wondered whether this had made things easier or harder for Kenyans. Those I interviewed were not really concerned as I was about privacy. They just wanted a simpler process. The 
lines at the Huduma center were quite bearable. However, taxpayers would still need to engage a third party to get their documents printed and uploaded despite going to a government center. These half working solutions are accepted by people as they feel like it's part of the way of doing things in Kenya. No one expects the government to deliver services as would be the case in a developed country.

The interactions taking place between the taxpayers, KRA as well as the other mediators interacting with ITax can be seen as descriptions (Akrich,1992). What we see in these examples are how ITax is being translated by these four women, each in their own way to comply with taxes. a choice they argue that they would avoid paying taxes. But ITax makes it mandatory for them? That is not voluntary compliance, the willingness to comply with the tax rules (Kircher et al.,2006). What they all acknowledge is that there is a Kenyan way of being a taxpayer as well as being a tax administrator that is only representative of the realities of Kenyan tax practices. The examples above also illustrate their cultural intimacy through the ironies, inversions, and paradoxes within their taxpayer engagement with ITax (Herzfeld,2004,109). Like in Mary's case, ITax was seen as having made her stupid. Nancy viewed her new relationship with KRA as one that would not involve any interactions due to the perceived fear that she now bore. According to Herzfeld (2004), divergent groups use rhetoric/images and tropes to defend opposing acts or ideas (109). He argues that the law and the lawless for example resort to the same cliches when acting in opposition with each other. Here I view the "Kenyan way" as a way of justifying the contradictions brought about by ITax.

The "Kenyan way" of being a taxpayer in Kenya is derived from frustrations as well as a lack of solution to the problems that arise when taxpayers are unable to use the system. Corruption as well as lack of taxpayer centric policies are accepted by taxpayers as they have little or no expectation from KRA. Taxpayers would rather go out of their way to find solutions rather than contact KRA for help. Another thing to mention is that the taxpayers in this section were all women. This was not planned as they happened to be the majority of those who struggled with ITax. I had approached several male taxpayers, some made comments about how complicated the process was. However, that was as far as the conversation would go. It was not seen as a problem that affected men as they according to the ICT expert interviewed later in this 
chapter. Men seemed not willing to be identified as not tech-savvy. It seemed like that whether taxpayers had the technical ability, or they were all unable to use ITax. I decided to go through the process of seeking help at the KRA center to see why taxpayers did not want to do this by themselves.

\subsection{Outsourcing ITax, The Kenyan Way}

In this section, I analyse the importance of mediators described as outsourcing by one of my interlocutors. I start with the most used one: cyber cafes and the importance it plays in the lives of taxpayers like Mary whose budget is limited but still must get help from a mediator.

\subsubsection{Cybercafes}

I conducted participant observations in Cybercafés. They have become quite important places for filing tax returns with ITax. Visiting a few around Nairobi city, I compared these to each other and the type of services that were offered. A new dynamic presented itself here. The cybercafé attendants became tax brokers. They would help customers comply with tax returns for a fee. The only difference between themselves and tax consultants was the tax knowledge and connections at the KRA. However, as I observed several times this was not something negative. Taxpayers preferred to use the services available at the Cybercafés because they were easier to locate and way cheaper than the consultants.

I interacted with the cybercafé attendants in the neighbourhood I was living in. The cybercafe attendant Peter had been in this industry for quite long. Peter offered all egovernance services however with regards to ITax services, most of his customers were taxpayers during filing seasons. When I inquired whether this was a lucrative business, he informed me, like Melvin did, that the Kenyan government has really uplifted his life. Before e-governance he would offer IT services like internet or printing services. With the shift to e-governance he has become an important cog in this wheel. He informed that he takes on any training that is offered and makes his customers trust the knowledge that he has acquired, especially within tax law.

Peter described taxpayers as customers who pay to receive tax services. Peter created emails for them and even helped them remember their passwords. I logged on to his computers and regardless of the slow Internet speeds offered here it was still a pleasurable service. Peter helped taxpayers for example navigate all the compliance 
steps involved with using ITax like printing, emailing, scanning, and even uploading documents. I even witnessed him filing on behalf of taxpayers. These local Internet shops have become so popular and central to offering citizens e-services. The KRA had conducted some training for cybercafé owners as well as adjusted some of their policies of one email and one pin because of the tax brokers. One big issue mentioned here is the lack of privacy. In one interview with a senior the KRA iTax officer revealed that they had recently discovered that cyber cafes had used one email to open several iTax accounts. This then impacted the system severely. They had now offered courses to the cybercafé attendants although this was voluntarily. They had then enforced one pin one email policy shutting many emails that had numerous pins attached to it. Peter had however not undergone any training as he was unaware of it until I brought it up. He was however willing to do so if the opportunity was presented.

Another issue is that most of these businesses were not sustainable, often getting bought out by someone new. Cyber cafes could close, leaving with taxpayer's data. Once this email is set up the taxpayer is quite dependent on the cyber cafe attendant to help them. While talking to the head of ITax at the KRA he mentioned that cyber cafes are very useful in closing the infrastructural gap. Most of their clients are illiterate and something as basic as operating an email account is considered complex. Yet it is one of the requirements for using the system. They however countered this problem by now requiring each taxpayer to have an email account that is unique to their identity. The Kenyan way would be that the cyber cafes would most probably still help the taxpayer create this unique email and they would be the ones who still have access to their accounts and their passwords

Men according to the Kenyan culture that is shared almost across the country must be strong and not admit to having the inability to do anything that women especially can. Men also are engaged more with technology than women as even recognised by the United Nations sustainability goals. I met Melvin, a self-declared ITax "whisperer" through a network of ICT specialists specifically made specifically for this research. 


\subsubsection{ICT Tax Experts}

Melvin who looked like he was in his early thirties, owned a blog that helped Kenyans use ITax ${ }^{51}$. We met one early morning. Melvin walked into the coffee shop and came with his laptop bag. When he sat down, he removed the laptop and made sure he was connected to his portable WIFI. Melvin looked "techy" carrying a sophisticated laptop. Melvin starts the meeting by saying "I was told that you met many taxpayers who do find ITax complex? ITax is quite a simple and straightforward system. Many Kenyan taxpayers have a phobia towards technology, and they do not like learning new skills". Melvin opens his laptop to demonstrate this to me. He shows how fast he can go through the modules. What I realised was that not only did he have the software and the hardware to comply he also had really gained a lot of expertise. It almost seemed robotic. It seemed very easy for him in comparison to the taxpayers interviewed in this study who had been struggling.

Melvin says that most of his clients are women because they are either not interested in learning how to use ITax or that they maybe are wired in a way that does not allow them to understand ITax. Women interviewed in this study were willing to share their experiences. Men were both at Huduma center as well as ITax centres however Melvin argues that they are very proud with asking for help especially when it comes to technology. Melvin does not consider himself a tax consultant as he makes it clear that he does not understand the tax rules. He described himself as a tax mediator. $\mathrm{He}$ stated that the helps taxpayers use ITax by either showing them how to file or doing it on their behalf. He however does not take any responsibilities for mistakes made during filing. ITax, he argues, has made him more compliant because he sees that the KRA is trying its best to make the services more available to taxpayers. He described this as "outsourcing".

He can get around the system, but he can't aid taxpayers who are attempting to figure out the tax laws. He said that the KRA had outsourced tax filing, he adds to mediators like him. This increases compliance as well as even creates employment like with his case. Melvin gets paid by his taxpayer clients between 1000 and 5000 shillings (10 and 50 dollars respectively) to help them comply with ITax despite his lack of tax

\footnotetext{
${ }^{51}$ the purpose of protecting his identity I do not disclose the blog as the information he revealed to me that he allowed me to use in this study could cause him some problems with the KRA
} 
knowledge. According to him the business was built on trust and the ability to deliver. His success in this ensured that he was popular among mid-level clients. His clients were able to pay the amount he asked for as he was mobile, and he did not have an office. His computer and internet were, according to him, enough to make him a tax expert.

He can navigate the system but could not help taxpayers trying to comprehend the laws pertaining to tax. The technical complexities posed by ITax made certain individuals like Melvin more competent than others. Here the tax skills were not really required according to Melvin. Mediators can be individuals, professional groups or experts who appropriate a model and relate it to their own understanding of both the model's origin and intention and the situation into which it is supposed to be immersed' (Behrends et al.,2014, b:2; 14). Mediators are individuals, professional groups, or specialists who take a model and relate it to their own understanding of both the model's origin and aim, as well as the circumstance into which it is supposed to be immersed. The role of mediators as central actors 'bridging the interstitial spaces between what we call a model's travel and its local reception' (Behrends et al.,2014, $\mathrm{b}: 14)$. As tax is being digitized so are its experts. The mediators need not necessarily have a background in tax and accounting to offer real time advice on tax matters. Virtual tax consultants, cyber cafes and tax consultants were very popular during my fieldwork.

Men according to Melvin did not pride themselves with not having the ability to use ITax or any other platform. He had male friends who discreetly reached out to him for help. Melvin mentioned that during the filing system he earns a living from helping individual taxpayers as well as multinational companies comply. Melvin managed to get himself trained at the KRA and he trains ICT personnel within MNEs on how to use ITax. He was very specific on the need to have ICT skills to use ITax. For Melvin, ITax has been important in his business as he is able to not only share his skills within his friends' group but also use it to make a living.

\subsubsection{Blogs}

Many blogs are privately owned and are seen as a marketing strategy. They would either get clients this way or get paid by their web host through advertisements. In one of my meetings at the university of Nairobi, I met a gentleman who had made a name 
for himself in the ITax blog world by owning a successful blog hosted on his website www.ushuru.co.ke. The site seemed like a website that the KRA would own because the word ushuru means taxes in Swahili. Andrew made his money from businesses that advertised based on his website based on the popularity of his page. The more hits his website got, the more money he made. He worked on this full time which according to him made him a tax consultant. He was at the seminar trying to recruit tax experts who could enrich the content of the website as he was an ICT not a taxation expert.

ICT experts like Andrew and Melvin had their own websites or YouTube pages that aimed to help taxpayers. They had websites and blogs that guided taxpayers' step by step on how to comply with ITax. They posed queries such as: 'Do you have a pin?... Do you want to apply for a PIN? ...' to get the attention of clients. The websites made sure to mention that the process was easy, however if it were as easy as they claimed, why would they need their help, I thought to myself? The simplicity is undermined by other requirements that are not explained on the website.

One of the most important things that are required here is an email address. Everyone who is registering for a pin code needs an email." One pin, one email" policy is repeated so many times in the media. This is because when ITax was rolled out many went to cybercafés to get registered. The cybercafes used one email to register almost 1000 taxpayers making it impossible for the KRA to track individual taxpayers. The KRA offered training for cybercafes however during my fieldwork this was still a problem that was lurking. I spoke to Charles about this, and he explained that the cybercafes were not licensed to offer this service, however they were not breaking any law by doing so. They find ways around the technology to make it work for them. Kenyan bloggers on social media especially twitter use social media as well as websites to help taxpayers that had gone online to complain about ITax.

They have created a niche for themselves by dedicating numerous websites to teaching the public on how to use ITax. What the ICT experts try to do to get taxpayers attention is to make the process seem simple and swift as though they were working for the KRA. What my fieldwork had shown was that this was not the case. These websites have become quite popular, mostly developed by ICT experts. This one caught my eye during my online research on online tutorials on how to file your taxation on ITax. The host of the blog describes himself as an IT expert, a web designer, and 
a social media marketer. He shows a full tutorial on how to use ITax. The bloggers give general advice and do not cater to peculiar and special cases. One visitor on this post asks, "how do I know when I have complied?". Bosire, the blogger answers "check your email. They will send you a copy". It wasn't only bloggers like Bosire that benefited from ITax complexity.

The first one(below) is teaching taxpayers on how to file nil-returns ${ }^{52}$.

'How to file tax returns nil-returns'

For the KRA filing tax returns is mandatory for any Kenyan citizen above the taxation bracket. You can file ITax the KRA returns for the nil category using the simple process below. Find the official KRA website then enter your PIN and password then answer the security question. You will then be redirected to the ITax page. At the top of the website, there is a navigation pane with 'Returns' as one of its features. Click on it then scroll downwards until you see the 'file nil return' option. Other options include filing for amended returns and the ETR supplier sales declaration. You will then be redirected to the tax obligation page where you should enter the type of taxation and tax obligation followed by your KRA PIN. ITax then issues a nil e-return form with a few mandatory questions which should be answered factually before clicking the submit button.

The second one is teaching taxpayers on how to file VAT and PAYE.

How to file PAYE and VAT on ITax

Log into ITax using your PIN and password then answer the security question. Navigate to the returns section and select income tax PAYE or VAT then download the required spreadsheet from the options provided. Fill in all the details required to save the document on your device where you access it easily then go back to the ITax page. Click file returns on the navigation bar and submit your PIN and tax obligation before pressing submit. The next page required you to fill in information regarding your return period, which is monthly for both PAYE and VAT, then upload the saved document on your device to the

\footnotetext{
52 www. tuko.co.ke
} 
ITax website. Agree to the terms and conditions at the bottom then click submit. Like the other processes discussed above, expect an acknowledgment receipt or an error message. If it's the former, then your VAT or PAYE returns have been successfully filed.

The instructions given above are like those given by Rachel in chapter four. The instructions are made to seem quite easy however as illustrated they require both ICT and tax knowledge to understand what to file. The inscriptions made by the ICT officers at KRA imagined the user of ITax as being tech-savvy. This idea was translated by the bloggers also giving similar instructions as Rachel as they were able to descript the instructions into technical terms. The complexities displayed by the instructions shows how ICT mediators have crafted an important space for themselves within the new tax architecture. They then master how to use ITax and like Melvin, they use their ICT expertise to help taxpayers comply. The instructions are used as click bait when taxpayers research on how to file on ITax and once you are led to their website, you are also provided with their contact numbers and emails to get help. They demonstrate through their tutorials that they understand how to use iTax. The ICT expertise involved in the design of ITax has thus made ICT expertise important in the tax discourse in Kenya with taxpayers required to have such expertise to comply or use a mediator.

In the next section we find tax consultants who are more official and even recognized by KRA. The Tax consultants are also finding new ways to gain technical expertise to remain as relevant mediators.

\subsection{Tax consultants}

"Everyone needs a tax consultant whether they can afford it or not! To avoid dealing with the KRA (Kenya revenue authority)" (George, one of the most successful tax consultants in Kenya).

George is a middle-aged man whose office was in a high-end area in Nairobi. George had a big office with three secretaries in an exclusive area. The meeting had been rescheduled four times. I heard from my contacts as well at KRA that he was the best tax consultant, however very expensive. George, I was told, was influential and particularly instrumental in pushing for the reforms that led to ITax. He had worked for an international tax consultancy company prior to becoming an independent financial 
consultant specializing in tax. The office was massive, and it had two floors.

According to George and my interlocutors, many taxpayers engage tax consultants, however they are limited with what they can afford as they can range from cybercafe attendants to Melvin to George. The more one paid the better service one would get as most of the high-level consultants like George either worked for the KRA before or have strong ties to the KRA. Tax consultants came in different scales. According to George his clientele is mostly rich businesspeople as he is well connected at KRA and can make any problem 'disappear'. George mentioned that he was crucial to the implementation of ITax as he had worked closely with the KRA to help design it. Their close connections to the KRA puts them in a strategic position to offer tax services. George argues that because of their knowledge of tax laws and procedure they are best equipped to offer their clients the best services like negotiating tax penalties and even tax reliefs.

During the interview he took me through why the KRA chose to go with ITax as a policy and why he supported its use. ITax, according to him, was going to take the KRA to the next level. Additionally, Kenya was going to increase its domestic revenues and become a 'developed and modern' country. As part of the expertise group brought to work on ITax he highlighted that "we needed a platform that could finally represent the KRA digitally..." When you think of ITax you should already envision that you are dealing with the KRA virtually. The only difference here is that you are not scared of ITax like many locals are." This was quite profound because he was part of setting the agenda for the KRA. Was ITax a positive representation of the KRA when it was perceived as complicated by taxpayers. He went on to argue that taxpayers need not worry about ITax's complexity as they had tax consultants who could help them. ITax had grown his business significantly as he helped wealthy taxpayers navigate these new waters. He also mentioned that now he hired more people with IT backgrounds to do tax analysis work which now also meant that accountants would need to get IT training if they are going to compete for the jobs. The tax expertise had now shifted from the mainstream to ICT.

Tax consultants like George have profited from the complexities that have arisen with ITax's implementation. He described ITax as a tool that would make him an important mediator because he had connections at KRA and because he was involved in its 
endorsement. George used ITax to transform his organisation to become digital technology centric with the recognition that mainstream tax expertise had been replace with ICT expertise. What however made George more different than the bloggers and Melvin the ICT expert was that he had tax expertise that was recognised by KRA. The other ICT experts seemed to have established some relationships but not as strong as George. George unlike many other tax consultants has embraced the ICT expertise and is benefiting from being part of both worlds What this shows is that the ideas that travelled with ITax were those that led to the creation of expertise like within ICT and crafting important spaces for mediators and consultants. While there has not been any other platform that has been endorsed by KRA other than ITax local innovators developed a platform that they hoped could replace ITax. This was not as easy as imagined by the innovators however they were able to inclusive in their design. In the next section, I analyse how the easy tax platform was developed by local innovators as a solution to ITax.

\subsection{Local innovation Easy Tax}

A local technical innovation company known as IHub developed an easy tax platform. The project was funded by the Swedish International Development Cooperation Agency (SIDA) (IHub,2018). The project assessed how and what ICT tools were used in various aspects of governance in Kenya, Uganda, and Tanzania. It was aimed at bridging the insights and research gap in ICT usage in East Africa. IHub held a workshop in Nairobi to launch the report from the project in an event that involved participants from the KRA, the Kenya society for the blind, tax experts as well as ITax users. 
Figure 8: Easy tax platform

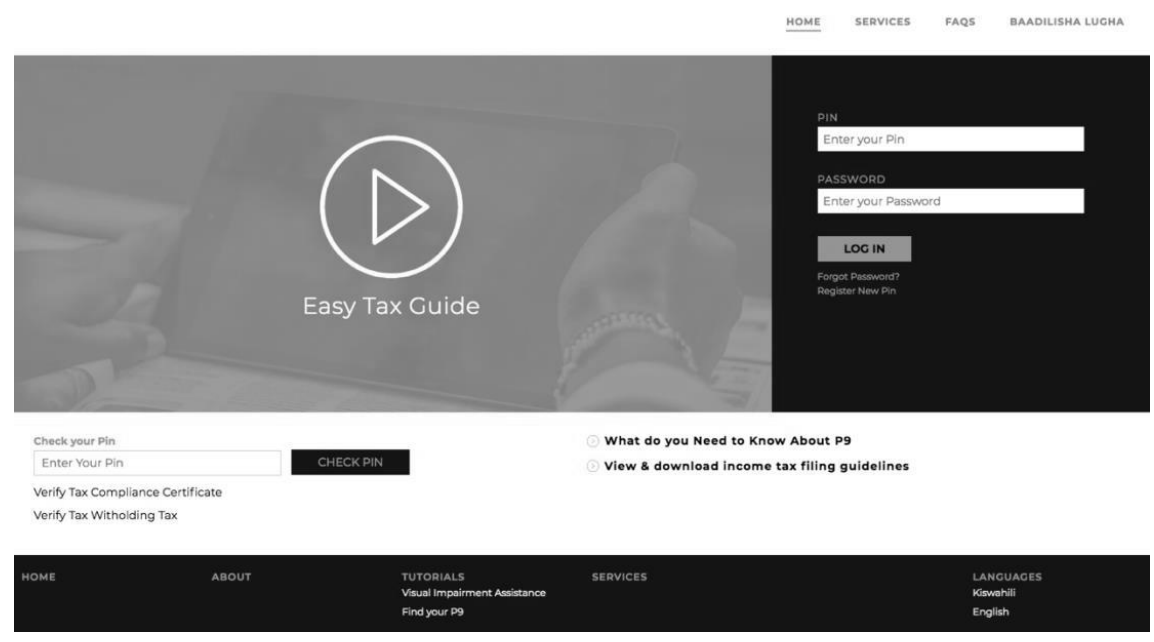

SOURCE: https://easytax.ihub.co.ke/

After identifying that ITax was too complex for taxpayers, IHub developed easy tax..$^{53}$ They worked closely with the KRA as well as taxpayers to develop it. This allows both the KRA and the taxpayers to give their views on how best the system can work. IHub involved accountants as well as e-government specialists to ensure that the platform worked well for the KRA and the taxpayers. The platform also featured videos of how to use the platform and they demonstrated at the workshop how the platform was in Kiswahili due to demand from the taxpayers. Another important feature with this platform included a page showing all transactions and stating whether the taxpayer has arrears or not. The feedback easy tax got from participants who engaged with it during the project was that it was: Simple, clutter free user interface, Fast and easy process of filing returns in just a few steps, having a video tutorial on the front page was helpful to guide them on how to file tax return.

It is important to note that Easy Tax is developed locally and that KRA did not choose to work with it despite being involved in its development. IHub claimed that they had put in a bid to compete for implementing ITax but the conditions to winning the bid were unfavourable to them. They had to have many years of experience as well as

\footnotetext{
53 https://easytax.ihub.co.ke/
} 
capital. Having engaged with ITax and now with easy tax I am impressed by how simple it looked. IHub recommended that governments implementing ICT platforms must be cognisant of the realities on the ground. According to IHub, the statistics of high e-literacy in the country are misleading as access to the internet they argue does not lead to literacy. A majority of those who are seen as being tech savvy are described as passive users where they might have access to the internet however, they are not using it for anything related to e-governance. ICT policy therefore must think about most citizens who are unable to fully utilise the stems. As one participant quoted in the report stated: "e-government is a highway only accessible by few." (IHub,2018,6).

IHub had been inclusive in its design, even reaching out to KRA and taxpayers in the designing of the easy tax platform. They, unlike Rachel, recognized the value of having an inclusive process. They then even went further and made easy tax into Swahili recognizing the importance of this as well. However, there is an understanding in the current digitisation policy that technological innovation must come from outside therefore not really taking entities like IHub as viable contenders when designing egovernance platforms like ITax.

IHub and Bosire showed how the tax architecture is changing whereby IT technicians are now becoming tax consultants. Interviews conducted at various tax consultancy firms confirms this where they now opt to hire individuals with IT expertise contrary to the accounting or legal background that was the norm in the past. When I went through this procedure with Charles, he was so happy that someone had understood the process. He however did not realise when I took it up with him at first that the process had become complicated. I wasn't a Kenyan taxpayer but reading the above statement I became anxious. How was a taxpayer expected to know all this? I thought to myself. ITax's complexity had turned taxpayers' complexities into business models for ICT experts. ITax's mantra as displayed in its logo above had promised to make taxation practices simpler, more swift and secure. Yet, many of my interlocutors, whether on a plane or at a restaurant, shared their negative thoughts on ITax without holding back. It was as though they were waiting to be asked about ITax to air their grievances. The channels of communications between the taxpayer and the KRA seemed quite weak as very few had attempted to give feedback on their dissatisfaction. One informant had remarked "it's not like we can call the KRA and tell them we are dissatisfied with their system". 
ITax's other objective, according to one of ITax managers at the KRA, was to make the services available to the public at their convenience. Visits at the service centres as well as the cybercafé shows that the convenience that had been promised 'at the comfort of your own house' seemed far-fetched. The taxpayers who would benefit were those who had access to the internet in their homes or even smartphones that could act as a hotspot for their computers. The taxpayer would also be expected to have a laptop or a smartphone something that is unfortunately not very common in Kenya regardless of whether it is urban or rural areas. What is evident here is that the process is not as simple, swift as claimed in ITax's mantra. The process requires ICT knowledge.

\subsection{Conclusion}

The Kenyan way of implementing ITax as introduced in this chapter is a form of cultural intimacy as argued by Herzfeld (2004). It is demonstrated through the paradoxes, ironies and contradictions connected to Kenyan national identity. Taxpayers as illustrated by the four women were able to comply with ITax using the 'Kenyan way' however, it did not increase their tax compliance as imagined in mainstream tax knowledge. Compliance in this case was based on fear as well as convenience as some of the taxpayers needed to access other government facilities as well as work contracts by complying. These were those I had interviewed while many others according to my research opt not to comply. Tax evasion and avoidance is quite high in Kenya, and it is estimated that KRA suffers great losses due to this.

The actual use of ITax reveals, like in Mary's case, that ITax has gone through various descriptions which led to unintended consequences. ITax had gone contrary to what it had set out to do. Despite having weak and limited ICT infrastructure, Kenya is imagined in the global ICT discourse as the perfect environment for ICT development in the region due to successful implementation of the mobile technology Mpesa. However, ITax was not built on this mobile platform rather as an interactive web application that requires internet connections, computers, and laptops. It is also required, as Charles demonstrated, for taxpayers to be 'tech savvy' due to the mandatory use of the platform. The assumption here is that digitized interactions between the KRA and the taxpayer would enhance trust between them. However, in practice, it seems not to be the case. It seems that there has been a disconnect 
between the rationale within ITax and the end-product which taxpayers like Mary have struggled with.

Taxpayers like Mary and Nancy prefer to go through an assemblage of brokers like the cyber cafés and the tax consultants to comply instead of reaching out to KRA. This is because ITax had widened the gap between the taxpayer and KRA. It had complicated the tax filing processes and like in Mary and Nancy's case made them feel vulnerable. Given these examples I discuss in this chapter that ITax did not deliver on its promise for being 'simple, swift and secure.' KRA aims for ITax hardly materialised in practice. The issue regarding reducing interactions has also not turned into a successful vision. In practice, taxpayers are turning to brokers and services centres to help mediate interactions with the system. Due to the high poverty rates in Kenya, most taxpayers can neither afford to own a computer nor hire a tax consultant and had to use cybercafes which had been seen as not being very reliable. ${ }^{54}$ As ITax travelled, its translations varied from the different sites it navigated in. The inscriptions within it expected Mary and the other taxpayers in this study to be tech savvy to use ITax. Those who could not use it were left feeling less competent because they were unable to translate the technology for their use. Akrich contended that the technology needs to be 'descripted' to make it more applicable to other networks (Akrich,1992). The inscriptions should be flexible to travel and be repurposed which was not the case as shown in this chapter.

This chapter shows as well how important mediators became crafting an important space for themselves. Taxpayers like Nancy and Mary do not opt to go to ITax centres choosing to pay extra to their providers to comply. This shows that the system did not become easier, rather it became outsourced to the so called "experts" who could help taxpayers navigate ITax. This made taxpayers' information vulnerable however taxpayers were willing to take that risk rather than deal with ITax or KRA directly. This also changed the tax expertise from tax experts to ICT experts. The ICT experts interviewed in this chapter had understood ITax and even created websites and empowerment that offered taxpayers with the help that they needed to comply. They were aware that they lacked tax knowledge, but they were clear that they did not need

\footnotetext{
54 This assumption is made based on UNICEF (United Nations Children's Education Fund) statistics where $45 \%$ of Kenyan live below the poverty line while another $25 \%$ live under 3 dollars a day.
} 
this in-order to help taxpayers comply. What also became clear dorm the mediators like cybercafes is that they made significant mistakes when helping taxpayers comply. The taxpayers like in the case of Nancy take responsibility for wrong filings. Compliance in this case shifted from complying with the tax laws to complying with the technical requirements.

ITax's other objective according to the KRA was to make the services available to the public at their convenience. Visits at the service centres as well as the cybercafé shows that the convenience that had been promised 'at the comfort of your own house' seemed far-fetched. The taxpayers who would benefit were those who had access to the internet in their homes or even smart phones and laptops. In the case of Nyambura it did help to stand in line with her laptop in her bag. The process requires ICT literacy and infrastructures. 


\section{Chapter Six: Taxable and Untaxables}

\subsection{Introduction}

"The government asserts that we do not pay our taxes and so does not care about our economic development. I think it is high time for the government to accept responsibility for its previous acts. In my county, both colonial and postindependence governments limited citizen participation. I'm referring to a sessional 10 paper, a government policy paper, in which financially marginalized northern areas are given instructions. Furthermore, in the 1970s, economic zones were created that completely ignored the development of my local county. How can the state anticipate high tax morale if it did not deem the region economically viable? The railway was only built where it was deemed economically feasible. The railway system was thus utilised by colonialists to further marginalize us. The idea of systematic marginalization has been maintained by successive post-independence regimes (my translation).

At a session on tax and development given at the local University in Nairobi, a law student made this insightful observation. He was reacting to a presentation made about increasing tax collection in rural areas in Kenya. The presenter had stated that the tax revenues in the marginalised areas of Kenya including the north-east as well as coastal regions of Kenya were lagging with regards to tax generation. The law student was from the North-East part of Kenya, referred to as the arid and semi-arid areas $(\mathrm{ASAL})^{55}$. He stated that the reason there was low tax revenues in that region was that his community were not considered potential taxpayers due to the nation's historical economic policies. His community's main source of livelihood pastoralism was not considered by the Kenyan government economically viable ${ }^{56}$. Historically there were several attempts to introduce agriculture as well as other economic activities however their lives revolved around pastoralism. Paradoxically, the ASAL's contribution to Kenya's livestock production is between $50 \%$ to $70 \%$ (GOK, 2005) with a large amount of this incoming going untaxed. Despite this contribution, huge portions

\footnotetext{
${ }^{55}$ The ASAL areas are both geographically and economically marginalized
} 
of the ASAL receive the worst and most ineffective service delivery. Pastoralism is practiced in $75 \%$ of ASAL areas, and these areas collectively represent the country's most marginalized places (Mugo et al, 2009). Pastoralism had been viewed with scepticism in Kenya since colonial times, according to the young law student, leading to the adoption of rules that barred the region from participating in the national economy since it was judged economically unviable.

This chapter deals with the implications of historical structures in the travels and translations of ITax. I look at how ITax's implementation is contingent on the historical structures that were developed to empower as well as marginalised select Kenyan citizens. I discuss how colonial policies and infrastructures have shaped the current economic landscape in Kenya. I us ethnography from two counties in Kenya who performs quite differently with regards to revenue generation: Kiambu and Isiolo. Those who were empowered by infrastructures and access to land that was fertile perform well economically while those who were marginalised perform poorly. The economic development has caused implications for the relationship between the tax administration and the citizens. In the marginalised county, the relationship is characterised by the historical fear of the administration as well as the enforcement measures used to get taxpayers to comply with the tax rules.

Kiambu and Isiolo counties are located not too far from each other but perform very differently economically. Kiambu is viewed as a role model for other counties in Kenya as it generates the second highest revenues after Nairobi as well as being a city that has digitised its public service delivery successfully. Isiolo, on the other hand, has been marginalised before and after independence and is seen as one of the counties with the lowest revenue generation even though some areas lack access to basic infrastructures like water and electricity. The comparison of the two counties in this study might not seem fair however it is precisely the differences that makes the arguments important. The implementation of digitalisation, projects in Kenya is yet to address the existing historical impediments to economic development in the country.

Based on Kenya's colonial infrastructural policies and implementation, the railroad, but also current governmental digitalisation and economic policies, I categorize the citizens in this study as taxable and untaxable depending on where they live. The taxables are regarded as economically viable while the untaxables are seen as not viable. The next two sections discuss how Kiambu and Isiolo fared, as examples of 
each such category, with regards to digitalizing tax collection in their respective counties. With the global discussions on tax for development it is imperative to understand how some developing countries like Kenya can empower some of their citizens with regards to certain discourses whilst marginalizing those already historically disempowered.

Developed nations view forestry and agriculture as being key in building strong economies (Scott 1998) with the result that those who could not be engaged in such activities were side-lined. In Chad, Janet Roitman (2005) was interested in how local histories of pre-colonial systems, as well as colonial taxation models, shaped residents' perceptions of fiscal relations (Roitman,2005). Roitman (2005) address the French colonial authorities' introduction of a tax system that required the creation of taxable African 'subjects" (p. 55). In this case study, I use this argument to show how colonial fiscal policies led to the creation of both taxable and untaxable citizens, a trait that is carried forward to present day Kenya where the taxable are favoured by the economic policies whilst the "untaxables" are engaged in an informal economy that is outside of the national economy

This chapter will therefore investigate how ITax travelled to the two counties and compare the outcomes of the implementation - how people use ITax. I will start by giving a brief background of the historical structures that have shaped the counties. The second section discusses Kiambu as the poster child of ICT and digitalisation in the country. The third section discusses how Isiolo deals with the digitalisation shift while still struggling to attain basic amenities like water and electricity, the final section draws conclusions from the discussion.

\subsection{Colonial Infrastructures: The Railway and Taxation}

Infrastructures have existed since colonial times and viewed as being "gifts" western imperial powers brought as an integral part of their colonizing mission (Suman, 2009). Infrastructures were used historically and currently to empower while marginalising those seen as being economically or not economically viable. Infrastructures continue to be advertised as a way to speed up modernisation, transformation, and development (Appel, 2018). Most infrastructure projects, from colonial railroads to modern technological breakthroughs, rely more on the promise of infrastructure than 
on whether or not they deliver (Appel 2018, 45). This created profound consequences for economic development (Acemoglu et al.2001,2002).

The Kenyan government used the same economic development plan that it inherited from the British government to implement its national economic policies. This is because as a protectorate ${ }^{57}$. They received support from the colonial administration in order to make their transition to independent Kenya smooth. The colonial administration used infrastructures like the railway to rule Kenya with the areas seen as being economically viable connected to markets as well as the ports in order to facilitate trade (Jedwab, Kerby, and Morad, 2017, s. 91). It symbolized the economic policy of Kenya, development on one side and underdevelopment on the other side James Scott (1998) described how states create realities by designing policies based on visions of modernity. Here the British invested heavily in agriculture to export to Europe totally ignoring the trade that arose from pastoralists who were the majority in the country and region. This investment has led to agriculture being an important revenue generator in the present-day Kenya. The railway lines were used to ferry the agricultural produce through the colonial empire in British East Africa and it made the start of the railway an important economic hub which later became the capital city, Nairobi.

The entire region where the railway passed became a hub of economic activities and to date generates high revenues for Kenya. However, at the end of the railway lines, the marginalised regions of Kenya like Isiolo lie were closed off from participating in the agricultural economy that was fast growing. The areas were semi-arid and arid meaning they were not favourable to the type of farming that was seen as desirable but they had other trades that were not seen as being economically viable. According to Jedwab et al. (2017), the railroad in Kenya created a unique situation in which lines travelled through sparsely inhabited areas with no Kenyan freight to transport. This was done in the hopes of establishing a primarily agricultural economy based on land that had been alienated and offered to European settlers (Jedwab, Kerby, and Morad, 2017, s. 91). 
The railroad also led to settlement and economic development along its lines (Jedwab, Kerby, and Morad, 2017). The railroad contributed to a concentration of both European and African communities near railroad terminals between 1901 and 1962, a year before Kenya gained independence. Coffee and tea cultivation grew along those lines, making them the most important cash crops to date. The post-independence infrastructures like the telephone and electricity grid followed the same path as the railway continuing to empower those who live along that line. The areas that were deemed economically viable were able to participate in the national economy not only generating high revenues which contributed to the national economy taxation but get services from the central government based on their contribution to the national economy. Those that were left out created an informal economy which Kenya is currently having a difficult time integrating into the national economy.

Figure 9: Maps showing the transformation of towns along the railway line.

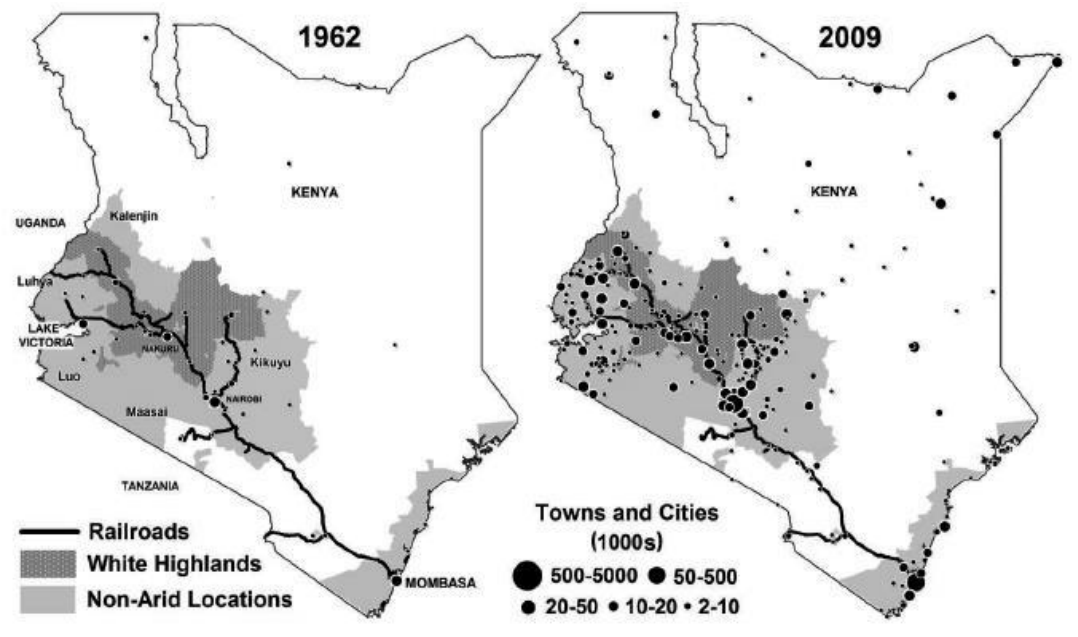

SOURCE: JEDWAB ET AL.2017

The map in figure 9 shows how the railway was strategically placed along the fertile areas in the countries. Built in 1896, the railway was initially aimed at connecting parts of British empire, in this case, Uganda, and Kenya (Jedwab et al.,2017). It was later used for military dominance in the empire as well as transporting the cash crops to the colony and even back to England. The map shows the railway infrastructure developing the areas closest to it while disconnecting those furthest away despite 
those disconnected occupying $84 \%$ of the country's territory (Jedwab et al.,2017). Here one can clearly see the development that happened along the railroad led to settlement and economic development along the railway lines. (Jedwab, Kerby, and Morad, 2017). The colonial railway not only increased the empire's revenue significantly, but it empowered the inhabitants closest to the railway while marginalising those furthest awaited failures of the government to successfully integrate them into the national economy played a pivotal role in their economic marginalisation. How is then relevant to the fairness in digitalisation processes in Kenya especially with regards to the use of ITax? ITax is reliant on Internet connectivity. What this would mean was those who are able to access internet connectivity would be better equipped to use the e-fling system. Those who are disconnected can use mobile data services however it is both costly and dependent on the use of smartphones.

Figure 10 Kenya's National Fiber optic Map in 2014

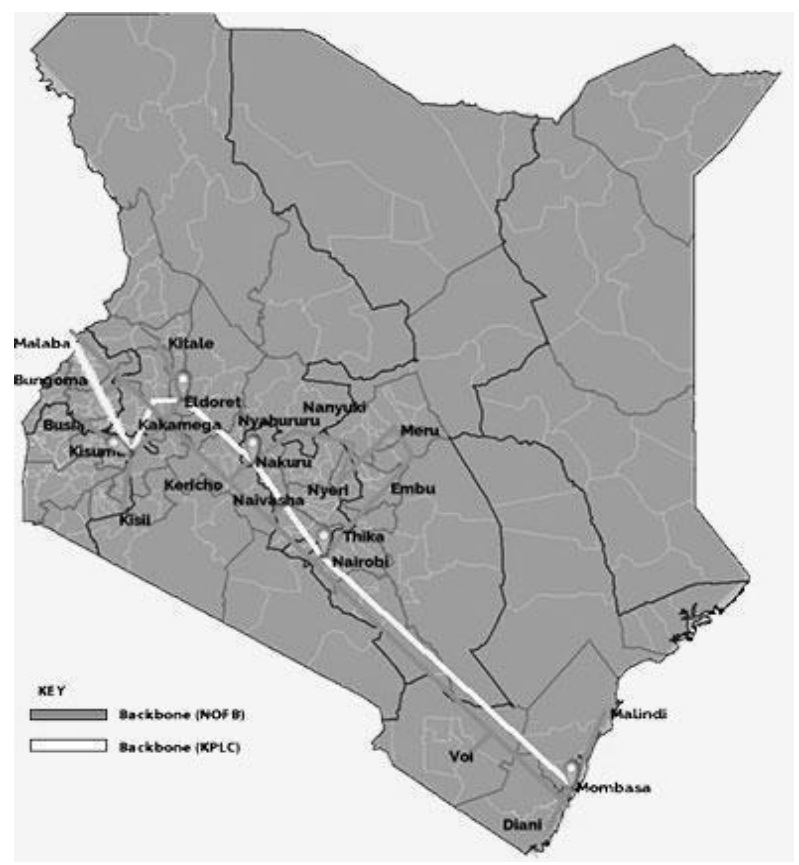

Source: $\underline{\text { http://icta.go.ke/national-optic-fibre-backbone-nofbi/ }}$ 
The figure above depicts the ICT ministry fiber-optic project called NOFBI ${ }^{58}$ (National optic fiber backbone). This NOFBI connection in figure 10 shows how infrastructural politics are used to empower a certain community while closing off others from this important grid. Historically this was used to marginalise the ASAL areas as they were not seen as being cooperative. I affirm that the Kenyan government built its infrastructures along these historical lines based on familiarity and unawareness on the economic potential of the region that is closed off. The Arid and Semi-Arid Lands (ASAL) regions make up almost $84 \%$ of the country's territory ${ }^{59}(\mathrm{GOK}, 2016$,). As depicted by the map above very little development has occurred in the areas furthest from the railway line. However, despite the promises of Kenya's decentralisation in 2010 as well as recent oil discovery which is estimated to be worth almost $70 \%$ of the country's national budget, the areas have limited access to water and electricity in these areas are still quite limited (GOK 2016).

Failure to pay attention to dominance structures disengages and prevents one from unpacking and comprehending the impact of the past on the present (Stoler,2008, 193). Areas that were seen to have 'abundant natural resources' were seen to be 'high-medium and low potential. What are the historical economic policies that are still at play and how are they shaping tax practices in Kenya? Crawford Young (1994) argued that African colonial governments' revenue imperative was a requirement for establishing European hegemony since it not only provided the required money, but also reflected the colonial state's authority and legitimacy. Understanding how colonial fiscal history continues to impact Kenya's current tax structure and subsequent efforts to achieve economic development through technology is crucial.

\subsection{Historical Economic Policies}

To 'take off' economically, the African post-colonies often adopted high modernist concepts (c. f Scott,1998). This was the case in several African countries, including Kenya, which adopted African socialist manifestos based on Rostow's modernisation theory (Rostow,1962). Although Kenya developed an African socialist manifesto in

\footnotetext{
58 http://icta.go.ke/national-optic-fibre-backbone-nofbi/

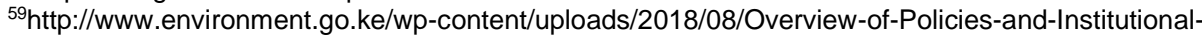
frameworks-on-SLM-in-Kenya-Feb-2016.pdf
} 
1965, their policies followed those of the British colonialists as they both viewed agriculture as being key in helping the country take off economically. ${ }^{60}$ Pastoralism was considered as backward and difficult to manage, especially when it came to taxation, by both the colonial and post-independence states as scepticism towards it was motivated by Kenya's first policy planning paper titled 'African socialism and its application to planning' as well as a 1902 'closed district' policy ${ }^{61}$. The policy gained popularity in the 1950's and 1960s and was inspired by Marxist and modernisation theories which were meant to guide economic growth in post-colonial countries (Ochola,2016). The most controversial paragraph that alludes to what the law student was saying was from Paragraph 133 on 'Provincial Balance and Social Inertia' categorically stating that:

"One of our problems is to decide how much priority we should give in investing in less developed provinces. To make the economy as a whole grow as fast as possible, development money should be invested where it will yield the largest increase in output. This approach will clearly favour the development of areas having abundant natural resources, good land and rainfall, transport and power facilities, and people receptive to and active in development. A million pounds invested in one area may raise net output by $£ 20,000$ while its use in another may yield an increase of $£ 100,000$. This is a clear case in which investment in the second area is the wise decision because the country is $£ 80,000$ per annum better off by doing so and is therefore able to aid the first area by making grants or subsidized loans (Sessional Paper No. 10, 1965 pg.46).

A rationale is here outlined investing in 'high' economic potential areas. This postindependence became an important tenet for 'African socialism'. African socialism pushed for community ownership of the means of production, rejecting private property (Wingo,2018). Kenya, for example, regarded African socialism as 'leapfrogging' the capitalistic system. Marxists had however viewed capitalism a necessary precursor to socialism (Wingo,2018, Ochola,2016). Without having a capitalistic society forged the

\footnotetext{
${ }^{60}$ http://siteresources.worldbank.org/INTAFRICA/Resources/257994-1335471959878/SessionalPaper-No-10(1965).pdf

${ }^{61}$ The 'closed district' policy was enforced by the colonial administration to restrict movement of the citizens in that area. They not only allowed to leave but very few people could enter the district as well. This policy was enforced in the northern frontier districts which later became the North-East province of Kenya. They are also referred to as the ASAL areas in current political discourses.
} 
country into economic zones where perceived output dictated investments. Kenya was at the time divided into high and low economic zones (Sessional Paper No.10 1956 pg. 46). This is the present political economy of Kenya. The maps above show how the areas that were considered high potential grew exponentially while those deemed as low potential did not make significant developmental strides.

Most African colonial regimes, according to Acemoglu et al. (2001), were not committed to the formation and growth of institutions. The colonies were governed based on economic value rather than known resources or existing trade links. The colonial state lacked the ability to compel its African people to comply (Gardner,2012). The fiscal control was ceded to African elites. Rather than increasing earnings, the colonial power aimed to minimize costs (Gardner,2012). Due to the fact that all of the money was funnelled to pay for the colonial administration, reciprocity was essentially non-existent. The African elites in charge of revenue collection exhibited what Bayart (2009) refers to as "extraversion." They were given complete revenue collection authority. After independence, a few elites, particularly in British East Africa, were empowered with tax knowledge and went on to design the current tax systems in use.

Historically, the British exploited tax exemptions to gain support from certain tribes and to form political settlements, which is still visible in Kenya's contemporary political system (Khan,2010). The tribes that were empowered and disempowered represent the majorities in the counties in this case study. The Kikuyu tribe, which the first president of Kenya, Kenyatta hailed from settled along the railway on the most fertile areas, in the highlands of Kenya. This is the area that they inhabit until today with Kiambu being the biggest county in the area. It is also regarded as one of the wealthiest counties in Kenya. The Somali tribe has in contrast since independence been attempting to reunite with Somalia, a division due to colonization. They constitute most of the population of the most marginalized areas in Kenya to date, Isiolo included.

The colonial administration implemented policies that resulted in dividing Kenyan into economic zones empowering some while others were marginalised economically. (Gardner,2012). Among the tactics used were infrastructures like the railway and policies like agriculture. Kenya had tried to address this with its new constitution as it was aware that there existed disparities with revenue generation and distribution. The new constitution introduced the equalisation fund that allocated more funds to areas 
that are not generating enough revenues. This has however not yet changed the situation significantly because of the marginalisation that had been ongoing since colonial times. Kenya's Constitution established a decentralized government in which the legislature and executive powers were devolved to the counties. Decentralization's main goal is to devolve power, resources, and representation to the local level. ${ }^{62}$

Fast forward to the present day where tactics like digitalisation are implemented using the same infrastructural lines as the railway did. Kenya adopted a new constitution in 2010 ushering in a new era of governance. Citizens could easily access services and effectively engage with the county administration because of the decentralized governance frameworks. To sustain themselves, county governments are required by the new constitution to generate their own revenues (Oduor, Sevilla, Wanyoike, and Mutua, 2016). The main purpose of taxation is to collect revenues for redistribution. In developing countries taxation, as shown by colonial fiscal history, was developed to increase the revenues in the British Empire. While this might have changed since independence it has however in the case of Kenya not yet taxation with a capital $\mathrm{T}$ as known in western countries. In the case of Kenya, the redistribution is mainly financed by foreign aid because the taxation that is generated is not enough for funding the country's development agenda. Kenya poverty rate for 2015 was estimated at $86.60 \%{ }^{63}$. The tax potential therefore lies within a small \%age including multinational companies as well as the growing digital economy that has grown significantly in the country.

Decentralization allowed for the 47 counties to manage their local revenues collection as well as decide on their county development projects. With regards to digitalizing county revenue collections, county governments have the autonomy to decide whether they digitize it or not. Isiolo, however due to weak governance and infrastructures opted to use a much older system 'laiforms' that had been operational in Kenya before it was replaced by IFMIS ${ }^{64}$. 'Laiforms', the older financial management system for

\footnotetext{
62 http://kenyalaw.org/kl/index.php?id=3979

${ }^{63}$ Poverty headcount ratio at $\$ 5.50$ a day is the \%age of the population living on less than $\$ 5.50$ a day at 2011 international prices. Poverty rates for individual countries cannot be compared with poverty rates reported in earlier editions(https://www.macrotrends.net/countries/KEN/kenya/poverty-rate) ${ }_{64}$ I have understood that Isiolo is now connected to the government financial management system IFMIS although my interlocutor in Isiolo have mentioned that they face technical difficulties in using the system due to weak ICT infrastructures.
} 
counties, was seen to be problematic as it was an older system that could not be easily upgraded. In 2013, Laiforms was replaced with IFMIS which during my study had not yet been implemented in Isiolo. The county governments found themselves in different digitalisation paths where Kiambu became the poster child for ICT in Kenya while Isiolo was lagging. Kiambu was able to almost triple its revenues after digitizing its revenue collection while Isiolo was still among the counties with lowest revenue generation.

The aim of the National Fiber Option Backbone (NOFBI) project was to roll out internet connectivity throughout Kenya's 47 counties. At the time of my research, it had only managed to implement it along the lines that are shown above. The areas to the north remained untapped. The map shows how infrastructures are being developed along economic lines which remain sparsely populated and developed despite almost 50 years of independence. How is then relevant to the fairness in digitalisation processes in Kenya especially with regards to the use of ITax? ITax is reliant on Internet connectivity. Internet connectivity would ease communication across counties and improve government service delivery to its citizens. To demonstrate the impact of the historical colonial policies I give examples of Kiambu and Isiolo. Kenya National Bureau of Statistics of 2017 observed that the year I conducted my research, Kiambu generated the third highest revenues while Isiolo generated the least ${ }^{65}$.

Table 3: Total Gross Domestic Product in Kenyan Counties:

\begin{tabular}{|l|l|l|l|l|}
\hline $\begin{array}{l}\text { Ran } \\
k\end{array}$ & County & $\begin{array}{l}\text { GDP } \\
\text { mil KES }\end{array}$ & $\begin{array}{l}\text { GDP } \\
\text { (PPP) }\end{array}$ \\
\hline 1 & Nairobi County & $1,492,323$ & 27,798 \\
\hline 2 & Nakuru County & 517,462 & 10,333 \\
\hline 3 & Kiambu County & 421,918 & 8,425 \\
\hline
\end{tabular}




\begin{tabular}{|l|l|l|l|}
\hline 4 & $\begin{array}{l}\text { Mombasa } \\
\text { County }\end{array}$ & 332,122 & 6,632 \\
\hline 47 & Isiolo County & 15,850 & 316 \\
\hline
\end{tabular}

Source: Kenya National Bureau of Standards ${ }^{66}$

In the next two sections I analyse how ITax travelled to Kiambu and Isiolo along the historical colonial lines.

\section{4 'Hapa tunadigitika!' (We are digitalising here! my translation from Kiswahili)}

This was a slogan that was used a lot on billboards and on social media in Kiambu. Kiambu, located about an hour from Nairobi city, describes itself as a digi-city signposting the adoption of technology in delivering services to its people ${ }^{67}$. The county has a website that at the time was highlighting the digital endeavours in the county http://www.digitika.kiambu.go.ke. The county government has developed the 'digitika' policy after its then governor had promised his constituents during the 2013 election campaign that he would digitize their county. The slang word 'digitika' is derived from 'digi' (from digital) and 'tika' from Swahili a connotation implying an ongoing act was used on billboards, on social media as well as on the tongues of my interlocutor in Kiambu county. The most popular feature was a 'digitika' card which, in partnership with a national bank Kenya Commercial Bank (KCB), enabled residents to make cashless payments to the county.

The 'digitika' program was launched in 2013 with the idea that ICT would enable Kiambu to reach its 'potential', socially, economically, and politically. Raising revenues and using the latest technology are important tenets of the 'digitika' program. The county government was strengthening its service delivery to increase tax compliance. Kiambu county surpassed Nairobi County in 2013 getting voted as the 'best use of ICT

\footnotetext{
${ }^{66}$ https://www.knbs.or.ke/?p=5150

${ }^{67}$ http://icta.go.ke/kiambu-road-map/
} 
in the counties.' ${ }^{6869}$ During the launch of the digitika program, the then Kiambu Governor Hon. William Kabogo said:

\begin{abstract}
"Automation of revenue collection was simply adopted by the county government of Kiambu in a bid to curb the shortcomings that came with the manual process of collecting money where lots of it was lost and the results are now tangible and can be seen by everyone. County Pro system that is helping seal loopholes, improve decision making and modernize revenue collection. This has given the county agility in finance ${ }^{70}$.
\end{abstract}

To see the transformations advertised all over Nairobi, I embark on an hour's journey by road to the county's headquarters, Thika. I had planned to use the railway. However, I quickly learned from the National Rail Service that despite Kiambu running up to $131 \mathrm{~km}$ of railway line with four railway stations in Ruiru, Thika, Kikuyu and Limuru towns, the connection was unstable and was rarely in use as many residents preferred private or public transport - buses- over the train. It would be risky to attempt to take the train I was told in case it wouldn't be working. According to Kenyan rail officials, rail had not been utilised to its capacity over the last 20 years despite having passenger trains that are expected to operate in the morning and evenings between Nairobi and the four stations.

The Thika superhighway, the road used to travel to Thika, Kiambu's headquarters, was inaugurated in 2012 and features Kenya's biggest 8-lane highway. The superhighway cost the Kenyan government over 31 billion $\mathrm{KSH}$ around 310 million USD. I was really confused about why Kenyans on social media or even among my interlocutors would speak negatively about government service delivery, yet they delivered this amazing road especially in a country like Kenya where the road infrastructures are usually old, in bad conditions or even disconnected. The government's presence was also felt during the journey. There were large posters with 'GoK delivers' (government of Kenya) written on them passed along pedestrian paths as well as large billboards. The highway seemed to have transformed the areas

\footnotetext{
68 https://www.ictak.or.ke/events/past-event-2013-ict-value-awards

${ }^{69} \mathrm{https}: / / w w w . t h e-s t a r . c o . k e / n e w s / 2016 / 09 / 29 /$ kiambu-county-revenue-rises-to-sh47-billion_c1428418
} 
around it as there were numerous shops. The highway had made travels locally and nationally easier, however this was the first time I was taking it to where the road had derived its name, Thika ${ }^{71}$. The road had however put Kenyan citizens in a huge debt burden as a huge amount of the money used to build the road was loans taken from the World Bank, The African Development Bank and from the Chinese government (AFDB,2010)..$^{72}$

When I arrived in Thika, I met with the county's ICT officer, Peter, my main interlocutor whom I had met at a digitization workshop in Nairobi. Peter's description of Kiambu during the workshop as well as the hype in the media had sparked great interest in my research on why the county was succeeding in its ICT transformation. The other interesting thing with Kiambu was that it generated between the second and third highest revenues in Kenya ${ }^{73}$. I was invited to witness this transformation first-hand. I arrive at their county administrative headquarters where most residents file both their county and national taxes. The building seemed deserted as there were no lines. It was mid-morning and I assumed that the lines were short due to the timing as they would be working like the taxpayers in Nairobi. I would learn however that Kiambu taxpayers were mostly entrepreneurs making their schedules more flexible. In addition to the county headquarters, the county boasted a Huduma centre and a fully-fledged KRA office with a ITax support center.

KRA had an office in Thika, Kiambu not too far from the Thika county headquarters. Peter accompanied me to their offices where there were customers being served by several KRA employees. KRA had offices in 14 counties in Kenya ${ }^{74}$ while the rest of the 33 counties are served by ITax centres. The taxpayers were not as many as any ITax or Huduma center in Nairobi however they were in lines. The lines were moving quite fast, and Peter introduced me to the assistant manager, James. Apart from being

\footnotetext{
${ }^{71}$ Thika is also home to the famous waterfalls known as "14 falls" often described as the "Niagara Falls'

of Kenya. The area is a popular destination for local and international tourists which also increased revenues for the county as a popular destination.

72 There were discussions on social media and on the local news on the growing debt burden in Kenya with infrastructural development such as new railway line that put the Kenyan government in heavy debt. This national debt is paid back with tax revenue thereby increasing the tax burden for Kenyan citizens.

${ }^{73} \mathrm{https}$ ://www.pulselive.co.ke/bi/finance/counties-revenue-collection-list-of-counties-with-the-highestand-lowest-revenue/5cwxe7h

${ }^{74}$ Nairobi, Mombasa, Kisumu, Thika, Embu, Nakuru, Garissa, Malindi, Kericho, Nyeri, Eldoret, Kakamega, Bungoma and Meru
} 
a manager he was also serving taxpayers. This for me was strange as the senior management at KRA in Nairobi did not directly deal with taxpayers. James explains that the tax agents have close relationships with the taxpayers, and they like to serve them efficiently. This was perhaps another explanation to why Kiambu was seen as having high tax compliance in Kenya. The taxpayers seemed more relaxed than the ones encountered in Nairobi thus making them more compliant.

Kiambu residents were being well served with government services through the Huduma center and ITax centres. Unlike Nairobi, there were very few cyber cafes around Thika town- Cybercafés had become quite unpopular according to Peter because of the efficiency of the service centres in Kiambu, perhaps also to the availability of free WIFI hotspots in five of Kiambu's twelve constituencies. A feature that was not even available in many developed countries let alone in Nairobi. In Nairobi some restaurants would offer complimentary Wi-Fi only to customers. This was not the case in Kiambu. Peter, working as an ICT officer, stated that the free Wi-Fi initiative helped drive the county's mission to better use technology to improve service delivery for all Kiambu County residents. Wanting to witness this first-hand, I accompanied Peter to a local shopping centre called Ridgeways. The Wi-Fi network was said to cover a radius of $5 \mathrm{kms}$ within the Kiambu, a capacity of 10 megabytes per second (Mbps). We get to the shopping mall and as we drive in, I log on to my phone. The Internet was not as fast as I had become accustomed to; however, it seemed sufficient for the residents who were gathered around in the mall browsing on their phones. ${ }^{75}$ Kiambu country had invested greatly in ICT developments like the internet going even further to contract a local university to provide them with additional tax technology known as County Pro. Its desirability was that it was locally developed. In the next subsection, I describe how the county pro-program enabled Kiambu county to maximize ITax's implementation.

\subsubsection{County Pro Program}

CountyPro is an online system used by county governments to collect and manage revenue. It allows residents to access county government services quickly and conveniently over the internet. The Strathmore Research and Consultancy Centre

\footnotetext{
${ }^{75}$ https://ilabafricastrathmore.wordpress.com/tag/kiambu-county/
} 
ILabAfrica had already implemented this invention in three counties: Kiambu, Taita Taveta, and Busia by 2017. CountyPro has the ability to examine the revenue base and offers citizens multiple, secure payment choices. ${ }^{76}$ Peter observed that the county boasted high county service delivery of public services at all levels as well as high tax compliance. There had been a deliberate policy by the government to ease tax management services for Taxpayers. As a result, Kiambu county implemented the CountyPro as an additional program to make the collection of local taxes easier for their residents. Being locally designed and managed, the County Pro platform allowed for integration with other financial management systems like ITax. Kiambu county was able to collect their own revenues as well as support the KRA in the collection of national taxes which is mainly in employment tax as well as VAT.

The county was able increase its revenues by $60 \%$ using the county pro program locally ${ }^{77}$.ITax was quite complex for taxpayers to use, prompting Kiambu to turn the complexity into an opportunity for the county to become innovative. The national government had initially envisioned ITax as being a tool that could be adopted by the county government to help them with their revenue collection. The complexities, as well as its inability to merge with their earlier financial management system, made it necessary for the county to install new programs that would enhance their revenue mobilisation. Kiambu became a role model for ICT development in the country. Peter explains their success was based on the availability of resources. He explained: "We had a budget within the county allocation for ICT development. We used it to commission ILab from Strathmore university (a local university) to develop the county pro platform". The platform was successful even being awarded a prestigious ICT award in Kenya for how it works with county governments. ${ }^{78}$

Peter believes its success is rooted in not only how the platform works but also how the engineers maintaining it are always available to adjust and make changes based on the user needs. This is quite remarkable as one of the main weaknesses of ITax

\footnotetext{
${ }^{76}$ https://ilabafricastrathmore.wordpress.com/2016/04/08/countypro-the-award-winning-revenuecollection-system/

77 https://strathmore.edu/news/kiambu-increases-revenue-collection-through-strathmore-universitysystem

${ }^{78}$ https://ilabafricastrathmore.wordpress.com/2016/04/08/countypro-the-award-winning-revenuecollection-system/
} 
was that it was very difficult to maintain during breakdowns. Charles had stated that it was difficult to get a hold of ITax technicians because they run numerous projects in Kenya, something that I witnessed as well during my fieldwork at the KRA. While attempting to get an interview from them they were either not around or when they were, they were busy solving problems as informed by Charles.

The point here according to both Charles and Peter, the ICT officer, was the importance of having local expertise in digitalisation. This enables the users, both the government and citizens to not only suggest relevant changes but also have real-time assistance when needed. ILab, the developers of county pro described its main objective as:

'CountyPro' to remedy the difficulties county governments have been facing in collecting and managing revenue collection. The system has enabled the county governments to increase their revenue collection by up to $60 \%$. County Pro is a Solution centred on holistic e-Governance that enables citizens to easily access county government services online. This innovation by the Strathmore Research and Consultancy Centre, allows Online application submissions, business process re-engineering, inter/intra departmental applications processing, workflow automation, electronic payments, digitized receipting and electronic delivery of services, documents, certificates, permits and licenses ${ }^{79}$

There has been an upsurge in county revenue in Kiambu after the automatization of revenue collection system (Oduor, Sevilla, Wanyoike, and Mutua, 2016). The first phase of the CountyPro system installation resulted in a $60 \%$ increase in revenue collection, according to the report. The study also revealed that $74 \%$ of respondents were satisfied with the automated revenue collection. It was not difficult to see why Kiambu service delivery was successful. Kiambu not only boasted a great road infrastructure but was home to cutting edge technology, even a state-of-the-art public hospital, a feature not even available in Nairobi.

\footnotetext{
${ }^{79}$ http://www.ilabafrica.ac.ke/index.php/projects/
} 
I met with the head of ILabAfrica, the developers of County Pro in Nairobi where they had their offices. James stated that it was developed according to the needs of the county government, KRA as well as the taxpayers. The system was piloted for several years before even being used. ILabAfrica is a Centre of ICT Innovation and Development located in Strathmore University. The centre is involved in multidisciplinary research, student participation, and partnership with government, business, and other funding organizations, as well as spearheading Research and Innovation in Information Communication Technology ${ }^{80}$. ILab was preferred by Kiambu county as it was also available for maintenance whenever necessary. County Pro was however being used at the county level and was not a replacement for ITax. Rather it was used to make its integration easier as it was able to feed the county taxes into ITax. KRA has also recognised the importance of County Pro even going ahead and endorsing its use at the county levels. ILab was seen as being more responsive to any issues faced at the county level contrary to KRA as some of their developers were sometimes unavailable slowing down the process of enhancing the system. The design of the program was implemented after a study was carried out giving recommendations on the best practice.

One taxpayer I met in Kiambu was a prominent businessman who operates both within Nairobi and Kiambu. The businessman sells tea and coffee both locally and internationally. Peter introduced me as they were acquaintances. Wambua, the businessman, chose to move his business registration from Nairobi to Kiambu because of the favourable conditions in Kiambu. Kiambu had a different tax policy for businessmen like Wambua where they not only received dedicated KRA agents working with them closely to help them comply, but they also waived certain fees to get businesses to stay in Kiambu. Wambua was registered in Nairobi however due to unfavourable conditions like random audits as well as penalties for late filing, Wambua had decided to move his businesses to Kiambu. When Kenya devolved its governance in 2010, as a cherry, Kiambu county reached out to him and gave him tax exemptions for one year. Wambua explains that in Kiambu the taxpayer is made to feel important as the relationship between the taxpayers and administration is quite strong. He knows

\footnotetext{
${ }^{80}$ http://www.ilabafrica.ac.ke.
} 
that the money he pays helps to benefit the county by knowing that even if he is late in filing his taxes, they would never penalise him. Wambua, like Peter, have strong tax compliance attitudes with both even explaining the among services provided by the Kiambu county including cutting edge state of the art hospital and government schools that are well equipped.

The local county in Kiambu found innovative ways to ease the process of filing for taxpayers like Wambua significantly increasing compliance and revenues. Not only do taxpayers in this county have many centres they can visit to file their taxes they have KRA agents who offer services that could potentially the need to engage mediators as seen in the case studies in chapter five. The perception of fairness and trust are quite strong here working favourably for KRA and for the economic benefit of Kiambu county. The county as has been the case historically has been favoured by colonial economic policies that still informs that government's policy. Kiambu is seen as a cornerstone in the Kenya economy, and it reinvests its revenues into creating solutions for its citizens, a feature that is rare even in Nairobi where taxpayers are left to craft their own solutions.

\subsection{The Untaxables: Isiolo}

"Can we eat technology? Our county has many poor citizens. What will they do with technology when they do not even have food? We are forgotten by the government; we are not yet Kenyans."

This statement was made by the deputy governor of Isiolo county when we met in an office in downtown Nairobi (most county governors in Kenya spend a lot of time in the capital). The governor, while shaking his head, discussed his real issues about the marginalisation that had been ongoing in Isiolo since colonial times. Isiolo county located not too far from the equator, is part of what is known as the arid and semi-arid lands (ASAL). His body language changed drastically when he explained the unfair treatment of his county. "You don't need anyone to convince you that we are marginalised, just look around there," he added.

Marginalised communities are defined in the Kenyan constitution (2010) defines as "a traditional community that, out of a need or desire to preserve its unique culture and identity from assimilation, has remained outside the integrated social economic life of 
Kenya as a whole, or an indigenous community that has retained and maintained a traditional lifestyle and livelihood based on hunter or gatherer economy; or pastoral persons and communities whether they are nomadic or a settled community that because of its relative geographic isolation has experienced only marginal participation in the integrated social and economic life of Kenya as a whole" (Article $27,4)$. Furthermore, the marginalised are defined as a group of individuals who were or are disadvantaged by discrimination on one or more of the grounds in Article 27 (4) due to laws or practices in place before, on, or after the effective date.

Discriminatory legislation first marginalised Kenya into various districts. The district ordinance act of 1902 created the 'closed districts' policy. The arid and semi-arid lands (ASAL) were 'closed' by the policy restricting movement of persons and goods This policy divided the colonial empire in Kenya creating 'two economic zones. The ASAL areas were geographically 'closed' from participating in the national economy as they were not seen as cooperating with the colonial economic policies which wanted the natives in these regions to settle down and become taxpayers. The other zone was the one that included Kiambu and its surrounding areas.

To understand this dynamic closer, I travel to Isiolo. The city after the end of the railroad. Isiolo county is a county located not too far from the equator. It took me about three hours to travel there from Nairobi with a private car that was hired for the trip as public transport to Isiolo took longer as buses made several stops in all the adjacent cities. I was surprised about how the landscape changed dramatically from Kiambu with the lush green surroundings and fresh air to very dusty surroundings within a short period. As we drove past the railway lines, the economic activities like side shops became less visible. The landscape changed as well; from a green area where tea, coffee and flowers are grown to a place where semi-arid shrubs dominated. We got into Isiolo which lives up to its reputation as being famous for being windy and dusty. As we drive in, we see herds of cattle being steered on the side of the road, a common activity among the pastoralists who move from one place to another in search of pasture for their livestock. The main feature in the town is a long stretch of a highway road where most of the business, offices, and mosque are built reflecting the people's socio-cultural activities.

The deputy governors' words of 'look around' became quite clear when I went to Isiolo. It was like time had stopped in this county. The county is relatively small with most of 
its businesses located along the highway that was incomparable to the Thika superhighway. The Isiolo highway was well maintained but it was a two-lane road carriage. The urban centre grew along the main highway that connects the rest of the arid and semi-arid areas to the other counties in Kenya. Only $20 \%$ of Isiolo's citizens live in the urban areas whereas most of the population live on the outskirts of the county maintaining their pastoralist lifestyle. Arid and semi-arid regions (ASAL) cover 70 to $80 \%$ of Kenya's land area. Pastoralism benefits Kenya's economy because livestock production accounts for $50 \%$ of agricultural GDP, which accounts for 20$30 \%$ of total GDP (Nyariki 2004; Fitzgibbon 2012). However, using GDP to estimate the value of pastoral livestock is insufficient because it only considers marketed livestock and livestock products, ignoring non-marketed products such as the value of livestock in subsistence and socio-cultural values, both of which are important aspects of pastoralism (Amwata et al.2015).

Despite its importance in national economies, pastoralism confronts several challenges, including misconceptions about pastoralism, climate change, globalization, urbanization, and undervaluation of the pastoral economy (Amwata et al. 2015). Therefore, pastoralism does not however contribute to the county's economic growth. The county government with the help of international donors and partners have tried to address the disconnect between the informal pastoralist economy and the (small) revenues generated. Since many of Isiolo's residents are pastoralists and do not even have national identity cards, they are closed out of accessing any type of government services. The governor told me that the youth were also having a hard time getting identification papers to prove their "Kenyaness". As a result, many choose to live and work outside of the government's jurisdiction. "The process by which the residents in the county have to go through to prove their Kenyan identity", argues the governor, "is quite problematic". A relevant question is how citizens can pay tax if they do not have the right papers or even formal jobs. The area lacks a university and there is only a polytechnics school available to offer the youth an education in vocational skills. According to the governor, this is not enough to serve the needs of the community. The issues that arose here seem to be connected to their Kenyan identity. They were marginalised during the colonial administration and it seems that very little has happened since independence to bring them into the fold of the national government. They too found innovative ways to go around this disconnect. 
One interesting thing is that the economy here remained cashless for quite a long time as the pastoralists still engage in barter trading (SID,2016). They go to the market and exchange their livestock for the goods they needed. Many of the pastoralists are unaware of what the tax system was. They did not understand what statehood they were as did not rely on the state for any services. As explained earlier the colonial administration attempted to get the pastoralist communities to settle down to become 'taxable'. When the citizens rejected this policy, the colonial administration developed policies which were meant to geographically marginalise them by restricting any economic activity in the area. They tried to restrict pastoralist activities to certain areas however this failed miserably (Guyo,2017).

As stated, it contributes to about $50 \%$ of the national livestock industry. Historically though the revenues generated were mainly taken by the central government but since the country adopted a new constitution, the revenues were partly being retained at the county. The deputy governor argues that despite the significant revenues generated the county was trying to 'catch up' to the national level seeing that they had been historically marginalised. The needs in the county are overwhelming and much of what they generate is reinvested in the county development projects. The county government, according to him, was unable to run its operations without contributions from the central government. At the time of my research this was quite controversial as the revenue allocation formula was based on contributions ${ }^{81}$. This would mean that countries would receive revenues from the central government based on their tax potential whereby those with higher revenues would get more allocations than those who had lower.

The governor and I talked about ICT development during our meeting in Nairobi. The governor lived both in Nairobi and in Isiolo as many government officials did. They preferred to live in the capital city so that their families could access school and health care. He informed me about the national fibre optic cables that were supposed to be implemented in Isiolo. The cables, he informed me, were put in place however they do not serve their purpose. He smiled and said, "yes we have the cables, but who is going to connect us?". The national fiber optic network had been brought to Isiolo, however

\footnotetext{
${ }^{81}$ There is a reform that is currently being undertaken in Kenya to change how this allocation formula works as it was understood to be quite unfair for the counties with lower revenues generation.
} 
that is where the ICT development ends. At the time of my fieldwork, they were yet to be connected. The county government mostly used mobile internet from the mobile providers, Safaricom. The problem with this however as he explains is that the county only has $2 \mathrm{G}^{82}$ connection. This means that the internet connectivity from this source is quite slow. Looking around the city I noticed what he was referring to. There were places that seemed like they had been taken back in time when I compared them to the cities nearby.

Most of the citizens in Isiolo are engaged in small-scale business mainly made up of the value chain from pastoralism, milk, and meat. I got there on a Friday afternoon and as I walked through the city, I could see that they were engaged mainly in informal business. It is an illustration that in the semi-arid areas like Isiolo, the economy is mainly cash-based in the urban areas. It is affirmed that barter trade is still used in some areas within the informal economy especially amongst pastoralists (SID,2016). There were numerous reasons for evaluating the implementation of ITax in Isiolo. Isiolo is infrastructurally marginalised and Allan the senior ITax manager in Nairobi told me that they had difficulties taxing areas like Isiolo as "We can't invest in offices in an area we don't understand how to tax" he said, "In addition the area is quite unsafe making our tax officers quite reluctant to working there" he affirmed. Allan had also mentioned that the area was better off served by Huduma centres with the risk shared with the central government.

The 'Arid and Semi-Arid lands (ASAL) as they were known, were historically seen to have harsh topography as well as citizens who were difficult to rule. The Cushitic communities who dominate in these regions, resisted the colonial rule due to their nomadic lifestyle which they felt was being restricted, misunderstood, and endangered by the colonialists (Turton 1972). The colonialists had planned to settle them down to make them 'taxable' (Guyo,2017). Settling down was non-negotiable due to the implication it brought to their pastoralist lifestyle. This then created an impediment to revenue generation because the citizens viewed the state as constrictive of their way

\footnotetext{
${ }^{82} 2 \mathrm{G}$ (or $2-\mathrm{G}$ ) is short for second-generation cellular technology. $2 \mathrm{G}$ technologies enabled the various networks to provide the services such as text messages, picture messages, and MMS (multimedia messages)). The current development is however $5 \mathrm{G}$.
} 
of life. Taxation has become viewed as an oppressive tool that was limiting their way of life. Realising the difficulty in taxing them, the administration ignored the area in terms of development occupying themselves with governing the regions along the highlands. For the duration of their rule, they remained underdeveloped (Turton 1972: 119-143). Isiolo County government officials questioned what digitalisation was going to help them with if they lacked the basic needs to survive.

My first stop during my fieldwork was at the Huduma centre. The centre was in what looked like a refurbished building. It looked new on the outside but seemed old on the inside, almost sounding like Mary's description of ITax. The centre seemed quite empty with only a few counters manned. The deputy governor stated that its citizens had not yet adjusted to the center and the facilities it can offer. Many still opted to go to nearby cities almost an hour away to access government services. The economic activities in this area had grown significantly however it remained informal. The informal sector in this region has posed a great challenge to the growth of tax revenues in the county as many were registered as taxpayers. The United Nations Development Programme-UNDP report (2009) states that: "Pastoralists have been ill-served by development policies and actions so far, since planners have almost without exception tried to convert the pastoralists into something else, judged more modern, more progressive and more productive". 83

Pastoralists in Kenya have long been marginalized by government policies. Pastoral livelihood was regarded as wasteful, administratively inconvenient, and not valuable to the colonial effort by the colonial structure. Moreover, pastoralists were not thought to be as hardworking as agricultural people (UNDP,2009). As a result, the colonial authority focused on areas that maintained the colonial political economy's extractive nature. The policy of marginalization was continued by the independent governments, later. The economic roadmap for Kenya's post-independence development was laid out in the Sessional Paper No. 10 on African Socialism and its Application to Planning in Kenya ${ }^{84}$, published in 1965.

\footnotetext{
${ }^{83}$ Resilience: Interdisciplinary Perspectives on Science and Humanitarianism, Volume 2, March 2011 ${ }^{84} \mathrm{http}: / /$ siteresources.worldbank.org/INTAFRICA/Resources/257994-1335471959878/SessionalPaper-No-10-(1965).pdf
} 
This blueprint, alarmingly indicated as a policy that the government would invest in the most productive regions. Unfortunately, the ASAL were not deemed "productive," and hence were mostly neglected. The impact of such policies may be observed in practice, where many people appear to be separated from the government and do not regard themselves as taxpayers. The following example, that of Abdi, a jack of all trades, demonstrates how the county's revenue potential in the informal sector is not being exploited even though its economic activities have revenue potential.

Abdi

I meet Abdi a young man who describes himself as a "hustler"5". Abdi looks like he is in his early twenties. He was born Isiolo and has lived here all his life. I met him when I bought bottled water in his kiosk. As it is in many parts of Kenya tap water is not fit for consumption and Kenyans who can afford to pay about 50cents to a dollar can purchase water to drink. I pay Abdi for my bottle through my mobile banking application, Mpesa. When the payment was confirmed, my name came up on his phone and he said in Swahili, "Asante Nimmo" meaning 'thank you, Nimmo'. At this point I had gotten used to this as many would use my mobile transactions to get to know my name. Abdi could tell I was new and he became curious about my visit as very few people visit Isiolo for research.

Abdi's shop is located at the very edge of the highway filled with noise from passing cars and people and filled with dust. The city center located along the highway looked out of place as though it was waiting to catch up to the highway's modernity. On one hand, the buildings were older while the roads connecting it to the rest of the country were newer and fresher creating this contrast. The roads were built by the national government whilst the local development was tasked to the county government and was lagging. The shop was a coca cola sponsored shop in red which is a common feature in Kenya. Many multinational companies pay the shop owners a small fee to use their shops to advertise their products.

\footnotetext{
${ }^{85}$ In the Kenyan context, "hustlers" are viewed as enterprising individuals determined to succeed with many businesses.
} 
Abdi had a lot going inside his shop. He had a copier machine which was powered by a makeshift generator. In addition to that, he sold groceries and provided Mpesa services. Abdi owned a 'boda boda' as well. It was packed in front of his shop. Boda boda are motorcycles that are used to ferry goods and customers cheaply. Abdi usually rides the boda-boda while his wife attends to the kiosk. His shop was a busy hub making it difficult for him to respond to my questions. There was a business licence hanging on his wall as a requirement for all businesses in the country. Yet, despite his business licence, Abdi was not a taxpayer. The county permits were not contingent on being registered as a taxpayer on ITax. Abdi had never paid any money to the KRA. He said that there had been some issues previously, but the county government decided to collect local taxes by giving them permits. He believes that he is not informal as he has a licence. The idea of informality according to him regarded those who had either makeshift shops or were businessmen without shops or offices. He was convinced that what he is paying for the county fees counted as taxes despite the amount he paid for the license being insignificant. He told me that he had paid 5000 (50 Dollars) shillings for a single business permit which would be much less than what he would be required to pay in taxes.

Abdi had been operating several businesses informally and the county licensing practices had allowed him to expand his business. With regards to taxation, Abdi knew that the Kenyan government collected revenues, but he did not understand what the taxes were being used for. When he was talking about the Kenyan government it was thought he was not Kenyan himself. Abdi claims to be self-sufficient paying for his children's school fees, their hospital bills and anything that is needed from his profits. He said that the only visible thing that he has received from the government is the highway, pointing to the direction of the road in front of his shop. Abdi is thus considered by the county government as an informal worker. The county government, according to Abdi, is unable to understand how much revenues he generates as he does not use an electronic register that could help determine this. He gladly paid the county business permit once a year and is complying with the requirements.

Abdi was not aware that KRA had made it mandatory to use the digital tax reporting system. He was perplexed. Abdi had dropped out of school due to financial problems. He was not tech savvy, but he knew how to use his smartphone. As I informed him of the new changes, he struggled understanding what ITax was. He asks me in Kiswahili 
"ni nini umesema? (What are you saying? My translation). He continues: "I don't understand what you are saying" (my translation). Abdi knew about the KRA because in the past they would come and try to close businesses in the region. He had however not heard about ITax and adds that he probably would not know as he felt that it seemed to be advanced. Many KRA employees opted to move away from Isiolo easing the problem that had existed before. the residents did not have a problem anymore as they now only dealt with the county government. Here they feared the local county police known as "askari" as they shut down businesses that run without permits. Abdi recognised the county government more than he did the national one.

Abdi continues to talk about how Isiolo has not changed much over the years. Prevalent water shortages which limit the electricity supply in the region. According to him, very few residents have access to water or electricity which regarding internet connectivity might seem far-fetched. Those are mostly the rich businessmen/women who mostly power their own supply through diesel fuelled generators. I notice a generator that he explains he uses to power some equipment in the store including a photocopying machine. The business was not as lucrative as he wished because he faced competition from the cyber cafes located not too far from his kiosk.

As I sat with Abdi, I realised that his Mpesa business was thriving. He was on his phone constantly as he talked to me transacting money for his clients. Some of the clients looked like nomads yet they were transacting huge amounts of money. Abdi smiles when I ask him where they get their money from. He explained that the pastoralists come into town to sell or buy livestock. However, because of growing insecurities in the region they opt to save their money in Mpesa. Did the pastoralist pay taxes? I thought to myself. I did not get the chance to talk to the nomads as they are usually in a hurry to leave town. I was advised not to travel to the rural part of Isiolo where they live as it was considered unsafe. It would have been interesting to see how innovations like Mpesa were changing their lives. They were in Abdi's shop however they looked quite busy and unapproachable.

On a phone call interview with the governor to follow up on some of my findings, I bring up Abdi's case. The governor sheds light on the situation. He said the county needed local revenues which meant they had to find a solution to get the informal sector to comply. They pay a yearly fee based on the size of their businesses. He said that he 
was not in the county government at the time this provision in law was enacted but he knows that it was a very consultative process that included dialogue between the county government and themselves. Since Abdi did not pay national taxes, I was determined to find Isiolo residents who used ITax. I went to the newly opened Huduma centre and cyber cafes in order to understand the process of taxing in this region.

\subsection{Huduma Centre Isiolo}

The Huduma centre in Isiolo was also located not too far from the highway. Huduma centres, as explained in chapter three, provide citizens access to most government eservices including ITax. I walk in and I see a similar décor like the other Huduma centres I had visited in Nairobi and Kiambu. A guard asks me how he can help me. In Nairobi there were too many people around for a guard to be concerned with which counter you were going to but the scarcity of people in this Huduma centre made the people around curious of your presence. I had tried to blend in with the natives as I looked like most of the inhabitants in this area. I informed the guard that I wanted to go to the KRA counter. He informed me that there was a tech hitch which was keeping the office from serving the clients well. The KRA counter was affected by this and due to this, the KRA officer had stepped out for a while. He advised me to either wait patiently or come back the next day. He also informed that the taxpayers would not be back in the afternoon as the semi-arid weather was unbearable making it difficult for some of the workers to fully man their counters. The electricity rationing and the systems being down were great indications that the centre might not be operational in the afternoon. What if I had an emergency, I thought to myself? I thought of Nyambura's case of how she spent seven hours in line waiting to be served. There were about 15 of us waiting patiently but I could see one by one losing hope and leaving the centre. I left after an hour and half.

I was advised to come back the next day at 8am. I went expecting to find the place buzzing with activity. It looked almost deserted with only a few counters being manned. The KRA counter was empty as the KRA officer was not there. There were a few people right in front of the counter waiting in anticipation for the counter to be opened. I sat next to a man who was in line and asked him what services he had come to seek from the KRA. He did not have print outs with him, a practice that is very common with 
the e-services in Kenya. Once you go online and fill in the documents you need to print them and produce them at the counter.

I spoke to a businessman Ali. He told me he needed to get a tax compliance certificate. However, he was unaware of ITax asking me what it was just like Abdi did. He had not heard about ITax, and I could safely say he would not find out about it on that day as it was almost midday and the KRA counter was still unmanned. Isiolo ICT corporate strategy 2015-2020 states that the national fiber optic installation program was terminated meaning that the only available internet connectivity in the region would be from the mobile network ${ }^{86}$. The strategy report also states that mobile penetration is at $22 \%$ for $2 \mathrm{G}$ and $12 \%$ for $3 \mathrm{G}$ while fixed tele-density is at $0.02 \%$ (Isiolo County, $2014 ; 14)$. What this translates to in practice is that the mobile network that the country relies on for its internet connectivity is quite weak. This could then explain why the Huduma center in general that is reliant on internet connectivity had slowed or reduced internet access that limited the e-services they could offer their citizens especially at the KRA counter. This became more the case of the chicken, and the egg should the government have invented in the ICT infrastructure before making the use of such platforms mandatory or should they now counter it with providing adequate ICT infrastructure.

Counties in Kenya experienced challenges in reporting their taxes to the revenue authority due to connectivity challenges and outdated IT systems/configuration (e.g., using old Local Authority system) (ASI, 2018). The older systems were outdated and were thus unable to integrate with ITax. This further reduced the government's revenue potential as the lack of appropriate systems and infrastructures did not allow KRA to accrue its tax potential. Furthermore, they stated ITax is also disconnected to the government's financial management system (IFMIS) increasing the risk of errors and missing data entering central tax data on tax. They also noted that revenue generation methods within the different counties vary making governments' forecast revenue streams quite difficult.

\footnotetext{
${ }^{86}$ http://icta.go.ke/pdf/9.pdf
} 
The Frontier Counties Development Council (FCDC), a council tasked with supporting development projects in the ASAL counties, consists of 8 counties of Isiolo, Marsabit, Wajir, Mandera, Turkana, Garissa, Lamu and Tana River. These counties constitute about $29 \%$ of the population, with a high unemployment rate. Many of them fall under the same category as Abdi and KRA estimated in its 2018 report that the Isiolo County Government's own source revenue (OSR) accounts for $14 \%$ of total generation. Specifically, Isiolo County's contribution is between 3 and $5 \%$ annually, demonstrating an over-reliance on the equitable share when the central government gives approximately 90-95\%revenues collected nationally (CRA, 2019). What this example from Isiolo and Kiambu show is that revenue administration in the two counties vary significantly leading to varied outcomes with Kiambu emerging as a strong revenue generating county while Isiolo continued to lag being among the counties with the lowest revenue generation in Kenya.

Kiambu and Isiolo perform quite differently with regards to tax generation. What has been affirmed in this chapter is that one of the reasons that explain this disparity is the colonial heritage in fiscal policies in Kenya. The two counties were historically geared towards their status as the policies that were in place during the colonial administration facilitated for the growth of certain economic activities like agriculture by developing infrastructures that boosted trade while economically "closing" others from being within the economic grid due their cultural lifestyle of pastoralism. While there might have been a way to engage the pastoralists economically it proved impossible to get them to settle down in order to get taxed. This therefore in my opinion created individuals who also to date are seen as "taxable" and "untaxable". Abdi and Wambua represent businessmen who have been empowered by their county policies with Wambua witnessing more growth and success as he is able to benefit from government policies on the redistribution of tax due to counties high tax revenues while Abdi is seen as a business owner with a permit that allows him to generate an income for his family and not enough to help with county development.

\subsection{Conclusion}

This chapter has shown how the colonial aftermath has significantly shaped taxation in countries like Kenya. Infrastructures like the railway were used historically to economically empower certain populations and marginalise those who were not 
connected. This rationale has been re-used in the current digitalisation implementation as shown with the NOFBI map. The implantation of the fiber network crucial to internet connectivity was fashioned after the existing railway and other infrastructures along that like. The two examples shown in this chapter shows how ITax's practice is influenced by the local structures in place. Kiambu and Isiolo were and are still being shaped by colonial infrastructures. The colonial infrastructures were used to implement digitalisation in Kenya with the areas connected to the railway receiving the latest cutting-edge technology making them a conducive environment for ITax's implementation.

Those who were connected to the grid historically have been described in this chapter as the taxables with Kiambu county emerging as the poster child of ICT development in Kenya. Historically the region had received a large portion of resources and manpower towards the development of economic policies and infrastructures that were also use to boose revenues in the region. Kiambu's case study is evident of these investments and has shaped the current taxation environment in the county leading to Kiambu being of the highest revenues in Kenya after Nairobi. between those who they governed. Kiambu as well benefited from the digitalisation shift with the county describing themselves as a digi-county. On the other hand, Isiolo, a historically marginalised area, lacks the basic infrastructures that are needed to help with the shift. Isiolo and Kiambu counties presented two unique cases that took different routes within this digitalisation journey, one describing itself as a digi-county providing free WIFI to its citizens while the other one struggles to provide $2 \mathrm{G}$ and $3 \mathrm{G}$ mobile network to its citizens. With regards to ITax, the counties also take different approaches with Kiambu implementing county pro program that would help the citizens collect their local taxes while Isiolo using small scale business licences to tax the few businesses that have become legitimate. Many businesses in Isiolo are informal, proving it a challenge for the county and central government to raise the taxes that are needed. In Kiambu however the use of the digital tax system almost tripled their revenues making them the second richest county after Nairobi County.

What is important to note in this chapter is that travelling models also collide with the local infrastructures. The implementation of National Fiber Optic Backbone Initiative (NOFBI)for example was planned maybe even unknowingly along the very colonial 
infrastructural lines that were meant to divide and rule. Those who were loyal to the colonial administration were settled along the most modern infrastructure at that time, the railway. Those who seemed 'un-colonizable' were left to their own way of life, pastoralism and forced into an economic exile where they could not engage in the national economy. 


\section{Chapter Seven: Concluding Remarks}

\subsection{Introduction}

“Why should we care so much about taxes? I feel like we don't pay taxes, rather we donate money to the government......What makes it worse is that the new tax systems (ITax)make us spend more money. Taxation has always oppressed us!"

The following statement was made by Nancy, one of my interlocutors, representing the views of most taxpayers I interviewed in this study. The description of taxes as donations, costly and oppressive was often implied and articulated by taxpayers when asked what they got out of paying taxes. Taxation according to them was always oppressive and did not give them any representation nor provision of services. There were low expectations from the taxes they paid contrary to the famous saying within taxation "no taxation without representation" that is premised on those taxes should ideally guarantee representation, provision of services and accountability. This saying that originated during the American revolution is important in understanding the low tax morale usually experienced in developing countries like Kenya.

The issues raised by Nancy drastically reduced taxpayers interviewed in this study willingness to comply with ITax. The findings in the study therefore are not aligned to aims and objectives of digitalising tax rather they indicate a disconnect from policy and practice as it was meant to increase voluntary compliance. ITax aimed to get taxpayers like Nancy to comply however as argued in this dissertation (see chapter five) their motivation for complying was disconnected from mainstream tax compliance theories that ideally should be voluntary compliance where taxpayers pay the required taxes. The lack of voluntary compliance goes against the said aims of using technology to increase revenues as it encourages tax evasion and avoidance. Taxpayer as shown in this thesis are unwilling to pay the "right" taxes to the KRA as they perceive the tax system to be "unfair" or "unjust".

The aim of this case study has been to ethnographically trace, follow and analyse the digitalisation of taxation in Kenya. By focusing on the travels, this study connected prominent global policies of development to local digital tax practices. What this study revealed was that travelling global models do not travel as seamless as imagined as 
they are impacted with the political, economic and historical structures at the local levels shaping its' practice. In this dissertation, I showed as well how global tax policy models were perceived by the international actors actively engaged in its travel. I compared It with how the local actors like KRA and taxpayers understood the models and repurposed it to serve their needs. Finally, I looked at the imagined end-user of the models. There are those who are deemed "non-users" because they are not imagined to be taxpayers. I show how historical and political structures shaped how platforms like ITax travels also locally empowering those who are the "taxable" users while rending others "untaxable" (see chapter six).

The main finding of this dissertation is that KRA did not achieve its objectives of increasing tax compliance and revenues. According to Migot and Paul (2019), the Kenya National Bureau of Statistics reported in 2016 a success rate of only $33 \%$ when it comes to ITax projects and late filing, suggesting a limited compliance whereas ITax was required to increase it. Decrease compliances suggests decreased revenues and as stated by the World Bank in 2018, "the recent administrative measures to support domestic revenue mobilisation, including integration of ITax and Integrated Financial Management Information System, rollout of integrated Customs management, and expansion of tax bases, are yet to yield the envisioned revenue increases" (cited in Gicobi, 2018).

My conceptual framework in this study was located within anthropological and science and technology studies. I approached my fieldwork ethnographically and paid attention to things like queues and expressions like "ITax makes me stupid" to connect it to larger conversations. By conducting ethnography of ITax, in Kenya. I analyse how ITax travels ethnographically by focusing on how ITax works technically and on the other hand how it is working socially, culturally, and politically as an object of technoscience. I argue that an ethnography of tax practices like e-filing on ITax allows the inclusion of perspectives that would otherwise go unnoticed and understudied like taxpayers' perception of ITax as well as understanding the processes they must undergo to comply. An anthropological approach in tax allows a closer analysis of how the social contract can be strengthened or weakened by practices like e-filing and platforms like ITax that as had been shown in this dissertation were complex for taxpayers going against KRA's mantra, simple swift and secure. 
Postcolonial technoscientific approaches in this study were used to make visible the role of colonial technological rationale in the current digitalisation trend. The approach helped make visible how ideas like digitalising tax use historical rationale and infrastructures to justify current policy within taxation. Digital technologies in taxation are therefore viewed as tools for leapfrogging sustainable development. As demonstrated in Chapter six, I argued that the new digitalisation trend builds up the colonial rationale that historically the colonial administration viewed infrastructures and technologies are bringing "modernity" to colonies. These policies must therefore be studied from a postcolonial perspective to make visible how the rationale is still embedded in the current development project like the financing for development.

This concluding chapter is divided into three sections. The first part presents the main findings. The second section considers the conceptual implications of our research. The final section highlights unaddressed questions and suggests avenues for further research.

\subsection{Main Findings}

\subsubsection{The Cultural Implications}

The Kenyan Way of implementing ITax is a major finding in this study. It highlights the impact the local structures, histories and cultures have in the outcome of policy. While it is imagined that policies can travel without any local intervention or interference it is important to understand that most models like ITax travel without their blueprints making them vulnerable to interpretations. KRA as shown in chapter four connected the international ideas of digitalising tax to their own understanding of transformation that were not really translated into practice like eh example of taxpayer being turned away at the KRA headquarters KRA's main objective at that time was to increase customer satisfaction. What became evident is that ideas of transformation remained with the top leadership at KRA. The lower-level staff found their own Kenyan way of translating ITax as it moved downwards within the organisation the idea of ITax changed.(see chapter four). KRA relied upon its existing structures as well as relationship with taxpayers to create an environment of change however they relied more on creating the perception through its media campaigns rather than 
implementing. This led to complexities prompting them to find "Kenyan ways" to comply, mostly described as their coping mechanism to new and complicated government policies. Taxpayers found ways to get their compliance certificates without filing the "right" taxes as they neither understood how the system worked nor what they really needed to comply with.

The Kenyan way of implementing and using ITax therefore made visible the historical, economical, and even political structures that influenced how ITax was adopted and used. KRA's aims for digitalisation were shaped by both local and international aims while taxpayers' reactions were shaped by the fears of non-compliance visibly changing the Kenyan tax architecture. It also altered the understanding of tax expertise with ICT experts now emerging as the new tax specialists based on their understanding of technical aspects of ITax. Kenyan taxpayers reacted to ITax's complexity by hiring cre middlemen or mediators to help them navigate ITax. These middlemen who replace KRA tax agents range from high to low levels and offer different services based on the client's financial capability. Some mediators became powerful, some not even being held liable for the mistakes they make while helping taxpayers like in the case of Nancy. This put them at risk for any mistakes made by the mediators as shown by Nancy who was heavily fined due to a mistake made by her tax consultant. Tax agents, consultants and IT experts charged extra fees for their services making them exclusive to those who can afford them (see chapter five). Those who were from lower income brackets had to use untrained cybercafes agents making them vulnerable to wrong filings.

What many examples in this study showed was that taxpayers struggled to comply creating an important role for the mediators who could then help them navigate ITax. The complexities led many taxpayers to comply with ITax with minimum effort with some even resorting to finding innovative ways of avoiding tax. The tax morale was low among my respondents who came from different backgrounds. This would be therefore indicative that ITax was being used as an e-filing system however it was not being used optimally. Contrary to the ideal of tax compliance, where taxpayers should comply willingly, taxpayers in this case study were mainly motivated only if they needed to get a compliance certificate to access either government contracts, bank account and even private work agreements. Taxpayers found loopholes thereby 
reducing the amount of taxes that should ideally be paid. This could explain the low tax generation in Kenya.

\subsubsection{Postcolonial Implications}

The idea of a global financing for development policy is based on the notion that countries like Kenya can achieve economic development if they receive the right "tools". These ideas are situated in colonial understandings of bringing "modernity" to the colonies. However, as shown by the examples in chapter five and six do not work in favour of such reforms rather they interface creating new identities and understandings of the policies being implemented in this case, taxation. The colonial administration used infrastructures as well like the railways to accelerate economic growth in certain areas of Kenya. As illustrated in chapter six, the same railway infrastructure was used to implement the National fiber optic backbone in Kenya and as well as electricity. Digital connectivity like the railway line strengthens certain communities while marginalising others based on their economic contributions.

ITax as shown by both this dissertation did not take the local and historical structures into account during its development and implementation. It did not take into consideration as well the infrastructural needs in order to make such a shift. Firstly, it was rapidly implemented giving taxpayers little time to adjust their filing practices to a digital system. To make matters worse, a year after it was implemented, its use was made mandatory. This meant that taxpayers were now unable to manually file their tax returns. Previously taxpayers were able to get help from KRA agents as indicated by the lines in picture at the beginning of this chapter. They would stand in line for hours, but they did not pay extra to get help with their manual filings. Furthermore, it was easier to amend any mistake made. Taxpayers had to now turn to mediators to help them navigate ITax.

The implementation of ITax made visible the economic injustices that exist in Kenya excluding those unable to use ITax. The marginalized groups who were already lagging economically, became digitally excluded from participating as taxpayers as they lacked the necessary infrastructure to allow them to use platforms like ITax. Historical structures that disallowed some taxpayers from even participating as taxpayers as they were not seen to be economically viable (see chapter six). I 
described these taxpayers as the "untaxables" however I also showed that there was a missed opportunity for generating tax revenues in these areas.

This dissertation has shown the two contradictory roles played by science and technology in the colonial discourse, whereby one was making it clear to the "natives" what type of knowledge they lacked, the other role was always giving them hope that this knowledge could be theirs by giving them technical assistance (Seth,2009,377). The global policymakers and donors aimed to show that their knowledge and policies were better and more superior. The end of colonialism left an institutional and infrastructural residue that still plays an important role in the determination of tax policies and the capacity to collect tax. This has not only shaped tax policy development in Africa but has also shaped the relationship between the policymakers and developing countries.

\subsubsection{User Approaches in Design}

Another major finding of this study is the importance of user approach in technological design. ITax's developers (the KRA and TATA) as well as global tax policy makers imagined a taxpayer who was e-literate and had access to the necessary ICT infrastructures. The first idea is the understanding of technology as being a tool for increasing revenues. These polices translate into different practices when they interface with the existing culture leading to resistance. Technologies that are not designed based on the local reality offer short term solutions and are often succeeded by another model. This is witnessed at the KRA with ITax seen as "revolutionary" replacing the earlier model which most likely was seen as being the best during its implementation

Another impediment to ITax was that because it was an online platform, it required infrastructure that most Kenyans cannot afford or have access to such as smartphones, computers and even internet connection. By enforcing the mandatory use of ITax, the KRA categories taxpayers as non-compliant based on their registration on the system. the KRA disconnected many taxpayers from using ITax a year after ITax was mandatory as they were unable to verify double registration as well as those filing wrong information

Local knowledge and realities, as demonstrated in this dissertation are often not taken into consideration in policy development and in the case of ITax not in the 
technological design. ITax as explained in chapter four was developed first by Chilean consultants and was later evolved and merged with the version developed by the Indian consultants. The design was therefore not inclusive of the Kenyan taxpayer's reality as well as the administration. As demonstrated in my previous chapters, both taxpayers and the KRA struggled with using the system showing a glitch in the design of the technology.

The importance of a user-centred approach to technology design cannot be overstated. What also became evident is that innovation, such as ITax should have paid attention to the realities on the ground, such as the criteria for compliance, such as a laptop, a smart phone, and the internet access. ICT skills were also needed as the process as shown in chapter four was quite complex requiring the taxpayer to complete several technical functions like downloading and uploading documents to comply. Taxation is a key structure in government and the tools developed to strengthen it should take the social contract between the state and the citizen quite seriously. Failure to do so works against the objectives that the projects the digitalisation of tax aims to achieve.

Ownership of the platform became an important issue here as the KRA was unable to recommend great changes due to their lack of access to the system. They were quite restricted, something that led to great problems for the taxpayers. For example, when the systems were down, it would take a long time before issues are resolved as they would have to wait for the international consultants to troubleshoot. ITax was also unable to develop features that could be used by the informal sector or even potential taxpayers as I illustrate in chapter six. By not including this big group of potential taxpayers, the KRA closes itself from millions of revenues as most of these pastoralists in the marginalised areas, supply the country with up to $70 \%$ of its livestock.

\subsubsection{E-readiness}

ITax was implemented with a misunderstanding of Kenya's e-readiness. Kenya was not ready for a mandatory shift as it required taxpayers to have access to both software and hardware. Items like laptops and even smart phones to fulfil the promise laid out in the introduction of this dissertation as well as internet connectivity were only privileged to a few. There were areas like Isiolo and its surrounding ASAL counties 
that were barely connected to second-generation mobile connectivity(2G). How would they be expected to use ITax?

The digitalisation policies in Kenya are mostly benchmarked on the successful and popular mobile money platform 'Mpesa' (see chapter one). Policymakers who endorsed the use of platforms like ITax banked on the success of 'Mpesa' the mobile platform that has been highly successful to benchmark for Kenya's e-readiness (Daniels, 2017). What was however omitted in the policy planning were the factors that facilitated Mpesa success. The factors that were overlooked were that Mpesa used the simplest mobile application, USSD application which allowed any one with the simplest of a phone to use. ITax required the user to either have a laptop or a smart phone in order to access it. As my informant at KRA told me "It's easy to use! you just log on to your smart phone". The assumptions where the users would have access to these facilities however the reality shows that smart phones and laptops are only owned by a minority. Pew Research (2018) estimates that of the $80 \%$ of Kenyans that have cell phones only $30 \%$ have smart phones. In addition to this there were many whom I observed during this study who were unable to access ITax on their smart phones as they experienced connectivity issues.

Based on the success of Mpesa, Kenya is viewed as a technologically advanced country that can use technology to develop itself. While this may be true in some cases, it has become entwined with the development goal, with technology being seen as a key tool for attaining economic progress. The contradiction here is that the country's infrastructure is not ready for such a transformation, as leveraging technology for growth enriches those who have traditionally been powerful while marginalizing others. (See chapter five). In the global information technology ranking, which ranks among other indicators, e-readiness, Kenya is ranked 86 out of 140 globally. ${ }^{87}$ This means that it still has a long way to go before it could make platforms like ITax mandatory for taxpayers.

E-literacy was also not as required for such a shift. This empowered people with ICT skills, making taxpayers reliant on mediators as well as cybercafes to access their tax

\footnotetext{
${ }^{87}$ http://reports.weforum.org/global-information-technology-report-2015/network-readinessindex/?doing_wp_cron=1520260268.1711950302124023437500
} 
accounts. The country was not infrastructurally ready for this shift. Kenya being a developing country Taxpayers had barely oriented themselves with the system when it was shortly after made mandatory as well as using digital enforcement tactics like the deactivation to make taxpayers comply. Using ITax as a taxpayer became quite tedious and complicated for the taxpayer. Kenya was not infrastructurally ready for the mandatory shift to ITax. The law had not yet passed an ICT law that could help govern the platform making translations of the platform to be quite vague. The KRA has for the third year in a row did not achieve its revenue targets. Tax practitioners criticized the KRA for making ITax mandatory claiming that the already weak relationship between the tax man and the taxpayer was not strengthened using complex systems. Digitalisation ushers in a new era, one that expands and deepens the influence of digitization in previously unimagined ways. It's worth devoting some time to thinking about what kinds of shifts we're seeing and how we might ensure that they benefit the many rather than the few, both collectively and individually.

As suggested by tax policy theorists, government should be efficient in designing and developing tax policies that are well suited to the local contexts (Baer and Silvani,1997), Baer and Silvani (1997) state this is even more urgent in low-income countries because they are already facing a myriad of problems that causes impediment to their tax collecting effort. In this case the biggest impediment to making ITax mandatory would be on whether Kenyans were infrastructurally ready for this mandatory shift. The introduction of new policies and regulations are backed by a sufficient time frame that the taxpayers can use to adjust to the system (Baer and Silviani,2017).

Digitalisation favoured some taxpayers like the tech savvy ICT experts while marginalising the taxpayers that were e-literate and illiterate. It also empowered some areas of Kenya including the capital while it further marginalised counties that had been historically undermined by colonial and current fiscal policies. As the platform was developed by IT consultants, new ICT tax expertise emerged creating a niche for themselves within the tax architecture in Kenya. While ITax was initially designed to help ease tax administration, the current version seems to have created hybrid identities of IT savvy experts and taxpayers. ITax's perception was mixed; among policymakers there was an almost gospel-like understanding of the 'power' of the 
technology whereas in practice, the end-users struggled to comply with its everchanging rules and regulations.

The process requires ICT as well as taxation knowledge. It requires the right infrastructure as well as a taxpayer centric approach both in its design and implementation. The rapid shift in the platforms might look seamless; its impact is however felt when taxpayers are required to re-register to the platform or go through mediators who may or may not even be experts. The Kenya national bureau of statistics estimates that 6.3 per cent of the population reported to have engaged in internet activities with Nairobi having the highest proportion of internet users at $25.9 \%$ (KNBS,2011). In this regard, it shows that the complexities inscripted within its use creates an impediment to the taxpayers who are not IT savvy.

The promise offered by sophisticated IT systems imported from the other tax environments present risks for revenue collection. Their complexities offer little value added and hinders users with limited IT skills. The cost of adapting software to local needs as well as the administrative and transactional costs and the overhead and transaction lead to unnecessarily high costs that taxpayers must bear. As outlined in policy and on their website, ITax is made to seem quite effective in solving most issues taxpayers face during filing season. However, as this dissertation showed, the belief in technology to solve issues within taxation is not as easy as imagined.

Philip, the ICT expert, described it as a new form of 'digitalized corruption' as he contended that both taxpayers and tax agents still find ways of going around the system as many of the problems are caused by the institution and not the system. He states that "systems don't develop themselves, organisations develop them". Even though he had not experienced any complications with ITax he based his views on his historical relations

\subsubsection{Trust and Fairness}

Another important finding in this study is that there has always been and still exists tension between the taxpayers and the 'tax-man'. History has shaped the current tax practices like digitalisation using coercive rhetoric as was done by colonial tax administrators. With regards to ITax, technology there was seen as a great opportunity to create a system that would not only serve the taxpayers' need but made tax 
administration easier for the authority. This 'tool and effect' logic has featured quite strongly in my dissertation where the digitalizing tax services were assumed to be important in increasing revenues as well as making the process as stated in ITax's mantra "simple, swift and secure". It has not however improved the weak relationship between taxpayers and the taxman.

The OECD (2019) report on tax morale discusses the importance of taxpayer's willingness to pay tax, advising governments to pay attention to what motivates taxpayers as this can help in the success of tax policies particularly in developing countries where compliance rates are low. The report also highlights how tax morale is greatly impacted by public services delivery. Tax systems influence taxpayer's decision making either positively or negatively (OECD,2019). However, what was neglected was that there was a certain level of trust from both parties that would be needed for ITax to flourish. This did not happen as taxpayers used innovative ways to go around the system only paying certain amounts of tax based on their perceptions of fairness. The KRA on the other hand digitally punished taxpayers by deactivating their PINs (see chapter five). KRA had assumed that taxpayers were complying which according to my findings was not the case for all taxpayers. Certain aspects had to be considered before the KRA could venture into such an ambitious project of digitizing tax services as well as making the use of the platform mandatory. If taxpayers are expected to not only use the platform as taxpayers but to also contribute to its management, who is then the real end user of ITax?

If ITax had for example, been implemented in the local language or even maybe as a mobile application in Kenya it could have been more successful. Making it mandatory was quite telling of the disconnect between policy and practice as many taxpayers I engaged with in this study were unable to comply on their own. The use of brokers, consultants and even cybercafe agents considerably altered the social contract by including these actors as an important part of the tax architecture as shown by my informant Nancy. These actors who were made relevant were empowered enough to comply on behalf of the taxpayers however they are not liable for their mistakes. Taxpayers were not in control over their information as the system proved complicated for them. As explained by Nancy, it's not a trust-based relationship, it's a wait and see. 
Adam Smith as early as 1776 recognized fairness as an important tenet of a good tax system. Taxpayers who are dissatisfied with the treatment they have received from tax authorities may adopt a combative attitude since their actions are linked to their perceptions of justice. The assumptions and the actual practices point to the difference between voluntary (which is the ideal) and enforced compliance. The KRA's promise of 'enhancing trust through facilitation' is challenged in practice. Some taxpayers in this study have no choice but to seek mediators to comply. Because of low trust of the KRA many of my interlocutors feared seeking the KRA's help on issues that could be solved either at their cybercafé or by their tax consultant. What is at stake therefore with the overall goal of increasing domestic revenues is that the government will not be able to achieve this if their policies are not viewed as particularly fair or even simple. The relationship between the taxpayer and the authority was not strengthened by this platform as it was envisioned.

\subsection{The Implications of Travelling Models of Development}

Digitalisation is seen as leading to long-term economic development however nuance is needed (Moore et al.2018). This is because some governments are adopting shortterm strategies like in revenue mobilisation which can lead to fiscal and developmental crises. Due to a lack of understanding of Kenyan tax systems, the existing weak relationship between the state and the citizen, weak democracy, and the use of travel models that were not effectively fitted to local norms and circumstances, the introduction of ITax was not as simple as expected. The local mechanisms used to tax are important as they shape the accountability relationships between the state and the taxpayer (Mumford,2002), (Brautigam et al.,2008). The mechanisms used are usually recommended to different contexts or even jurisdictions making it difficult for it to address the problems it set out to solve. The lack of attending to differences between the sites where the models travel causes the creation of new forms of ideas and practices that are foreign and not considered favourable (Gichuki,2013,17).

This thesis has affirmed how the rapid adoption of digitized tax applications, like ITax, has led to numerous consequences that has shaped taxpayers' attitudes towards taxation in Kenya. As shown in chapters 5 and 6, taxpayers both e-literate and illiterate found it be complicated. The platform was also in English disallowing Kiswahili or native language speakers the ability to use ITax independently. It empowered 
taxpayers who had been historically empowered while further marginalising those who had been socially economically as well as infrastructurally marginalised historically. ITax was expected to make revenue collection in Kenya easier by allowing taxpayers to update their tax registration information, file their returns online, and record their tax payments, according to the newspaper mentioned in chapter one. This did not pan out as planned as shown in chapter five, taxpayers had to turn to mediators to comply with iTax.

The KRA's rapid adoption of ITax resorted to coercive compliance measures like pindeactivation. This was seen to be a quick fix solution to get people to pay taxes but according to a report from the National treasury, it seems that the KRA has not for several years since ITax's implementation, achieved its revenue targets. It thus seemed that ITax had complicated taxation in Kenya. Deactivation and other issues I take up in my dissertation could be used to explain the low tax revenues that the KRA has been experiencing. Tax practitioners criticized the KRA ability to deactivate one's pin citing a violation of taxpayers' rights. ${ }^{88}$ Some tax consultants expressed concern because of the vagueness of the tax laws with regards to I-Tax. One told me that the authority had now shifted its enforcement digitally. Whose responsibility was it to ensure that the pins were shifted from their older to the newer system? If taxpayers are expected to not only use the platform as taxpayers but to also contribute to its management, who is then the real end user of I-Tax? Was I-Tax implemented to make tax administration easy for the KRA or was it supposed to make it easier for the taxpayer?

According to Charles, my main interlocuter, taxpayers could not be trusted to use ITax willingly and Nancy would rather risk getting fined by using a consultant rather than going to KRA. Taxpayers interviewed in this study complied with using ITax because they either feared the consequences of not doing so or needed to comply to fulfil some other government obligation like being awarded government contracts. They compiled however in unique ways described in this dissertation as the Kenyan way. They were

\footnotetext{
${ }^{88} \mathrm{https}$ ://www.nation.co.ke/business/Lawyers-fault-the KRA-plan-of-deactivating-PINs/996-4047840t3nyeu/index.html
} 
therefore able to achieve compliance however they did not improve the taxpayer's morale.

Countries in the global south are perceived as having weak governance due to their restricted access to ICT infrastructures- which is deemed necessary for economic success, have recently turned to digitalisation. There is an assumption that ICT will trigger better governance as well as strengthen legitimacy. In Kenya, technologies like ITax were rapidly adopted and implemented not only to make e-filings easier for taxpayers but as to also achieve the sustainable development as understood in the global arena. This becomes as shown problematic as demonstrated in this these travelling ideas are modelled after ideas from countries from the global north who have strong economic foundations. The knowledge created by international organizations in the global sphere are thought to be generalizable policy concepts that could bring about social and technical transformation.

In the Kenyan case was the problem with the ideas behind ITax, that they imagined users to be tech-savvy, as well as having stable access to the internet as well as computers, laptops, or smartphones. Kenya's infrastructure, like many other African countries, was unable to support the shift to mandatory use of ITax, infrastructurally and even economically. Many taxpayers regardless of their e-literacy found ITax to be quite problematic. What was astounding in this case study as well was that there were some of the KRA staff who also struggled with ITax as well, showing that the platform was not as efficient and effective as imagined by the policymakers who endorsed it. The goal of ITax globally and locally was to eventually lead to increased revenues. The KRA has been unable to meet the national treasury's revenue target since switching to ITax. While there could be a variety of reasons for this, it was clear that ITax's implementation was challenging and complex, resulting in lower tax compliance, which worsened rather than improved the situation.

The idea of increasing revenues as a global policy goes back to Kaldor's concern for what he described as 'underdeveloped states needed to be taught how to tax (Kaldor,1963). This as shown in the introductory chapter is rooted in developmental rationale based on the idea that there is a certain model of economic growth that can be exported globally within models. This has shaped taxation reform politics in developing countries like Kenya leading to various movements like the "financing for 
development" aimed at helping countries 'catch up' economically with the latest trend being revenue authorities digitising its activities especially e-filings.

\subsection{Conclusion}

This study contended that technology shapes practices like taxation and in turn getting shaped through its enactments and entanglements (Latour, 2005). ITax was inscripted with multiple aims of increasing revenues, tax compliance as well as making tax administration more efficient. In practice however, due to misinformed policies and ideas, the technologies like ITax travelled along the local historical, political and economic structures creating unintended consequences like the creation of new tax experts (ICT experts) as well as marginalising those who were already historically marginalised. This as shown in this thesis altered the state-citizen relationships creating a bigger rift rather than closing it as had been imagined by KRA and policymakers. Taxpayers were now turning to mediators instead of KRA in resolving their tax matters. Technologies are shown in this thesis build upon the existing relationships thereby extending its impact in new and unanticipated ways.

Development practitioners' policymakers and donors are almost always seeing modernity and transformation from so called "western" countries as having the ability to 'trickle down' to developing countries sooner or later. The various methods in which technology travels and adapts to different times and spaces cast doubt on this assumption (Anderson and Adams, 2007). Even though non-Western projects were developed and tested first, there is still a belief that development occurs abroad (Breckenridge, 2014). The rapid development of 'mobile money' (payment through mobile phone) in Kenya is a first example that has framed future innovations, with Kenya being seen as infrastructurally suitable for innovations such as e-filings. The issue is not with the implementation; it's with the speed with which it's adopted and made mandatory.

This dissertation also contends that contrary to this widely held assumption, technologies cannot solve problems in a vacuum. Structures and sound tax policies need to be in place if domestic revenues are to be increased. This study does not deny that technology advancements and innovations have the capacity to revolutionize fiscal institutions and practices; rather, it emphasizes the importance of considering 
the design, context, and histories that may help or hinder implementation. Technologies are not neutral as assumed, rather they are loaded with specific information, rules and cultures that post challenges when adopting them to other contexts.

Taxation is quite complex however coupling mandatory use of e-filing makes it even more complicated. What is happening in Kenya is not exclusive to the country. Rather there is a global paradigm shift where governments are embracing technologies as a tool for increasing effectiveness both in government and governance related issues. The African development bank (AFDB) in its strategy 2013-2022 states that "Africans have realized the need to develop frameworks, supported by legislation for egovernance that are linked to strategic development objectives," (AFBD,2013). While governments, banks and policymakers are supporting this shift, very little of the policy formulation is organic and has consensus for the users, taxpayers. Many of the taxpayers interviewed in this study had not really understood why the KRA would go so far and make the use of ITax mandatory.

The success of platforms such as ITax are dependent on preconditions that must be considered. As a mandatory e-filing system, ITax has mostly excluded people who are unable to comply with its demands because of being isolated from the ICT grid, being unable to afford intermediaries such as a tax adviser or even a cybercafé, or just missing the necessary e-literacy to comply. ITax was established on the assumption that Kenya had the infrastructure in place to adopt, implement, and enforce ITax. However, the reality on the ground was not as envisioned. Kenya continues to struggle to meet the needs of over $60 \%$ of the population that live in poverty and are unable to access essential services such as water and electricity, the latter being a significant driver of ICT.

By tracing the global models to the Kenyan taxation discourse, I showed how ITax was an end-product of global policies modelled after strong economies. The translation of the aims into practice proved problematic. The process of tax compliance in Kenya became complicated with the use of technology. By making ITax mandatory, KRA further weakened the already fragile relationship between themselves and the taxpayers. Digitalisation being a feature of the fourth industrial revolution brings on a new era that builds and extends the impact of digitization in new and unanticipated ways. It is therefore worthwhile taking some time to consider exactly what kind of shifts 
we are experiencing and how we might, collectively and individually, ensure that it creates benefits for the many, rather than the few. 
Bibliography

Abuiyada, R. (2018). Traditional Development Theories have failed to Address the Needs of the Majority of People at Grassroots Levels with Reference to GAD. International journal of Business and Social science.

Acemoglu, D., Johnson, S., and Robinson, J. A. (2001). The Colonial Origins of Comparative Development: An Empirical Investigation. The American Economic Review, 91 (5), 1369-1401.

Amwata, D., Campbell, B, M., Cofier, O.,Frid Nielsen, S., Girvetz, E., Kinyangi, J. Mapfumo, Mul. ,M. Nyasimi,M, Speranza,C,I. Williams,T,O.(2015)Climate Smart Agriculture in the African Context. Background Paper. Feeding Africa Conference 21-23 October 2015.

Akrich, M. (1992). The De-Scription of Technical Objects. In Shaping Technology in Bijker \& Law. Shaping Technology / Building Society: Studies in Sociotechnical Change

Allingham, M. G., and Sandmo, A. (1972). Income Tax Evasion: A Theoretical Analysis. Journal of Public Economics, 1, 323-338.

Alshehri, M.and Drew, S. (2010), "Implementation of e-Government: Advantages and Challenges",79-86.

Anders, G. (2008). Fiscal disobedience: An anthropology of economic regulation in central Africa by Janet Roitman. Political and Legal Anthropology Review. https://doi.org/10.1111/j.1555-2934.2008.00011_1.x

Anderson, W. (2002). Introduction: Postcolonial Technoscience. Social Studies of Science, 643-658.

Appadurai A. (1990). Disjuncture and Difference in the Global Cultural Economy. Theory, Culture and Society, Vol 7, Issue 2-3, pp. $295-310$.

Appel, H. (2018). Infrastructural Time. In N. Anand, A. Gupta, and H. Appel, The Promise of Infrastructure (p. 264). Duke University Press.

Asad, T. (1973). Anthropology \& the colonial encounter. Ithaca Press. 
Asher, A. D., \& Miller, S. (2011). So, you want to do anthropology in your library? Or a practical guide to ethnographic research in academic libraries. Retrieved from http://www.erialproject.org/publications/toolkit/

ATAF. (2016). Time for Taxes. African Tax Administration Forum. ATAF.

Avgerou, C. (2014). Technologies of Power: Essays in Honour of Thomas Parke Hughes and Agatha Chipley Hughes 20041Edited by Michael Thad Allen and Gabrielle Hecht. Cambridge, MA: MIT Press 2001., ISBN: 0-262-51124-X. Information Technology and People, 17(2).

Backus, M. (2002). E-Governance and Developing Countries. Author.

Barbone, L., Das-Gupta, A., Wulf, D. L., and Hansson, A. (1999). Reforming tax systems: The World Bank record in the 1990s. The World Bank.

Basalla,G. (1967).The Spread of Western Science.Vol. 156, Issue 3775, pp. 611-622 Bayart, J.-F. (2009). The State in Africa: The Politics of the Belly. Comparative Politics, 1-420.

Bayart, J.-F. (2009). The State in Africa: The Politics of the Belly. Comparative Politics, 1-420.

Behrends, A, Park, S.-J and Rottenburg, R eds. (2014). Travelling Models in African Conflict Management: Translating Technologies of Social Ordering. Leiden: Brill.

Bierschenk, Thomas and Chauveau, Jean-Pierre and Olivier de Sardan, Jean-Pierre. (2002). Local Development Brokers in Africa: The Rise of a New Social Category.

Birch, K. (2017). Technoeconomic Assumptions. Science as Culture.

Bird, M. R., and Vazquez, M. J. (2008). Tax Effort in Developing Countries and High Countries: The Impact of Corruption, Voice and Accountability. Department of Economics.

Björklund Larsen, L. (2016). Sweden: Failure of a Cooperative Compliance Project? In FairTax Working Paper Series No. 07.

Björklund Larsen, L. (2017). Shaping Taxpayers. Values in actions at the Swedish Tax Authority. Bergham Books. 
Björklund L, L, Boll, K, B, Brögger, J, Kettunen, T, Potka-Soininen, J, Pellinen, Mette Johannsen and Aziz, K. (2018). Nordic experiences of co-operative compliance programmes: comparisons and recommendations.

Boll, K. (2011). Tax Assemblages: Laborious and Meticulous achievements of tax compliance. Copenhagen: IT University of Copenhagen.

(2014a) Shady car dealings and taxing work practices: an ethnography of a tax audit process. Accounting, Organizations and Society 39(1), 1-19. — 2014b. (2014). Mapping Tax Compliance: Assemblages, Distributed Action and Practices: A New Way of Doing Tax Research. Critical Perspectives on Accounting, Vol.25, No.4-5,7.2014, p. 293-303

Boll, K., and Brehm Johansen, M. (2018). Tax Governance: Corporate Experiences with Cooperative Compliance in Denmark. Umeå: Umeå Universitet. FairTax Working Paper Series, No. 17

Brautigam, Deborah A., 2008, "Introduction: Taxation and State-building in Developing Countries," in Taxation and State-building in Developing Countries: Capacity and Consent, ed. by Deborah Brautigam, Odd-Helge Fjelstad, and Mick Moore, pp. 133 (Cambridge: Cambridge University Press).

Burkey S. (1993).People First: A Guide to Self-Reliant, Participatory Rural Development. Zed Books.

Callon, M. (1986). Some elements in the sociology of translation. domestication of the scallops and the fisherman of St. Brieuc. Power, Action and Belief: A New Sociology of Knowledge, 196-223.

Callon, M. (1991). Techno-economic networks and irreversibility. In J. Law (Ed.), A sociology of monsters (pp. 132-161). London: Routledge.

Callon, M., \& Muniesa, F. (2005). Peripheral Vision: Economic Markets as Calculative Collective Devices. Organization Studies, 26(8), 1229-1250.

Castells, M. (1998). End of Millennium. Volume 3 of The Information Age: Economy, Society, and Culture. Oxford: Blackwell. The Informational City: Information Technology, Economic Restructuring, and the Urban Regional Process. Oxford: Blackwell. 
Chatterjee, P. (2004). The Politics of the Governed. Reflections on Popular Politics in Most of the World. New York: Columbia University Press.

Chua, W. F. (1995). Experts, networks, and inscriptions in the fabrication of accounting images: A story of the representation of three public hospitals. Accounting, Organizations and Society, 20(2-3), 111-145.

Clark, R. (1988). Information Technology and Data surveillance. Communications of the ACM, 498-512.

Clifford, J. (1992). Chapter 7: Traveling Cultures. In L. Grossberg, C. Nelson, and P. A. Treichler (Eds.), Cultural studies. New York: Routledge.

CONSTITUTION OF KENYA (2010). the National Council for Law Reporting with the Authority of the Attorney-General. https://www.kenyalaw.org

Cornwall, A. (2007). Buzzwords and Fuzzwords: Deconstructing Development Discourse. Development in Practice, 17(4/5), 471-484.

Compeau, D. R., \& Higgins, C. A. (1995). Computer Self-Efficacy: Development of a Measure and Initial Test. MIS Quarterly, 19(2), 189.

Czarniawska, B., and Sévon, G. (2005). Global Ideas. How Ideas, Objects and Practices Travel in the Global Economy. Copenhagen: Liber.

Daniels, C. (2017). Science, Technology, and Innovation in Africa. Conceptualisations, Relevance and Policy Directions. In C. C. Mavhunga, what do Science, Technology and Innovation mean from Africa. Boston: MIT University Press.

De Laet, M. and Mol. A (2000, April). The Zimbabwe Bush Pump. Social Science Studies, 30, 225-263.

De Wit, Sara. (2011). (Forthcoming 2015). Global Warning. An ethnography of the encounter between global and local climate change discourses in the Bamenda Grassfields Cameroon. Master's thesis. Leiden: African Studies Center.

Draude, A. (2018). Third World Thematic: A TWQ Journal Translation in motion: a concept's journey towards norm diffusion studies Translation in motion: a concept's journey towards norm diffusion studies. TWQ Journal, 2(5). https://doi.org/10.1080/23802014.2017.1436984 
European Commission (2017). COMMISSION STAFF WORKING DOCUMENT. Europe's Digital Progress Report 2017. Brussels.

Fairclough, N. (2003). Analysing Discourse: Textual analysis for Social Research. London: Routledge.

Fallan, K. (2008). De-scribing Design: Appropriating Script Analysis to Design History. Design Issues, 24(4), 61-75.

Falzon, Mark-Anthony (2009) Introduction. Multi-sited ethnography: theory, praxis and locality in contemporary research, in Falzon, M.-A. (ed.) Multi-Sited Ethnography. Theory, Praxis and Locality in Comtemporary Research, London, Routledge, pp. $1-15$.

Fangen K. (2005). Deltagande observation [Participant observation.] Malmö: Liber ekonomi.

Farah, K., Nyariki, D., Ngugi, R., Noor, I., \& Guliye, A. (2004). The Somali and the Camel: Ecology, Management and Economics. The Anthropologist, 6(1), 45-55. https://doi.org/10.1080/09720073.2004.11890828.

Ferro E. Helbig, N and Ramón Gil-García. J, (2009). Understanding the complexity of electronic government: Implications from the digital divide literature, Government Information Quarterly, Volume 26, Issue 1, Pages 89-97.

Fisher, E. (2010). Contemporary Technology Discourse and the Legitimation of Capitalism. European Journal of Social Theory, 13(2), 229-252.

Fjeldstad, O. (2001). Taxation, coercion, and donors: Local government tax enforcement in Tanzania. The Journal of Modern African Studies, 39(2), 289-306.

Fjeldstad, O., \& Rakner, L. (2003). Taxation and tax reforms in developing countries: Illustrations from sub-Saharan Africa.

Gardner, L. A. (2012). Taxing Colonial Africa: The Political Economy of British Imperialism. Oxford: Oxford University Press.

Gardner, L. A. (2013). Taxing Colonial Africa: The Political Economy of British Imperialism. In Taxing Colonial Africa: The Political Economy of British Imperialism. https://doi.org/10.1093/acprof:oso/9780199661527.001.0001 
Geertz, C. (1973). Thick Descriptions: Towards and Interpretive Theory of Culture.

Gichoya D. (2005) "Factors Affecting the Successful Implementation of ICT Projects in Government" The Electronic Journal of e-Government Volume 3 Issue 4, pp. 175184, available online at I-Taxwww.ejeg.com.

Gichuki E.N. (2015). Tax Administration Reforms in Kenya. Identifying lessons to models a Strategy for Sustainable Administration of County Taxes. PhD Dissertation University of Nairobi.G80/90021/2013.

GOK. (2006). National policy for the sustainable development of arid and semiarid lands of Kenya.

Gough, K.(1968a). New proposals for anthropologists. Current Anthropology 9.5: 403433

(1968b). Anthropology and imperialism. Monthly Review 19.11: 12-24.

Gracia, Louise and Oats, Lynne, (2012), Boundary work and tax regulation: A Bourdieusian view, Accounting, Organizations and Society, 37, issue 5, p. 304321.

Guyo, F.B. (2017). Colonial and post-colonial changes and impact on pastoral women's roles and status. Pastoralism 7, 13. https://doi.org/10.1186/s13570-0170076-2

Gwynne, N, R. (2009). Modernization Theory. International Encyclopaedia of Human Geography (Second Edition), Elsevier, Pages 163-167.

Hammersley, M. (1985). From Ethnography to Theory: A Programme and Paradigm in the Sociology of Education. Sociology, 19(2), 244-259.

Hanseth, O., Monteiro, E., \& Hatling, M. (1996). Developing Information Infrastructure:

The Tension Between Standardization and Flexibility. Science, Technology, \& Human Values, 21(4), 407-426.

Harding, S. (1994). Is Science Multicultural? Challenges, Resources, Opportunities', Configurations, Vol. 2 (1994), 301-30, at 327

Harding, S. (2011). The Postcolonial Science and Technology Studies Reader. Durham and London: Duke University Press. 
Haraway, D. (1991). "A Cyborg Manifesto: Science, Technology, and Socialist Feminism in the Late Twentieth Century," in Simians, Cyborgs and Women: The Reinvention of Nature (New York; Routledge), pp.149-181.

Herzfeld, M. (2004). Cultural Intimacy: Social Poetics and the Real Life of States, Societies, and Institutions (Routledge Classic Texts in Anthropology) (2nd ed.). Routledge.

Heyneman, S. (1980). Differences between Developed and Developing Countries:

Comment on Simmons and Alexander's "Determinants of School Achievement". Economic Development and Cultural Change, 28(2), 403-406. Retrieved August 13, 2021, from http://www.jstor.org/stable/1153389

Hughes, C. C. (1992). "Ethnography": What's in a Word-Process? Product? Promise? Qualitative Health Research, 2(4), 439- 450.

Hughes OE. (2003) Public Management and Administration: An Introduction" Palgrave Macmillan ISBN 10: 00333961880/ISBN 13:9780333961889.

IMF. (2015). An Empirical Study of The Impact on Taxpayer Compliance and Administrative Efficiency. Fiscal Affairs Department. IMF.

(2017). IMF Country Report 2017. IMF.

(2020). Digitalization in Sub-Saharan Africa". In Regional Economic Outlook, April 2020, Sub-Saharan Africa. USA: International Monetary Fund. Retrieved Aug 12, 2021, from https://www.elibrary.imf.org/view/books/086/28915-9781513536835en/ch03.xml

Jedwab, R., Kerby, E., and Morad, A. (2017). How Colonial Railroads Defined Africas Economic Geography. In E. Papaioannou, and S. Michalopoulous, The Long Economic and Political Shadow of History: Volume II Africa and Asia (pp. 88-99). London: CEPR Press.

Kaldor, N. (1963). Will Underdeveloped Countries Learn to Tax? Foreign Affairs (41), 410-419.

(1963). Taxation for Economic Development. The Journal of Modern African Studies, 1(1), 7-23. doi:10.1017/S0022278X00000689 
Khan, M. H. (2010). Political Settlements and the Governance of Growth-Enhancing Institutions. Political Settlement, Political Stabilization, and Implication for Growth, 1-139. https://eprints.soas.ac.uk/9968/1/Political Settlements internet.pd

Kopytoff, I. (1986). The cultural biography of things: Commoditization as process. In A. Appadurai (Ed.), The Social Life of Things: Commodities in Cultural Perspective (pp. 64-92). Cambridge: Cambridge University Press.

KRA (2014). ICT Strategic Plan. KRA, 6th corporate plan (2014-2018).

(2014). Tender Document for the Supply, Delivery, Installation and Commissioning of an Enterprise Datawarehouse and Business Intelligence Solution. Tender No.the KRA/HQS/ICB-016/2014-2015. Nairobi: Kenya Revenue Authority. Retrieved from www.revenue.gov.ke.

Kruse, C. (2016). The social life of forensic evidence. Oakland: University of California Press.

Kenya, Republic of. (2005) Sessional Paper on Sustainable Development of Arid and Semi-Arid Lands of Kenya (Draft). Page 30. Office of the President, Nairobi.

Latour, B., and S. Woolgar. 1979. Laboratory Life: The Social Construction of Scientific Facts. Beverly Hills: Sage Publications.

Latour, B., and S. Woolgar. 1986. Laboratory Life: The Construction of Scientific Facts, revised edition. Princeton: Princeton University Press. Originally published as Laboratory Life: The Social Construction of Scientific Facts in 1979.

Law, John (1992), 'Notes on the Theory of the Actor-Network: Ordering, Strategy and Heterogeneity', Systems Practice, 5, 379-393.

Law, J., \& Wen-yuan, L. (2017). Provincializing STS: Post-coloniality, Symmetry, and Method. East Asian Science, Technology and Society: An International Journal 11(2), 211-227. https://www.muse.jhu.edu/article/656014.

Lewis, D. (1973). Anthropology and Colonialism. Current Anthropology, 14(5), 581-602.

Lledó, V., \& Poplawski-Ribeiro, M. (2011). Fiscal Policy Implementation in SubSaharan Africa, IMF Working Papers, 2011(172), A001. Retrieved Aug 12, 2021, from https://www.elibrary.imf.org/view/journals/001/2011/172/article-A001-en.xml 
Loos, E., Haddon, L., and Meijer, E. M. (2008). The Social Dynamics of Information and Communication Technology. Surrey, England: Ashgate.

Makovicky, N. \& R. Smith 2020. Introduction: tax beyond the social contract. Social Analysis 64(2) Special Issue: Beyond the social contract: an anthropology of tax (ed.) N. Makovicky \& R. Smith, 1-17.

Marcus, G. E. (1995). Ethnography in/of the World System: The Emergence of MultiSited Ethnography. Annual Review of Anthropology, 24(1) https://doi.org/10.1146/annurev.an.24.100195.000523

McCoon, M. (2011). Tax Compliance in Latin America. Journal of Accounting and Finance.

Mc Kerchar, M. A., \& Evans, C. C. (2009). Sustaining Growth in Developing Economies Through Improved Taxpayer Compliance: Challenges for Policy Makers and Revenue Authorities. SSRN Electronic Journal. Published.

McNeil M. (2005). Introduction: Postcolonial Technoscience. Science as Culture.Vol.14, No.2,105-112.June 2005

Mol, A., and De Laet, M. (2000). The Zimbabwe Bush Pump. Social Science Studies, 30, 225-263.

Migot, L., \& Paul, S. (2019). Determinants of successful implementation of integrated tax projects of Kenya Revenue Authority, Kenya. Journal of Entrepreneurship and Project Management, 4(1), 26-51.

Mills D, Ratcliffe R. After method? Ethnography in the knowledge economy. Qualitative Research. 2012;12(2):147-164.

Mkandawire, T. (2010). On Tax Efforts and Colonial Heritage in Africa. Journal of Development Studies, 46(10), 1647-1669.

Mosse, D. (2004a). Cultivating Development: An Ethnography of Aid Policy and Practice. In Development and Change.

Mosse, D. (2004b). Is good policy unimplementable? Reflections on the ethnography of aid policy and practice. Development and Change. https://doi.org/10.1111/j.0012-155X.2004.00374.x 
Moyi, E., \& Ronge, E.A. (2006). Taxation and Tax Modernisation in Kenya: A Diagnosis of Performance and Options for Further Reform.

Mosco V (2004) The Digital Sublime: Myth, Power, and Cyberspace. Cambridge, MA: The MIT Press.

Mugo, J., Ogwenyi, Z. and Ruto, J. Educational Marginalisation in Northern Kenya. UNESCO. 2009.

Mukand, S., \& Rodrik, D. (2005). In Search of the Holy Grail: Policy Convergence, Experimentation, and Economic Performance. The American Economic Review, 95(1), 374-383. Retrieved August 13, 2021, from http://www.jstor.org/stable/4132684

Musgrave Richard A. (1992). "Social contract, taxation and the standing of deadweight loss." Journal of Public Economics 49, p. 369-381.

Mumford, A. (2002). Taxing Culture: Towards a Theory of Tax Collection Law (SocioLegal Studies) (1st ed.). Routledge.

Mwega F. (2009). A CASE STUDY OF AID EFFECTIVENESS IN KENYA VOLATILITY AND FRAGMENTATION OF FOREIGN AID, WITH A FOCUS ON HEALTH. Brookings Institute

Nader, L. (1972). Up the Anthropologist-Perspectives gained from Studying Up. In D. H. Hymes, Reinventing Anthropology. New York: Pantheon Books.

Ndemo, B., and Weiss, T. (2017). Making Sense of Africa's Emerging Digital Transformation and its Many Futures. Africa Journal of Management. https://doi.org/10.1080/23322373.2017.1400260

Ndombi, D. M. (2012, October). Challenges of Implementation of Integrated Tax Management System Strategy at Kenya Revenue Authority (Research Project). University of Nairobi.

Ngigi, S., \& Busolo, D. N. (2019). Devolution in Kenya: The Good, the Bad and the Ugly.

Nyaegah, J. O. (2018). INFLUENCE OF I-TAX PROJECT ON TAX RETURN COMPLIANCE BY TAXPAYERS AT CENTRAL BUSINESS DISTRICT OF 
NAKURU, KENYA. INTERNATIONAL JOURNAL OF BUSINESS AND PROCESSES, 4(1), 17-17.

Nyariki, D. M., \& Amwata, D. A. (2019). The value of pastoralism in Kenya: Application of total economic value approach. Pastoralism, 9(1). https://doi.org/10.1186/s13570-019-0144-x

Poggiali, L. (2016). Digital Futures, Analog Pasts? Technology and Ethnicity in Nairobi.

Proceedings of the African Futures Conference, 1(1). https://doi.org/10.1002/j.2573-508X.2016.tb00009.x

Poggiali, L. (2016). Seeing (from) Digital Peripheries: Technology and Transparency in Kenya's Silicon Savannah. Cultural Anthropology, 31(3). https://doi.org/10.14506/ca31.3.07

Poggiali, L. (2017). Digital futures and analogue pasts? Citizenship and ethnicity in techno-utopian Kenya. Africa, 87(02) https://doi.org/10.1017/S0001972016000942

Prasad, A. (2008). Imperial Technoscience: Transnational Histories of MRI in the United States, Britain, and India. MIT Press.

Pribilsky, J. (2013). Technoscience in Las Americas: STS Engagements in Latin American Anthropology. The Journal of Latin American and Caribbean Anthropology, 18, 371-375.

Prospera, T. S. (2015). TNS Rankings. TNS SIFO Prospera.

Rostow, W. W. (1962). The stages of Economic Growth. London: Cambridge University Press.

Rottenburg, R. (2009). Far Fetched Facts: A Parable of Development Aid. Cambridge, Massachusetts, USA: MIT Press.

Said, E. (1978). Orientalism. New York: Vintage Books.

Said, E. (1983). The World, the Text and the Critic. Cambridge: Columbia University. Schnitzler, A. V. (2016). Democracy's Infrastructures: Techno-politics and Protests after Apartheid. Princeton, New Jersey: Princeton 
Pieterse, J. N. (2010). Development theory: Deconstructions/reconstructions. SAGE Publications Ltd, https://www.doi.org/10.4135/9781446279083

Porter DJ (1995) Scenes from childhood: the homesickness of development discourses. In: Crush J (ed) Power of Development. Routledge, London, pp 6386

Ochola, S. (2016, September). ASSESSMENT OF SESSIONAL PAPER NO 10, 1965 IN THE CONTEXT OF EQUITY AND DEVELOPMENT IN KENYA. THE IBP, SID \& KATIBA INSTITUTE EQUITY WEEK (SEP 19-24), Nairobi, Kenya.

Odour, C., Sevilla, J., Wanyoike, T., and Mutua, N. (2016). Automating Revenue Collections in Kenya: A Case of Kiambu County. IST Africa 2016. IST Africa.

OECD.(2014)Perspectives on Global Development 2014: Boosting Productivity to Meet the Middle-Income Challenge, OECD.

(2016). Technologies for Better Tax Administration. Paris: OECD.

(2018). Tax Challenges Arising from Digitalisation - Interim Report 2018: Inclusive Framework on BEPS, OECD/G20 Base Erosion and Profit Shifting Project, Paris: OECD.

(2019), Tax Morale: What Drives People and Businesses to Pay Tax? OECD Publishing, Paris, https://doi.org/10.1787/f3d8ea10-en.

Ortner, S. (2006). Anthropology and Social Theory: Culture, Power, and the Acting Subject. DURHAM; LONDON: Duke University Press.

Onyango, M. (2010). Postcolonial Politics in Kenya. In Omeje K. The Crisis of Postcoloniality in Africa. Codeseria.

Oracle. (2012). Oracle Tax Analytics. Oracle.

Oppenheimer, J. (2011). Universals, Knowledge Claims and Methods. The Good Society, 20(2), 249-280. http://doi.org/10.1353/gso.2011.0022

Owen, O. (2018) 'Revenue and Representation: The political economy of public participation'. In Levan, C. \& Ukata, P. (eds) The Oxford Handbook of Nigerian Politics, Oxford: OUP.

Oudshoorn, N., and Pinch, T. (2003). How Users Matter: The Co-Constructions of Users and Technologies. Mass: MIT Press 
Ouma O. D. (2019). Revenue Effects of Tax Reforms, Economic Growth and Political Environment in Kenya. African Journal of Economic Review, Volume VII, Issue I, January 2019.

Reeves, S., Perrier, L., Goldman, J., Freeth, D., \& Zwarenstein, M. (2013). Interprofessional education: effects on professional practice and healthcare outcomes (update). The Cochrane database of systematic reviews, 2013(3).

Regional Department East A (OREA). (2010, November). Domestic Resource Mobilization for Poverty Reduction in East Africa: Kenya Case Study. African Development Bank Group, 1-67.

Rist, G. (2014). The History of Development: From Western Origins to Global Faith. Zed Books.

Roitman, J. (2005). Fiscal Disobedience: An Anthropology of Economic Regulation in Central Africa. PRINCETON; OXFORD: Princeton University Press. Retrieved August 13, 2021, from http://www.jstor.org/stable/j.ctv36zp9f.

Rostow, W. W. (1962). The stages of Economic Growth. London: Cambridge University Press.

Rottenburg, R. (2009). Far Fetched Facts: A Parable of Development Aid. Cambridge, Massachusset, USA: MIT Press.

Ruto, S. J., Ongwenyi, Z. N., \& Mugo, J. K. (2009). Educational Marginalisation in Northern Kenya. Education for All Global Monitoring Report 2010, 8-45. https://www.dlci-hoa.org/assets/upload/educationdocuments/20200804021314369.

Sardan, J.O., Diarra, A., and Moha, M. (2017). Travelling models and the challenge of pragmatic contexts and practical norms: the case of maternal health. Health research policy and systems.

Said, E. (1978). Orientalism. New York: Vintage Books.

Said, E. (1983). The world, the text, and the critic. Cambridge, Mass: Harvard University Press.

Saxena, K. B. C. (2005). Towards excellence in e-governance. International Journal of Public Sector Management, 18(6). https://doi.org/10.1108/09513550510616733 
Schnegg, M., and Linke, T. (2016). Travelling models of participation: Global ideas and local translations of water management in Namibia. International Journal of the Commons, 10(2), 800-820. DOI: http://doi.org/10.18352/ijc.705

Schnitzler, A. V. (2013, November). Travelling Technologies: Infrastructure, Ethical Regimes and Materiality of Politics in South Africa. Cultural Anthropology, 670693.

(2013). Travelling Technologies: Infrastructures, Ethical Regimes and The Materiality of Politics in South Africa. Cultural Anthropology.

Scott, J. C. (1998). Seeing like the State. Yale University Press.

Seth, S. (2009). Putting knowledge in its place: science, colonialism, and the postcolonial. Postcolonial Studies, 12(4), 373-388. https://doi.org/10.1080/13688790903350633.

Sigwejo, A., \& Pather, S. (2016). A Citizen-Centric Framework for Assessing EGovernment Effectiveness. The Electronic Journal of Information Systems in Developing Countries, 74(1), 1-27.

Stewart, M. (2003). Global Trajectories of Tax Reform: The Discourse of Tax Reform in Developing and Transition Countries. Harvard International Law Journal.

Stoler, A. L. (2008). Imperial debris: Reflections on ruins and ruination. Cultural Anthropology. https://doi.org/10.1111/j.1548-1360.2008.00007.x

Stevenson, M., \& Helmond, A. (2020). Legacy systems: internet histories of the abandoned, discontinued and forgotten. Internet Histories, 4(1), 1-5. https://doi.org/10.1080/24701475.2020.1725854

Sunstein, C. R. (2014). Nudging: A Very Short Guide. SSRN Electronic Journal. Published. https://doi.org/10.2139/ssrn.2499658

Thaler, R. H., \& Sunstein, C. R. (2009). Nudge: Improving Decisions About Health, Wealth, and Happiness (Revised Expanded ed.). Penguin Books.

Tsing, A. (2004). Friction: An Ethnography of Global Connections. Princeton: Princeton University Press. 
Turner F (2006) From Counterculture to Cyberculture: Stewart Brand, the Whole Earth Network, and the Rise of Digital Utopianism. Chicago: University of Chicago Press.

Turton, E. (1972). Somali Resistance to Colonial Rule and the Development of Somali Political Activity in Kenya 1893-1960. The Journal of African History, 13(1), 119143.

Tyce, M. (2020). 'KRA Has the Capacity, but It Is Kept on a Tight Leash': The Politics of Tax Administration and Policy in Kenya. SSRN Electronic Journal. Published.

Urry, J. 2000 Sociology Beyond Societies, London: Sage.

Venton, C. C., Fitzgibbon, C., Shitarek, T., Coulter, L., \& Dooley, O. (2012). The Economics of Early Response and Disaster Resilience: Lessons from Kenya and Ethiopia. Economics of Resilience Final Report.

Verran, H.(2001). Science and an African Logic Chicago: University of Chicago Press. Hardback. Vii + 277 pages. ISBN: 0-226-85389-6.

Waema, T. M., and Adera, E. O. (2011). Local Governance and ICTs in Africa. Nairobi: Pambazuka.

Walter Waitman Rostow. (2005). Development theory Rostow's five-stage model of development and its relevance in Globalization. In Development theory Rostow's five-stage model of development.

Waris, Attiya. 2008. 'Taxation Without Principles: A Historical Analysis of the Kenyan Taxation System'. Kenya Law Review 272.

Weisser, F., Bollig, M., Doevenspeck, M., and M??ller-Mahn, D. (2013). Translating the "adaptation to climate change" paradigm: The politics of a travelling idea in Africa. Geographical Journal, 180(2). https://doi.org/10.1111/geoj.12037

Wingo, A. H. (2018). Philosophical Perspectives on the History of African Socialism locked. African History. Published. https://doi.org/10.1093/acrefore/9780190277734.013.297

Winterhalt, K. R. (2018). Truman's New Deal: Point Four and the Genesis of Modern Global Development. USURJ: University of Saskatchewan Undergraduate Research Journal. https://doi.org/10.32396/usurj.v4i2.318 
World Bank. (2008). The Growth Report: Strategies for Sustained Growth and Inclusive Development. In Commission on Growth and Development, World Bank.

Wood, R., \& Bandura, A. (1989). Social Cognitive Theory of Organizational Management. The Academy of Management Review, 14(3), 361. 
Online Links

1. ATI (2015): https://www.addistaxinitiative.net/sites/default/files/resources/ATIDeclaration-EN.pdf.

2. CRA(2019).https://cra.go.ke/2020/12/01/explanation-of-the-third-basis-forrevenue-sharing-among-county-governments/

3. IHub (2018):https://blog.ihub.co.ke/wp-content/uploads/2018/08/GovernmentResponsiveness-in-the-Age-of-ICTs.pdf (assessed 25.02.2018).

4. ICPAK (2012): https://www.icpak.com/resource/icpak-2012-annual-report2/(accessed 14.05.2018).

5. KNBS (2014). https://www.knbs.or.ke/?wpdmpro=statistical-abstract2013(accessed 12. Aug.2021)

6. KNBS (2016). https://www.knbs.or.ke/?wpdmpro=economic-survey-2016

7. KNBS (2011). https://www.knbs.or.ke/?wpdmpro=economic-survey-2011

8. KRA 2021(accessed www.KRA.gov.ke on 29.01.2021

9. Deactivation of PINs

Mwakilishi.Com. https://www.mwakilishi.com/article/business-news/2017-09-

07/kra-de-activates-thousands-of-non-compliant-pin-numbers.

10. Nyambura, S. (2015, October 15). The 7-hour itch: Diary of a Kenyan eCitizen. Making All Voices Count. https://www.makingallvoicescount.org/blog/the-7hour-itch-diary-of-a-kenyan-ecitizen/

11.PCT (2018) https://www.imf.org/external/np/fad/pct/pdf/20progress\%20report

12. https://publikationer.sida.se/contetassets/c1cabe27d46c4383a4dfe11c5b45d6 21/de2019_26_62256en.pdf(Accessed 21. May 2021).

13. UN.

(2014).(https://www.un.org/en/development/desa/policy/wesp/wesp_current/2 014wesp_country_classification.pdf.

14.UNECA (2019) ERA report: https://archive.uneca.org/sites/default/files/PublicationFiles/era-en-finalweb.pdf.

15. Ushuru KRA tax filing solutions. (2021, July 1). https://wwww.ushuru.co.ke. 
Appendix 1

\begin{tabular}{|c|c|c|c|}
\hline Date & Location & Fieldwork Activities & Sites and People \\
\hline March 2017 & Nairobi & $\begin{array}{l}\text { 1. Participant } \\
\text { observation } \\
\text { 2. Interviewed } \\
\text { employees from } \\
\text { SIDA; the KRA } \\
\text { 3. Interviews with Tax } \\
\text { consultants }\end{array}$ & $\begin{array}{l}\text { The KRA } \\
\text { Marketing Department } \\
\text { ITax Department } \\
\text { IT Support Department } \\
\text { The research Department } \\
\text { Domestic Tax Department } \\
\text { Strategy and Research department } \\
\text { Others } \\
\text { Swedish Tax authority } \\
\text { Development officer SIDA (Swedish } \\
\text { International Development Agency) } \\
\text { Swedish Finance Department } \\
\text { Tax Consultants (3) } \\
\text { ILAB (County Pro technology } \\
\text { developers) } \\
\text { Tax experts at the local university } \\
\text { The UN Women representative on } \\
\text { taxpayer's rights in Kenya } \\
\text { Head of Tax Justice Network in Kenya } \\
\text { Uber drivers } \\
\text { Service centres } \\
\text { Cyber cafes } \\
\text { ICT experts }\end{array}$ \\
\hline
\end{tabular}




\begin{tabular}{|c|c|c|c|}
\hline April 2017 & Nairobi, Kiambu & $\begin{array}{l}\text { Participant } \\
\text { observation } \\
\text { Interviews }\end{array}$ & $\begin{array}{l}\text { Huduma Centres } \\
\text { Nairobi, Kiambu, Isiolo } \\
\text { Tax centres (run by the KRA } \\
\text { themselves and they are in smaller } \\
\text { county s } \\
\text { Huduma Centres } 4 \\
\text { ( } 2 \text { in Nairobi, } 1 \text { in Isiolo, } 1 \text { in Kiambu) } \\
\text { ITax Centres } 3 \text { ( } 2 \text { in Nairobi, } 1 \text { in Isiolo) } \\
\text { Service Centre Employees } \\
\text { Tax brokers }\end{array}$ \\
\hline August 2017 & Isiolo & $\begin{array}{l}\text { Participant } \\
\text { Observation } \\
\text { Interviews }\end{array}$ & $\begin{array}{l}\text { Shop-owners } \\
\text { Huduma Centre } \\
\text { the KRA Centres } \\
\text { County Office }\end{array}$ \\
\hline August 2017 & Isiolo & $\begin{array}{l}\text { Participant } \\
\text { observation } \\
\text { Interviews }\end{array}$ & $\begin{array}{l}\text { Taxpayers } \\
\text { Government Office } \\
\text { Huduma centres }\end{array}$ \\
\hline August 2017 & Nairobi & $\begin{array}{l}\text { Participant } \\
\text { observation, } \\
\text { Interviews }\end{array}$ & $\begin{array}{l}\text { Huduma Centres } \\
\text { Taxpayers } \\
\text { Cyber Cafes }\end{array}$ \\
\hline
\end{tabular}





\section{FACULTY OF ARTS AND SCIENCES}

Linköping Studies in Arts and Sciences No. 813

Division of technology and social change

Department of Thematic Studies. Institute of technology and social change

Linköping University

SE-581 83 Linköping, Sweden

www.liu.se 